\title{
Identifizierung und funktionelle Charakterisierung von vegetal lokalisierten RNAs in der Xenopus laevis Oozyte
}

\author{
Dissertation \\ zur Erlangung des Doktorgrades \\ der Mathematisch-Naturwissenschaftlichen Fakultäten \\ der Georg-August-Universität zu Göttingen
}

vorgelegt von

Maike Claußen

aus Oldenburg

Göttingen 2002 
D7

Referent: Prof. Dr. T. Pieler

Korreferent: Prof. Dr. G. Braus

Tag der mündlichen Prüfung: 25.04.2002 


\section{Inhaltsverzeichnis}

Abkürzungen

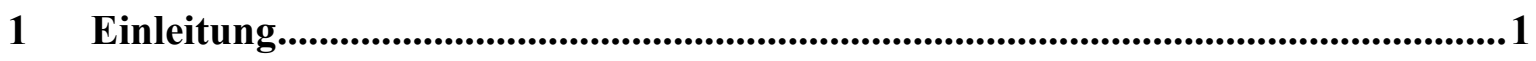

\begin{tabular}{|c|c|}
\hline 1.1 & Lokalisierte RNAs üben wichtige Funktionen bei der Differenzierung somatischer Zellen und der \\
\hline früh & 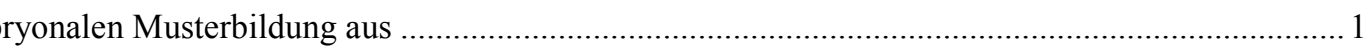 \\
\hline$\overline{1.2}$ & "Mechanismen der subzellulären mRNA-Lokalisation. \\
\hline 1.3 & Lokalisierte RNAs in Xenopus laevis Oozyten............. \\
\hline 1.4 & Cis-agierende Sequenzen.... \\
\hline 1.5 & 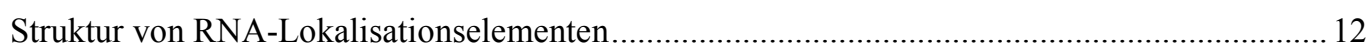 \\
\hline 1.6 & Trans-agierende Faktoren.. \\
\hline 1.7 & Die Xenopus-Oogenese..................... \\
\hline 1.8 & Die Rolle des Zytoskeletts bei der Lokalisation von RNAs in Xenopus Oozyten ......... \\
\hline 1.9 & Zielsetzung der Arbeit ....... \\
\hline
\end{tabular}

\section{$2 \quad$ Materialien, Methoden und Klonierungen.................................................................19}

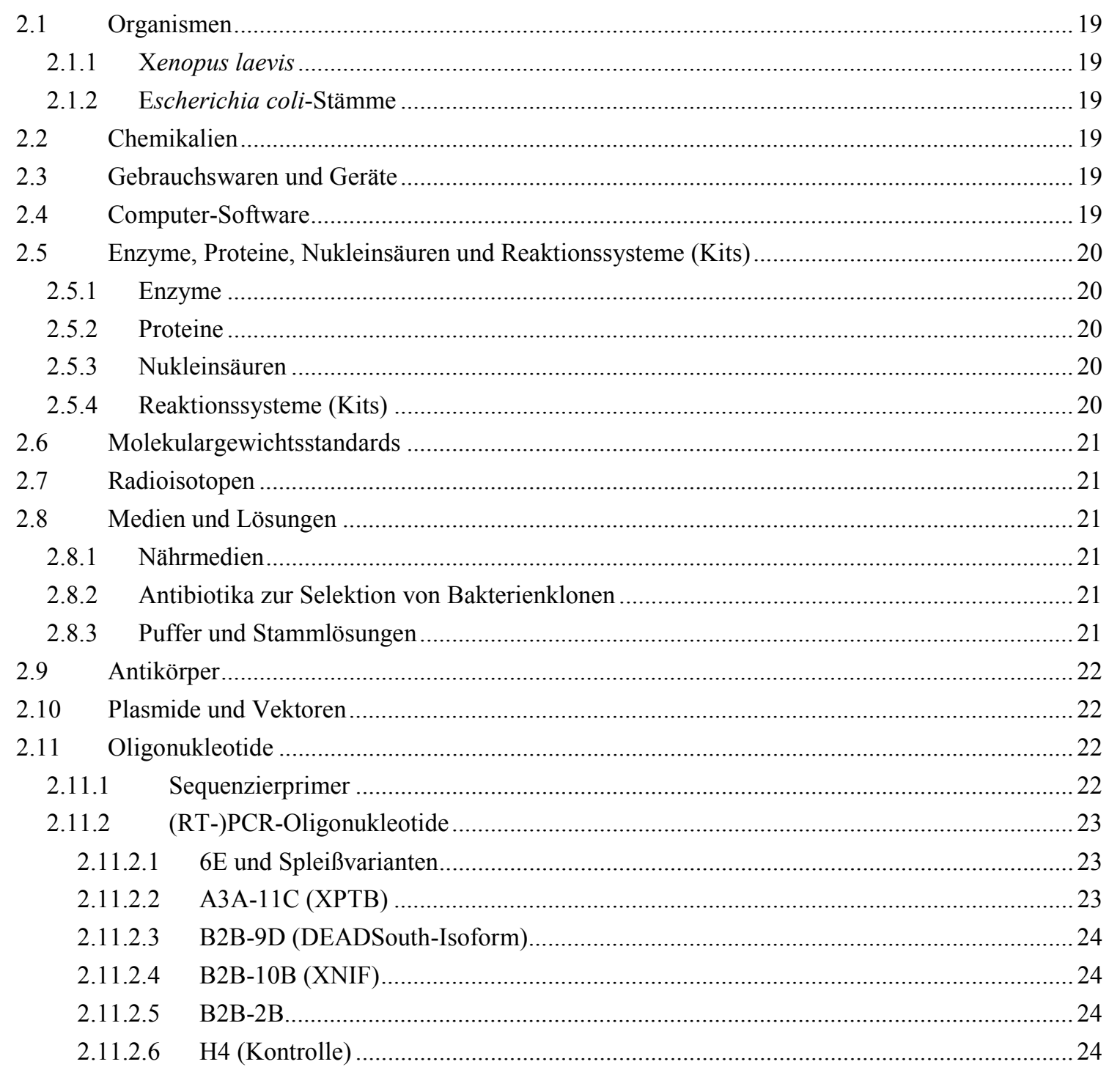




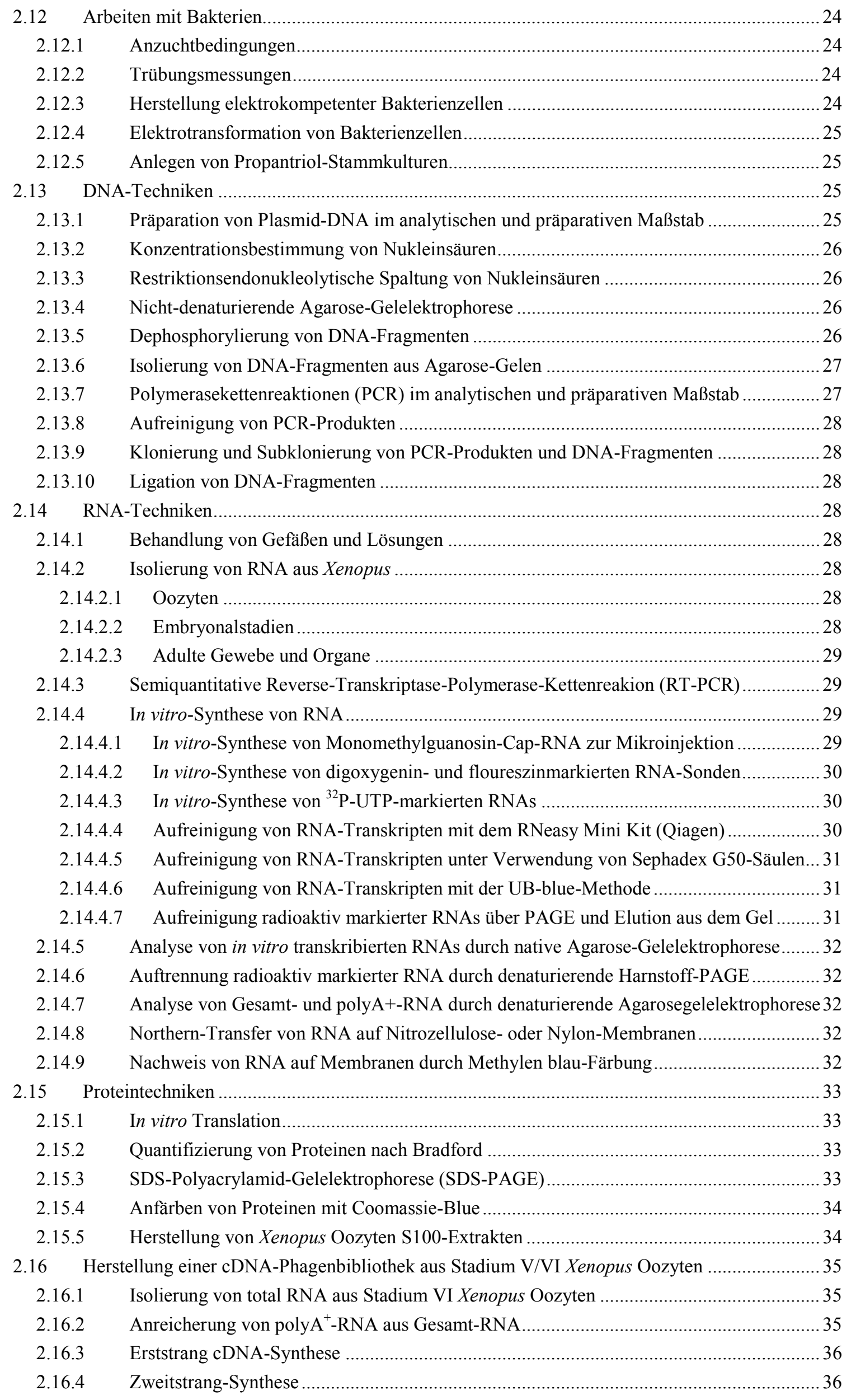




\begin{tabular}{|c|c|}
\hline 2.16 .5 & Glätten der cDNA-Termini und Ligation von EcoRI-Adaptoren ........................................ 36 \\
\hline 2.16 .6 & Größenfraktionierung der cDNA-Fragmente \\
\hline 2.16 .7 & Quantifizierung der cDNA durch Ethidiumbromid-Agarose-Platten.... \\
\hline 2.16 .8 & Ligation der cDNA in den ZAP Express Vektor. \\
\hline 2.16 .9 & Verpacken der Phagen. \\
\hline 2.16 .10 & Plattieren und Bestimmung des Phagentiters \\
\hline 2.16 .11 & Amplifikation der Stadium V/VI Oozyten Phagen-Bibliothek . \\
\hline 2.16 .12 & Anlegen von Gefrierkulturen der fraktionierten Phagenbibliothek .................. \\
\hline$\overline{\mathrm{H}}$ & lung einer cDNA-Phagenbibliothek aus vegetalen Kortizes . \\
\hline 2.17 .1 & 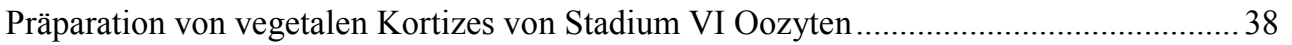 \\
\hline 2.17 .2 & Isolierung von Gesamt-RNA aus vegetalen Kortizes........................... \\
\hline 2.17 .3 & Erststrang cDNA-Synthese \\
\hline 2.17 .4 & cDNA-Amplifikation über LD-PCR und Ligation in den $\lambda$ TriplEx2-Vektor. \\
\hline 2.17 .5 & Massenexzision der $\lambda$ TriplEx2-Phagenbibliothek in BM25.8-Zellen ............... \\
\hline 2.17 .6 & Vorbereitung der Einzelklone für die Durchmusterung nach lokalisierten Transkripten in \\
\hline
\end{tabular}

$2.18 \quad$ Suche nach vegetal lokalisierten Transkripten mittels der whole mount in situ-Hybridisierung in

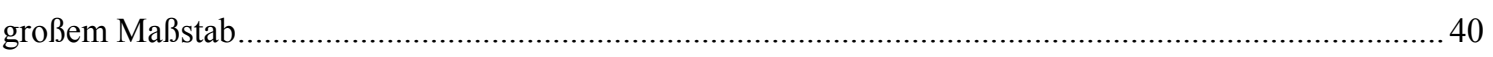

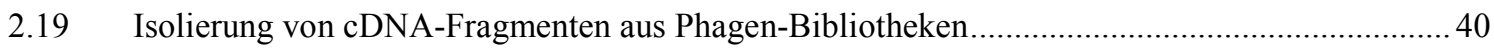

$2.19 .1 \quad$ Plattieren und Kultivieren von Phagen............................................................... 41

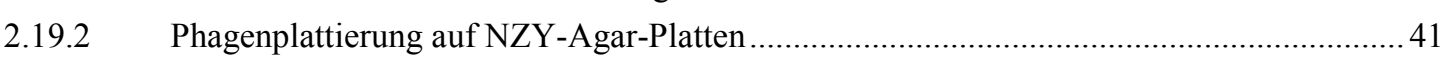

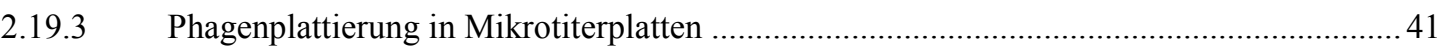

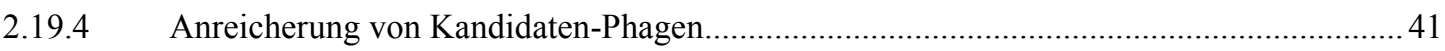

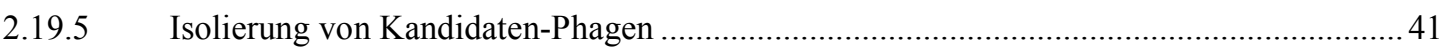

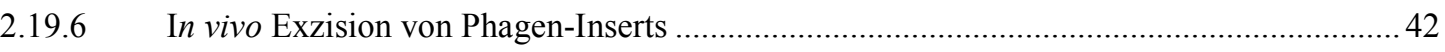

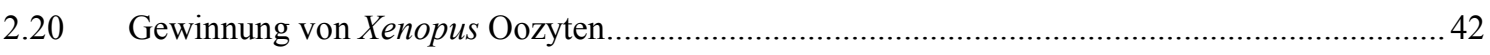

$2.21 \quad$ Präparation von Xenopus-Embryonalstadien ................................................................ 43

$2.22 \quad$ Nachweis von RNA-Transkripten durch die whole mount in situ-Hybridisierung...................... 43

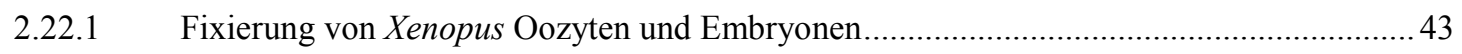

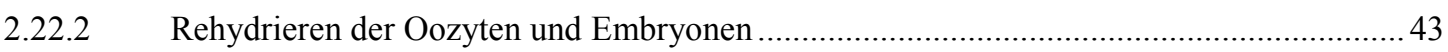

$2.22 .3 \quad$ Permeabilisieren der Oozyten und Embryonen durch Proteinase K-Behandlung ...............44

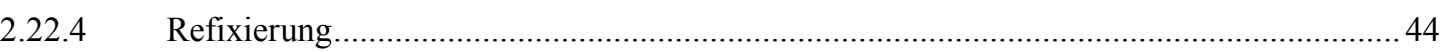

$2.22 .5 \quad$ Hybridisierung mit markierten antisense RNA-Sonden ...................................... 44

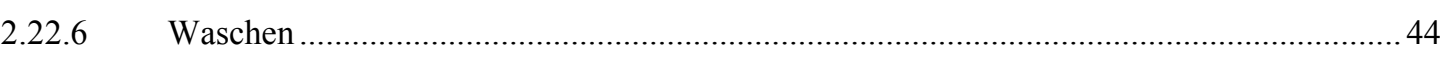

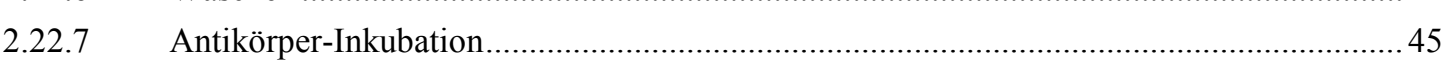

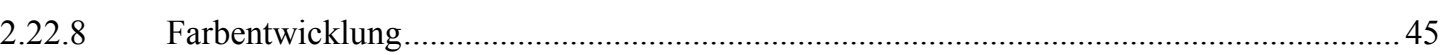

2.22.9 Abstoppen der Färbereaktion, Auswertung und Konservierung der Präparate .................. 45

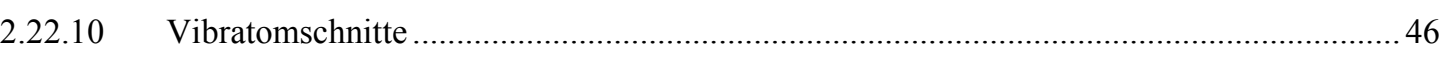

$2.23 \quad$ Isolierung von RNA-Lokalisationselementen in Mikroinjektionsexperimenten ........................46

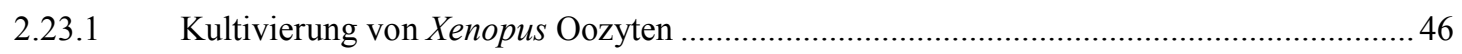

2.23.2 Präparation von Vitellogenin aus Froschserum...................................................... 46

$2.23 .3 \quad$ Injektion und Detektion von lacZ-RNA-Fusionen in Xenopus Oozyten ............................47

$2.24 \quad$ Analyse von RNA-Protein-Wechselwirkungen ............................................................ 47

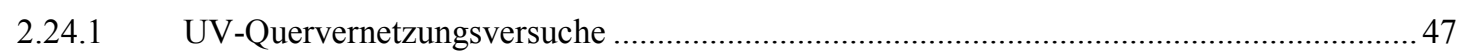

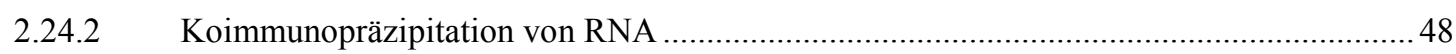

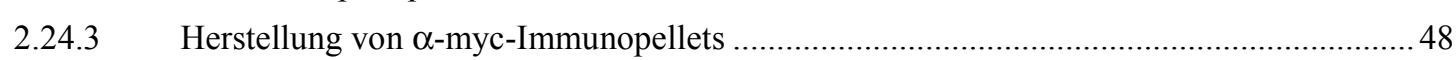

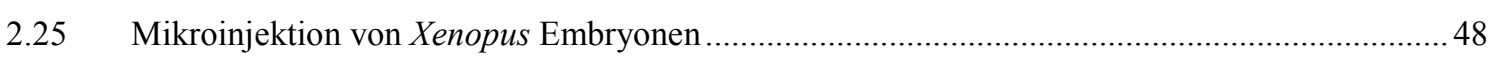




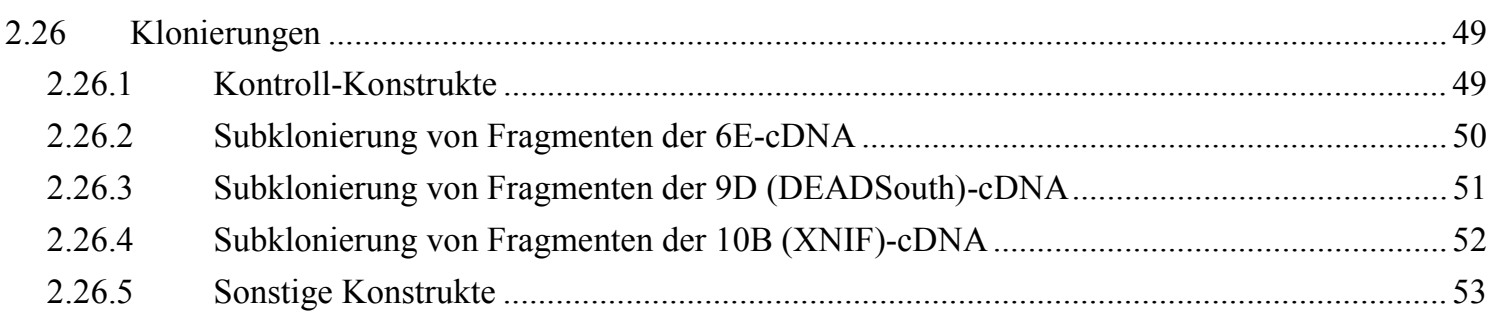

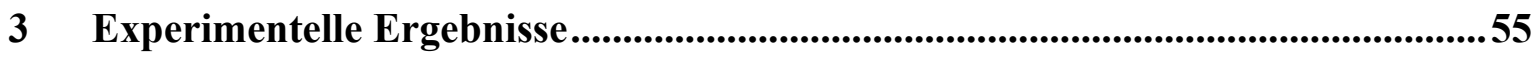

3.1 Identifizierung lokalisierter RNAs mittels whole mount in situ-Hybridisierung .......................55

3.2 Neu identifizierte lokalisierte RNAs weisen charakteristische Verteilungs- und Expressionsmuster in Xenopus Oozyten und Embryonenstadien auf...................................................... 57

3.2.1 Das 6E-Transkript ist eine spät lokalisierte RNA und kodiert für ein Protein bisher unbekannter Identität.......

3.2.2 Räumlich-zeitliche Expressionsanalyse von 6E und Expression in adulten Geweben ............60

3.2.3 Das XPTB (A3A-11C)-Transkript ist eine spät lokalisierte RNA und kodiert für ein Protein

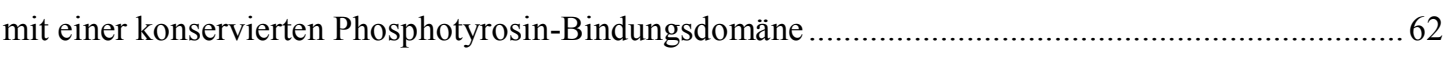
3.2.4 Räumlich-zeitliche Expressionsanalyse von XPTB (A3A-11C) und RT-PCR-Analyse der

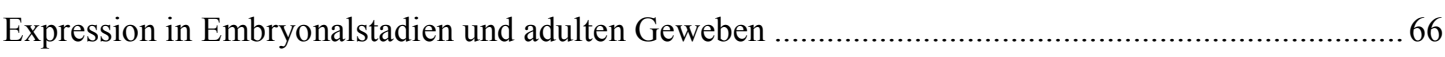

3.2.5 Das B2B-9D-Transkript ist eine früh lokalisierte RNA und kodiert für eine keimzellspezifisch

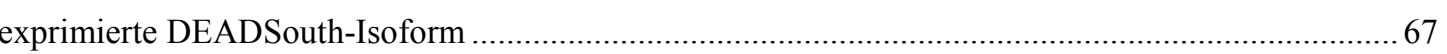

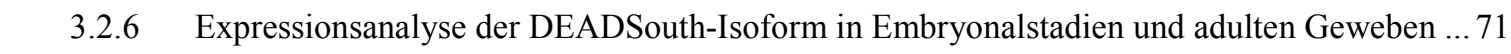

3.2.7 Das XNIF (B2B-10B)-Transkript ist eine früh lokalisierte RNA, die für ein hypothetisches Protein einer konservierten Proteinfamilie kodiert................................................................... 73 3.2.8 Räumlich-zeitliche $\quad$ Expressionsanalyse von XNIF (B2B-10B) und Expression in

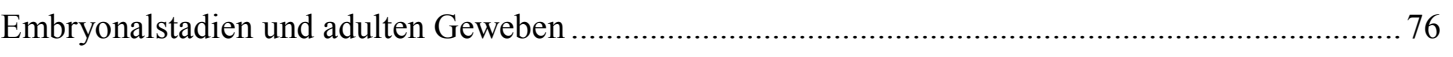
3.2.9 Die B2B-2B-RNA wird über einen neuartigen Lokalisationsweg am äquatorialen Kortex der

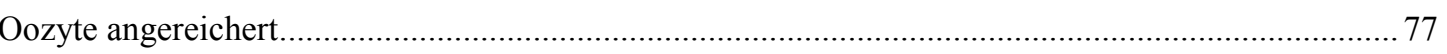

3.2.10 Expression von B2B-2B in Embryonalstadien und adulten Geweben ........................... 78

$3.3 \quad$ In Mikroinjektionsexperimenten können die RNA-Lokalisationselemente in den untranslatierten

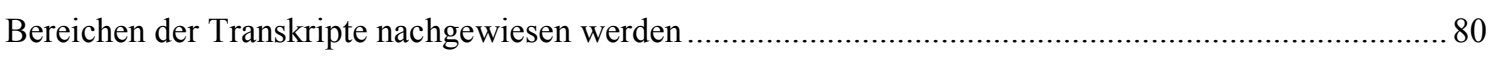
3.3.1 Das 3'-UTR des spät lokalisierten 6E Transkriptes enthält ein 75 Nukleotide langes RNALokalisationselement.

3.3.2 Die früh lokalisierende XNIF-RNA enthält zwei funktionelle RNA-Lokalisationselemente im

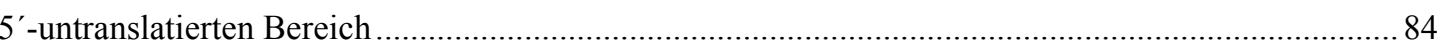

3.3.3 Das 3'-UTR der früh lokalisierten DEAD-South mRNA enthält zwei Lokalisationselemente 87 3.3.4 Die Lokalisationselemente der XNIF- und DEADSouth-RNAs vermitteln nach Injektion in Stadium I Oozyten die Anreicherung des Transkriptes in der mitochondrialen Wolke .....................90 3.3.5 Der nichtkodierende Bereich des B2B-2B-Transkriptes vermittelt eine schwache äquatoriale Lokalisation.....

3.4 Nachweis der Protein-Bindung an RNA-Lokalisationselemente in UV-Quervernetzungs-

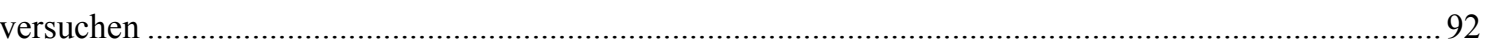
$3.5 \quad$ Vg1-RBP und Prrp weisen ein differentielles Bindungsverhalten für Lokalisationselemente früh

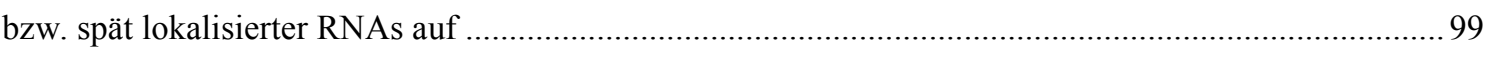
3.6 Eine mögliche Funktion von DEADSouth bei der Entwicklung der primordialen Keimzellen . 101 


\begin{tabular}{|c|c|}
\hline 4.1 & Die 6E- und XPTB-Transkripte sind spät lokalisierte RNAs .... \\
\hline 4.2 & XNIF und DEADSouth lassen sich dem Transportweg früh lokalisierter RNAs zuordnen ....... 105 \\
\hline 4.3 & Äquatorial lokalisierte RNAs-ein neuer Transportweg?. \\
\hline 4.4 & Analyse der Transportsignalsequenzen lokalisierter RNAs... \\
\hline 4.5 & Rekrutierung zellulärer Faktoren durch RNA-Lokalisationselemente: früh und spät lokalisierte \\
\hline \multicolumn{2}{|r|}{ 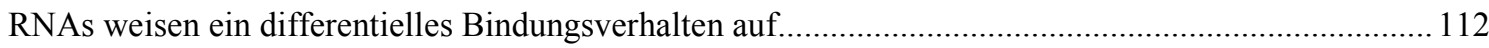 } \\
\hline 4.6 & Korrelation des Proteinbindungs- und Lokalisationsverhaltens vegetal lokalisierter RNAs ...... 117 \\
\hline 4.7 & DEADSouth ist möglicherweise in die Entwicklung der primordialen Keimzellen involviert .. 119 \\
\hline 4.8 & Funktion von XNIF (B2B-10B) während der Oogenese und Embryogenese.. \\
\hline 4.9 & Mögliche Funktionen von XPTB während der Embry \\
\hline 4.10 & $\mathrm{rOo}$ \\
\hline
\end{tabular}

5 Zusammenfassung

$6 \quad$ Literaturverzeichnis

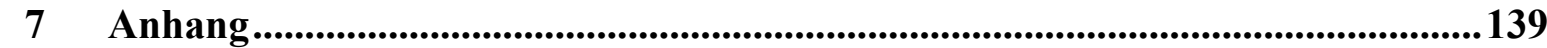

\begin{tabular}{|c|c|}
\hline 7.1 & Nukleotid- und Aminosäuresequenz der A3A-3A und B2B-6E-Klone.... \\
\hline 7.2 & otid- und Aminosäuresequenz des isolierten 6E-Klons. \\
\hline 7.3 & Nukleotid- und Aminosäuresequenz des isolierten A3A-11C(XPTB)-Klons....... \\
\hline 7.4 & Nukleotid- und abgeleitete Aminosäuresequenz der DEADSouth cDNA.. \\
\hline 7.5 & ukleotid- und abgeleitete Aminosäuresequenz von B2B-10B (XNIF)................ \\
\hline 76 & $\bar{D}$ \\
\hline
\end{tabular}

Danksagung

Lebenslauf 


\section{Abkürzungen}

A

AA

ad

Amp

antisense

APS

AS

ATP

$\%$

bp

BSA

$\mathrm{C}$

c

${ }^{\circ} \mathrm{C}$

cDNA

$\mathrm{Ci}$

cpm

d

$\mathrm{Da}$

dATP

$\mathrm{dCTP}$

dGTP

D.m.

DMSO

DNA

DNase

dNTP

dpm

ds

DTT

dTTP

EDTA

g

G

G.g.

$\mathrm{h}$

HEPES

IgG

$\mathrm{k}$

Kan

$\mathrm{kb}$

1

LB

$\mathrm{M}$

$\mathrm{m}$
Adenin

Acrylamid

auf (auffüllen)

Ampicillin

Gegenstrang

Ammoniumperoxydisulfat

Aminosäuren

Adenosintriphosphat

Prozent

Basenpaare

Rinderserumalbumin (bovine serum albumine)

Cytosin

centi

Grad Celcius

komplementäre DNA

Curie, $1 \mathrm{Ci}=37 \mathrm{GBq}$

Zählimpulse pro Minute (counts per minute)

destilliert

Dalton, relative Molekülmasse

Desoxyadenosintriphosphat

Desoxycytidintriphosphat

Desoxyguanosintriphosphat

Drosophila melanogaster, Fruchtfliege

Dimethylsulfoxyd

Desoxyribonukleinsäure

Desoxyribonuklease

Desoxynukleosidtriphosphat

Zerfälle pro Minute (desintegrations per minute)

doppelsträngig

1,4-Dithiothreitol

Desoxythymidintriphosphat

Ethylendiamintetraessigsäure

Gramm

Guanin

Gallus gallus, Hühnchen

Stunde

N-(2-Hydroxymethyl)piperazin, $\mathrm{N}^{\prime}$-3-propansulfonsäure

Immunglobulin $\mathrm{G}$

Kilo

Kanamycin

Kilobasenpaare

Liter

Luria-Bertani

$\operatorname{molar}(\mathrm{mol} / \mathrm{l})$

milli 


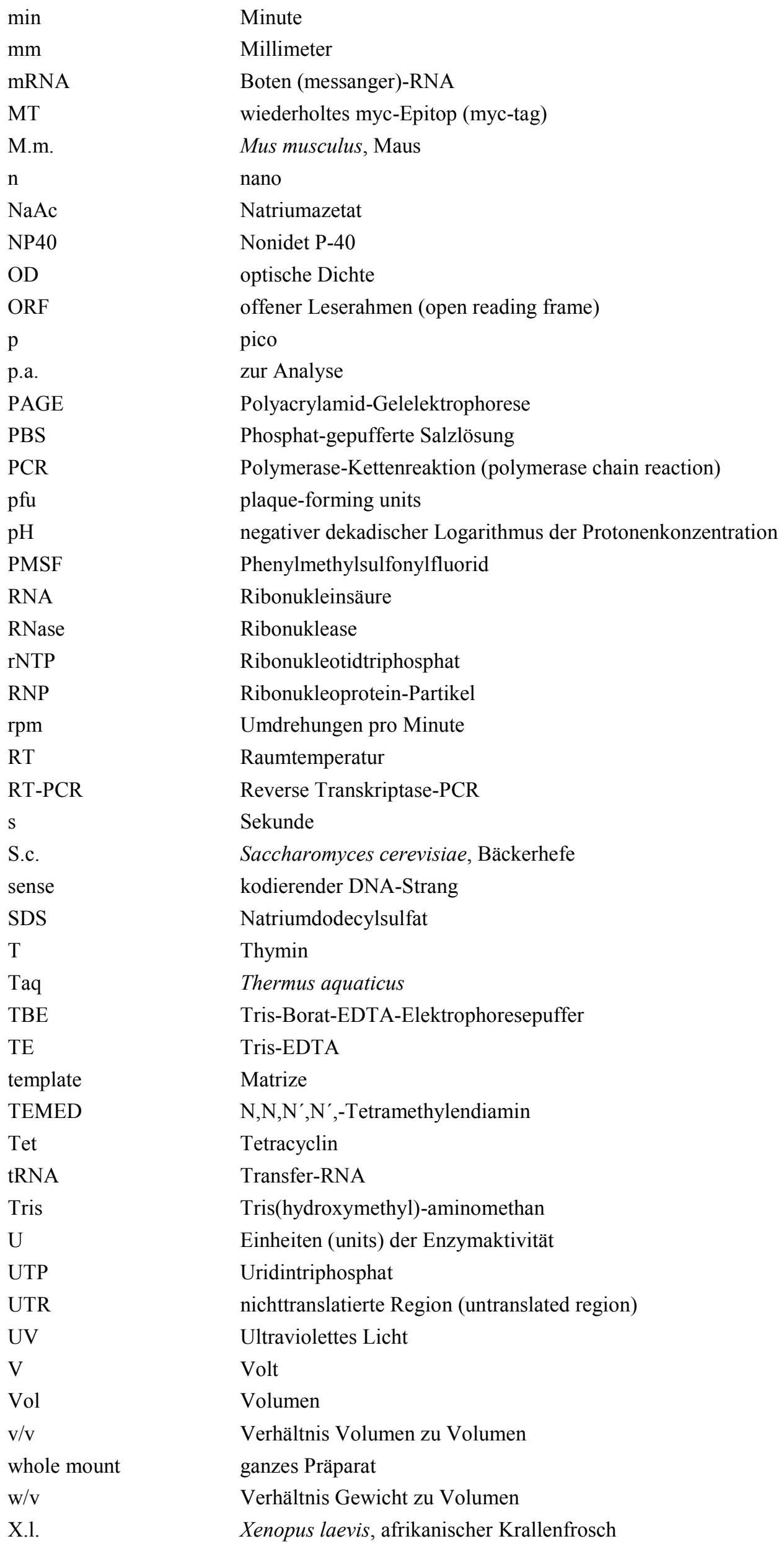




\section{Einleitung}

Durch die asymmetrische Verteilung von Makromolekülen innerhalb der eukaryotischen Zelle können funktionell spezialisierte subzelluläre Bereiche geschaffen werden. Die Ausbildung einer solchen funktionalen Polarität erfordert ein hochorganisiertes Sortierungssystem, welches die Bestandteile einer Zelle an ihren Bestimmungsort bringt. Ein heute sehr gut verstandener Bereich ist in diesem Zusammenhang der Transport von spezialisierten Eiweißen zu ihren Wirkungsorten, der unter dem Begriff der Proteinsortierung oder „Proteintargeting“ zusammengefaßt wird. Der gerichtete Transport von Proteinen ist jedoch nicht der einzige Mechanismus, über den diese an den Ort ihrer Bestimmung verbracht werden können. So stellt auch die differentielle Lokalisation von mRNA-Molekülen einen effektiven Mechanismus dar, über den die Translation dieser Transkripte schon primär auf bestimmte subzelluläre Bereiche beschränkt wird.

Lokalisierte mRNAs konnten in einer Vielzahl unterschiedlicher somatischer Zelltypen sowie in Keimzellen verschiedener Organismen, aber auch in pflanzlichen Zellen oder sogar einzelligen Organismen wie der Hefe, nachgewiesen werden.

\subsection{Lokalisierte RNAs üben wichtige Funktionen bei der Differenzierung somati- scher Zellen und der frühembryonalen Musterbildung aus}

Die Lokalisation von $\beta$-Aktin-mRNA an den Lamellipodien migrierender embryonaler Hühnerfibroblasten führt zu einer lokalen Synthese und Polymerisation von Aktin, das eine gerichtete Zellbewegung vorantreibt (Kislauskis et al., 1993; Kislauskis et al., 1994). Auch die differentielle Verteilung von Transkripten in dendritische oder axonale Bereiche von Neuronen spielt vermutlich eine Rolle bei der Aufrechterhaltung der ausgeprägten Zellpolarität (Bassell et al., 1998). Während beispielsweise die Tau-mRNA in proximalen Regionen der Axone lokalisiert wird, sind MAP2-Transkripte von diesen ausgeschlossen und akkumulieren selektiv in dendritischen Auswüchsen der Neurone (Aronov et al., 2001; Garner et al., 1988; Kleiman et al., 1990).

Besonders evident ist die Etablierung von Zellasymmetrien bei der Entwicklung einer zunächst radialsymmetrischen Eizelle zu einem so komplexen, aus Zelltypen unterschiedlichster Funktion und Struktur zusammengesetzten Lebewesen wie dem sich entwickelnden Embryo. Lokalisierte Determinanten, die während der Zellteilungen selektiv an bestimmte Tochterzellen weitergegeben werden, ermöglichen die asymmetrische Verteilung maternaler Information und stellen ein wesentliches Prinzip der frühembryonalen Differenzierung dar (Bashirullah et al., 1998). Die Funktion lokalisierter maternaler mRNAs bei der Ausbildung der anterior-posterioren Körperachse des Embryos konnte durch Studien am Drosophila Ei sehr anschaulich belegt werden (Johnstone and Lasko, 2001; Riechmann und Ephrussi, 2001). Anteriore Strukturen werden so durch die Lokalisa- 
tion von bicoid-mRNA bestimmt, die für einen Homeodomänen-Transkriptionsfaktor kodiert und einen posterior gerichteten Morphogengradienten ausbildet (Berleth et al., 1988; Driever et al., 1990). Die Determinierung des posterioren Pols und der Keimbahnvorläuferzellen wird von einer ganzen Reihe im sogenannten Polplasma des Eis lokalisierter Transkripte wie oskar, nanos, germ-cell-less, aber auch von nichtkodierenden RNAs wie polar-granule-component und sogar von mitochondrialen ribosomalen RNAs festgelegt (Mahowald, 2001; Starz-Gaiano und Lehmann, 2001).

Auch die Xenopus Oozyte weist eine Polarität auf, die sich äußerlich durch eine intensive Pigmentierung der sogenannten animalen Hemisphäre und einer schwächeren Pigmentierung der vegetalen Hemisphäre, wie auch durch die Lage des Zellkerns und die Verteilung der Dotterschollen auszeichnet. Wie im Drosophila Ei konnten auch hier lokalisierte RNAs identifiziert werden, die wichtige Aufgaben bei der embryonalen Achsen- und Keimblattausbildung sowie bei der Entwicklung der primordialen Keimzellen erfüllen.

\subsection{Mechanismen der subzellulären mRNA-Lokalisation}

Unterschiedlichen Modellen zufolge kann die subzelluläre Lokalisation bestimmter mRNAs auf verschiedene Weisen erreicht werden (Palacios und Johnston, 2001). So ist zum Beispiel vorstellbar, daß die zu lokalisierenden Transkripte zunächst frei im Zytoplasma der Zelle diffundieren, dann jedoch durch selektive Bindung an spezifische „Anker“ an bestimmten Foci subzellulär angereichert werden. Evidenzen für die Existenz eines solchen Lokalisationsmechanismus konnten bei Untersuchungen zur RNALokalisation während der Oogenese der Fruchtfliege Drosophila melanogaster gewonnen werden. So scheint die posteriore Anreicherung der nanos-mRNA abhängig vom Vorhandensein bereits lokalisierter Faktoren wie Oskar, Vasa und Tudor zu sein (Wang et al., 1994). Hier konnte gezeigt werden, daß die experimentelle Mislokalisierung von oskarmRNA an das anteriore Ende der Oozyte auch in einer dortigen Akkumulation der normalerweise posterioren nanos-mRNA resultiert (Ephrussi und Lehmann, 1992). Intensive zytoplasmatische Strömungen die während der Oogenese in Drosophila beobachtet werden, können dabei vermutlich die freie Diffusion der anzureichernden Transkripte unterstützen (Gutzeit, 1986; Theurkauf et al., 1992).

Alternativ oder parallel zur lokalen Anreicherung von Transkripten durch Ankerproteine ist ein Mechanismus denkbar, der ursprünglich homogen in der Zelle verteilt vorliegende Transkripte lokalisiert vor einer generellen Degradation schützt, bzw. daß diese nur in bestimmten Regionen selektiv abgebaut werden. So ist zum Beispiel die hsp 83 mRNA in fertilisierten Drosophila Eiern homogen über das Zytoplasma verteilt und bildet erst mit Beginn der Kernteilungen einen nach posterior verlagerten Gradienten aus. Späterhin ist das Transkript nur noch auf den Bereich der Polzellen beschränkt und scheint dort vom Polplasma lokal vor der Degradation geschützt zu werden (Bashirullah et al., 1999; Ding et 
al., 1993). Bei der spezifischen Verteilung der hunchback- und caudal-mRNAs ist der Mechanismus der lokalen Stabilitätskontrolle der RNA zusätzlich mit dem der translationalen Kontrolle verknüpft. So wird hunchback am posterioren Ende des Drosophila Embryos durch Nanos translational reprimiert und gleichzeitig auch die Stabilität der RNA herabgesetzt. Umgekehrt wird sowohl die Translation, als auch die Stabilität der caudal-mRNA am anterioren Ende des Embryos durch Bicoid negativ beeinflußt. Diese spiegelbildliche Anreicherung der hunchback- und caudal-mRNAs zu ihren „Repressoren“ Nanos und Bicoid spielt bei der korrekten Ausbildung von Kopf-, Thorax- und Abdominalsegmenten des Embryos eine wichtige Rolle (Dubnau und Struhl, 1996; Rivera-Pomar und Jäckle, 1996; Rivera-Pomar et al., 1996; Wharton und Struhl, 1991).

Nicht nur die freie Diffusion, sondern auch die lokalisierte Synthese einer RNA verbringen diese an den Ort ihrer Bestimmung. So erfolgt in Drosophila die Transkription von gapund pair-rule-Genen während des Stadiums des synzytialen Blastoderms nur in spezifischen Gruppen von Kernen und beschränkt so die Anwesenheit der Transkripte auf relativ begrenzte Bereiche der vielkernigen Zelle (diese mRNAs werden später aktiv in apikale Bereiche transportiert, s.u.). Ein weiteres Beispiel einer RNA-Lokalisation, der die lokalisierte Transkription zugrunde liegt, ist die Akkumulation von mitochondrialen ribosomalen RNAs in den sich einander vermutlich sowohl strukturell als auch funktionell entsprechenden Strukturen des Polplasmas in Drosophila, dem Keimplasma der Xenopus Oozyte sowie dem Myoplasma der sich entwickelnden Ascidien (Kashikawa et al., 2001; Kashikawa et al., 1999; Kobayashi et al., 1998; Kobayashi et al., 1994; Kobayashi et al., 1993; Oka et al., 1999).

Der bislang am intensivsten untersuchte und diskutierte Mechanismus der RNALokalisation ist der des signalvermittelten, gerichteten zytoplasmatischen Transports an Zytoskelettfilamenten entlang und der anschließenden Verankerung des Transkriptes am Ort der Bestimmung. Einem nach Wilhelm und Vale, 1993 weiterentwickeltem Modell zufolge ist der Mechanismus der RNA-Lokalisation in mehrere aufeinander folgende Schritte zu unterteilen (siehe Abb. 1.1):

1. Während der Assemblierung eines nukleären Ribonukleoprotein-Komplexes wird die neu synthetisierte, zu lokalisierende RNA im Kern von Proteinen des Cap-BindungsKomplexes (CBC), nukleären hnRNP-Proteinen, Exportfaktoren und möglicherweise auch von Proteinen, die spezifisch mit dem zytoplasmatischen Lokalisationssignal der RNA interagieren, gebunden (Abb. 1.1 A).

2. Nach dem Export dieses Komplexes aus dem Kern erfolgt die Maturierung des zytoplasmatischen RNPs, während derer die Exportfaktoren und einige hnRNP-Proteine dissoziieren und wieder in den Zellkern reimportiert werden, bzw. zytoplasmatische RNPProteine mit dem zu transportierenden RNA-Partikel assoziieren. Ein wichtiger Schritt ist 
die nachfolgende Rekrutierung von molekularen Motorproteinen, die auch über ein entsprechendes Adaptorprotein vermittelt werden kann (Abb. 1.1 B).

3. Dieser Transportkomplex wird dann entlang der Filamente des Zytoskeletts zum Bestimmungsort der RNA, wie zum Beispiel der Zellperipherie, transportiert (Abb. 1.1 C).

4. Dort erfolgt vermutlich eine Umordnung der Proteinkomponenten des lokalisierten RNPs, sowie die stabile Assoziation der RNA über Ankerproteine mit dem lokalen Zytoskelett. Am Zielort kann dann auch die Rekrutierung von Ribosomen und die translationale Aktivierung der RNA erfolgen (Abb. 1.1 D).

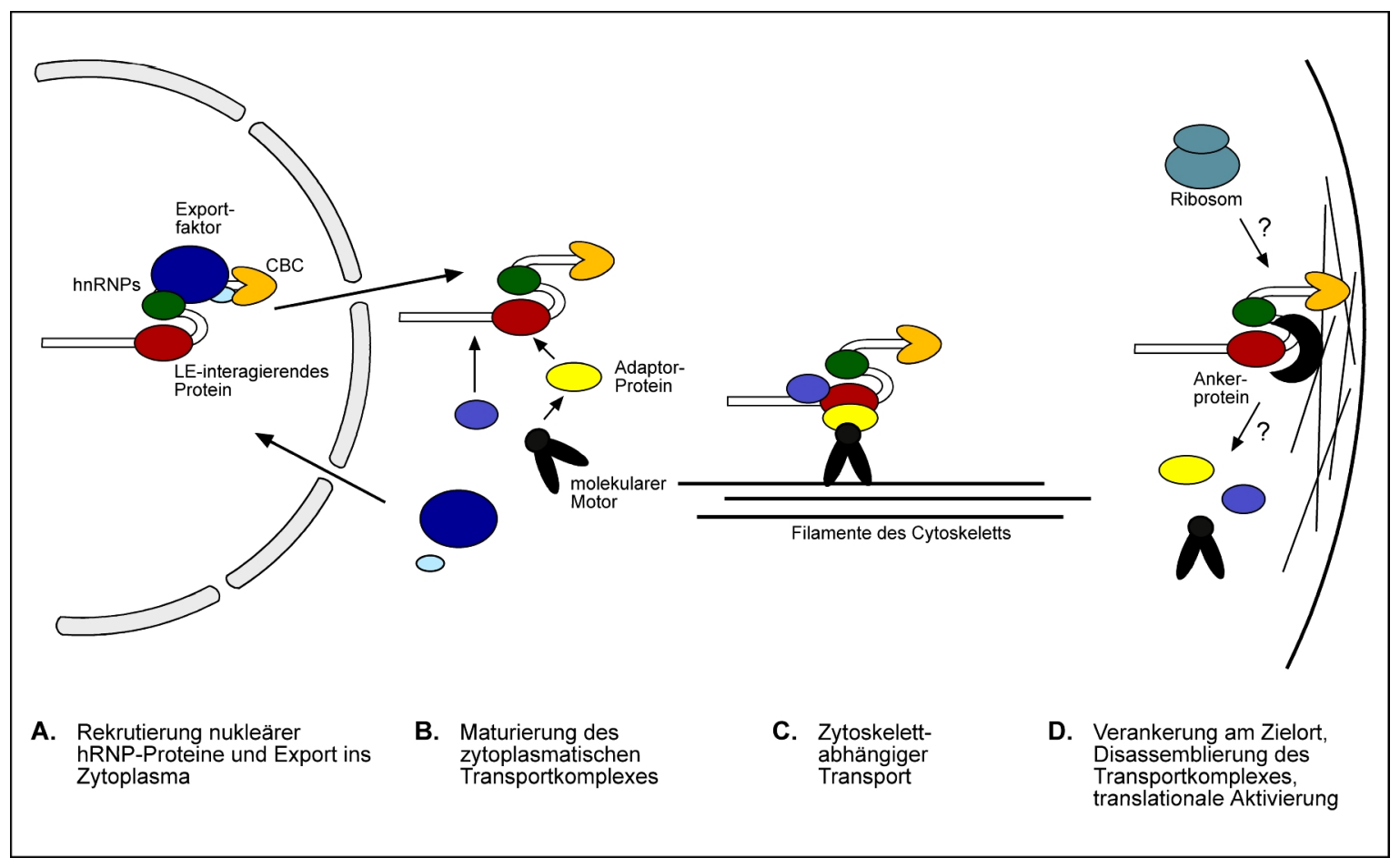

Abb. 1.1 Modell der aktiven und signalvermittelten Lokalisierung von mRNAs.

A. Assemblierung des nukleären Ribonukleoprotein-Komplexes: Neu transkribierte RNA wird im Zellkern von Proteinen des Cap-Bindungs-Komplexes (CBC; gelborange), verschiedenen hnRNPProteinen (hnRNPs; grün und hellblau) sowie nukleären Exportfaktoren (Exportfaktor; dunkelblau) gebunden. Darüber hinaus wird das RNA-Lokalisationselement des Transkriptes möglicherweise schon im Zellkern von einem oder mehreren spezifisch mit diesem interagierenden Proteinen gebunden (LE-interagierendes Protein; rot). Dieser RNA-Protein-Komplex wird dann durch die Kernpore aus dem Zellkern ins Zytoplasma der Zelle transportiert. B. Maturierung des zytoplasmatischen RNATransportkomplexes: Exportfaktoren und hnRNP-Proteine dissoziieren aus dem Komplex und werden in den Zellkern reimportiert. Entscheidend für den aktiven Transport ist die Rekrutierung eines zytoplasmatischen Motorproteins (molekularer Motor; schwarz), die vermutlich von Adaptorproteinen (Adaptor; gelb) vermittelt wird. C. Zytoskelettabhängiger, gerichteter Transport: Der mit dem Motorprotein assoziierte Komplex wird an Filamenten des zellulären Zytoskeletts entlang zum Ort der Bestimmung verbracht. Alternativ kann der RNA-Proteinkomplex möglicherweise auch an das ER oder andere membranöse Strukturen gebunden und mit diesen kotransportiert werden. D. Verankerung der RNA am Zielort: Hier erfolgt die Deassemblierung des Transportkomplexes. Motor- und Adaptorproteine werden aus dem Komplex entlassen und spezifische Ankerproteine (Ankerprotein; schwarzer Halbmond) dienen der festen Assoziation der RNA mit Elementen des Zytoskeletts oder Membranen am Zielort. Hier kann dann unter Umständen auch die translationale Aktivierung der RNA oder die Derepression der Translation erfolgen. (Abbildung modifiziert nach Jansen, 2001) 
Eines der am besten charakterisierten Beispiele des aktiven RNA-Transports ist die Lokalisation der Ash1-mRNA am Kortex der sich abschnürenden Tochterzelle in der Hefe Saccharomyces cerevisiae (Chartrand et al., 2001). Ash1 kodiert für einen Repressor der HO-Endonuklease, die für die Regulation des Geschlechterwechsels in der Hefe verantwortlich ist. Die Ash1-mRNA wird im Zellkern vom nukleären Faktor Loc1p und vermutlich auch vom Lokalisationselement-bindenden Protein She2p gebunden (Long et al., 2001). Nach dem Transport ins Zytoplasma erfolgt die Assemblierung in eine als Lokasom bezeichnete Struktur, wobei ein She3p genanntes Protein hier als Adaptor zwischen dem Komplex aus Ash1-mRNA/She2p und dem unkonventionellen Myosin Myo4p/She1p fungiert (Böhl et al., 2000; Long et al., 2000; Münchow et al., 1999; Takizawa und Vale, 2000). In in vivo Untersuchungen konnte außerdem die Zytoskelettabhängigkeit des Lokalisationsprozesses, einem wichtigen Kriterium des aktiven RNA-Transportes, gezeigt werden. So bewegt sich der Transportpartikel mit einer für Typ V Myosine charakteristischen Geschwindigkeit von 200-440 nm/sec an Aktinfilamenten entlang von der Mutterzelle zum Kortex der knospenden Tochterzelle (Bertrand et al., 1998). Dort angekommen, wird die Ash1-mRNA translational aktiviert und in einer Bnilp-, Bud6p- und vermutlich auch Ash1p-abhängigen Weise am Zytoskelett verankert (Beach et al., 1999).

Während der aktinabhängige RNA-Transport bislang nur in wenigen Systemen nachgewiesen werden konnte und vermutlich dem Transport über eher kurze Distanzen dient (Bassell et al., 1999), werden die meisten lokalisierten Transkripte in einer mikrotubuliabhängigen Weise transportiert. Einen Hinweis darauf, daß der posteriore Transport von oskar-mRNA von einem Kinesin-Motor vom Minus- zum Plus-Ende der Mikrotubuli vermittelt wird, konnte zum Beispiel bei der Analyse von oskar-Transkripten in gurken-Mutanten gewonnen werden, in denen die Polarität der Mikrotubuli so verändert ist, daß sich ihr Plus-Ende hier im Zentrum der Drosophila Oozyte (und nicht wie im Wildtyp posterior gelegen) befindet, die Minus-Enden der Filamente jedoch an beiden Polen der Oozyte (normalerweise befinden sich diese anterior) lokalisiert sind. oskar-mRNA, wie auch Kinesin- $\beta$-GalFusionen sind in diesen Mutanten im Zentrum der Oozyte mislokalisiert (Clark et al., 1994; Clark et al., 1997; Gonzalez-Reyes et al., 1997; Gonzalez-Reyes et al., 1995; Pokrywka und Stephenson, 1995; Theurkauf et al., 1992 und Palacios und Johnston, 2001 zur Übersicht). Außerdem wird oskar-mRNA in den Eikammern homozygoter KeimbahnNullmutanten der schweren Kinesinkette nicht zum posterioren Pol transportiert, sondern verbleibt im anterioren Zytoplasma (Brendza et al., 2000).

Der apikale Transport von pair-rule-Transkripten im Embryonalstadium des synzytialen Blastoderms, sowie die anteriore Lokalisation in Oozyten, wird hingegen von Dyneinen an Mikrotubuli entlang von deren Plus- zum Minus-Ende hin vermittelt. In der ZeitlupenVideomikroskopie konnte beobachtet werden, daß Fluorophor-markierte, injizierte Transkripte in Transportpartikel assembliert werden und mit einer Geschwindigkeit von 
20-60 $\mu \mathrm{m} / \mathrm{min}$ zur apikalen Membran transportiert werden, was durch Koinjektion von gegen Dynein-gerichtete Antikörpern, spezifisch unterdrückt wird (Wilkie und Davis, 2001).

Die anteriore bicoid-mRNA Lokalisation beinhaltet mehrere sukzessive Transportschritte (Palacios und Johnston, 2001 zur Übersicht). Die RNA wird zunächst in Ammenzellen synthetisiert und dort in sponge bodies genannte Strukturen verbracht. Nach der Translokation durch die Ringkanäle ins Zytoplasma der Oozyte wird die RNA mikrotubuliabhängig anterior verankert. Die Abhängigkeit dieses Transports von einem zum Minus-Ende der Mikrotubuli gerichteten Motor wird durch die Beobachtung gestützt, daß bicoid-mRNA im Gegensatz zur vorangehend beschriebenen oskar-RNA in gurken-Mutanten an beide Pole der Oozyte fehlsortiert wird (Gonzalez-Reyes et al., 1995; Pokrywka und Stephenson, 1995; Pokrywka und Stephenson, 1991). Auch konnte die Interaktion des SwallowProteins, welches für die anteriore Verankerung der bicoid-mRNA benötigt wird, mit der leichten Kette des Dyneins nachgewiesen werden (Hays und Karess, 2000; Schnorrer et al., 2000). Überraschenderweise wurde kürzlich gezeigt, daß in Drosophila vermutlich dieselben konservierten zellulären Mechanismen und Lokalisationssignale für die Akkumulation maternaler Transkripte in der frühen Oozyte, und auch für die apikale Lokalisation von Transkripten in Embryonen des Blastoderm-Stadiums verantwortlich sind (Bullock und Ish-Horowicz, 2001).

\subsection{Lokalisierte RNAs in Xenopus laevis Oozyten}

Das Phänomen der differentiellen lokalen Anreicherung von RNAs in der animalen bzw. vegetalen Hemisphäre konnte schon sehr früh in der Xenopus Oozyte nachgewiesen werden (Rebagliati et al., 1985; Weeks et al., 1985). In der radialsymmetrischen Oozyte lassen sich aufgrund ihrer Pigmentierung die animale Hemisphäre und die vegetale Hemisphäre gut voneinander unterscheiden (siehe auch Abb1.3). Mit der Fertilisierung des Eis kommt es zu einer Rotation des Ei-Kortex gegenüber dem darunterliegenden Zytoplasma. Diese kortikale Rotation führt zu einer Umverteilung lokalisierter Determinanten und definiert somit durch Etablierung einer zweiten Zellasymmetrie die spätere dorsale Seite des Embryos gegenüber der Eintrittsstelle des Spermiums. In der Oozyte vegetal lokalisierte RNAs werden während der frühen Zellteilungen selektiv an bestimmte Blastomere des Embryos weitergegeben und ermöglichen so eine asymmetrische Verteilung maternaler Komponenten. Die aus vegetalen Bereichen hervorgehenden dotterreichen Blastomeren sind der Ursprung endodermalen Gewebes und so scheinen auch vegetal lokalisierte RNAs wie zum Beispiel XBic-C und VegT an der Bildung und Regulation einer keimblattspezifischen Genexpression beteiligt zu sein (Clements et al., 1999; Wessely und De Robertis, 2000; Xanthos et al., 2001; Zhang et al., 1998). 
Die lokale Anreicherung von RNAs erfolgt in der Xenopus Oozyte hauptsächlich durch drei charakteristische Sortierungswege. So wurden zwei voneinander unterscheidbare Wege beschrieben, durch die eine ganze Reihe bisher untersuchter RNAs zum vegetalen Kortex verbracht werden sowie ein dritter bislang nur wenig charakterisierter Sortierungsweg, der zur Anreicherung von RNAs in der animalen Hemisphäre der Oozyte führt (zur Übersicht: Etkin und Lipshitz, 1999; King et al., 1999; Kloc et al., 2001; Mowry und Cote, 1999; Rand und Yisraeli, 2001; Yaniv und Yisraeli, 2001). Während sich vegetal lokalisierte RNAs durch eine strikte Beschränkung ihrer Lokalisation auf kortikale Bereiche der vegetalen Hemisphäre auszeichnen, scheinen die meisten animal lokalisierten RNAs vermutlich nicht am Kortex verankert $\mathrm{zu}$ werden, sondern weisen nur eine relative Anreicherung in dieser Hemisphäre auf.

Der Transport von RNAs zur vegetalen Hemisphäre kann aufgrund von Unterschieden in der räumlich-zeitlichen Einordnung der Prozesse, sowie durch Unterschiede in der Abhängigkeit der Transportvorgänge von zytoskeletalen Elementen, in zwei Wege unterteilt werden (siehe Abb. 1.2). Eine ganze Reihe von RNAs, die mit dem Keimplasma assoziieren und vermutlich in die Determinierung und Entwicklung der primordialen Keimzellen involviert sind, werden entlang des frühen, mikrotubuliunabhängig-vermittelten Sortierungsweg verteilt (Tab. 1.1 und Abb. 1.2)(Houston und King, 2000; Kloc et al., 2001; Kloc et al., 1996). Diese können schon in prä-Stadium I Oozyten in der Nähe der mitochondrialen Aggregate nachgewiesen werden und akkumulieren dann im Stadium I der Oogenese in der Struktur der mitochondrialen Wolke. Einem Modell von Kloc und Etkin, 1995 zufolge werden diese dann in der sogenannten METRO (,messanger transport organizer“)-Region der mitochondrialen Wolke angereichert und zusammen mit dieser zum vegetalen Kortex transportiert (siehe Abb. 1.2). Während des Stadiums II der Oogenese deassembliert diese Struktur in inselartige Fragmente und die früh lokalisierten RNAs sind nun in einer begrenzten Region in Assoziation mit der intermitochondrialen fibrillären Matrix oder den Keimgranula nachweisbar (Kloc et al., 2001; Kloc et al., 2000; Kloc et al., 2002). Die Lokalisation dieser RNAs ist in späteren Oozytenstadien auf einen relativ kleinen Bereich des vegetalen Kortex beschränkt. In unfertilisierten und fertilisierten Eiern sind diese RNAs in Bereichen des Keimplasmas des vegetalen Kortex nachzuweisen und kosegregieren, mit Beginn der einsetzenden Zellteilungen mit diesem auf die vegetalen Blastomeren des sich entwickelnden Embryos (Houston et al., 1998; Hudson und Woodland, 1998; Kloc et al., 2002; Kloc et al., 1998).

Vg1-mRNA und wahrscheinlich auch Transkripte wie VegT, X-Bic-C, die vermutlich wichtige Funktionen bei der frühembryonalen Musterbildung ausüben, sowie einige andere, nur wenig charakterisierte RNAs werden entlang des späten oder mikrotubuliabhängigen Sortierungsweges zum vegetalen Kortex der Oozyte verbracht (Tab. 1.1) (Horb und Thomsen, 1997; King, 1995; Lustig et al., 1996; Melton, 1987; Rebagliati et al., 1985; 
Stennard et al., 1996; Wessely und De Robertis, 2000; Zhang und King, 1996). Während die Lokalisation der früh lokalisierten Transkripte in den Stadien I und II der Oogenese durch ihre Assoziation mit der mitochondrialen Wolke schon eingeleitet wird, liegen die RNAs des späten Lokalisierungstyps zu diesem Zeitpunkt noch homogen im Zytoplasma verteilt vor, wobei die Struktur der mitochondrialen Wolke von diesen jedoch ausgespart bleibt (Abb. 1.2).

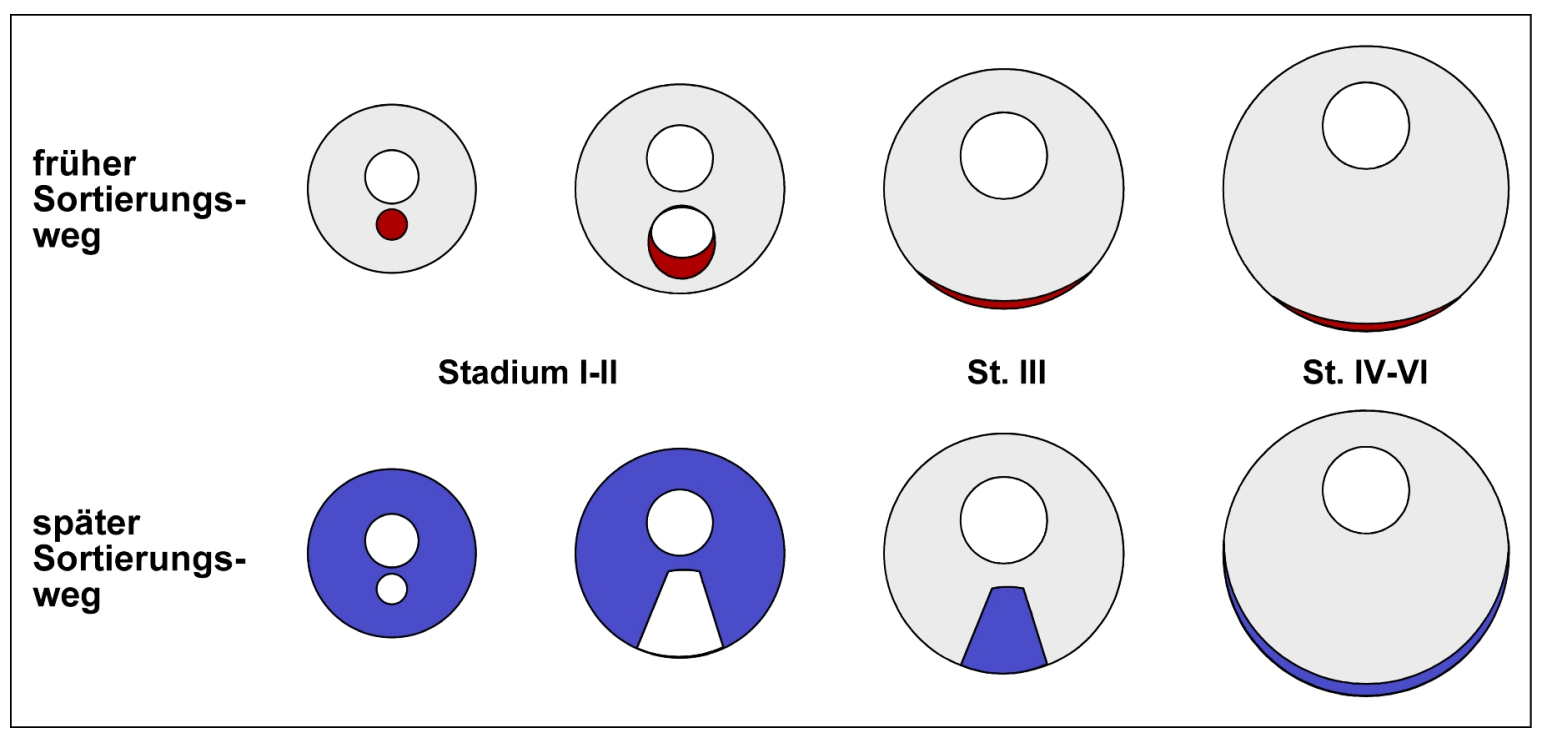

Abb. 1.2 Schematische Darstellung des frühen und späten vegetalen RNA-Transportweges in Xenopus Oozyten. A. Früher Sortierungsweg: RNAs wie Xcat 2 sind in Stadium I Oozyten mit der Struktur der mitochondrialen Wolke assoziiert und migrieren während des Stadiums II in der METRORegion zusammen mit dieser zum vegetalen Kortex der Oozyte. Dort sind sie am Apex des vegetalen Kortex in Assoziation mit der intermitochondrialen fibrillären Matrix oder den Keimgranula nachweisbar. B. Später oder mikrotubuliabhängiger Sortierungsweg: in Stadium I-II Oozyten liegen diese Transkripte homogen im Zytoplasma verteilt vor, wobei jedoch die Region der mitochondrialen Wolke ausgespart bleibt. In Stadium III Oozyten sind diese RNAs in einer keilförmigen Region unterhalb des Nukleus nachweisbar. Von dort aus werden die RNAs in einer mikrotubuliabhängigen Weise vermutlich in Assoziation mit dem endoplasmatischen Retikulum zum vegetalen Kortex transportiert. Anfolgend werden die RNAs über den Kortex der gesamten vegetalen Hemisphäre verteilt und verankert. (Abbildung modifiziert nach Kloc und Etkin, 1995 und King et al., 1999).

Erst gegen Ende des Stadiums II der Oogenese akkumulieren diese RNAs offenbar zunächst in einer halbmondförmigen Region unterhalb des Zellkerns, die neben Spektrinen und Tubulinen auch Vesikel des rauhen endoplasmatischen Retikulums enthält (Chan et al., 1999; Kloc et al., 2001). Während des frühen Stadiums III ist die Vg1-mRNA in einer keilförmigen Region, die auch von einem Subtyp des rauhen endoplasmatischen Retikulums eingenommen wird, zwischen der Halbmondstruktur unterhalb des Kernes und dem vegetalen Kortex nachweisbar, entlang derer vermutlich auch die mitochondriale Wolke und mit dieser assoziierte RNAs transportiert wurden (Forristall et al., 1995; Kloc und Etkin, 1994; Kloc und Etkin, 1995; Yisraeli und Melton, 1988). Im Laufe des Stadiums IIIIV der Oogenese werden die spät lokalisierten RNAs zum vegetalen Kortex transloziert und vom Pol ausgehend über den Kortex der gesamten vegetalen Hemisphäre verteilt und dort verankert (Elinson et al., 1993; Melton, 1987; Pondel und King, 1988; Rand und Yis- 
raeli, 2001; Yisraeli et al., 1990). Im Gegensatz zu den früh lokalisierten RNAs sind die spät lokalisierten RNAs nicht im Keimplasma der Oozyten bzw. Embryonen nachweisbar (Kloc et al., 2001; Kloc et al., 2000; Kloc und Etkin, 1998; Kloc et al., 1998).

Aufgrund der Beobachtung, daß die mitochondriale Wolke schon im Stadium I der Oogenese vom endoplasmatischen Retikulum begleitet wird, das sich in Form einer Kappe an diese anlagert, und daß dieses anfolgend in Stadium III Oozyten in eben jener keilförmigen Region zusammen mit Vg1 kolokalisiert, wurde die Hypothese aufgestellt, daß die mitochondriale Wolke und die Region des METRO in die Organisation der Verteilung des vegetalen ERs und auch der möglicherweise damit zusammenhängenden strukturellen Organisation des späten Verteilungsweges involviert sind und so eine Kontinuität zwischen dem frühen und späten Verteilungsweg zu bestehen scheint (Deshler et al., 1997; Kloc und Etkin, 1998). In frühen Stadium I Oozyten sind so auch Reste des Zentrosoms, in Form von mit gegen $\gamma$-Tubulin gerichtete Antikörpern nachzuweisenden Strukturen, in der mitochondrialen Wolke und in späteren Stadien auch am vegetalen Kortex nachzuweisen, was zu der Hypothese leitete, diese könnten als Mikrotubuli-organisierendes Zentrum (MTOC) für die am Transport spät lokalisierender RNAs beteiligten Filamente dienen (Gard, 1994; Kloc und Etkin, 1998).

Neben diesen beiden relativ klar voneinander abgrenzbaren vegetalen Lokalisierungswegen, scheinen einige RNAs, wie beispielsweise fatvg über einen Mechanismus lokalisiert $\mathrm{zu}$ werden, der Charakteristika beider vorangehend beschriebener Wege aufweist (Tab. 1.1)(Chan et al., 2001; Kloc et al., 2001). So ist zum Beispiel die fatvg-RNA, entsprechend einer spät lokalisierten RNA, in frühen Stadium I Oozyten unter Aussparung der mitochondrialen Wolke homogen im Zytoplasma verteilt. Erst im späten Stadium I liegt sie mit dieser assoziiert vor, migriert jedoch vermutlich nicht mit dieser zusammen zum vegetalen Pol, sondern ist auch in den für Vg1- und spät lokalisierte RNAs typischen Halbmond- und keilförmigen Strukturen zwischen Zellkern und vegetalem Kortex nachweisbar. In Stadium VI Oozyten ähnelt die Lokalisation der fatvg-RNA eher der für spät lokalisierte RNAs typischen Verteilung über einen weiteren Bereich des Kortex der vegetalen Hemisphäre. Interessanterweise kann im Bereich des vegetalen Pols eine Assoziation der RNA mit dem Keimplasma nachgewiesen werden, die bislang nur von früh lokalisierten RNAs bekannt war (Chan et al., 2001; Kloc et al., 2001; Kloc et al., 2002). Interessanterweise können auch RNAs, die normalerweise dem früh lokalisierten Typ zuzuordnen sind, nach Injektion in spätere Oozytenstadien, entlang des mikrotubuliabhängigen Sortierungsweges der spät lokalisierenden RNAs verteilt werden (Hudson und Woodland, 1998; Kloc et al., 1993; Zhou und King, 1996). 
Tabelle 1.1 Übersicht über vegetal lokalisierte RNAs in Xenopus Oozyten, ihren Sortierungsweg und ihre vermutliche Funktion

\begin{tabular}{|l|l|l|}
\hline \multicolumn{2}{|l|}{ Früh lokalisierende RNAs } \\
\hline RNA & Struktur/Funktion & Referenz \\
\hline Xcat2 & RNA bindendes Zn-Finger-Protein & (Mosquera et al., 1993) \\
\hline Xlsirts & nichtkodierende RNA, Verankerung von Vg1-mRNA & (Kloc et al., 1993) \\
\hline Xpat & unbekannt & $\begin{array}{l}\text { (Hudson und Woodland, } \\
\text { 1998) }\end{array}$ \\
\hline Xdazl & RNA-Bindung, Migration primordialer Keimzellen & (Houston et al., 1998) \\
\hline DEADSouth & RNA-Helikase & (MacArthur et al., 2000) \\
\hline Xwnt11 & sezerniertes Signalprotein & (Ku und Melton, 1993) \\
\hline Fingers (B7) & Zn-Finger-Protein & (King et al., 1999) \\
\hline XFACS (C10) & LA-CoA-Synthetase & (King et al., 1999) \\
\hline Xotx1 & $\begin{array}{l}\text { Homeodomänen-Transkriptionsfaktor ; neurale Musterbil- } \\
\text { dung }\end{array}$ & (Pannese et al., 2000) \\
\hline
\end{tabular}

\begin{tabular}{|c|c|c|}
\hline \multicolumn{3}{|c|}{ Spät lokalisierende RNAs } \\
\hline RNA & Funktion & Referenz \\
\hline Vg1 & TGF $\beta$-artiges Signalmolekül & $\begin{array}{l}\text { (Rebagliati et al., 1985; } \\
\text { Weeks und Melton, } \\
\text { 1987) }\end{array}$ \\
\hline Xcat4 & unbekannt & (King et al., 1999) \\
\hline$\beta-T r C P-2$ und -3 & unbekannt & (Hudson et al., 1996) \\
\hline VegT & $\begin{array}{l}\text { T-Box-Transkriptionsfaktor; Endodermentwicklung, } \\
\text { Mesoderm-Induktion }\end{array}$ & $\begin{array}{l}\text { (Horb und Thomsen, } \\
\text { 1997; Stennard et al., } \\
\text { 1996; Zhang et al., 1998; } \\
\text { Zhang und King, 1996) }\end{array}$ \\
\hline $\mathrm{XBic}-\mathrm{C}$ & RNA-bindendes Protein; Endoderm-Induktion & $\begin{array}{l}\text { (Wessely und De Rober- } \\
\text { tis, 2000) }\end{array}$ \\
\hline B9 & unbekannt & $\begin{array}{l}\text { (Forristall et al., 1995; } \\
\text { King, 1995) }\end{array}$ \\
\hline
\end{tabular}

\begin{tabular}{|l|l|l|}
\hline Intermediärer Lokalisationsweg \\
\hline RNA & Mutmaßliche Funktion & Referenz \\
\hline fatvg & ADRP-verwandt & (Chan et al., 1999) \\
\hline XRMC/hermes & RNA-bindendes Protein & (Gerber et al., 1999) \\
\hline
\end{tabular}

\subsection{Cis-agierende Sequenzen}

Die subzelluläre Lokalisation eines Transkripts wird von cis-agierenden Elementen der RNAs vermittelt, die von spezifischen trans-agierenden Proteinen der Zelle erkannt und über diese einem gerichteten Transportprozeß zugeführt werden.

Mit Ausnahme der yemanuclein- $\alpha$ - und gurken-mRNAs aus Drosophila, sowie der Ash1mRNA aus Saccharomyces cerevisiae, konnten bislang alle Lokalisationssequenzen in den 3'-untranslatierten Bereichen der entsprechenden Transkripte nachgewiesen werden (Capri et al., 1997; Chartrand et al., 1999; Gonzalez et al., 1999; Saunders und Cohen, 1999; Thio et al., 2000). Aufgrund der Vielzahl bisher identifizierter Lokalisationselemente sollen anfolgend nur diejenigen beschrieben werden, denen eine Rolle bei der vegetalen Lokalisation in der Xenopus Oozyte zugeschrieben werden konnte. 
Während vom Lokalisationselement der Xpat-RNA bislang lediglich dessen Lokalisation innerhalb des 3'-UTR bekannt ist (Hudson und Woodland, 1998), konnten die entsprechenden Elemente der mRNAs Vg1, fatvg und Xcat2, sowie der nichtkodierenden Xlsirts detaillierter charakterisiert werden. In Injektionsexperimenten wurde das für die Lokalisation der Vg1-mRNA notwendige und hinreichende Transportelement auf einen 340 Nukleotide umfassenden Bereich des 3'-untranslatierten Bereiches festgelegt (Mowry und Melton, 1992). Versuche, dieses auf engere Sequenzbereiche einzugrenzen, ließen auf eine komplexe Redundanz verschiedener Subelemente schließen. Während kleinere Deletionen in beliebigen Bereichen des Elementes keinen Verlust dessen transportvermittelnder Aktivität zur Folge haben, konnten nach Einfügen größerer Deletionen im 5'- und 3'-Bereich dieses Elementes für die Lokalisation der RNA essentielle Sequenzen identifiziert werden. Diese scheinen jedoch redundant $\mathrm{zu}$ sein, da zum Beispiel die Duplikation eines 5'gelegenen Subelementes hinreichend ist, um den vegetalen Transport einer Reporter RNA zu vermitteln (Gautreau et al., 1997). Mutationen in charakteristischen repetitiven Sequenzen der RNA, wie den sogenannten VM1- (UUUCUA) oder E1-Elementen (UUCAC) führen dabei zu einem Verlust der Transportkompetenz des duplizierten 5'-Elementes. Die Beobachtung, daß multiple Mutationen anderer, ebenfalls repetitiver Elemente (E2, E3 und E4) im Kontext des ganzen Lokalisationselementes ähnliche Effekte hervorrufen, führen zu der Annahme, daß an der Lokalisation der Vg1-mRNA kooperative Interaktionen zwischen multiplen, partiell redundanten Elementen beteiligt sind (Deshler et al., 1997). Eine partielle, funktionelle Redundanz der Lokalisationselemente konnte auch für die fatvgmRNA gezeigt werden (Chan et al., 1999). Eines ihrer, in den ersten 102 Nukleotiden des 3'-UTRs enthaltene, Lokalisationselemente konnte bis auf 25 Nukleotide eingegrenzt werden, die die effiziente Lokalisation der RNA am vegetalen Kortex entlang des späten Verteilungsweges erlauben. Der Transport der Familie der nichtkodierenden Xlsirts genannten Transkripte in Xenopus Oozyten wird von den sehr abundanten ca. 80 Nukleotide langen repetitiven Sequenzen dieser RNAs vermittelt (Kloc und Etkin, 1998; Kloc et al., 1996; Kloc et al., 1993). Die Analyse des Lokalisationselementes im 3'-untranslatierten Bereich der früh lokalisierten Xcat2-mRNA zeigt, daß dieses aus funktionell unterschiedlichen Elementen zusammengesetzt ist (Kloc et al., 2000; Zhou und King, 1996; Zhou und King, 1996). So konnte ein direkt an den offenen Leserahmen des Transkriptes anstoßender Bereich des UTRs identifiziert werden, der die Akkumulation in der mitochondrialen Wolke vermitteln kann und in dem auch die Sequenzelemente enthalten sind, die den Transport der RNA entsprechend dem späten Lokalisationsweg vermitteln. Die Anreicherung in den Keimgranula der mitochondrialen Wolke wird hingegen von einem unabhängigen ,germinal granule“ Lokalisationselement (GGLE) der RNA vermittelt. (Kloc et al., 2000). 


\subsection{Struktur von RNA-Lokalisationselementen}

Anders als DNA weisen RNA-Moleküle eine große strukturelle Flexibilität auf, die die Anordnung der primären RNA-Sequenz in komplexe Sekundär-, Tertiär- und sogar die Ausbildung intermolekularer Quartärstrukturen erlaubt. So liegen RNAs in der Zelle nicht als einzelsträngige Moleküle vor, sondern bilden durch Watson-Crick- sowie unkonventionelle Basenpaarungen charakteristische dreidimensionale Strukturen wie hairpin-loops („Haarnadelschleifen“), interne-loops und sogenannte bulge-loops aus, bei denen die Kontinuität des RNA-Doppelstranges durch kurze einzelsträngige Bereiche unterbrochen ist. Diese RNA-Strukturen ermöglichen spezifische Interaktion mit RNA-bindenden Proteinen, wobei angenommen wird, daß doppelsträngige Bereiche primär der Präsentation von Einzelstrangbereichen dienen, die dann eine basenspezifische Proteininteraktion erlauben. Auch beim mRNA-Transport scheint die Struktur eines Lokalisationselementes eine wichtige Rolle zu erfüllen, wie dies bisher am deutlichsten für das Lokalisationselement der bicoid-mRNA aus Drosophila gezeigt werden konnte. In phylogenetischen Sequenzvergleichen, gekoppelt mit computerbasierter RNA-Strukturvorhersage, konnte für das bicoidLokalisationselement ein Strukturmodell erstellt werden, das fünf stem-loop-Bereiche aufweist (MacDonald, 1990; Seeger und Kaufman, 1990). Das für den Transport der RNA aus den Ammenzellen in die Oozyte erforderliche Lokalisationselement BLE1, ist dabei im distalen Bereich des stem-loops V gelegen und Mutationen, die diesen stem-loop zerstören, resultieren in einem Verlust der Lokalisationsfähigkeit der RNA, während stem-looperhaltende Doppelmutationen keinen Effekt zeigen (Macdonald und Kerr, 1998). Aufgrund von Basenkomplementaritäten zwischen zwei Einzelstrang-loops des bicoid-3'-UTRs wurden auch intermolekulare Interaktionen der RNA vorhergesagt (Ferrandon et al., 1997). Und so konnte kürzlich auch tatsächlich die Wichtigkeit dieser intermolekularen Dimerisierung bei der Rekrutierung der RNA in Staufen-haltige Partikel und der charakteristischen Lokalisation dieser an astralen Mikrotubuli der mitotischen Spindel durch kinetische Interaktionsstudien, Anwendung von antisense Oligonukleotiden und gezielten Mutagenesen demonstriert werden (Wagner et al., 2001). Die Ausbildung von stemloop-Strukturen kann der computerbasierten Strukturvorhersage nach für eine ganze Anzahl von Lokalisationselementen angenommen werden, was die Vermutung stützt, das die Erkennung von Lokalisationselementen durch zelluläre Transportfaktoren aufgrund deren spezieller dreidimensionaler Struktur erfolgt. Die funktionelle Bedeutung dieser Strukturen beim RNA-Transport wurde bislang jedoch nur in wenigen Fällen detaillierter untersucht (Ainger et al., 1997; Chartrand et al., 1999; Gonzalez et al., 1999; Serano und Cohen, 1995). 


\subsection{Trans-agierende Faktoren}

Während unter Verwendung verschiedener experimenteller Ansätze die Lokalisationssignale einer ganzen Reihe von RNAs charakterisiert und zum Teil bis auf wenige Nukleotide eingegrenzt werden konnten, sind die mit diesen spezifisch interagierenden Proteine nur in wenigen Fällen bekannt. Eines dieser RNA-bindenden Proteine ist das bereits beschriebene Staufen-Protein, das sowohl an den mikrotubuliabhängigen Prozessen der anterioren Verankerung von bicoid-mRNA und dem posterioren Transport von oskarmRNA in Oozyten (Ephrussi et al., 1991; Kim-Ha et al., 1991; Micklem et al., 2000; St Johnston et al., 1991), aber interessanterweise auch an der aktinabhängigen Lokalisation von prospero-mRNA in Drosophila Neuroblasten beteiligt ist (Broadus und Doe, 1997; Broadus et al., 1998; Li et al., 1997). Die Vermutung einer konservierten Funktion homologer Staufen-Proteine anderer Organismen wird durch Beobachtungen gestützt, daß diese zum Beispiel auch in Transportgranula in kultivierten Neuronen der Ratte nachgewiesen werden können (Kiebler et al., 1999; Köhrmann et al., 1999). Ein weiteres sehr gut charakterisiertes direkt mit RNA-Lokalisationselementen interagierendes Protein ist das She2pProtein aus der Hefe. Dieses Doppelstrang-spezifisch RNA-bindende Protein ist in der Lage, jedes der vier Lokalisationselemente der Ash1-mRNA zu binden und die Interaktion mit dem Myosinmotorprotein Myo4p über das Adaptorprotein She3p zu vermitteln (Böhl et al., 2000; Long et al., 2000; Münchow et al., 1999; Takizawa und Vale, 2000). Auch Proteinen aus der Gruppe der hnRNPs konnten in verschiedenen Organismen eine Funktion bei der sequenzspezifischen Interaktion und Lokalisation von mRNAs zugewiesen werden (Hoek et al., 1998; Lall et al., 1999; Norvell et al., 1999).

In UV-Quervernetzungsstudien konnten bislang sechs Proteine identifiziert werden, die spezifisch an das 340 Nukleotide lange Lokalisationselement der Vg1-mRNA binden und vermutlich an deren vegetalem Transport beteiligt sind (Mowry, 1996). Die Isolierung und genauere Analyse Vg1-mRNA-interagierender Proteine erfolgte bisher für das Vg1RBP oder VERA-Protein, das VgRBP60 sowie das Prolin-reiche RNA-bindende Protein Prrp. Das Xenopus Vg1RBP ist ein RNA-bindendes Protein mit einer RRM (RNA recognition motif) sowie vier KH-Domänen (hnRNP K-Homologe), das an die für die Lokalisation der Vg1-mRNA essentiellen VM1- und E2-Elemente bindet (Deshler et al., 1998; Havin et al., 1998). Evidenzen für eine direkte Beteilung des Proteins am Transport der Vg1-mRNA konnten unter anderem in Experimenten gewonnen werden, in denen gezeigt wurde, daß mutierte RNAs, die nicht mehr von Vg1RBP gebunden werden können auch ihre Fähigkeit zur vegetalen Lokalisation einbüßen. Weitere Hinweise für eine Transportfunktion des Vg1RBPs konnte aus der Kolokalisation des Proteins mit der Vg1-RNA, sowie einer Assoziation mit Mikrotubuli und dem rauhen endoplasmatischen Retikulum gewonnen werden (VERA steht für Vg1-ER-Associated) (Deshler et al., 1997; Elisha et al., 1995). 
Wie auch das vorangehend beschriebene Staufen-Protein, scheint Vg1RBP strukturell wie funktionell konserviert zu sein. So ist zum Beispiel das ZBP-1, welches zu 78\% identisch mit Vg1RBP ist, an der mikrofilamentabhängigen Lokalisation von $\beta$-Aktin-mRNA in kultivierten Fibroblasten des Hühnchens beteiligt (Ross et al., 1997). Ähnlich wie Staufen scheint also auch Vg1RBP bzw. ZBP-1 die Interaktion mit unterschiedlichen Zytoskelettelementen vermitteln $\mathrm{zu}$ können. Weitere Vg1RBP-Homologe konnten ebenfalls im Zebrafisch, der Fruchtfliege, der Maus sowie im Menschen nachgewiesen werden (Doyle et al., 1998; Mueller-Pillasch et al., 1999; Nielsen et al., 2001; Nielsen et al., 1999; Nielsen et al., 2000; Zhang et al., 1999).

Das VgRBP60, welches das Xenopus Homologe des humanen hnRNP I oder PTB (polypyrimidine tract-binding protein) repräsentiert, interagiert mit VM1-Elementen der RNA und zeigt ebenfalls eine strikte Kolokalisation mit der Vg1-mRNA am vegetalen Pol der Oozyte (Cote et al., 1999). Kürzlich konnte in einem North-Western-Screen ein RNA-bindendes Protein (Prrp) identifiziert werden, das ebenfalls an das 340 Nukleotide lange Vg1Lokalisationselement bindet sowie mit VegT-RNA, nicht jedoch mit früh lokalisierten mRNAs wie Xcat2 und Xwnt11, interagiert (Zhao et al., 2001). Die Prolin-reichen Bereiche dieses Proteins können mit Profilin interagieren, das an der Polymerisation von Aktinfilamenten beteiligt ist und an mikrofilamentassoziierte Proteine binden kann (Wear et al., 2000). Da die Verankerung von vegetal lokalisierten RNAs von Filamenten des Aktin-Zytoskeletts abhängig ist, wird postuliert, daß Prrp nicht nur am Transport der RNAs zum Kortex, sondern auch an der dortigen Interaktion mit dem lokalen Mikrofilamentsystem beteiligt sein könnte.

\subsection{Die Xenopus-Oogenese}

Die Oogenese in Xenopus ist in sechs aufeinander folgende Stadien unterteilt, die sich durch Größe und Erscheinungsbild der Oozyten bestimmen lassen (siehe Abb. 1.3) (Dumont, 1972). Neben der auffälligen Änderung der Pigmentierung der Oozyte und der rezeptorvermittelten Endozytose und Speicherung großer Mengen Vitellogenin aus dem Blut, finden während der Oogenese aber auch Umordnungen subzellulärer Strukturen und des Zytoskeletts statt.

Die Stadium I Oozyte ist durch eine Größe von 50-300 $\mu \mathrm{m}$ im Durchmesser, sowie ein transparentes Zytoplasma ausgezeichnet, aufgrund dessen der zentrale Zellkern, sowie die mitochondriale Wolke gut sichtbar erscheinen (siehe Abb. 1.4 A). Während des Stadiums II (300-450 $\mu \mathrm{m})$ zerfällt die mitochondriale Wolke in kleinere Fragmente, die entweder perinukleär lokalisiert und später über das gesamte Zytoplasma verteilt oder zum vegetalen Kortex transportiert werden und dort Bestandteile des Keimplasmas bilden (siehe Abb. 1.4 $B$ und $C$ ). 


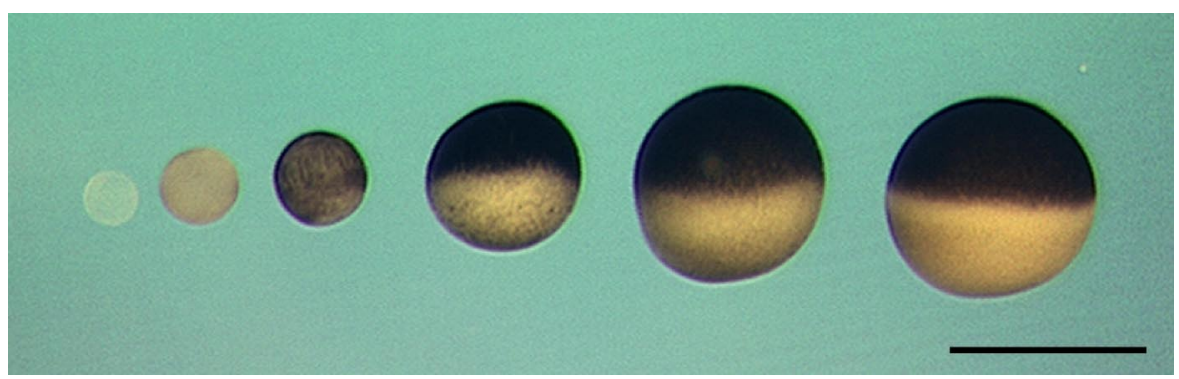

Abb. 1.3 Stadien I-VI der Xenopus-Oogenese. Oozyten des Stadiums I weisen eine Größe von 50-300 $\mu \mathrm{m}$ und ein transparentes Zytoplasma auf. Mit Fortschreiten der Oogenese erfolgt die Aufnahme von Vitellogenin in zytoplasmatischen Dotterschollen, sowie die Einlagerung kortikaler Pigmentgranula in der animalen Hemisphäre der Oozyte. Charakteristisch für das Stadium VI ist der unpigmentierte äquatoriale Bereich der Oozyte, die eine Größe von bis zu 1,3 mm im Durchmesser erreichen kann. Die Bestimmung der Oozytenstadien erfolgte nach Dumont, 1972. Der Balken im unteren Bildrand repräsentiert ca. $1 \mathrm{~mm}$.

Mit Beginn des Stadiums III der Oogenese, in dem die Oozyten eine Größe von 450-600 $\mu \mathrm{m}$ im Durchmesser erreicht haben, setzt die Vitellogenese genannte Aufnahme von Dotterproteinen aus dem Blutstrom in die Oozyte ein. Vitellogenin wird im Zytoplasma in Phosvitin und Lipovitellin gespalten und bildet den Hauptbestandteil der Dotterschollen. Zum Ende dieses Stadiums beginnt auch die Einlagerung von Pigmentgranula, die zunächst noch über den gesamten Kortex verteilt sind. Während des Stadiums IV der Oogenese wird die animal-vegetale Polarität der Oozyte auch äußerlich durch eine differentielle Verteilung dieser Pigmentgranula offenbar (siehe auch Abb. 1.4 D und E). Während der vegetale Pol der Oozyte nur schwach pigmentiert ist, zeichnet sich der animale durch eine starke Pigmentierung aus. Mit dem Stadium V hat die Oozyte mit einem Durchmesser von 1000-1200 $\mu \mathrm{m}$ ihre endgültige Größe fast erreicht. Aufgrund der ungleichen Verteilung der Dotterproteine zwischen animalem und vegetalem Zytoplasma ist der Zellkern nun nicht mehr zentral gelegen, sondern zum animalen Pol verschoben (siehe auch Abb. 1.4 D und E). Im Stadium VI hat die Oozyte mit bis zu $1300 \mu \mathrm{m}$ ihre endgültige Größe erreicht. Charakteristisch für dieses Stadium ist die Trennung der dunklen animalen Hemisphäre von der nur wenig pigmentierten vegetalen Hemisphäre durch einen nichtpigmentierten äquatorialen Gürtel (siehe Abb. 1.3). 


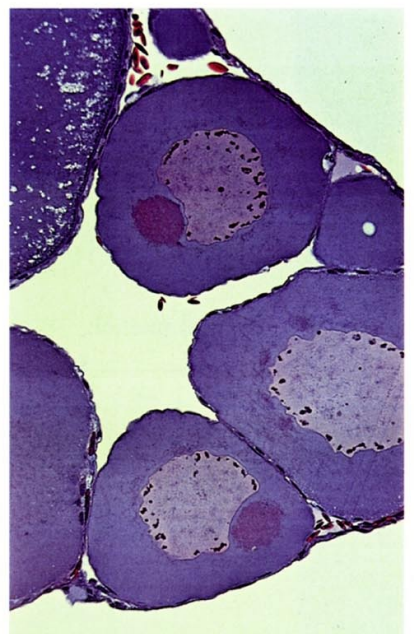

A

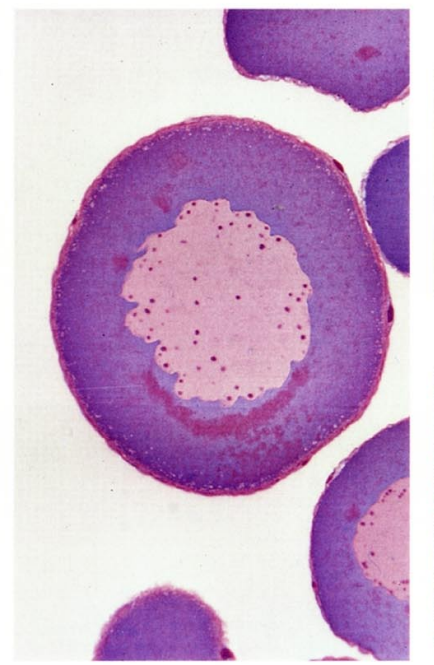

B

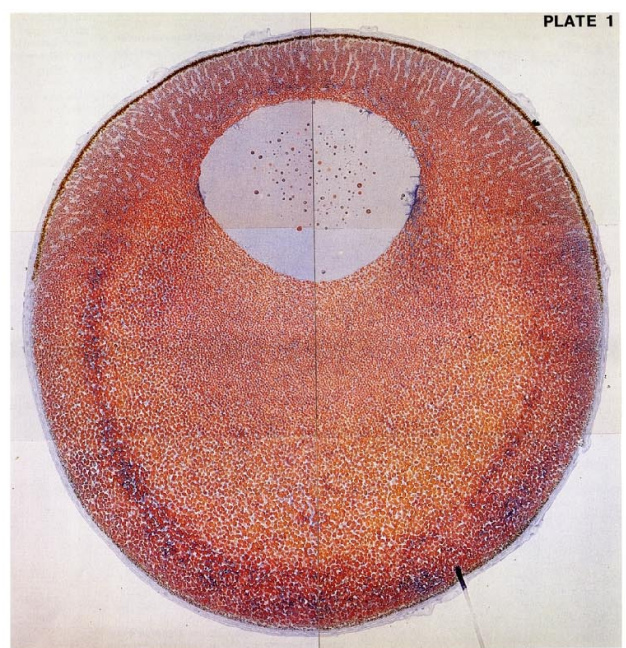

D

$\mathbf{E}$

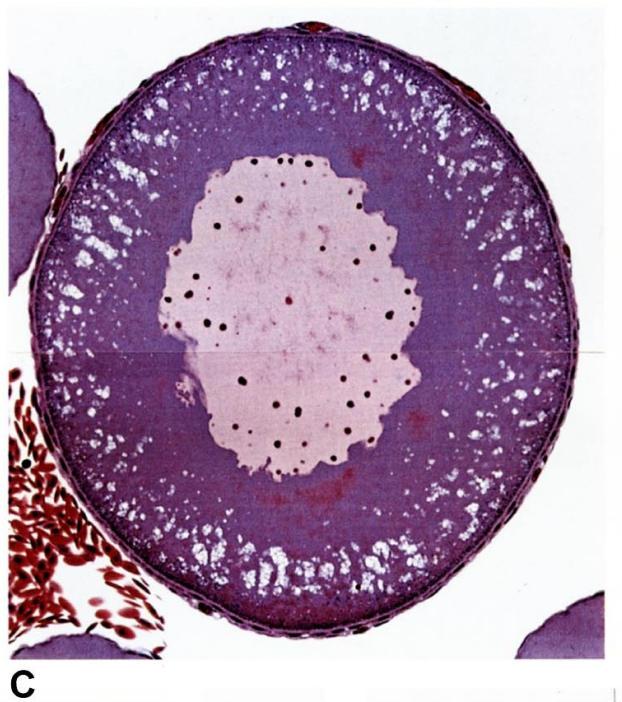

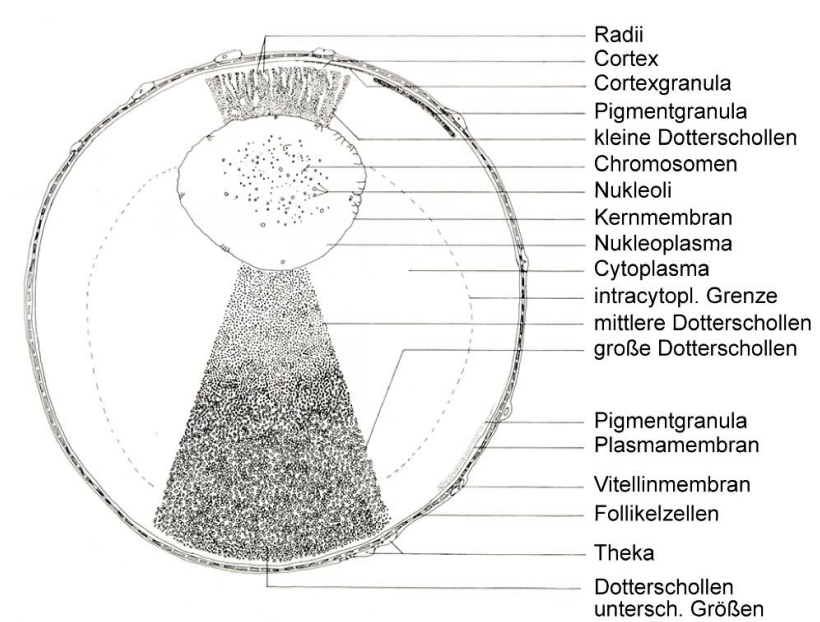

Abb. 1.4 Histologische Schnitte durch Xenopus-Oozyten unterschiedlicher Stadien. A. Der zentral gelegene Zellkern sowie die klar vom Zytoplasma abgegrenzte mitochondriale Wolke sind in Stadium I gut erkennbar. B. In frühen Stadium II Oozyten zerfällt die Struktur der mitochondrialen Wolke und deren Bestandteile werden in Form von inselartigen Strukturen zum vegetalen Kortex verbracht. C. Spätes Stadium II: Die Komponenten der mitochondrialen Wolke haben den Kortex der Oozyte erreicht und bilden dort Bestandteil des Keimplasmas. D. und E. Die Stadium VI Oozyte weist eine deutliche animal-vegetale Polarität auf. Der Zellkern, der Chromosomen sowie zahlreiche Extranukleoli enthält, ist im Zytoplasma der animalen Hemisphäre lokalisiert, deren Kortex sich aufgrund der Einlagerung von Pigmentgranula nun deutlich von dem der vegetalen Hemisphäre unterscheiden läßt. Eine Polarität der Oozyte ist auch durch die asymmetrische Verteilung von Dotterschollen unterschiedlicher Größe ausgebildet (Abbildungen entnommen aus Hausen und Riebesell, 1991).

\subsection{Die Rolle des Zytoskeletts bei der Lokalisation von RNAs in Xenopus Oozyten}

Die Xenopus Oozyte enthält ein komplexes, untereinander verbundenes Netzwerk aus hauptsächlich drei Formen von zytoplasmatischen Filamenten: Mikrotubuli (MTs), die aus Tubulinen und den mit ihnen assoziierten Proteinen (MAPs) zusammengesetzt sind, Mikrofilamente, deren Komponenten Aktin und andere assoziierte Proteine sind, sowie 
Intermediärfilamente, die sich hauptsächlich aus epidermalen Keratinen sowie quervernetzenden Proteinen wie dem Plektin zusammensetzen. Die Organisation dieser Filamente erfüllt wichtige Aufgaben bei der Etablierung und Aufrechterhaltung der animal-vegetalen Polarität der Xenopus Oozyte (Gard, 1995; Gard, 1999; Gard und Klymkowsky, 1998; Klymkowsky, 1995). Aufgrund der Tatsache, daß in Detergenz-unlöslichen Fraktionen des Zytoplasmas eine signifikante Anreicherung von vegetal lokalisierten RNAs nachzuweisen ist, konnten schon sehr früh Hinweise auf eine mögliche Beteiligung des Zytoskeletts am Transport und der Verankerung von vegetal lokalisierten RNAs gewonnen werden (Forristall et al., 1995; Pondel und King, 1988; Yisraeli et al., 1989; Yisraeli et al., 1990).

Über die Rolle des Zytoskeletts beim Transport der früh lokalisierten RNAs in Assoziation mit der mitochondrialen Wolke ist bislang nur wenig bekannt. Weder Nocodazol noch Cytochalasin B scheinen den Transport dieser Transkripte vom Nukleus zur mitochondrialen Wolke oder die Assoziation mit dieser Struktur zu beeinflussen (Kloc et al., 1996). Möglicherweise ist der zytoskelettunabhängige Transport der früh lokalisierten RNAs dem oben beschriebenen Mechanismus der Diffusion und lokalen Anreicherung zuzuordnen. Hingegen scheint jedoch die Verankerung dieser Transkripte nach erfolgter Lokalisation von einem intakten Mikrofilamentsystem abzuhängen, wie für Xlsirts, Xcat2 und Xwnt11 und die spät lokalisierende Vg1-mRNA gezeigt werden konnte (Alarcon und Elinson, 2001; Kloc und Etkin, 1995; Yisraeli et al., 1989; Yisraeli et al., 1990). Die Verankerung der letzteren scheint transient auch von einem intakten Mikrotubulisystem abzuhängen, da nach Nocodazol-Behandlung von Stadium III Oozyten eine Ablösung der RNA vom vegetalen Kortex in inselartige Strukturen zu beobachten ist (Kloc und Etkin, 1995). Ebenso konnte die Mikrotubuliabhängigkeit des Vg1-mRNA-Transports in Injektionsexperimenten demonstriert werden (Yisraeli et al., 1989). Neuere Untersuchungen zur kortikalen Verankerung vegetal lokalisierter RNAs lassen vermuten, daß der Effekt Mikrofilamentzerstörender Drogen auf lokalisierte RNAs jedoch nur indirekter Natur zu sein scheint (Alarcon und Elinson, 2001). In isolierten vegetalen Kortizes können lokalisierte RNAs nach Cytochalasin B-Applikation in inselartigen Strukturen nachgewiesen werden, die denen der Zytokeratin-Fraktion entsprechen. Eine vollständige Ablösung vom Kortex und Entlassung der RNA ins Zytoplasma kann so auch erst nach Destabilisierung und Auflösung des Zytokeratinsystems erzielt werden.

Überraschenderweise scheinen auch vegetal lokalisierte RNAs selbst strukturelle Funktionen bei der Verankerung am vegetalen Kortex zu übernehmen. So konnte nach Injektion von antisense Oligonukleotiden zu repetitiven Elementen der nichtkodierenden Xlsirts und der daraus resultierenden Depletion dieser Transkripte eine Aufhebung der kortikalen Verankerung der Vg1-mRNA, nicht jedoch von früh lokalisierten RNAs wie Xcat2 hervorgerufen werden (Kloc und Etkin, 1994). Die Xlsirt-RNAs sind jedoch nur bis zu Stadium IV der Oogenese am Kortex der Oozyte nachweisbar und scheinen anschließend degradiert oder ins Zytoplasma entlassen zu werden, so daß bei der Verankerung von Vg1- 
mRNAs zumindest in späten Stadien noch andere Faktoren eine Rolle zu spielen scheinen (Kloc et al., 1993). Interessanterweise konnte so auch kürzlich gezeigt werden, daß durch eine antisense Oligonukleotid-vermittelte Depletion von VegT-mRNA eine Auflösung der kortikalen Assoziation spät lokalisierter mRNAs wie Vg1- und XBic-C, sowie der früh lokalisierten Xwnt11 in Stadium VI Oozyten hervorzurufen ist (Heasman et al., 2001). Keinen Einfluß hingegen scheint eine VegT-RNA-Depletion auf die kortikale Verankerung der früh lokalisierten Xcat2 und Xotx1-Transkripte zu haben, was auf die unterschiedliche Art der kortikalen Verankerung der früh lokalisierten, Keimplasma-assoziierten RNAs schließen läßt.

\subsection{Zielsetzung der Arbeit}

Vegetal angereicherte RNAs der Xenopus Oozyte üben wichtige Funktionen bei der frühembryonalen Entwicklung und Determination von Zellschicksalen aus. Um bisher unbekannte, am vegetalen Pol der Xenopus Oozyte lokalisierte RNAs zu identifizieren, sollte eine Xenopus Oozyten cDNA Bibliothek erstellt werden, die primär vegetal und kortikal angereicherte Transkripte enthält. Einzelne Klone dieser cDNA-Bibliothek sollten dann unter Anwendung von whole mount in situ-Hybridisierungstechniken auf ihre subzelluläre Lokalisation in der Oozyte hin untersucht werden. Die Identifizierung vegetal angereicherter RNAs ist nicht nur im Hinblick auf ihre mögliche Funktion bei der frühen Embryonalentwicklung des Frosches von Bedeutung, sondern soll vor allem auch Einblikke in die grundlegenden zellulären Transportmechanismen, auf denen die subzelluläre Anreicherung der Transkripte basiert, ermöglichen. Nach Klonierung der VolllängencDNAs der neu identifizierten vegetal angereicherten RNAs sollten daher die für ihre Lokalisation verantwortlichen cis-agierenden Sequenzen in Injektionsexperimenten charakterisiert und eingegrenzt werden, sowie spezifisch mit diesen interagierende Proteine untersucht werden. 


\section{Materialien, Methoden und Klonierungen}

\subsection{Organismen}

\subsubsection{Xenopus laevis}

Der Afrikanische Krallenfrosch (Xenopus laevis) gehört zu der Familie der zungenlosen Froschlurche (Pipidae) der Ordnung Anura. Pigmentierte und Albino Frösche wurden von Dipl.-Ing. Horst Kähler (Hamburg) und den Firmen Xenopus I (Ann Arbor, USA) und Nasco (Ft. Atkinson, USA) erworben. Die Tiere wurden gemäß den Tierschutzbestimmungen gehalten und behandelt. Die Bestimmung der Embryonalstadien erfolgte nach (Nieuwkoop und Faber, 1967).

\subsubsection{Escherichia coli-Stämme}

Es wurden Escherichia coli-Stämme der folgenden Genotypen verwendet (Stratagene GmbH, Heidelberg; New England Biolabs, Schwalbach/Taunus):

TG1: ist eine Variante des K12-Stamms, die durch die Mutationen $\Delta($ lac-proAB), supE44, thi, hsdD5 [F'traD36 proAB ${ }^{+}$lac $I^{\mathrm{q}}$ lacZ $\left.\Delta \mathrm{M} 15\right]$ gekennzeichnet ist.

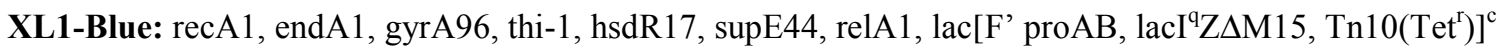

XL1-Blue MRF': $\Delta$ (mcrA)183, $\Delta$ (mcrCB-hsdSMR-mrr)173, endA1, supE44, thi-1, recA1, gyrA96, relA1 lac[F' proAB, lacl $\left.{ }^{\mathrm{q}} \mathrm{Z} \Delta \mathrm{M} 15, \operatorname{Tn} 10\left(\mathrm{Tet}^{\mathrm{r}}\right)\right]^{\mathrm{c}}$

XLOLR: $\Delta(m c r A) 183, \Delta(m c r C B-h s d S M R-m r r) 173$, endA1, thi-1, recA1, gyrA96, relA1 lac[F' proAB, la$c I^{\mathrm{a}} \mathrm{Z} \Delta M 15, \operatorname{Tn} 10\left(\right.$ Tet $\left.\left.^{\mathrm{r}}\right)\right]^{\mathrm{c}}$, Su ${ }^{-}$(nonsuppressing), $\lambda^{\mathrm{r}}$ (lambda resistant)

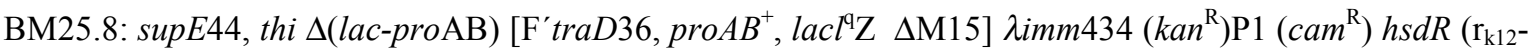
$\left.\mathrm{m}_{\mathrm{k} 12^{-}}\right)$

\subsection{Chemikalien}

Biochemische Feinchemikalien wurden von den Firmen Boehringer Mannheim, Fluka, Roth, Serva und Biomol bezogen. Alle anderen Chemikalien stammten von den Firmen Fluka, Baker oder Merck und wiesen den höchsten Reinheitsgrad (p.A.) auf. Die komplexen Medienbestandteile wurden von DIFCO Laboratories (Detroit, Michigan, USA) bezogen.

\subsection{Gebrauchswaren und Geräte}

Gebrauchswaren und Geräte wurden, soweit nicht anders erwähnt, von den folgenden Firmen bezogen: Abimed (Hannover), Costar (Bodenheim), Eppendorf (Hamburg), Falcon (Heidelberg), Schütt (Göttingen), Greiner (Frickenhausen), Kranich (Göttingen), Qiagen (Hilden), Sarstedt (Langenhagen), Siemens (Hannover).

Microinjector 5242 (Eppendorf, Hamburg), Nadelzieher (Leitz, Wetzlar), UNOII Thermoblock (Biometra, Göttingen), TRIO Thermoblock (Biometra, Göttingen), Stereomikroskop (Stemi SV6, Zeiss, Oberkochen), Kameraaufsatz (MC80, Zeiss, Oberkochen), Fotomikroskop (Axioskop, Zeiss, Oberkochen), Farbvideokamera JVC company, Japan, Vibratom (Typ 1000, Pelco International, Redding, California, USA), Mikrotom (Leica Instruments GmbH, Nussloch), Phosphoimager (Molecular Dynamics).

\subsection{Computer-Software}

Bild- und Graphikbearbeitung: Adobe Photoshop Version 5.5 (Adobe Systems Europe Ltd., Edinburgh, Schottland); Macromedia Freehand Version 9 (Macromedia Inc., San Francisco, USA); ImageQuant Version 3.3 (Molecular Dynamics) 
Nukleotid- und Aminosäuresequenzbearbeitung: Lasergene-Softwarepaket (DNASTAR Inc., Madison, USA); BLAST-Datenbanksuchsystem (Altschul et al., 1990); RNA-Sekundärstrukturvorhersageprogramm Mfolfd 3.1 (Mathews et al., 1999; Zuker et al., 1999); RNA-Struktur-Darstellungsprogramm RNAdraw V1.1 (http://mango.mcf.ki.se/"'ole/rnadraw/rnadraw.htnl)

Textverarbeitung: Microsoft Word 2000

\subsection{Enzyme, Proteine, Nukleinsäuren und Reaktionssysteme (Kits)}

\subsubsection{Enzyme}

Shrimps alkalische Phosphatase (1 U/ $\mu 1)$ : Boehringer Mannheim, Mannheim

Restriktionsendonukleasen: New England Biolabs GmBH, Schwalbach, Boehringer Mannheim, Mannheim RNAsin (40U/ $\mu$ l): Promega Deutschland GmbH, Mannheim RNase A: Sigma-Aldrich Chemie GmbH, Deisenhofen

RNase T1: Sigma-Aldrich Chemie GmbH, Deisenhofen

Proteinase K: Merck KGaA, Darmstadt

SP6 RNA-Polymerase (50 U/ $\mu$ l): Stratagene GmbH, Heidelberg

T3 RNA-Polymerase (50 U/ $\mu 1)$ : Stratagene GmbH, Heidelberg

T7 RNA-Polymerase (50 U/ $\mu \mathrm{l})$ : Stratagene $\mathrm{GmbH}$, Heidelberg

Taq DNA-Polymerase ( $5 \mathrm{U} / \mu \mathrm{l})$ : Perkin-Elmer, Weiterstadt

Pfu DNA-Polymerase (2.5 U/ $\mu \mathrm{l})$ : Stratagene GmbH, Heidelberg

T4 DNA-Ligase (1 U/ $\mu 1$ ): GibcoBRL, Eggenstein, New England Biolabs GmBH, Schwalbach

T4-Polynukleotidkinase (10 U/ $\mu 1)$ : New England Biolabs GmBH, Schwalbach

Dnase I: Boehringer Mannheim, Mannheim

\subsubsection{Proteine}

BSA: Sigma-Aldrich Chemie GmbH, Deisenhofen

\subsubsection{Nukleinsäuren}

E. coli tRNAs: Boehringer Mannheim, Mannheim

\subsubsection{Reaktionssysteme (Kits)}

PCR purification Kit: Qiagen GmbH, Hilden

QIAEX Gel Extraction Kit: Qiagen GmbH, Hilden

RNeasy Mini Kit: Qiagen GmbH, Hilden

RT-PCR Kit: Perkin-Elmer, Weiterstadt

SP6, T3 und T7 mMESSAGE mMACHINE Kits: Ambion Inc., Austin, USA

pGEM-T Kit: Promega Deutschland GmbH, Mannheim

$\mathrm{T}_{\mathrm{N}} \mathrm{T}$-Coupled Reticulozyte Lysate System: Promega Deutschland GmbH, Mannheim

QuickChange Site-Directed Mutagenesis Kit: Stratagene GmbH, Heidelberg

RNA in vitro Transcription Kit: Stratagene GmbH, Heidelberg

MEGAshortscript in vitro Transcription Kit, Ambion Inc., Austin, USA

Dye Terminator Cycle Sequencing Kit, Applied Biosystems GmbH, Weiterstadt 


\subsection{Molekulargewichtsstandards}

$1 \mathrm{~kb}$ DNA ladder: GibcoBRL/Intvitrogen

Broad-range Protein-Molekulargewichtsstandard: BioRad

RNA Ladder: New England Biolabs GmBH, Schwalbach

\subsection{Radioisotopen}

$\left[\alpha-{ }^{32} \mathrm{P}\right]-\mathrm{rUTP}, 800 \mathrm{Ci} / \mathrm{mmol}, 20 \mathrm{mCi} / \mathrm{ml}$, Amersham Buchler, Braunschweig L- $\left[{ }^{35} \mathrm{~S}\right]-$ Methionin, $1.000 \mathrm{Ci} / \mathrm{mmol}, 10 \mathrm{mCi} / \mathrm{ml}$, Amersham Buchler, Braunschweig $\left[{ }^{14} \mathrm{C}\right]$-methylierter Proteinstandard $5 \mu \mathrm{Ci} / \mathrm{ml}$, Amersham Buchler, Braunschweig

\subsection{Medien und Lösungen}

Alle nicht gesondert aufgeführten Medien und Pufferlösungen wurden nach Sambrook et al., 1989 hergestellt. Wenn nicht anders beschrieben, wurden die Lösungen mit doppelt destilliertem Wasser angesetzt und durch Autoklavieren für $20 \mathrm{~min}$ bei $121^{\circ} \mathrm{C}$ sterilisiert. Hitzelabile Substanzen wurden durch Membranfilter (Porendurchmesser $0.2 \mu \mathrm{m}$, Sartorius) sterilfiltriert.

\subsubsection{Nährmedien}

Luria-Bertani (LB)-Medium: 1\% (w/v) Bacto-Trypton (DIFCO), 0.5\% (w/v) Hefeextrakt (DIFCO), 1\% (w/v) $\mathrm{NaCl}, \mathrm{pH} 7.5$

LB-Agar: $1.5 \%(\mathrm{w} / \mathrm{v})$ Agar (DIFCO) in LB-Flüssigmedium

NZY-Medium: 1\% (w/v) NZ-Amin (Casein Hydrolysat), 0.5\% (w/v) Hefeextrakt (DIFCO), 0.5\% (w/v)

$\mathrm{NaCl}, 8.1 \mathrm{mM}$ MgSO4.7 $\mathrm{H}_{2} \mathrm{O}, \mathrm{pH} 7.5$

NZY-Agar: $1.5 \%(w / v)$ Agar in NZY-Flüssigmedium

NZY-Top-Agar: $0.7 \%(w / v)$ Agar in NZY-Flüssigmedium

\subsubsection{Antibiotika zur Selektion von Bakterienklonen}

Ampicillin: $100 \mathrm{mg} / \mathrm{ml}$ in $\mathrm{dH}_{2} \mathrm{O}$, Verdünnung 1:1.000 (Endkonzentration: $100 \mu \mathrm{g} / \mathrm{ml}$ ) Tetracyclin: $5 \mathrm{mg} / \mathrm{ml}$ in Ethanol, Verdünnung 1: 400 (Endkonzentration: $12.5 \mu \mathrm{g} / \mathrm{ml}$ )

Kanamycin: $10 \mathrm{mg} / \mathrm{ml}$ in $\mathrm{dH}_{2} \mathrm{O}$, Verdünnung 1: 200 (Endkonzentration: $50 \mu \mathrm{g} / \mathrm{ml}$ )

Carbenicillin: $50 \mathrm{mg} / \mathrm{ml}$ in $\mathrm{dH}_{2} \mathrm{O}$, Verdünnung 1:1000 (Endkonzentration: $50 \mu \mathrm{g} / \mathrm{ml}$ )

\subsubsection{Puffer und Stammlösungen}

Tris-HCl-Puffer (pH 7.5 - 9.5): 1 M Tris-HCl, pH 7.5 - 9.5

TBE (10 x): 0.9 M Tris Base, 0.9 M Borsäure, 0.02 M EDTA

PBS (10 x): 8\% (w/v) NaCl, 2\% (w/v) KCl, $65 \mathrm{mM} \mathrm{Na}_{2} \mathrm{HPO}_{4}, 18 \mathrm{mM} \mathrm{KH}_{2} \mathrm{PO}_{4}, \mathrm{pH}$ 7.2-7.4

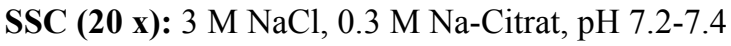

SSPE (20 x): $3 \mathrm{M} \mathrm{NaCl}, 0.2 \mathrm{M} \mathrm{Na}_{2} \mathrm{HPO}_{4}, 20 \mathrm{mM}$ EDTA, pH 7.4

$\mathbf{M g C l}_{2}$-Lösung: $1 \mathrm{M} \mathrm{MgCl}_{2}$

MgSO$_{4}$-Lösung: $1 \mathrm{M} \mathrm{MgSO}_{4}$

LiCl-Lösung: $4 \mathrm{M}$ bzw. $8 \mathrm{MLiCl}$

NaCl-Lösung: $5 \mathrm{M} \mathrm{NaCl}$

KCl-Lösung: $1 \mathrm{M} \mathrm{KCl}$

Natrium-Azetat-Lösung: $3 \mathrm{M} \mathrm{NaCH}_{3} \mathrm{COO}$

Natriumdihydrogenphosphat-Lösung: $1 \mathrm{M} \mathrm{NaH}_{2} \mathrm{PO}_{4}$

Di-Natriumhydrogenphosphat-Lösung: $1 \mathrm{M} \mathrm{Na}_{2} \mathrm{HPO}_{4}$

Ethidiumbromid-Lösung: $10 \mathrm{mg} / \mathrm{ml}$ Ethidiumbromid 
Ficoll: $10 \%(\mathrm{w} / \mathrm{v})$ Ficoll, sterilfiltriert

EDTA: 0.5 M EDTA, $\mathrm{pH} 8.0$

Maltose-Lösung: $20 \%$ Maltose $\cdot \mathrm{H}_{2} \mathrm{O}$, sterilfiltriert

SDS-Lösung: $10 \%(\mathrm{w} / \mathrm{v})$ Natriumdodecylsulfat

Tween-20-Lösung: $20 \%(\mathrm{v} / \mathrm{v})$ Tween-20

Denhardt's (100 x): 2\% (w/v) BSA, 2\% (w/v) PVP, 2\% (w/v) Ficoll

\subsection{Antikörper}

Anti-Digoxigenin/AP (Boehringer Mannheim, Mannheim): Fab-Fragmente von Digoxigenin-spezifischen Antikörpern (aus Ziege), konjugiert mit alkalischer Phosphatase

Anti-Fluorescin/AP (Boehringer Mannheim, Mannheim): Fab-Fragmente von Fluoreszin-spezifischen Antikörpern (aus Ziege), konjugiert mit alkalischer Phosphatase

Anti-c-Myc (9E10; Santa Cruz Biotechnology, Santa Cruz, CA, USA): Myc-Epitop-spezifischer, Monoklonaler Antikörper (Maus)

\subsection{Plasmide und Vektoren}

pBK-CMV: Stratagene, GmbH, Heidelberg

pTriplEx2: Clontech Laboratories GmbH, Heidelberg

pGEM-T: Promega Deutschland GmbH, Mannheim

pCS2+MT: (Rupp et al., 1994)

pAX4: (Markmeyer et al., 1990)

Xpat: (Hudson und Woodland, 1998) 2kb des Xpat 3'-UTR im pBluescript Vektor; wurde nach Linearisierung mit EcoRI in einer T7-Promoter-vermittelten in vitro Transkriptionsreaktion zur Erstellung von in situHybridisierungs-Sonden benutzt.

pMT-21: (Zhao et al., 2001) Prrp cDNA wurde in die BamHI-Schnittstelle des pCS3+MT-Vektors eingefügt. Dieses im Retikulozytenlysat-System in vitro translatierbare Fusionsprotein besitzt am C-Terminus wiederholte myc-Epitope und wurde in Koimmunopräzipitationsanalysen verwendet.

Vg1-RBP-his in pET-21a(+):(Havin et al., 1998) cDNA des Vg1-RBPs; wurde zur Subklonierung in den pCS2+MT-Vektor verwendet.

fl-L5 in pCS2+MT: (Claußen et al., 1999) enthält die cDNA des ribosomalen Proteins L5 aus Xenopus in in vitro translatierbarer Form. Dieses Protein wurde als Negativkontrolle in den Koimmunopräzipitationsanalysen eingesetzt.

Alle anderen Plasmidkonstrukte, die während der experimentellen Phase der Arbeit erstellt wurden, sind in Abschnitt 2.26 detailliert beschrieben.

\subsection{Oligonukleotide}

Oligonukleotide wurden von den Firmen MWG-Biotech (Ebersberg), metabion (Martinsried), Gibco BRL (Karlsruhe) und NAPS (Göttingen) bezogen. Die Sequenzen sind jeweils in 5'- 3'-Richtung angegeben. Üblicherweise wurden die Oligonukleotide im Synthesemaßstab 0,01 $\mu$ mol und HPSF-gereinigt angefordert.

\subsubsection{Sequenzierprimer}

Angegeben sind Oligonukleotide die zur Sequenzierung verschiedener Plasmide verwendet wurden.

T7-primer:

T3-primer:

GTAATACGACTCACTATAGGGC

Sp6-primer:

AATTAACCCTCACTAAAGGG

5' $\lambda$ TriplEx2Seq:

TTAGGTGACACTATAGAATAC

3' $\lambda$ TriplEx2Seq:

CTCCGAGATCTGGACGAGC

TAATACGACTCACTATAGGGC 


\begin{tabular}{|c|c|}
\hline 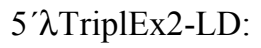 & CTCGGGAAGCGCGCCATTGTGTTGGT \\
\hline $3{ }^{\prime} \lambda$ TriplEx2-LD: & ATACGACTCACTATAGGGCGAATTGGCC \\
\hline pmRR67 : & GAGCTTGGGCGACCTCA \\
\hline pCS-rev : & AАATAAAGCAATAGCATCAC \\
\hline 6E-up-Seq-1: & TAGGCACTACAGCAGTCC \\
\hline 6E-up-Seq-2: & ATGCAGAAGGCGAGGAGC \\
\hline 6E-up-Seq-3: & TCAACCTGTAATGGAGAGG \\
\hline 6E-up-Seq-4: & TCAGTCATTGTCTGAACC \\
\hline 6E-up-Seq-5: & ACTGGGTTGGAAGAGGTGC \\
\hline 11C-Seq-primer: & TGATGTGTTAAATGCCAGTGAC \\
\hline 11C-Seq-low: & ATGCACATATTCATATCACC \\
\hline 11C-Seq-up2: & TACTGGACAAATCCTTCATG \\
\hline 11C-Seq-up3: & TCAAGCTTTTAAAGTAGC \\
\hline 11C-low-seq-2: & AGCTGGAAGGAGACAAGC \\
\hline 11C-low-seq-3: & AAGGTGTACAGATGCTTCG \\
\hline S-9D-up-1: & TTCTCAAGCGGAATTGTTGG \\
\hline S-9D-up-2: & TGCTATGGGCTTCAACAGACC \\
\hline S-9D-up-3: & TGAAGTCATCTATGCCTTACG \\
\hline S-9D-up-4: & TGCTGAAAGAATTGTACCAG \\
\hline S-9D-up-5: & TGACATGATACAAAGATTCC \\
\hline S-9D-up-6: & TATGGACATGGATGAGATGG \\
\hline S-9D-low-1: & ACAATGGCACAGTAACACAGG \\
\hline S-9D-low-2: & TGTACCGCAGTCAACACTTGC \\
\hline S-9D-low-3: & АACTAAGTCTCTACAGACCG \\
\hline S-9D-low-4: & TTTGGCATTGTTGCAAGTGC \\
\hline S-9D-low-5: & AGAGAGTGATTGGCTAGGTCC \\
\hline 10B-up-Seq-1: & AGTATTGATATACACACG \\
\hline 10B-up-Seq-2: & ACCAGCTCATTCTCTGCC \\
\hline 10B-up-Seq-3: & TCACCCAGGTCTCTAACC \\
\hline 10B-up-Seq-4: & ACAATACATCAGGTCTATG \\
\hline 10B-up-Seq-5: & AATAAGTTATGTAACAGG \\
\hline 2B-up-Seq: & AGGAATTCTAAAGGGCTCCATG \\
\hline 2B-low-Seq: & TGGCATCCCAGTCCAACACTGG \\
\hline
\end{tabular}

\subsection{2 (RT-)PCR-Oligonukleotide}

Die angegebenen Oligonukleotide wurden zur Expressionsanalyse in Embryonalstadien und adulten Geweben sowie zur PCR-vermittelten Durchmusterung der Stadium V/VI Oozyten cDNA-Bibliothek benutzt. Die generellen Bedingungen der PCR-Reaktionen sind unter 2.13.7 angegeben. Oligonukleotidspezifische Bedingungen bezüglich der Anlagerungstemperatur, Amplifikationszyklenzahl und die resultierende Produktlänge sind unten angegeben.

\subsubsection{6E und Spleißvarianten}

B2B-6E-UP2:

TAAAAATGAACACGACGGCACCTC

B2B-6E-LOW:

Annealing-Temp.:

Zyklenanzahl:

CACAGCCTTTACCGTCTGAACTATGT

Produktlänge:

34

429 bp

\subsubsection{A3A-11C (XPTB)}

A3A-11C-UP1:

A3A-11C-LOW1:

Annealing-Temp.:

Zyklenanzahl:

Produktlänge:
TCCTGCAGCCATTTTAGAACCAA ATAGCAGGGAAGACCAAACGAAATG $54^{\circ} \mathrm{C}$

34

378 bp 


\subsubsection{B2B-9D (DEADSouth-Isoform)}

B2B-9D-UP2:

B2B-9D-LOW:

Annealing-Temp.:

Zyklenanzahl:

Produktlänge:
ACAAATTGTGTAGAATCGCCCACTTCAC

CAGACCGAAATAACTGTTGCTAAA

$52^{\circ} \mathrm{C}$

34

$251 \mathrm{bp}$

\subsubsection{B2B-10B (XNIF)}

B2B-10B-UP2:

B2B-10B-LOW:

Annealing-Temp.:

Zyklenanzahl:

Produktlänge:

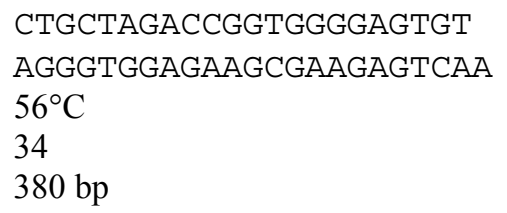

\subsubsection{B2B-2B}

B2B-2B-UP2:

B2B-2B-LOW:

Annealing-Temp.:

Zyklenanzahl:

Produktlänge:

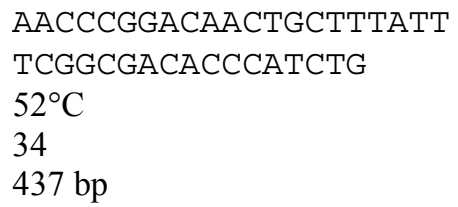

\subsubsection{H4 (Kontrolle)}

$\begin{array}{ll}\text { H4-F: } & \text { CGGGATAACATTCAGGGTATCACT } \\ \text { H4-R: } & \text { ATCCATGGCGGTAACTGTCTTCCT } \\ \text { Annealing-Temp.: } & 56^{\circ} \mathrm{C} \\ \text { Zyklenzahl: } & 24 \\ \text { Produktlänge: } & 200 \mathrm{bp}\end{array}$

\subsection{Arbeiten mit Bakterien}

\subsubsection{Anzuchtbedingungen}

Aerobe Anzuchten erfolgten in 12 ml-PPN-Röhrchen (Greiner) oder in Erlenmeyerkolben aus Duranglas bis $2000 \mathrm{ml}$ Volumen (Schott, Mainz), die mit 10-15\% des Nennvolumens mit Nährmedium gefüllt wurden. Die Inkubation der Kulturen erfolgte je nach Bakterienstamm bei $30-37^{\circ} \mathrm{C}$ im Rundschüttelinkubator (New Brunswick Scientific, Edison,NY, USA). In $12 \mathrm{ml}$ PPN-Röhrchen wurden $3 \mathrm{ml}$ des entsprechenden Anzuchtmediums mit einer Einzelkolonie bzw. einer Stammkultur inokuliert. $100 \mu 1$ der Vorkultur dienten als Inokulum der Hauptkultur.

\subsubsection{Trübungsmessungen}

Der Wachstumsverlauf von Bakterienkulturen wurde durch Bestimmung der optischen Dichte der Zellsuspension bei einer Wellenlänge von $600 \mathrm{~nm}$ im Extinktionsbereich 0-1 gegen einen Leerwert mit unbeimpften Nährmedium in einem Spektralphotometer (Pharmacia) verfolgt. Es wurden Einmal-Halbküvetten (1 ml) mit einer Schichtdicke von $\mathrm{d}=1 \mathrm{~cm}$ verwendet.

\subsubsection{Herstellung elektrokompetenter Bakterienzellen}

Zur Anzucht elektrokompetenter E. coli-Zellen (z.B. TG1 oder XL1-Blue) wurde zunächst ein Einzelkolonieaustrich auf einer Minimal-Agarplatte mit $12,5 \mu \mathrm{g} / \mathrm{ml}$ Tetracyclin angefertigt und eine Einzelkolonie dieser Platte zum Beimpfen einer $25 \mathrm{ml}$ Flüssigkultur verwandt und bei $37^{\circ} \mathrm{C}$ über Nacht im Schüttelinkubator inkubiert. $250 \mathrm{ml}$ Nährlösung in einem $1000 \mathrm{ml}$ Erlenmeyerkolben wurden dann mit dieser Vorkultur 
beimpft und bei $37^{\circ} \mathrm{C}$ mit $200 \mathrm{rpm}$ bis zu einer OD 600 von $0,8-1,0$ (mid log-Phase) inkubiert und und anschließend in einem Eisbad gekühlt. Die Zellen wurden mit $7000 \mathrm{rpm}$ im GSA-Rotor der Sorvall CL6BKühlzentrifuge (DuPont, Bad Homburg) bei $4^{\circ} \mathrm{C}$ für 10 min pelletiert und mit vorgekühlten $\left(4^{\circ} \mathrm{C}\right)$ Lösungen jeweils vollständig resuspendiert und gewaschen.

$1 \times$ Vol. $\quad \mathrm{dH}_{2} \mathrm{O}$

$1 \times 1 / 2$ Vol. $\quad 10 \%(\mathrm{~V} / \mathrm{V})$ Propantriol in $\mathrm{dH}_{2} \mathrm{O}$

$1 \times 1 / 2$ Vol. $10 \%(\mathrm{~V} / \mathrm{V})$ Propantriol in $\mathrm{dH}_{2} \mathrm{O}$

Das Zellpellet wurde anschließend in 1/500 bis $1 / 1000$ Volumen des ursprünglichen Kulturvolumens resuspendiert. Die elektrokompetenten Bakterienzellen wurden in 1,5 ml Eppendorfreaktionsgefäßen zu $90 \mu 1$ aliquotiert (ausreichend für zwei Transformationsansätze), in flüssigem Stickstoff schockgefroren und bis zum Gebrauch bei $-70^{\circ} \mathrm{C}$ gelagert.

\subsubsection{Elektrotransformation von Bakterienzellen}

Zur Elektrotransformation von E. coli-Zellen mit Plasmid-DNA wurden $40 \mu 1$ elektrokompetente Zellen auf Eis aufgetaut und mit 1,5 $\mu 1$ Ligationsansatz versetzt. Dieser Ansatz wurde in eine Elektrotransformationsküvette pipettiert und bei $2,5 \mathrm{kV}$ ca. 4,8 bis $5 \mathrm{msec}$ elektrotransformiert. Hierzu wurde ein Elektroporationsgerät „E. Coli Pulser“ der Firma Biorad Laboratories GmbH, München verwendet. Anschließend wurde der Ansatz mit $1 \mathrm{ml}$ LB-Medium versetzt und für 30 min bei $37^{\circ} \mathrm{C}$ im Inkubator belassen. Von diesem Ansatz wurden dann jeweils 20 und $200 \mu$ lauf einer LB-Agarplatte mit entsprechendem Antibiotikum ausgestrichen und für $10 \mathrm{~h}$ bei $37^{\circ} \mathrm{C}$ inkubiert. Konnte zur Kontrolle der Insertion eines DNAFragmentes in das Plasmid eine Blau/Weiß-Selektion durchgeführt werden, wurden die LB-Agarplatten vor dem Ausplattieren der Zellen mit IPTG und X-Gal versetzt.

\subsubsection{Anlegen von Propantriol-Stammkulturen}

Zur Stammhaltung wurden die Bakterien in Flüssigmedium kultiviert und nach Wachstum über Nacht mit $1 / 3$ Vol. Propantriol versetzt und bei $-70^{\circ} \mathrm{C}$ eingefroren. Die Bakterienstämme wurden zur Anzucht aus Stammkulturen auf entsprechenden Agarplatten ausplattiert und eine Einzelkolonie hiervon zum Beimpfen einer Flüssigkultur verwandt.

\subsection{DNA-Techniken}

\subsubsection{Präparation von Plasmid-DNA im analytischen und präparativen Maßstab}

Zur Präparation geringer Mengen von Plasmid-DNA wurde die Methode der alkalischen Lyse von Bakterienzellen verwendet. Für die Plasmidpräparation wurden dazu zunächst $2 \mathrm{ml}$ einer $3 \mathrm{ml}$ Über-NachtBakterienkultur in einem $2 \mathrm{ml}$ Eppendorfreaktionsgefäßes bei $8000 \mathrm{rpm}$ für $2 \mathrm{~min}$ in einer EppendorfTischzentrifuge pelletiert. Der Überstand wurde verworfen und das Zellpellet in $100 \mu 1$ Mini-Lösung 1 resuspendiert. Nach 5 min Inkubation bei RT wurden zur alkalischen Lyse der Zellen $200 \mu 1$ Mini-Lösung 2 hinzugegeben und sorgfältig durchmischt. Zur Ausfällung von Proteinen und SDS wurden dann $150 \mu 1$ MiniLösung 3 hinzugegeben und der Ansatz nach vorsichtigem Durchmischen für 10 min auf Eis inkubiert. Durch 15 min Zentrifugation bei $4^{\circ} \mathrm{C}$ und $14000 \mathrm{rpm}$ in der Tischzentrifuge wurden Zelltrümmer, Proteine und genomische DNA pelletiert. Der Überstand wurde in ein neues Reaktionsgefäß überführt und zur Fällung von Nukleinsäuren mit 2,5 Vol. Ethanol versetzt. Anschließend wurden die Ansätze für 15 min bei $14000 \mathrm{rpm}$ zentrifugiert, das Pellet mit $1 \mathrm{ml} 70 \%$ Ethanol gewaschen, getrocknet und in $30 \mu \mathrm{ld} \mathrm{d}_{2} \mathrm{O}$ oder $1 \times \mathrm{TE}$ aufgenommen. Bei Bedarf erfolgte vorangehend die Entfernung der RNA aus der Präparation durch RNAse ABehandlung und anschließende Phenol/Chloroform-Extraktion. 
Mini-Lösung 1: $50 \mathrm{mM}$ Glukose; $50 \mathrm{mM}$ Tris/HCl, pH 8,0; $10 \mathrm{mM}$ EDTA, pH 8,0

Mini-Lösung 2: 0,2 M NaOH; 1\% SDS

Mini-Lösung 3: 3M NaAc, pH 5,5

Zur Präparation großer Mengen von Plasmid-DNA für Klonierungen oder präparative Restriktionsendonukleolytische Spaltungen wurde das Reaktionssystem "Plasmid Midi Kit" (Qiagen, Hilden) nach Angaben des Herstellers verwendet.

\subsubsection{Konzentrationsbestimmung von Nukleinsäuren}

Nukleinsäure-Konzentrationen wurden in einem Spektralphotometer (Pharmacia Biotech) bei $260 \mathrm{~nm}$ gegen einen Leerwert bestimmt. Die Konzentration wurde aus der $\mathrm{OD}_{260} \mathrm{~nm}$ wie folgt errechnet:

- $\mathrm{OD}_{260}=1$ entspricht $50 \mu \mathrm{g}$ dsDNA

- $\mathrm{OD}_{260}=1$ entspricht $40 \mu \mathrm{g}$ RNA

Um die Reinheit (Proteinfreiheit) einer Nukleinsäure-Präparation abzuschätzen, wurde außerdem die Extinktion bei $280 \mathrm{~nm}$ gemessen. Der Quotient $\mathrm{OD}_{260 \mathrm{~nm}} / \mathrm{OD}_{280 \mathrm{~nm}}$ beträgt bei proteinfreier DNA bzw. RNA 1.8-2. In den meisten Fällen wurde das automatische Programm des Photometers zur Bestimmung von DNA- bzw. RNA-Konzentrationen verwendet.

\subsubsection{Restriktionsendonukleolytische Spaltung von Nukleinsäuren}

Zur analytischen und präparativen Spaltung von DNA wurde diese mit 2 bis $10 \mathrm{U}$ einer Restriktionsendonuklease pro $1 \mu \mathrm{g}$ DNA $1 / 2$ bis $24 \mathrm{~h}$ bei 25,30 bzw. $37^{\circ} \mathrm{C}$ im entsprechenden Restriktionspuffer inkubiert.

\subsubsection{Nicht-denaturierende Agarose-Gelelektrophorese}

Analytische und präparative Agarose-Gelelektrophoresen wurden in 50-100 ml Gelvolumen fassenden, horizontalen Elektrophoresekammern durchgeführt (hauseigene Werkstatt). Die eingesetzten AgaroseKonzentrationen lagen zwischen $0,5-2 \%(\mathrm{w} / \mathrm{v})$ in $1 \times$ TBE-Puffer, der mit $0,5 \mu \mathrm{g} / \mathrm{ml}$ Ethidiumbromid versetzt wurde.

5×TBE-Puffer: 445 mM Tris; 445 mM Borsäure; 10 mM EDTA/NaOH (pH 8,0)

Die aufzutrennende DNA wurde vor dem Auftrag mit 1/5 Vol. Einer Farbstoffschwerelösung versetzt. Die Elektrophoresen wurden je nach Kammergröße und Laufpuffervolumen bei 80-150 V konstant durchgeführt. DNA-Farbstoff-Schwerelösung: 0,25 \% (w/v) Bromphenolblau; 0,25 \% (w/v) Xylenecyanol; $15 \%$ (w/v) Ficoll (Type 400, Pharmacia) in $\mathrm{dH}_{2} \mathrm{O}$.

Nach erfolgter Auftrennung wurden die Nukleinsäure-Banden auf einem UV-Transilluminator (Herolab) sichtbar gemacht. Zur Dokumentation wurde ein Videosystem (Easy View) der Firma Herbold, Wiesbach verwendet. Durch paralleles Auftrennen eines Molekulargewichts-Standards konnte die Größe der DNAFragmente abgeschätzt werden.

\subsubsection{Dephosphorylierung von DNA-Fragmenten}

Um bei geschnittenen Vektoren mit kompatiblen Enden eine Religation zu verhindern, wurden diese an ihren 5'-Enden dephosphoryliert. Hierzu wurde die zu dephosphorylierende DNA mit 2-10 U Shrimps Alkaline Phosphatase (SAP) in $1 \times$ SAP-Inkubationspuffer bei $37^{\circ} \mathrm{C}$ für $1 \mathrm{~h}$ inkubiert. Anschließend wurde das Enzym bei $70^{\circ} \mathrm{C}$ für 15 min hitzeinaktiviert und die DNA durch Elution aus dem Agarosegel aufgereinigt und in die Ligation eingesetzt. 


\subsubsection{Isolierung von DNA-Fragmenten aus Agarose-Gelen}

Zur präparativen Isolierung einzelner DNA-Fragmente aus Restriktionsendonukleolytischen Spaltungen wurden das QIAEX-System der Firma Qiagen entsprechend den Angaben des Herstellers verwendet.

\subsubsection{Polymerasekettenreaktionen (PCR) im analytischen und präparativen Maß- stab}

Die Polymerase-Kettenreaktion (PCR) dient der enzymatischen Amplifikation spezifischer DNA-Segmente. Hierzu wurden Oligonukleotide einer Länge von 18-30 Nukleotiden aus geeigneten flankierenden Bereichen der zu amplifizierenden Sequenz ausgewählt und von verschiedenen Herstellern synthetisiert. Als Matrize (template) dienten gereinigte Plasmid-DNA, einzelne Bakterienkolonien, oder Flüssigkultur-Aliquots von Phagen oder Bakterien. Ein Reaktionsansatz war wie folgt zusammengesetzt:

- $1 \times$ PCR-Puffer (Perkin-Elmer)

- je $0.2 \mathrm{mM}$ dNTPs

- je 0.15 - $1.5 \mu \mathrm{M}$ sense- und antisense Oligonukleotid

- 0.5-1 U/20 $\mu 1$ Taq-Polymerase (Perkin-Elmer)

-1-100 ng DNA-"template"

Das Reaktionsvolumen betrug 20-100 $\mu 1$.

Zum Schutz vor Verdunstung während der Temperaturzyklen wurde der Ansatz mit ca. $80 \mu 1$ Mineralöl überschichtet. Die Abfolge der einzelnen Schritte der PCR wurde durch Variation der Inkubationstemperatur im PCR-Gerät gesteuert; das Denaturieren der DNA-Matrize erfolgte bei $94{ }^{\circ} \mathrm{C}$, das Anlagern der Oligonukleotide je nach Spezifität und Schmelzpunkt der Oligonukleotide bei $48-60^{\circ} \mathrm{C}$ und der Elongationsschritt bei $72^{\circ} \mathrm{C}$. Ein Standardprotokoll für die Synthese eines bis zu 1.000 bp großen DNA-Segmentes bestand aus 3040 Zyklen von je 1 min Denaturierung bei $94^{\circ} \mathrm{C}$, 1 min Anlagerung der Oligonukleotide bei $50-60^{\circ} \mathrm{C}$ und 1 min Polymerisierung bei $72{ }^{\circ} \mathrm{C}$. Diesem Programm wurde ein Denaturierungsschritt von $2-3$ min bei $94^{\circ} \mathrm{C}$ vorgeschaltet und nach Beendigung der Zyklen ein zusätzlicher Elongationsschritt von 10 min bei $72^{\circ} \mathrm{C}$ durchgeführt.

Um die Fehlerfrequenz bei der DNA-Amplifikation zu reduzieren, wurde zur Synthese von DNAFragmenten, die für eine Umklonierungen verwendet werden sollten, Pfu-Polymerase (Stratagene) mit 3' $\rightarrow$ 5' Exonuklease ("proofreading")-Aktivität verwendet.

Um Bakterienklone zu identifizieren, die nach Ligation und Transformation das gewünschte Insert enthielten, wurde neben der Analyse durch Präparation von Plasmid-DNA mit anschließender Restriktionsendonukleolytischer Spaltung, häufig auch eine analytische PCR direkt mit Koloniematerial durchgeführt ("colony-PCR"). In die "colony-PCR" wurde in den meisten Fällen eine Kombination von zwei gegenläufigen Oligonukleotiden eingesetzt, von denen das eine komplementär zu Vektorsequenzen und das andere komplementär zu Insertsequenzen war. Das resultierende Produkt konnte somit nur bei erfolgreicher, gerichteter Integration des Inserts gebildet werden. Die Insertion von DNA-Fragmenten, deren Sequenz nicht bekannt war, konnte durch Verwendung zweier gegenläufiger vektorspezifischer Oligonukleotide überprüft werden, wobei die Integration des DNA-Fragmentes an der Produktgröße der PCR-Reaktion zu erkennen ist. Hierzu wurde zunächst eine Einzelkolonie mit einer „Kristall“-Pipettenspitze aufgenommen und in einen einfachen Ansatz der "colony-PCR" (22.5 $\mu$ l Gesamtvolumen) ausgewaschen. Mit derselben Pipettenspitze wurde hernach ein Ausstrich auf einer Agarplatte mit Selektionsantibiotikum durchgeführt. Konnten so mittels der PCR-Reaktion Bakterienklone identifiziert werden, die das gewünschte Insert trugen, wurden zur Plasmidisolierung im präparativen Maßstab entsprechende Bakterienausstriche zum Beimpfen einer Flüssigkultur verwandt. 


\subsubsection{Aufreinigung von PCR-Produkten}

Um Produkte aus präparativen PCR-Ansätzen oder linearisierte Vektor-DNA aufzureinigen, wurde das "PCR Purification Kit" (Qiagen) nach Angaben des Herstellers verwendet.

\subsubsection{Klonierung und Subklonierung von PCR-Produkten und DNA-Fragmenten}

Zur ungerichteten Klonierung von PCR-Produkten wurde das pGEM-T-System von Promega nach Angaben des Herstellers verwendet.

Zur gerichteten Klonierung von DNA-Fragmenten (Inserts) in Vektoren wurden falls möglich zwei verschiedene Restriktionsendonukleasen gewählt, die inkompatible, überhängende DNA-Enden generieren. Der Vektor und das zu inserierende DNA-Fragment wurden mit entsprechenden Restriktionsendonukleasen gespalten, gelelektophoretisch isoliert und in die Ligation eingesetzt. Vektoren, die glatte oder kompatible DNA-Enden aufwiesen, wurden vor der Auftrennung dephosphoryliert um eine Religation des Vektors zu vermeiden. Beim Fehlen geeigneter Restriktionsschnittstellen in den zu klonierenden DNA-Segmenten konnten diese in der PCR angefügt werden, indem Oligonukleotide verwendet wurden die an ihrem 5'-Ende um das entsprechende Restriktionsmotiv sowie einige zusätzliche Nukleotide verlängert waren.

\subsubsection{Ligation von DNA-Fragmenten}

Die Ligation kompatibler DNA-Enden wurde unter Verwendung von T4-DNA-Ligase (NEB bzw. Gibco) in einem $15 \mu$ Reaktionsansatz unter Verwendung des vom Hersteller mitgelieferten $5 \times$ bzw. 10× Puffers durchgeführt. Vektor und zu inserierendes Fragment wurden dabei im üblicherweise im Mengenverhältnis 1:3 eingesetzt. Die Ligation wurde bei RT oder $16^{\circ} \mathrm{C}$ für 2 bis $12 \mathrm{~h}$ durchgeführt.

\subsection{RNA-Techniken}

\subsubsection{Behandlung von Gefäßen und Lösungen}

Zur Inaktivierung von RNasen wurden die zum Arbeiten mit RNA bestimmten Gefäße mit $0,5 \mathrm{M} \mathrm{NaOH}$ für mindestens 10 min behandelt und anschließend sorgfältig mit DEPC-behandeltem $\mathrm{dH}_{2} \mathrm{O}$ gespült. Kunststoffgefäße wurden fabrikneu und unbehandelt verwendet. Hitzelabile Substanzen wurden in DEPC-behandeltem $\mathrm{H}_{2} \mathrm{O}$ gelöst. Bei Arbeiten mit RNA wurden stets filtergestopfte Pipettenspitzen verwendet.

\subsubsection{Isolierung von RNA aus Xenopus}

\subsubsection{Oozyten}

siehe 2.16.1 und 2.17 .2

\subsubsection{Embryonalstadien}

Um Gesamt-RNA aus Xenopus-Embryonen zu extrahieren, wurde in einem $1.5 \mathrm{ml}$-Eppendorfreaktionsgefäß pro Ansatz je $0.4 \mathrm{ml}$ Extraktionspuffer in einem Thermoblock (Gesellschaft für Laborgeräte, Wertheim/Main) auf $45^{\circ} \mathrm{C}$ vorgewärmt. Zu dem Puffer wurden $20 \mu \mathrm{l}$ einer Proteinase K-Lösung $(20 \mathrm{mg} / \mathrm{ml})$ gegeben und diese Mischung sofort auf die gefrorenen Embryonen (je 10 pro Präparation) pipettiert. Durch 8 faches Auf- und Absaugen der Probe in einer 1 ml-Einmalspritze mit G30-Kanüle wurden die Embryonen homogenisiert und die DNA geschert. Das Homogenat wurde bei $45^{\circ} \mathrm{C}$ für 45 min inkubiert und anschlieBend wie folgt extrahiert: $1 \times 1$ Vol. Phenol, $1 \times 1$ Vol. Phenol/Chloroform, $1 \times 1$ Vol. Chloroform). Die RNA wurde durch Zugabe von 0.1 Vol. $10 \mathrm{M}$ Ammoniumazetat und 2.5 Vol. Ethanol durch Zentrifugation in einer Eppendorf-Tischzentrifuge (14000 rpm, $30 \mathrm{~min}, \mathrm{RT}$ ) gefällt und in $40 \mu \mathrm{l} \mathrm{DEPC}-\mathrm{dH}_{2} \mathrm{O}$ aufgenommen. Um evt. Im Ansatz enthaltene genomische DNA zu entfernen, wurde die RNA-Lösung nach Zugabe von $2 \mu 1$ 


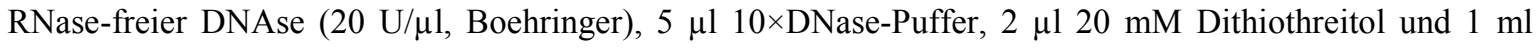
RNasin (40 U/ $\mu 1$, Stratagene) 30 min bei $37^{\circ} \mathrm{C}$ inkubiert. Anschließend wurde die RNA über RNeasy-Säulen aufgereinigt und die Konzentration photometrisch bestimmt.

Extraktionspuffer (1 x): $50 \mathrm{mM}$ Tris- $\mathrm{HCl}(\mathrm{pH} 7.5), 5 \mathrm{mM}$ EDTA (pH 8), $40 \mathrm{mM} \mathrm{NaCl}, 0.5 \%$ SDS in DEPC- $\mathrm{dH}_{2} \mathrm{O}$

DNase-Puffer (10 x): $400 \mathrm{mM}$ Tris-HCl (pH 8.0), $60 \mathrm{mM} \mathrm{MgCl}_{2}, 100 \mathrm{mM} \mathrm{NaCl}, 1 \mathrm{mM} \mathrm{CaCl}{ }_{2}$ in DEPC$\mathrm{dH}_{2} \mathrm{O}$

\subsubsection{Adulte Gewebe und Organe}

Dem Tier entnommene Gewebe und Organe wurden mit $1 \times \mathrm{MBSH}$ gewaschen, in Flüssigstickstoff eingefroren und mit einem in Flüssigstickstoff gekühlten Mörser pulverisiert. Das Pulver wurde in vorgekühlten 1.5 ml-Eppendorfreaktionsgefäßen in $50 \mu$ l-Aliquots aufgeteilt und bis zur Extraktion bei $-70^{\circ} \mathrm{C}$ gelagert. Die RNA-Extraktion wurde wie vorangehend beschrieben durchgeführt.

\subsubsection{Semiquantitative Reverse-Transkriptase-Polymerase-Kettenreakion (RT- PCR)}

Die reverse Transkription von RNA wurde in einem Ansatz des RT-PCR Kits (Perkin Elmer) durchgeführt, der wie folgt zusammengesetzt war:

$2 \mu 1$ 10×PCR-Puffer II

$4 \mu 125 \mathrm{mM} \mathrm{MgCl}_{2}$

je $2 \mu \mathrm{l}$ dATP, dCTP, dGTP, dTTP-Lösung (10 mM)

$1 \mu \mathrm{l}$ RNase Inhibitor $(20 \mathrm{U} / \mu \mathrm{l})$

$1 \mu \mathrm{l}$ Random Hexamers $(50 \mu \mathrm{M})$

$1 \mu l$ Reverse Transkriptase $(50 \mathrm{U} / \mu \mathrm{l})$

bis zu $3 \mu$ l DNA-freie Gesamt-RNA (bis zu $1 \mu \mathrm{g}$ )

RNase-freies $\mathrm{dH}_{2} \mathrm{O}$ ad $20 \mu \mathrm{l}$

Der Ansatz wurde gemischt und mit $50 \mu 1$ Mineralöl überschichtet. In einem PCR-Gerät (Trio, Biometra) durchlief er mit das folgende Temperaturprofil:

$10 \mathrm{~min}$ RT (Anlagerung der Oligonukleotide), $30 \mathrm{~min} 42^{\circ} \mathrm{C}$ (reverse Transkription), $5 \mathrm{~min} 99^{\circ} \mathrm{C}$ (Inaktivierung der reversen Transkriptase), Abkühlen auf $4^{\circ} \mathrm{C}$

Die so erhaltene cDNA wurde anschließend in eine PCR-Reaktion eingesetzt wofür jedem Ansatz folgende Komponenten hinzugefügt wurden:

- 8 ㅅ 10×PCR-Puffer II

- $2 \mu 125 \mathrm{mM} \mathrm{MgCl}_{2}$ (Endkonzentration $1.5 \mathrm{mM}$ )

- $1 \mu \mathrm{l}$ je $15 \mu \mathrm{M}$ sense und antisense Oligonukleotid-Lösung

- $0.5 \mu 1$ Taq-Polymerase (5U/ $\mu 1$, Perkin-Elmer)

- ad $\mathrm{dH}_{2} \mathrm{O}$ auf $80 \mu \mathrm{l}$ (Gesamtvolumen der Reaktion: $100 \mu \mathrm{l}$ )

Die PCR wurde wie unter 2.13.7 beschrieben durchgeführt. Zur Kontrolle auf DNA-Verunreinigungen der eingesetzten RNA-Präparationen, wurden zusätzlich Kontrollreaktionen angesetzt, die keine Reverse Transkriptase enthielten.

\subsubsection{In vitro-Synthese von RNA}

\subsubsection{In vitro-Synthese von Monomethylguanosin-Cap-RNA zur Mikroinjektion}

Synthetische mRNA für Mikroinjektionen in Xenopus Embryonen oder Nuklei von Oozyten wurde unter Verwendung von mMESSAGE mMACHINE Kits der Firma Ambion hergestellt. Bei der in vitro Synthese mit Sp6-, T7- oder T3-Polymerasen wurde dabei am 5'-Ende der Transkripte eine 7-Monomethylguanosin- 
Cap-Struktur angefügt, die für effizienten Export der injizierten Transkripte aus dem Zellkern sowie zur Translationsinitiation benötigt wird. Ein Reaktionsansatz erhielt dabei folgende Komponenten:

$2 \mu 110 \times$ Reaktionspuffer

$10 \mu 12 \times$ rNTP/Cap-Mix

$5 \mu$ linearisierte template DNA $\left(0,2 \mu \mathrm{g} / \mu\right.$ in RNase-freiem $\left.\mathrm{dH}_{2} \mathrm{O}\right)$

$2 \mu 1$ Enzym-Mix

ad RNAse freies $\mathrm{dH}_{2} \mathrm{O}$ auf $20 \mu 1$

Der Ansatz wurde für $2-3 \mathrm{~h}$ bei $37^{\circ} \mathrm{C}$ inkubiert und anschließend mit $1 \mu \mathrm{l}$ DNAseI versetzt und weitere 15 min bei $37^{\circ} \mathrm{C}$ inkubiert, um die template DNA aus dem Transkriptionsansatz zu entfernen.

\subsubsection{In vitro-Synthese von digoxygenin- und floureszinmarkierten RNA-Sonden}

Zur Synthese von markierten antisense RNA-Sonden für in situ-Hybridisierungen wurden in vitro Transkriptionen in Anwesenheit von digoxigenin- bzw. floureszinmarkiertem rUTP durchgeführt. Als template für die RNA-Polymerase wurde linearisierte Plasmid-DNA eingesetzt, die nach präparativer Restriktionsendonukleolytischer Spaltung mit dem RNeasy Mini Kit(Qiagen) aufgereinigt worden war. Es wurde der in vitro RNA-Transkriptions-Kit von Stratagene verwendet, wobei sich ein einfacher Transkriptionsansatz wie folgt zusammensetzte:

$5 \mu 15 \times$ Transkriptionspuffer

$1 \mu 110 \mathrm{mM}$ rATP

$1 \mu 110 \mathrm{mM} \mathrm{rCTP}$

$1 \mu 110 \mathrm{mM}$ rGTP

$0.64 \mu 110 \mathrm{mM}$ rUTP

$0.36 \mu 110 \mathrm{mM}$ Digoxigenin-bzw.Floureszin-rUTP (Boehringer)

$1 \mu 10.75 \mathrm{M}$ DTT

$1 \mu 1$ RNAsin $(40 \mathrm{U} / \mu \mathrm{l})$

$5 \mu 1$ linearisierte "template"-DNA $\left(0.2 \mu \mathrm{g} / \mu \mathrm{l}\right.$, in RNase-freiem $\left.\mathrm{dH}_{2} \mathrm{O}\right)$

$1 \mu \mathrm{T}$ 3, T7 oder SP6-RNA-Polymerase (10 U/ $\mu \mathrm{l})$

ad RNase-freies $\mathrm{dH}_{2} \mathrm{O}$ auf $25 \mu \mathrm{l}$

Der Ansatz wurde bei $37^{\circ} \mathrm{C}$ für $2 \mathrm{~h}$ inkubiert und das DNA-template anschließend durch Zugabe von $1 \mu \mathrm{l}$ RNase-freier DNAse I (Boehringer) 15 min bei $37^{\circ} \mathrm{C}$ entfernt. Nicht-eingebaute Nukleotide sowie Salze des Reaktionspuffers wurden mit Hilfe des RNeasy Mini Kits (Qiagen) entfernt.

\subsubsection{In vitro-Synthese von ${ }^{32}$ P-UTP-markierten RNAs}

Zur in vitro-Synthese radioaktiv markierter RNAs wurde ebenfalls der in vitro-Transkriptions-Kit der Firma Stratagene verwendet. Der Ansatz wurde dabei insofern modifiziert, als daß diesem anstelle des nichtradioaktiv markierten rUTPs, $5 \mu \mathrm{l}[\alpha 32 \mathrm{P}]$-rUTP (kalibriert auf $20 \mu \mathrm{Ci} / \mu \mathrm{l}$ ) hinzugefügt wurden. Die Aufreinigung radioaktiv markierter RNAs erfolgte je nach Anwendung mit dem RNeasy Mini Kit (Qiagen), über Sephadex G50-Säulen (Pharmacia), die UB-blue-Methode (nach D.S. Goldfarb) oder durch Elution der radioaktiven Probe nach denaturierender Harnstoff-PAGE. Die Aktivität der Probe wurde durch Messung der cpm oder dpm im „Quick-Counter“ (Bioscan, Washington DC, USA) bestimmt.

\subsubsection{Aufreinigung von RNA-Transkripten mit dem RNeasy Mini Kit (Qiagen)}

Um synthetische RNA von Salzen, Enzymen und Nukleotiden abzutrennen wurden die Ansätze mit Hilfe des RNeasy Mini Kits (Qiagen) nach Angaben des Herstellers aufgereinigt. 


\subsubsection{Aufreinigung von RNA-Transkripten unter Verwendung von Sephadex G50- Säulen}

Zur Abtrennung von nicht-inkorporierten radioaktiv markierten Nukleotiden aus einem in vitro Transkriptionsansatz kann die Methode der Gelfiltration unter Verwendung von Sephadex MicroSpinTM G-50 Säulen (Amersham Pharmacia Biotech) angewendet werden. Dabei werden die kleineren nichtinkorporierten Nukleotide in der Gelmatrix zurückgehalten während größere Moleküle wie die zu reinigenden RNAs eluiert werden können. Die Chromatographiematrix der Säule wurde dazu durch vortexen gut durchmischt und der Suspensionspuffer durch einmaliges Zentrifugieren bei $735 \times \mathrm{g}$ (3000 rpm) für $1 \mathrm{~min}$ in der Eppendorf Tischzentrifuge abgetrennt. Danach wurde die RNA-Probe in einem Volumen von $50 \mu 1$ auf die Säule aufgebracht und ebenfalls bei $735 \times \mathrm{g}$ für zwei min zentrifugiert. Anfolgend wurde die Aktivität der Probe im QuickCounter bestimmt, sowie ein Aliquot auf einem denaturierenden Harnstoff PA-Gel analysiert.

\subsubsection{Aufreinigung von RNA-Transkripten mit der UB-blue-Methode}

Zur Aufreinigung von radioaktiv markierten RNAs wurde hierbei das Volumen des Ansatzes durch Zugabe von UB-blue auf $200 \mu \mathrm{l}$ adiert. Anschließend wurde die RNA mit Phenol/Chloroform und Chloroform extrahiert und durch Zugabe des 2,5-fachen Volumens Ethanol bei $-20^{\circ} \mathrm{C}$ gefällt. Bei geringen RNAKonzentrationen wurden dem Ansatz $1 \mu \mathrm{g}$ E. coli tRNA oder $1 \mu \mathrm{g}$ Glykogen hinzugefügt. Nach Zentrifugation des Ansatzes bei 14000 rpm für 30 min wurde das Pellet $1 \times$ mit $70 \%$ Ethanol gewaschen, getrocknet und in einem angemessenen Volumen RNase-freiem $\mathrm{dH}_{2} \mathrm{O}$ oder Harnstoff-RNA-Auftragspuffer aufgenommen.

UB-blue: $175 \mathrm{mM} \mathrm{NaCl} ; 5$ mM Tris/HCl (pH 7,4); 5 mM EDTA; 0,5 \% SDS; 0,05 \% Methylen-Blau; 7M Harnstoff

Harnstoff-RNA-Auftragspuffer: 7M Harnstoff; 1× TBE; 0,05 (w/v) Bromphenolblau; 0,05 (w/v) Xylenecyanol

\subsubsection{Aufreinigung radioaktiv markierter RNAs über PAGE und Elution aus dem Gel}

Zur Abtrennung nichteingebauter radioaktiv markierter Nukleotide sowie verkürzter RNA-Fragmente aus in vitro Transkriptionsansätzen, wurde die RNA in einer präparativen Harnstoff-PAGE aufgereinigt. Dazu wurde der gesamte Transkriptionsansatz auf ein präparatives 10\% denaturierendes Polyacrylamid-Gel aufgetragen. Um größere Mengen radioaktiver Nukleotide abzutrennen, wurde die RNA eventuell vorher über eine G50-Sepharose-Säule oder durch Phenol/Chloroform-Extraktion und anschließender Ethanolfällung aufgereinigt. Nach der erfolgten Elektrophorese wurde das Gel in Folie eingeschlagen und ein Röntgenfilm exponiert. An der signalintensivsten Bande des als Schablone dienenden Filmes wurde anschließend das entsprechende Stück herausgetrennt. Der Film wurde dann auf das Gel aufgelegt und das entsprechende Gelstück sehr vorsichtig mit einem Skalpell ausgeschnitten und in ein EppendorfReaktionsgefäß überführt. Die Elution der RNA aus dem Gelstück erfolgte über Nacht bei RT in RNAElutionspuffer, dem zusätzlich noch variable Mengen an Carrier-RNA oder Glykogen zugefügt wurden (1-5 $\mu \mathrm{g})$. Anschließend wurde die RNA Phenol/Chloroform-Extrahiert, Ethanol-gefällt und in einem entsprechenden Volumen DEPC-behandeltem Wasser resuspendiert.

RNA-Elutionspuffer: $0,5 \mathrm{M}$ Ammoniumazetat $\mathrm{pH}$ 6,5; 0,2 \% SDS; 0,1 mM EDTA 


\subsubsection{Analyse von in vitro transkribierten RNAs durch native Agarose- Gelelektrophorese}

Zur Kontrolle von in vitro transkribierten RNAs zur Injektion in Xenopus Oozyten oder Sonden für die in si$t u$-Hybridisierung, wurden diese nach der Aufreinigung über RNeasy-Säulen auf einem nichtdenaturierenden Agarosegel mit Ethidiumbromid analysiert.

\subsubsection{Auftrennung radioaktiv markierter RNA durch denaturierende Harnstoff- PAGE}

Üblicherweise wurden für die Auftrennung radioaktiv markierter RNAs 6-10 \%ige Harnstoff-Acrylamidgele (7M Harnstoff; 38:2 Acrylamid/Bisacrylamidlösung in 1×TBE) verwendet. Die Elektrophorese erfolgte dabei in $1 \times \mathrm{TBE}$ in einer vertikalen Gelelektrophoresekammer bei $250-300 \mathrm{~V}$ konstant. Die mit Harnstoff-RNAAuftragspuffer versetzten Proben wurden vor dem Auftrag für 3 min bei $95^{\circ} \mathrm{C}$ hitzedenaturiert. Nach der Elektrophorese wurden die Gele entweder in Methanol/Essigsäure (jeweils $10 \%$ in $\mathrm{H}_{2} \mathrm{O}$ ) fixiert, getrocknet und exponiert oder in Frischhaltefolie eingeschlagen und direkt auf einem Phosphoimager Screen exponiert.

\subsubsection{Analyse von Gesamt- und polyA+-RNA durch denaturierende Agarosegelelek- trophorese}

Um RNAs vor dem Transfer auf Nitrozellulose ihrer molekularen Größe nach aufzutrennen, wurde eine denaturierende Formaldehyd-Agarosegelelektrophorese durchgeführt. Für ein $100 \mathrm{ml}$ Agarosegel wurden dazu zunächst $1 \mathrm{~g}$ Agarose in $60 \mathrm{ml}$ DEPC-behandeltem Wasser durch erhitzen gelöst. Danach wurden $20 \mathrm{ml} 20$ $\mathrm{ml}$ eines 5×MOPS-FA-RNA-Gellaufpuffers zugefügt und erst kurz vor dem gießen des Gels $22 \mathrm{ml}$ einer 37 $\%$ Formaldehydlösung. Sowohl das gießen des Gels als auch der Gellauf selbst wurden stets unter dem Abzug durchgeführt. Bei Bedarf wurde ebenfalls ein Molekulargewichtsstandard „RNA-Lader“ (NEB) mitaufgetragen.

5×MOPS-FA-RNA-Gellaufpuffer: 0,1 M MOPS, pH 7,0; 40 mM Natriumazetat; 5 mM EDTA

\subsubsection{Northern-Transfer von RNA auf Nitrozellulose- oder Nylon-Membranen}

Nach der Elektrophoretischen Auftrennung der RNA-Moleküle wurde das Gel für 15 min in destilliertem Wasser gespült um Formaldehyd und Salze des Puffers zu entfernen. Danach wurde das Wasser entfernt, durch $10 \times$ SSC ersetzt und erneut für 15 min inkubiert. Dieser Schritt wurde nochmals wiederholt bevor der Transfer auf Nitrozellulose- oder Nylon-Membranen erfolgte. Dazu wurden zunächst sechs WhatmanPapiere (Schleicher und Schüll; Dassel) in Größe des Gels sowie ein größeres Stück als „Pufferbrücke“ ausgeschnitten und in $10 \times \mathrm{SSC}$ getränkt. Dann wurde eine Glasplatte über ein mit $10 \times \mathrm{SSC}$-gefülltes Pufferreservoir gelegt und die Pufferbrücke sowie drei der kleineren Whatmanpapiere luftblasenfrei daraufgelegt. Dann wurden das Agarosegel und die Nitrozellulose- oder Nylonmembran (Hybond, Amersham Biosciences Europe GmbH, Freiburg ) aufgelegt. Der Aufbau wurde dann mit wiederum drei Whatmanpapieren sowie einem ca. $10 \mathrm{~cm}$ Stapel Einmalhandtüchern bedeckt und mit einem ca.1 kg schwerem Gewicht beschwert. Üblicherweise wurde der Northern-Transfer über Nacht durchgeführt und die Apparatur am nächsten Morgen abgebaut. Zur irreversiblen Fixierung der Nukleinsäuren auf der Zellulose- oder Nylonmatrix, wurde die Membran im Stratalinker der Firma Stratagene unter Verwendung des „Autocrosslink“Programms quervernetzt.

\subsubsection{Nachweis von RNA auf Membranen durch Methylen blau-Färbung}

Ribonukleinsäuren können nach dem Transfer auf eine Membrane durch Anfärben in Methylen blau-Lösung sichtbar gemacht werden. Nach dem Quervernetzen wurde die Membrane dazu in eine Plastikfärbeschale ge- 
legt und mit Methylen blau-Lösung vollständig bedeckt und unter schütteln angefärbt. Nach ca.10 min kann die unspezifisch an die Membran gebundene Färbelösung in destilliertem Wasser abgewaschen werden und nur die RNA ist in spezifisch angefärbten Banden sichtbar.

Methylen blau-Färbelösung: 0,04\% Methylen blau in 0,5 M Natriumacatat, $\mathrm{pH}$ 5,2

\subsection{Proteintechniken}

\subsubsection{In vitro Translation}

Das $\mathrm{T}_{\mathrm{N}} \mathrm{T}$ Coupled Reticulozyte Lysate System (Promega) eignet sich dazu, von einer Plasmid-DNA in einem einzigen Ansatz die Synthese von mRNA (Transkription) und die Umsetzung der RNA-Sequenz in die Aminosäuresequenz des entsprechenden Proteins (Translation) durchzuführen. Das System wurde zur Kontrolle der Proteingröße eines subklonierten Konstruktes sowie für den Nachweis von RNA-Proteininteraktionen mittels der Koimmunopräzipitation eingesetzt.

in vitro $\mathrm{T}_{\mathrm{N}} \mathrm{T}$-Ansatz:

$0,5 \mu \mathrm{g}$ Plasmid-DNA

$0,5 \mu 1 \mathrm{~T}_{\mathrm{N}} \mathrm{T}$-Puffer

$0,25 \mu 1$ Aminosäure-Mix ohne Methionin

$0,125 \mu \mathrm{l}$ RNasin

$6,75 \mu 1 \mathrm{~T}_{\mathrm{N}} \mathrm{T}$-Retikulozytenlysat

$1 \mu 1{ }^{35} \mathrm{~S}-$ Methionin $(10 \mu \mathrm{Ci} / \mu 1 ; 1000 \mathrm{Ci} / \mathrm{mmol})$

$0,25 \mu \mathrm{Sp} 6, \mathrm{~T} 3$ oder T7 RNA-Polymerase (10 U/ $\mu \mathrm{l})$

ad RNase-freies $\mathrm{H}_{2} \mathrm{O}$ auf $12,5 \mu 1$

Der Ansatz wurde für $1,5 \mathrm{~h}$ bei $30^{\circ} \mathrm{C}$ inkubiert und anschließend auf ein SDS-Gel aufgetragen oder für Koimmunopräzipitationsexperimente mit dem entsprechenden Interaktionspartner versetzt. Für die Koimmunopräzipitationsexperimente erfolgte die Translation in Abwesenheit radioaktiv markierten Methionins. In diesem Fall wurde dann ein Aminosäuremix zugegeben, der alle Aminosäuren enthält.

\subsubsection{Quantifizierung von Proteinen nach Bradford}

Das Prinzip der quantitativen Proteinbestimmung basiert auf der Änderung der Absorptionseigenschaften des Coomassie-R-250-Farbstoffes nach Anlagerung an Proteinmoleküle über hydrophobe Wechselwirkungen. Die durch Anwesenheit von Proteinen erhöhte Extinktion der Coomassie-Lösung bei $600 \mathrm{~nm}$ ist dabei direkt proportional zum Proteingehalt der Lösung. Durch Verwendung einer Eichlösung kann so die Proteinkonzentration einer Probe bestimmt werden. Für das Erstellen der Eichgerade wurde eine Verdünnungsreihe aus einer BSA-Stammlösung $\left(1 \mathrm{mg} / \mathrm{ml}\right.$ in $\left.\mathrm{H}_{2} \mathrm{O}\right)$ in einem Volumen von $800 \mu \mathrm{l}$ in $\mathrm{H}_{2} \mathrm{O}$ angesetzt. Parallel wurden ebenfalls verschiedene Verdünnungen der Lösung unbekannter Proteinkonzentration erstellt und ebenfalls in $800 \mu \mathrm{l} \mathrm{H}_{2} \mathrm{O}$ verdünnt. $\mathrm{Zu}$ diesen Ansätzen und einem $\mathrm{H}_{2} \mathrm{O}$-Leerwert wurden $200 \mu \mathrm{l}$ der BradfordReagenzlösung gegeben und durchmischt. Nach 15 min Inkubation wurde die Absorption der Probe bei 600 $\mathrm{nm}$ im Photometer bestimmt und die Proteinkonzentration der zu bestimmenden Lösung durch Extrapolation mit den Werten der Eichgerade ermittelt.

Bradford-Reagenz: 5×konzentrierte Lösung von Coomassie Brilliant Blue R250 in Phosphorsäure/Methanol

\subsubsection{SDS-Polyacrylamid-Gelelektrophorese (SDS-PAGE)}

Bei der Methode der SDS-PAGE (Laemmli, 1970) werden Proteine ihrem Molekulargewicht entsprechend in einem vertikalen, denaturierenden Polyacrylamidgel aufgetrennt. Dazu wird die Proteinprobe mit einem reduzierenden Agens ( $\beta$-Mercaptoethanol) und SDS versetzt (SDS-sample-buffer). SDS verleiht Proteinen eine negative Gesamtladung, die proportional zur Masse des Proteins ist. Die Komplexe aus SDS und denaturierten Proteinen lassen sich so beim Lauf durch ein Polyacrylamidgel durch Ladung und Siebeffekt der Matrix 
auftrennen. Durch die Verwendung zweier aufeinander folgenden Gelsysteme (Sammelgel und Trenngel) mit unterschiedlichen $\mathrm{pH}$-Bedingungen wird der Trenneffekt durch eine erhöhte Auflösung verstärkt.

Trenngel: $10-15 \%(\mathrm{v} / \mathrm{v})$ Acrylamid/Bisacrylamidlösung (30:0,8); 0,375 M Tris/ $\mathrm{HCl}(\mathrm{pH} 8,8) ; 0,1 \%(\mathrm{w} / \mathrm{v})$ SDS

Sammelgel: 3,4\% Acrylamid/Bisacrylamidlösung (30:0,8); 0,125 M Tris/HCl (pH 6,8); 0,1\% (w/v) SDS

Elektrophorese-Laufpuffer: $25 \mathrm{mM}$ Tris/ $\mathrm{HCl}(\mathrm{pH} 8,8) ; 0,192 \mathrm{M}$ Glycin; 0,1\%(w/v) SDS

2×SDS-sample-buffer: 62,5 mM Tris/HCl (pH 6,8); 10\% (v/v) Propantriol; 2\% (w/v) SDS; $700 \mathrm{mM} \beta$ Mercaptoethanol; $0,05 \%$ (w/v) Bromphenolblau

Die Trenngellösung wurde mit 10\% APS und TEMED, als Radikalbildner und Radikalstarter, versetzt und zwischen zwei Glasplatten bis ca.2,5 cm unter den Rand gegossen und sofort mit $0,1 \%$ (w/v) SDS überschichtet. Nach vollständiger Polymerisation des Trenngels wurde das Sammelgel gegossen und ein Taschenformer zwischen die Glasplatten geschoben. Anschließend wurde das Gel in eine vertikale Elektrophoresekammer mit Laufpuffer eingespannt (hauseigene Werkstatt). Die Proteinproben wurden mit einem entsprechenden Volumen $2 \times \mathrm{SDS}$-sample buffer versehen, für $3 \mathrm{~min}$ Bei $95^{\circ} \mathrm{C}$ hitzedenaturiert und in die Taschen des Gels aufgetragen. Die Elektrophorese wurde bei $35 \mathrm{~mA}$ konstant für 2,5-3,5 h durchgeführt. Die aufgetrennten Proteine konnten anschließend durch Anfärbung mit Coomassie blue sichtbar gemacht werden. Handelte es sich um radioaktiv markierte Proteine, so wurde das Gel in 10\% (v/v) Essigsäure und $10 \%(\mathrm{v} / \mathrm{v})$ fixiert $(3 \times 10 \mathrm{~min})$, gewässert und auf einem Whatman-Papier unter Vakuum getrocknet und auf dem Phospoimagerscreen exponiert.

\subsubsection{Anfärben von Proteinen mit Coomassie-Blue}

Nach elektrophoretischer Auftrennung der Proteine wurden SDS-Polyacrylamidgele hierzu für ca.1h oder über Nacht unter leichtem Schwenken bei RT in der Coomassie-Färbelösung angefärbt. Anschließend wurde die Färbelösung entfernt, das Gel $2 \times$ in $\mathrm{dH}_{2} \mathrm{O}$ gewaschen und anschließend gegen Entfärberlösung ausgetauscht. Durch mehrmaliges Wechseln dieser Lösung konnte die Hintergrundfärbung entfernt werden und die angefärbten Proteinbanden wurden sichtbar. Anschließend wurden die Gele zwischen zwei Zellophanfolien im Luftstrom oder auf Whatmanpapier unter Vakuum getrocknet und zur Dokumentation am Computer eingescannt.

Coomassie-Färbelösung: 0,25 \% (w/v) Comassie Brilliant Blue R 250; $45 \%$ (v/v) Methanol; 10 \% (v/v) Essigsäure

Entfärberlösung: 30\% (v/v) Methanol; 10\% (v/v) Essigsäure

\subsubsection{Herstellung von Xenopus Oozyten S100-Extrakten}

Kollagenisierte Xenopus Oozyten wurden hierzu mit 1 Vol. S100-Puffer versetzt und auf Eis mit $5 \mathrm{ml}-$ Spritzen mit Injektionsnadeln unterschiedlicher Größe homogenisiert. Das Homogenat wurde anschließend für $15 \mathrm{~min}$ bei $1900 \times \mathrm{g}$ und $4^{\circ} \mathrm{C}$ in der Sorvall-Zentrifuge (SS34-Rotor) zentrifugiert um grobe Zellbestandteile, Pigment- und Dotterproteine abzutrennen. Membranöse Bestandteile wurden dann in durch $2 \mathrm{~h}$ Zentrifugation bei $100000 \times \mathrm{g}$ und $4^{\circ} \mathrm{C}$ in einer Beckmann Ultrazentrifuge (52000 rpm im TLA100.2Rotor) abgetrennt. Die Extrakte wurden nach der Zentrifugation den Zentrifugenröhrchen vorsichtig entnommen und die Proteinkonzentration mit der Bradford-Methode ermittelt. Danach wurden diese aliquotiert, in flüssigem Stickstoff schockgefroren und bis zum weiteren Gebrauch bei $-70^{\circ} \mathrm{C}$ gelagert. Üblicherweise wiesen die so gewonnenen S100-Extrakte eine Konzentration von 10-20 mg/ml GesamtProtein auf. Zur qualitativen Einschätzung der Proteinpräparation wurde auch die Auftrennung der Extrakte im SDS-PAGE mit anschließender Coomassie-blue-Färbung durchgeführt.

S100-Puffer: 50 mM Tris/HCl (pH 8,0); 50 mM KCl; 0,1 M EDTA; 25\% (v/v) Propantriol; Proteaseinhibitor-Coctail (Complete, Roche Diagnostics $\mathrm{GmbH}$, Mannheim) 


\subsection{Herstellung einer cDNA-Phagenbibliothek aus Stadium V/VI Xenopus Oozyten}

Die Präparation Isolierung der eingesetzten RNA aus Xenopus Oozyten sowie die Gewinnung der polyA+RNA, aus der die cDNA-Bibliothek erstellt wurde sind hier angegeben. Die Herstellung der Stadium V/VI Oozyten cDNA-Bibliothek erfolgte unter Verwendung des $\lambda$ ZAP Express cDNA-Synthese Systems der Firma Stratagene nach Angaben des Herstellers.

\subsubsection{Isolierung von total RNA aus Stadium VI Xenopus Oozyten}

Zur Isolierung von Gesamt-RNA aus Xenopus Oozyten wurden ca. 0,5 ml kollagenisierte Stadium V-VI Oozyten mit $2 \mathrm{ml} 2 \times$ Extraktionspuffer, $2 \mathrm{ml}$ DEPC-behandeltem $\mathrm{H}_{2} \mathrm{O}$ und $500 \mu$ Proteinase $\mathrm{K}$ (Boehringer) versetzt und unter Verwendung von $5 \mathrm{ml}$ Spritzen mit Kanülen unterschiedlicher Größe (Durchmesser 0,8$0,2 \mathrm{~mm}$ ) homogenisiert und anschließend unter mehrmaligem Durchmischen bei $45^{\circ} \mathrm{C}$ für $1 \mathrm{~h}$ im Heizblock inkubiert. Anschließend wurden die Proteinbestandteile durch mehrmalige Extraktionsschritte mit ungepuffertem Phenol, Phenol/Chloroform/Isoamylalkohol sowie Chloroform/Isoamylalkohol entfernt. Zur Fällung der RNA wurde das gleiche Volumen $8 \mathrm{M} \mathrm{LiCl}$ zugesetzt und für $2 \mathrm{~h}$ bei $-20^{\circ} \mathrm{C}$ belassen. Das nach Zentrifugation erhaltene Pellet wurde dann in $2 \mathrm{ml}$ DEPC-behandeltem $\mathrm{H}_{2} \mathrm{O}$ gelöst und die RNA durch Zufügen von 1/10 Vol. 10M Ammoniumazetat und 2,5 Vol. Ethanol erneut gefällt. Das erhaltene RNA-Pellet wurde in $80 \%$ Ethanol gewaschen, getrocknet, in $1 \mathrm{ml}$ DEPC-behandeltem $\mathrm{H}_{2} \mathrm{O}$ aufgenommen und anschließend zur Entfernung von genomischer und mitochondrialer DNA mit DNAse behandelt. Dazu wurden folgende Reagenzien zugefügt:

$125 \mu 110 \times$ DNAse-Puffer

$62,5 \mu 120 \mathrm{mM}$ DTT

$25 \mu \mathrm{l}$ RNAsin (Promega)

$60 \mu 1$ DNAse (Boehringer)

und das Reaktionsgemisch bei $37^{\circ} \mathrm{C}$ für $1 \mathrm{~h}$ inkubiert. Zur Entfernung von Proteinbestandteilen wurde die RNA erneut mit Phenol, Phenol/Chloroform/Isoamylalkohol sowie Chloroform/Isoamylalkohol extrahiert und mit Ammoniumazetat/Ethanol ausgefällt. Die erhaltene RNA wurde in $500 \mu 1$ Wasser aufgenommen und zur Messung im Photometer 1:50 verdünnt eingesetzt. Üblicherweise konnten so aus 0,5 ml Oozyten 0,7-1,2 mg Gesamt-RNA gewonnnen werden.

\subsubsection{Anreicherung von poly $A^{+}-R N A$ aus Gesamt-RNA}

Zur Isolierung von polyA ${ }^{+}$-RNA aus Gesamt-RNA wurde zunächst eine entsprechende Menge Oligo dTZellulose abgewogen und in $0,1 \mathrm{~N} \mathrm{NaOH}$ quellen lassen. Nach mehrmaligem waschen der Zellulose wurde diese dann in eine mit Glaswolle verschlossene $1 \mathrm{ml}$ Spritze eingetropft und die so hergestellt Säule dreimal mit einem Säulenvolumen DEPC-behandeltem $\mathrm{H}_{2} \mathrm{O}$ gewaschen sowie mit einem Säulenvolumen $1 \times$ Auftragspuffer $\left(30^{\circ} \mathrm{C}\right)$ äquilibriert. Die einzusetzende Gesamt-RNA wurde dann für 5 min bei $70^{\circ} \mathrm{C}$ denaturiert mit 1 Vol. 2× Auftragspuffer versetzt und auf die Säule aufgebracht. Der Durchlauf wurde erneut denaturiert und wiederum auf die Säule gegeben. Zur Entfernung von ribosomaler und anderer ,nicht polyA ${ }^{+}-$RNAs“ wurde die Säule sukzessive mit dem sechsfachen Säulenvolumen Waschpuffer versetzt. Die Durchlauffraktionen wurden hierbei aufgefangen und im Photometer auf ihren RNA-Gehalt hin überprüft. Die an die Säule gebundene polyA ${ }^{+}$-RNA wurde dann mit $6 \times 300 \mu 1$ Elutionspuffer eluiert und die Fraktionen mit höchstem RNA-Gehalt zusammengeführt und mit 1/10 Vol. Ammoniumazetat (M) und dem 2,5-fachen Volumen Ethanol gefällt. Auf diese Weise konnten die 1-2\% der durchschnittlich in Gesamt-RNA enthaltenen polyA ${ }^{+}$-RNA gewonnen werden.

2×Säulenauftragspuffer: $40 \mathrm{mM}$ Tris/ $\mathrm{HCl}, \mathrm{pH} 7,6 ; 1 \mathrm{M} \mathrm{NaCl} ; 2 \mathrm{mM}$ EDTA, pH 8,0; $1 \%$ SDS

Waschpuffer: $20 \mathrm{mM}$ Tris/HCl, $\mathrm{pH}$ 7,6; 0,1 M NaCl; $1 \mathrm{mM}$ EDTA, pH 8,0; 0,5\% SDS

Elutionspuffer: $20 \mathrm{mM}$ Tris/HCl, $\mathrm{pH}$ 7,6; $1 \mathrm{mM}$ EDTA, $\mathrm{pH}$ 8,0 


\subsubsection{Erststrang cDNA-Synthese}

Zur Denaturierung von Sekundärstrukturen wurde die eingesetzte polyA ${ }^{+}$RNA für 5 min auf $65^{\circ} \mathrm{C}$ erhitzt, anschließend in Eiswasser auf $0^{\circ} \mathrm{C}$ herabgekühlt und dort bis zur weiteren Verwendung belassen. Zur Erststrang cDNA-Synthese wurden folgende Komponenten zusammenpipettiert:

$5 \mu 110 \times$ Erststrang-Puffer

$3 \mu \mathrm{l}$ Erststrang Methylnukleotid-Mix

$2 \mu 1$ linker-primer

ad RNAse-freies Wasser auf 48,5 $\mu 1$

$1 \mu 1$ RNase Inhibitor $(40 \mathrm{U} / \mu \mathrm{l})$

$5 \mu \mathrm{g}$ polyA+RNA

Das Reaktionsgemisch wurde dann für $10 \mathrm{~min}$ bei Raumtemperatur belassen und dann die Erststrang-

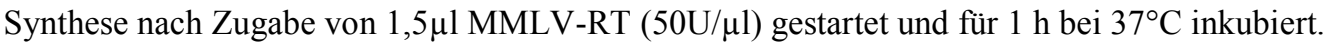

\subsubsection{Zweitstrang-Synthese}

Die Erstrang-Synthese Reaktion wurde unter $16^{\circ} \mathrm{C}$ herabgekühlt und folgende Reagenzien auf Eis hinzugefügt:

$20 \mu 110 \times$ Zweitstrang-Puffer

$6 \mu 1$ Zweitstrang dNTP-Mix

$117 \mu \mathrm{l}$ dest. Wasser

$2 \mu \mathrm{l}$ Rase $\mathrm{H}(1,5 \mathrm{U} / \mu \mathrm{l})$

$11 \mu 1$ DNA-Polymerase I $(9 \mathrm{U} / \mu \mathrm{l})$

Die Reaktion wurde für $2,5 \mathrm{~h}$ bei $16^{\circ} \mathrm{C}$ inkubiert und dann auf Eis gestellt.

\subsubsection{Glätten der cDNA-Termini und Ligation von EcoRI-Adaptoren}

Zum Gätten der cDNA Termini wurde der Reaktion $23 \mu 1$ blunting dNTP-Mix sowie $2 \mu 1$ cloned Pfu DNAPolymerase $(2,5 \mathrm{U} / \mu \mathrm{l})$ hinzugefügt und für $30 \mathrm{~min}$ bei $72^{\circ} \mathrm{C}$ inkubiert. Anschließend wurden die in der Reaktion enthaltnen Proteine durch Phenol/Chloroform und Chloroform-Extraktion entfernt und die cDNA nach Zugabe von $1 / 10$ Vol. $3 \mathrm{M}$ Natriumazeat und $2 \mathrm{Vol}$ Ethanol über Nacht bei $-20^{\circ} \mathrm{C}$ gefällt. Das nach Zentrifugation erhaltene Pellet wurde mit $70 \%$ Ethanol gewaschen, getrocknet und dann in $9 \mu$ EcoRI-Adaptoren resuspendiert und nach Zugabe von jeweils $1 \mu 1$ 10×Ligase-Puffer, 10mM rATP und T4 DNA-Ligase (4U/ $\mu \mathrm{l})$ bei $5^{\circ} \mathrm{C}$ für zwei Tage ligiert. Nach Hitzeinaktivierung der Ligase für 30 min bei $70^{\circ} \mathrm{C}$ wurden der Reaktion zur Phosphorylierung der EcoRI-Enden folgende Komponenten zugefügt:

$1 \mu 110 \times$ Ligase-Puffer

$2 \mu 110 \mathrm{mM}$ rATP

$6 \mu 1$ ster. Wasser

$1 \mu \mathrm{T} 4$ Polynukleotid-Kinase $(10 \mathrm{U} / \mu \mathrm{l})$

und bei $37^{\circ} \mathrm{C}$ für 30 min inkubiert. Nach 30 -min. Hitzeinaktivierung der Kinase bei $70^{\circ} \mathrm{C}$ wurden zur selektiven Restriktionsenzymatischen Spaltung der 3'cDNA-Enden $28 \mu 1$ XhoI-Puffer sowie $3 \mu 1$ XhoI (40U/ $\mu 1)$ hinzugefügt und bei $37^{\circ} \mathrm{C}$ für $1,5 \mathrm{~h}$ inkubiert.

\subsubsection{Größenfraktionierung der cDNA-Fragmente}

Zur Größenfraktionierung wurde die erhaltene cDNA über eine Sephacryl 500 Säule aufgetrennt. Dazu wurde eine $1 \mathrm{ml}$ Spritze mit ein wenig Glaswolle verschlossen und 1ml Säulenvolumen mit Sephacryl 500 gepackt. Dazu wurde die Säule in ein PPN-Reaktionsgefäß gestellt und bei $1400 \mathrm{rpm}$ in einer Heraeus Zentrifuge für 2 min zentrifugiert. Nach zweimaligem waschen der Säule mit 1×STE-Puffer (jew. 100 $\mu$ l) wurde die cDNA Probe auf die Säule gegeben. Nach Zugabe von jeweils $60 \mu 1$ 1×STE-Puffer wurden 4 Fraktionen der 
Eluate in Eppendorfreaktionsgefäßen gesammelt und mit 1×STE-Puffer auf ein Volumen von 100 $\mu 1$ eingestellt. Nach Ethanolfällung wurde die cDNA dann zur Quantifizierung in den Ethidiumbromid-Platten-Test eingesetzt.

\subsubsection{Quantifizierung der cDNA durch Ethidiumbromid-Agarose-Platten}

Zur Quantifizierung der nach der Größenfraktionierung erhaltenen cDNA Mengen wurden aliquote Teile der Fraktionen zusammen mit einer Reihe von DNA-Lösungen bekannter Konzentration in Tropfen auf eine

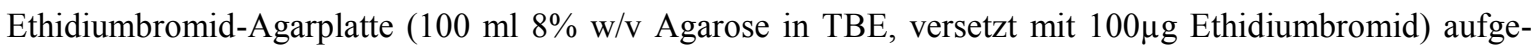
bracht und unter UV-Licht eine visuelle Mengenabschätzung der erhaltenen cDNA in den einzelnen Fraktionen vorgenommen.

\subsubsection{Ligation der cDNA in den ZAP Express Vektor}

Die cDNA der ausgewählten Fraktionen wurde dann in den ZAP Express Phagen-Vektor ligiert. Dazu wurden

$4,5 \mu 1$ resuspendierte, fraktionierte cDNA (100ng)

$0,5 \mu 110 \times$ Ligase-Puffer

$0,5 \mu 110 \mathrm{mM}$ rATP

$1 \mu \mathrm{l}$ ZAP-Express-Vektor $(1 \mu \mathrm{g} / \mu \mathrm{l})$

$0,5 \mu \mathrm{l}$ T4 DNA-Ligase $(4 \mathrm{U} / \mu \mathrm{l})$

zusammengefügt und über $\mathrm{Nacht}$ bei $12^{\circ} \mathrm{C}$ ligiert.

\subsubsection{Verpacken der Phagen}

Zum Verpacken der Phagen wurde der Phagen Verpackungsextrakt Gigapack III Gold Packaging Extract von Stratagene verwendet. Aliquotierte Mengen des Phagen-Verpackungsextraktes wurden bei RT aufgetaut, mit 1-4 $\mu \mathrm{l}$ cDNA versetzt und für $2 \mathrm{~h}$ bei $22^{\circ} \mathrm{C}$ belassen. Nach dem Verpacken des Phagens in seine Hüllproteine wurden $500 \mu 1$ SM-Puffer sowie $20 \mu 1$ Chloroform zugesetzt und das Phagengemisch bis zur weiteren Verwendung bei $4^{\circ} \mathrm{C}$ aufbewahrt.

SM-Puffer: $10 \mathrm{mM}$ Tris/HCl (pH 7,5); $8 \mathrm{mM} \mathrm{MgSO}_{4} ; 100 \mathrm{mM} \mathrm{NaCl} ; 0,01 \%$ Gelatine; sterilfiltriert.

\subsubsection{Plattieren und Bestimmung des Phagentiters}

Zunächst wurde ein Einzelkolonieaustrich des Wirtsbakteriums E.coli XL1-blue MRF'auf tetracyclinhaltigen LB-Agarplatten angefertigt. Mit einer MRF'- Einzelkolonie wurde eine Übernachtkultur von $10 \mathrm{ml}$ LBFlüssgmedium mit Tetracyclin, $10 \mathrm{mM} \mathrm{MgSO} 4$ und 0,2\% Maltose, inokuliert und diese zum Animpfen einer $50 \mathrm{ml}$ Tageskultur verwendet. Nach ca. 4-6 h Wachstum ( $\left(\mathrm{OD}_{600}\right.$ ca.1) wurden die Zellen bei $500 \mathrm{~g}$ für $10 \mathrm{~min}$ pelletiert und bis zu einer OD600 von 0,5 in sterilem 10mM MgSO4 aufgenommen und verdünnt. AnschlieBend wurden jeweils $200 \mu 1$ dieser Bakteriensuspension mit $1 \mu 1$ der Verpackungsreaktion bzw. 1:10 und 1:100 Verdünnungen derselben versetzt, bei $37^{\circ} \mathrm{C}$ für15 min mit den Phagen infiziert und anschließend mit $3 \mathrm{ml}$ flüssigem NZY-Topagar, $15 \mu 1$ 0,5M IPTG (Roth, Karlsruhe) und $50 \mu 1 \mathrm{X}$-Gal (GibcoBRL) $(250 \mathrm{mg} / \mathrm{ml}$ in DMF) versetzt und sofort auf NZY-Agar ausplattiert. Nach Inkubation über Nacht konnte dann der Phagentiter anhand der Phagenplaques sowie die Rekombinationsrate über das Mengenverhältnis von blauen (Hintergrund) und weißen (Rekombinante) Phagenplaques bestimmt werden.

\subsubsection{Amplifikation der Stadium V/VI Oozyten Phagen-Bibliothek}

Zur Amplifikation der Phagenbibliothek wurde die primäre Phagenbank auf $50150 \mathrm{~mm}$ NZY-Agar-Platten mit einer Dichte von 50000 pfu ausplattiert und für $8 \mathrm{~h}$ bis zu einer Plaque-Größe von $1 \mathrm{~mm}$ inkubiert. Danach wurde auf jede Platte $10 \mathrm{ml}$ SM-Puffer gegeben und die Phagen so bei Übernachtinkubation bei $4^{\circ} \mathrm{C}$ 
suspendiert. Anschließend wurden die Phagensuspensionen in Polypropylene-Gefäße überführt, mit $500 \mathrm{ml}$ Chloroform versehen, nach durchmischen restliche Zellbestandteile bei $500 \times \mathrm{g}$ für $10 \mathrm{~min}$ abzentrifugiert und bis zum weiteren Gebrauch bei $4{ }^{\circ} \mathrm{C}$ aufbewahrt.

\subsubsection{Anlegen von Gefrierkulturen der fraktionierten Phagenbibliothek}

Zur Langzeitaufbewahrung wurden von den Phagensuspensionen Gefrierkulturen angesetzt. Dazu wurden die einzelnen Fraktionen mit 7\% (v/v) DMSO versetzt und bei $-80^{\circ} \mathrm{C}$ eingefroren und aufbewahrt.

\subsection{Herstellung einer cDNA-Phagenbibliothek aus vegetalen Kortizes}

Die cDNA-Bibliothek aus RNA-Präparationen von vegetalen Kortizes von Stadium VI Xenopus Oozyten erfolgte unter Verwendung des SMART-cDNA Library Construction Systems der Firma Clontech. Die Präparation der Kortizes und RNA sowie die Schritte der Erstellung der cDNA-Bibliothek sind hier aufgeführt.

\subsubsection{Präparation von vegetalen Kortizes von Stadium VI Oozyten}

Die Präparation von vegetalen Kortizes von Stadium VI Oozyten erfolgte nach Zhang und King, 1999. Hierzu wurden zunächst Stadium VI Oozyten in MBSH-Puffer unter Verwendung von Uhrmacherpinzetten (Dumont/Plano) manuell von der Follikelzellschicht befreit und anschließend in P10EM-Puffer überführt. Mit einer Skalpellklinge wurden ca. 20 Oozyten zerteilt und die vegetalen, unpigmentierten Hälften mit Hilfe von Haarschlingen auf eine Zellulose-Azetat-Membrane aufgebracht. Mit einem Deckgläschen wurden die Kortizes vorsichtig auf der Membran ausgebreitet. Die Kortizes wurden durch mehrmaliges wechseln des P10EM-Puffers mit Pasteurpipetten vom Zytoplasma und Dotter befreit. Die gereinigten Kortizes wurden dann in einem Tropfen P10EM-Puffer auf Parafilm gesammelt und auf Trockeneis eingefroren. Der Tropfen wurde mit gekühlten Pinzetten in ein Eppendorf Reaktonsgefäß überführt und die Kortizes bis zur weiteren Verwendung bei $-80^{\circ} \mathrm{C}$ gelagert.

P10EM-Puffer: 100 mM PIPES (pH 6,9), 10 mM EGTA, 1 mM MgSO 4

\subsubsection{Isolierung von Gesamt-RNA aus vegetalen Kortizes}

Die Isolierung von Gesamt-RNA aus vegetalen Kortizes wurde nach Zhang und King, 1999 durchgeführt. Hierzu wurden die gesammelten Kortizes mit $50 \mu 1$ Proteinase K in $500 \mu 11 \times$ Proteinase K-Puffer vesetzt, homogenisiert und bei $56^{\circ} \mathrm{C}$ für 30 min unter leichtem Schütteln inkubiert. Nach mehrmaligen Extraktionsschritten mit Phenol, Phenol/Chloroform/Isoamylalkohol sowie Chloroform/Isoamylalkohol wurde die RNA in Ammoniumazetat/Ethanol gefällt und in $20 \mu \mathrm{l}$ DEPC-behandeltem $\mathrm{H}_{2} \mathrm{O}$ resuspendiert. Aus ca. 25 vegetalen Kortizes konnten so 2-5 $\mu \mathrm{g}$ total RNA gewonnen werden.

1× Proteinase K-Puffer (nach Zhang und King, 1999): $50 \mathrm{mM}$ Tris/HCl, pH 7,5; 5 mM EDTA, pH 8,0; $1 \%$ SDS; 4M Harnstoff

\subsubsection{Erststrang cDNA-Synthese}

Für die Erststrang cDNA-Synthese mit dem des SMART cDNA Library Construction System (Clontech) wurden zunächst die eingesetzte total RNA zusammen mit den in der Erst- und Zweitstrangsynthese eingesetzen Oligonukleotiden für 2 min bei $72^{\circ} \mathrm{C}$ denaturiert.

$2 \mu \mathrm{l}$ total RNA (ca. $1-2 \mu \mathrm{g}$ )

$1 \mu 1$ SMART III Oligonukleotid

$1 \mu 1$ CDS III, 3'-Oligonukleotid

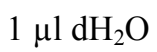

nach Abkühlen des Ansatzes in Eiswasser wurden dem Ansatz folgende Komponenten hinzugefügt: 
$2 \mu 15 \times$ Erststrangsynthese-Puffer

$1 \mu 1$ DTT (20mM)

$1 \mu \mathrm{ldNTP}-M i x(10 \mathrm{mM})$

$1 \mu \mathrm{l}$ MMLV Reverse Transkriptase $(200 / \mu \mathrm{l})$ (GibcoBRL)

Nach einstündiger Synthesereaktion bei $42^{\circ} \mathrm{C}$ wurden dann jeweils $2 \mu 1$ dieses Ansatzes in die Zweitstrangsynthese und Amplifikation der cDNA eingesetzt.

SMART III Oligonukleotid: 5'-AAGCAGTGGTATCAACGCAGAGTGGCCATTATGGCCGGG

CDS III, 3'-Oligonukleotid: 5'-ATTCTAGAGGCCGAGGCGGCCGACATG_d $(\mathrm{T}){ }_{30} \mathrm{~N}_{-1} \mathrm{~N}\left(\mathrm{~N}=\mathrm{A}, \mathrm{G}, \mathrm{C}\right.$ oder T; $\mathrm{N}_{-1}=$ A, G oder C)

\subsection{4 cDNA-Amplifikation über LD-PCR und Ligation in den $\lambda$ TriplEx2-Vektor}

$\mathrm{Zu}$ den $2 \mu \mathrm{l}$ der Erststrang-Reaktion wurden:

$80 \mu \mathrm{ld} \mathrm{H}_{2} \mathrm{O}$

$10 \mu 1$ 10×cDNA PCR-Puffer

$2 \mu \mathrm{l}$ dNTP-Mix

$2 \mu 1$ 5'-PCR-Oligonukleotid

$2 \mu \mathrm{l}$ CDSIII, 3'-Oligonuklotid sowie

$2 \mu 1$ 50×Advantage cDNA Polymerase Mix

hinzugefügt und die Zweitstrangsynthese mit anschließender Amplifikation der cDNA im GeneAmp2400 Thermocycler (Perkin Elmer) unter Verwendung des folgenden Synthese-Protokolls durchgeführt:95 ${ }^{\circ} \mathrm{C}, 20 \mathrm{~s}$ Denaturierung; $95^{\circ} \mathrm{C}, 5 \mathrm{~s} ; 68^{\circ} \mathrm{C}, 6$ min; 22 Cyclen.

$70 \mu 1$ der amplifizierten cDNA (ca. 2-3 $\mu \mathrm{g}$ ) wurden dann zur Entfernung von Proteinen mit Proteinase K be-

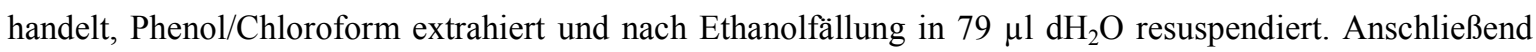
wurden die cDNA an den über die verwendeten Oligonukleotide eingefügten SfiI-Schnittstellen für 2 h bei $50^{\circ} \mathrm{C}$ restriktionsenzymatisch gespalten. Zur Abtrennung von cDNAs kleinerer Größe wurde der PCR Ansatz unter Verwendung einer CHROMA-SPIN-400 Säule (Clontech) fraktioniert. Die Säule wurde zunächst mit $700 \mu \mathrm{l}$ Coloumn loading buffer gewaschen und dann die mit $2 \mu 1$ Xylene Cyanol-Farbstoff versehene cDNA aufgetragen. Nach Einziehen der Probe wurden dann weitere $600 \mu$ l Coloumn loading buffer zugegeben und Ein-Tropfen-Fraktionen (jeweils ca.35 $\mu \mathrm{l}$ ) des Eluates gesammelt und aliquote Teile davon auf einem Ethidiumbromid-Gel analysiert. Die Fraktionen mit cDNAs großer Größen wurden dann zusammengefügt und

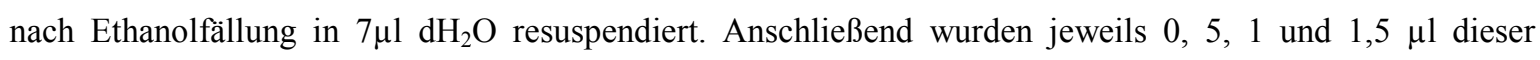
cDNAs in den $S f i$ I-geschnittenen $\lambda$ TriplEx2-Vektor bei $16^{\circ} \mathrm{C}$ über Nacht ligiert.

0,5 bzw. 1 bzw. $1,5 \mu l$ fraktionierte cDNA

$1 \mu \mathrm{l}$ Vektor

$0,5 \mu 1$ 10× Ligase-Puffer

$0,5 \mu \mathrm{ATP}(10 \mathrm{mM})$

$0,5 \mu 1$ T4 DNA-Ligase

ad $\mathrm{dH}_{2} \mathrm{O}$ auf $5 \mu \mathrm{l}$

Zum Verpacken der Phagen wurde der Phagen Verpackungsextrakt Gigapack III Gold Packaging Extract von Stratagene verwendet. Aliquotierte Mengen des Phagen-Verpackungsextraktes wurden bei RT aufgetaut, mit 1-4 $\mu \mathrm{l}$ cDNA versetzt und für $2 \mathrm{~h}$ bei $22^{\circ} \mathrm{C}$ belassen. Nach dem Verpacken des Phagens in seine Hüllproteine wurden $500 \mu \mathrm{l}$ SM-Puffer sowie $20 \mu \mathrm{l}$ Chloroform zugesetzt und das Phagengemisch bis zur weiteren Verwendung bei $4^{\circ} \mathrm{C}$ aufbewahrt.

SM-Puffer: 10 mM Tris/ $\mathrm{HCl}(\mathrm{pH} 7,5) ; 8$ mM MgSO $4 ; 100 \mathrm{mM} \mathrm{NaCl} ; 0,01 \%$ Gelatine; sterilfiltriert. 


\subsubsection{Massenexzision der $\lambda$ TriplEx2-Phagenbibliothek in BM25.8-Zellen}

Zunächst wurde ein Einzelkolonieaustrich des Wirtsbakteriums E.coli BM25.8 auf LB Kanamycin/Chloramphenicol-Agarplatten angefertigt. Dann wurden $10 \mathrm{ml}$ LB-Flüssigmedium mit einer Einzelkolonie inokuliert und bei $31^{\circ} \mathrm{C}$ über Nacht inkubiert. $1 \mathrm{ml}$ dieser Primärkultur wurden dann verwendet um $10 \mathrm{ml}$ LB-Flüssigmedium zu beimpfen. Nach dem Erreichen einer Zelldichte von ca. $\mathrm{OD}_{500} 1,2$ wurden der Kultur 10mM MgSO4 hinzugefügt. $200 \mu 1$ dieser Zellsuspension wurden dann mit ca.60000-90000 pfu der primären Phagenbibliothek versetzt und für $1 \mathrm{~h}$ bei $31^{\circ} \mathrm{C}$ infiziert. Anschließend wurden dem Ansatz 500 $\mu 1$ LB-Flüssigmedium hinzugefügt und nach einer einstündigen Inkubation bei $31^{\circ} \mathrm{C}$ und $190 \mathrm{rpm}$ jeweils 10 und $100 \mu \mathrm{l}$ auf $150 \mathrm{~mm}$ LB-Carbenicillin-Platten ausgestrichen. Nach Übernachtinkubation konnte dann der Titer der rekombinanten Bakterien bestimmt werden.

\subsubsection{Vorbereitung der Einzelklone für die Durchmusterung nach lokalisierten Transkripten in der whole mount in situ-Hybridisierung}

Zur Durchmusterung der Kortex-cDNA-Bibliothek nach lokalisierten RNAs in Xenopus Oozyten, wurden einzelne Bakterienklone nach der Massenexzision in $100 \mu \mathrm{l}$ LB-Medium (Carbenicillin) in 96-Loch Mikrotiterplatten angeimpft und über Nacht im Schüttelinkubator inkubiert. Jeweils $50 \quad \mu l$ dieser Bakteriensuspensionen wurden dann in neue 96-Loch Mikrotiterplatten überführt, mit $15 \mu$ Propantriol versehen und zur Lagerung bei $-70^{\circ} \mathrm{C}$ eingefroren. Jeweils 1-2,5 $\mu 1$ der Bakteriensuspension wurden dann in 96Loch PCR-Reaktionsgefäße überführt und die inserierten Fragmente unter Verwendung der 5' $\lambda$ TriplEx2-LD und 3' $\lambda$ TriplEx2- Oligonukleotide in der PCR amplifiziert. $5 \mu 1$ dieser PCR-Produkte dienten dann jeweils als Matrize bei der T7-Polymerase-vermittelten Generierung von antisense in situ-Hybridisierungs-Sonden in der in vitro Transkriptionsreaktion (beschrieben unter 2.14.4.2). Unter Verwendung von Floureszin-rUTP wurden die Sonden dabei markiert und ein Aliquot derselben konnte so nach Auftrennung in der Agarosegelelektrophorese auch ohne Zugabe von Ethidiumbromid visualisiert werden. Die so hergestellten Transkripte dienten dann als antisense RNA-Sonden in der whole mount in situ-Hybridisierung.

\subsection{Suche nach vegetal lokalisierten Transkripten mittels der whole mount in situ- Hybridisierung in großem Maßstab}

Zur großangelegten Suche nach lokalisierten RNAs mittels der whole mount in situ-Hybridisierung wurde diese unter 2.22 beschriebene Methode wie folgt modifiziert: Alle Schritte der Prozedur bis zur Prähybridisierung der Oozyten wurden in einem, auf ein Volumen von 12,5 ml eingestellten, gemeinsamen Ansatz durchgeführt. Nach Entfernen der Prähybridisierungslösung wurden die Oozyten dann auf die Vertiefungen von vier 36-Loch-Zellkulturplatten aufgeteilt und mit der entsprechenden spezifischen fluoreszinmarkierten antisense RNA-Sonde versetzt. Alle weiteren Behandlungen und Waschschritte der Oozyten wurden ebenfalls in diesen Zellkulturplatten durchgeführt. Zur Detektion der Sonden wurden in diesem Falle FabFragmente von Fluoreszin-spezifischen Antikörpern (aus Ziege), konjugiert mit alkalischer Phosphatase verwendet. Vor der Färbereaktion wurden die Oozyten in neue Platten überführt, und dann mit dem NBT/BCIP-haltigem APB versetzt. Die Färbereaktion wurde für eine Stunde bis über Nacht durchgeführt und anschließend mit MEMFA gestoppt. Eventuell erfolgte dann ebenfalls eine Entfärbung der Oozyten in einer absteigenden Methanolreihe.

\subsection{Isolierung von cDNA-Fragmenten aus Phagen-Bibliotheken}

Um einen Phagen zu isolieren, der die gesuchte Volllängen cDNA enthielt, wurde die fraktionierte Xenopus Stadium V/VI Oozyten-cDNA-Phagenbibliothek mit Hilfe der PCR unter Verwendung spezifischer Oligonukleotide durchmustert. Durch wiederholte Verdünnung und Amplifikation positiver Fraktionen wurde der gesuchte Phage angereichert bis ein reiner Phagenklon isoliert werden konnte. Der isolierte Einzelphage 
wurde schließlich mittels eines Helferphagen in ein zirkuläres Phagemid konvertiert, das im weiteren als Plasmid in Bakterien vermehrt werden konnte.

\subsubsection{Plattieren und Kultivieren von Phagen}

Zunächst wurde ein Einzelkolonieausstrich des Bakterienstammes E. coli XL1-Blue MRF' auf tetracyclinhaltigen LB-Agarplatten angefertigt. Mit einer MRF'-Einzelkolonie wurde eine Tageskultur in $50 \mathrm{ml}$ LBFlüssigmedium mit Tetracyclin, $10 \mathrm{mM} \mathrm{MgSO}_{4}$ und $0,2 \%$ Maltose angeimpft. Nach ca. $5 \mathrm{~h}$ Wachstum wurden die Zellen bei $4.000 \mathrm{rpm}$ für $10 \mathrm{~min}$ in einem GSA-Rotor pelletiert und in $10 \mathrm{mM} \mathrm{MgSO}_{4}$ zu einer $\mathrm{OD}_{600}$ von 0.5 resuspendiert. Zur Infektion mit Phagen wurden $600 \mu \mathrm{l}$ der Bakteriensuspension zusammen mit 2.5 $\mu 1$ der Phagensuspension 20 min bei $37^{\circ} \mathrm{C}$ geschwenkt.

\subsubsection{Phagenplattierung auf NZY-Agar-Platten}

Das Präadsorptionsgemisch aus Bakterien und Phagen wurde zu je $3 \mathrm{ml}$ flüssigem NZY-Top-Agar in $12 \mathrm{ml}-$ PPN-Röhrchen pipettiert, welche in einem Heizblock auf genau $48^{\circ} \mathrm{C}$ vorgewärmt worden waren. Nach der Zugabe wurden die Röhrchen zum Durchmischen kurz zwischen den Handflächen gerollt und der Inhalt auf vorgewärmten NZY-Agarplatten $(\mathrm{d}=9.5 \mathrm{~cm})$ verteilt. Nach $1 \mathrm{~h}$ Inkubation bei RT, bis zum vollständigen Erstarren des Top-Agars, wurden die Platten invertiert bei $37^{\circ} \mathrm{C}$ über Nacht inkubiert.

\subsubsection{Phagenplattierung in Mikrotiterplatten}

Sollten die Phagen in Titerplatten amplifiziert werden, wurden $6.4 \mathrm{ml} \mathrm{NZY-Flüssigmedium} \mathrm{zu} \mathrm{dem} \mathrm{Gemisch}$ aus Bakterien und Phagen in das 12 ml-PPN-Röhrchen pipettiert und jeweils in Aliquots zu $100 \mu 1$ auf $8 \times 8$ Vertiefungen einer 96-Loch-Titerplatte verteilt. Die Platten wurden mit Klebefolie verschlossen und über Nacht bei $37^{\circ} \mathrm{C}$ und $250 \mathrm{Rpm}$ geschüttelt. Eine gute Amplifikation der Phagen war am folgenden Tag an einem klaren Phagenüberstand und Sedimenten aus Bakterienzelltrümmern zu erkennen.

\subsubsection{Anreicherung von Kandidaten-Phagen}

Um positive Phagenfraktionen zu identifizieren, wurden Aliquots einzelner Fraktionen einer cDNA-Bank in einer PCR mit spezifischen Oligonukleotiden getestet, wobei wie in der PCR unter Verwendung von Bakteriensuspensionen vorgegangen wurde. Verschiedene Verdünnungen (unverdünnt bis $10^{-5}$ ) der positiven Phagen-Einzelfraktionen wurden in $8 \times 8$ Aliquots à $100 \mu$ in Mikrotiterplatten plattiert und diese nach der Amplifikation erneut in der PCR analysiert. Um das Verfahren zu vereinfachen, wurden jeweils $8 \mu 1$ der horizontalen Reihen A (1-8) bis H (1-8) der Platte zu einem Gemisch (Pool) vereint. Aliquots von Pools der Reihen A-H wurden in der PCR getestet. Zeigte eine Reihe ein positives Signal, konnte die positive Fraktion in dieser Reihe durch eine zweite PCR auf Aliquots der Einzelfraktionen lokalisiert werden. Positive Fraktionen wurden in 1.5 ml-Eppendorfgefäße überführt und nach Zugabe von zwei Tropfen Chloroform zur Konservierung der Phagen bei $4^{\circ} \mathrm{C}$ aufbewahrt. Es wurde jeweils mit den positiven Fraktionen weitergearbeitet, welche aus der höchsten Verdünnungsstufe hervorgingen. Die Verdünnungs- und Amplifikationsrunden wurden mehrfach wiederholt, bis der gesuchte Phage in der Fraktion gegenüber anderen Phagen möglichst stark angereichert war.

\subsubsection{Isolierung von Kandidaten-Phagen}

Um einen reinen Klon des gesuchten Phagen zu isolieren, wurde die angereicherte Fraktion auf NZY-AgarPlatten ausplattiert. Einzelne Phagen-Plaques von ca.1 mm Durchmesser wurden mit der Spitze einer Pasteurpipette ausgestochen und in je $100 \mu 1$ SM-Puffer überführt. Aliquots der Plaque-Suspensionen wurden in der PCR getestet. Positive Einzelplaques konnten nach Zugabe von zwei Tropfen Chloroform bei $4^{\circ} \mathrm{C}$ in 1.5 ml-Eppendorfgefäßen gelagert werden. Um die Reinheit des Phagen sicherzustellen, wurden Aliquots der po- 
sitiven Einzelphagensuspension erneut ausplattiert und ca. 8-12 Plaques ausgestochen. Waren sämtliche der ausgestochenen Phagenplaques in der PCR erneut positiv, konnte davon ausgegangen werden, daß ein reiner Klon vorlag.

\subsubsection{In vivo Exzision von Phagen-Inserts}

Zur Exzision des Phagemids aus dem reinen Phagenklon mußte im folgenden zunächst eine hoch-TiterPhagensuspension erzeugt werden. Dazu wurde eine solche Menge des Phagen auf Agarplatten ausplattiert, welche konfluentes Wachstum des Phagen erbrachte. Die konfluenten Phagen wurde durch Zugabe von 2-3 ml SM-Puffer zur Agar-Platte für ca. $3 \mathrm{~h}$ bei RT durch Inkubation auf einer Wippe abgeschwemmt und die Phagensuspension in ein $50 \mathrm{ml}$ Falcon-Röhrchen überführt. Nach Zugabe von $75 \mu 1$ Chloroform wurde gemischt, 10 min bei $10.000 \mathrm{Rpm}$ zentrifugiert und der Überstand in ein $1.5 \mathrm{ml}$-Eppendorfgefäß überführt. Der konzentrierte Phagenüberstand wurde unter Zugabe von $0.3 \%$ Chloroform bei $4{ }^{\circ} \mathrm{C}$ gelagert. Zur Vorbereitung der Exzision wurden Über-Nacht-Kulturen der E. coli Stämme XL1-Blue MRF' und XLOLR angeimpft, aus welchen Tageskulturen inokuliert wurden. Die XLOLR-Zellen wurden bis zum Erreichen einer $\mathrm{OD}_{600}=1.0$ kultiviert. Die $\mathrm{OD}_{600}$ der MRF'-Zellen wurde in $10 \mathrm{mM} \mathrm{MgSO}_{4}$ auf 1.0 eingestellt. In einem 12 ml-PPN-Röhrchen wurden $200 \mu 1$ der MRF'-Zellsuspension zusammen mit $250 \mu 1$ der hochkonzentrierten Einzelphagensuspension und $1 \mu \mathrm{l}$ ExAssist-Helferphage $15 \mathrm{~min}$ bei $37^{\circ} \mathrm{C}$ unter Schwenken inkubiert. Nach Zugabe von $3 \mathrm{ml}$ LB-Flüssigmedium wurde $2.5 \mathrm{~h}$ bei $37^{\circ} \mathrm{C}$ geschüttelt. Hierbei wurde ein definierter Bereich des Phagen, welcher die inserierte cDNA enthielt, vom Helferphagen einzelsträngig amplifiziert, zirkularisiert und als Phagemid verpackt aus dem Wirtbakterium ausgeschleust. Zum Abtöten des Wirtsbakteriums wurde der Ansatz anschließend für 15 min auf $70^{\circ} \mathrm{C}$ erhitzt, die Bakterien abzentrifugiert und der PhagemidÜberstand in ein neues 12 ml-PPN-Röhrchen überführt. Um den E. coli Stamm XLOLR mit dem Phagemid zu infizieren, wurden in 1.5 ml-Eppendorfgefäßen je $10 \mu$ oder $100 \mu$ l Phagemid-Überstand mit $200 \mu 1$ frischen XLOLR-Zellen $\left(\mathrm{OD}_{600}=1.0\right) 15 \mathrm{~min}$ bei $37^{\circ} \mathrm{C}$ geschwenkt. Nach Zugabe von $300 \mu \mathrm{l}$ LB-Medium wurde für weiter 45 min unter Schwenken bei $37^{\circ} \mathrm{C}$ inkubiert. Aus jedem Ansatz wurden $2 \times 200 \mu 1$ auf LBAgarplatten mit Kanamycin ausplattiert und über Nacht bei $37^{\circ} \mathrm{C}$ inkubiert. Mit den entstandenen Einzelkolonien konnten im Anschluß Flüssigkulturen angeimpft und das isolierte Plasmid mit der gesuchten cDNA amplifiziert werden.

\subsection{Gewinnung von Xenopus Oozyten}

Zur Entnahme von Ovarialgewebe wurden weibliche, adulte Xenopus laevis Albinos für 20 min in 0,25 \% 3Aminobenzoesäureethylesther anästhesiert. Nach erfolgter Betäubung des Tieres wurde mit einer Skalpellklnge ein kleiner Einschnitt in die obere Bauchhaut sowie das darunterbefindliche Muskelgewebe eingeführt. Danach konnten mit zwei Pinzeten Ovariallobi der gewünschten Menge entnommen werden. Die Einschnitte wurden anschließend desinfiziert und mit Katzendarm verschlossen. Zur Vereinzelung der Oozyten und Entfernung von Bindegewebe und Follikelzellen wurden die Oozyten für zwei bis drei Stunden in Kollagenase-Puffer mit $1 \mathrm{mg} / \mathrm{ml}$ Kollagenase (Sigma) inkubiert. Nach Vereinzelung der Oozyten wurden diese intensiv in $1 \times \mathrm{MBSH}$ gewaschen und über Nacht bei $18^{\circ} \mathrm{C}$ belassen. Die Bestimmung der Oozytenstadien erfolgte nach Dumont, 1972. Die Größensortierung der Oozyten erfolgte entweder manuell oder unter Zuhilfenahme von Sieben aus Nylongewebe unterschiedlicher Stärke.

1×MBSH (modified Barth solution/HEPES): $80 \mathrm{mM} \mathrm{NaCl} ; 1 \mathrm{mM} \mathrm{KCl} ; 2,4 \mathrm{mM} \mathrm{NaHCO} 3,20 \mathrm{mM}$ HEPES (pH 7,5); $0,82 \mathrm{mM} \mathrm{MgSO}_{4}, 0,33 \mathrm{mM} \mathrm{Ca}\left(\mathrm{NO}_{3}\right)_{2} ; 0,41 \mathrm{mM} \mathrm{CaCl}_{2}$

Kollagenase-Puffer: $82,5 \mathrm{mM} \mathrm{NaCl} ; 2 \mathrm{mM} \mathrm{KCl} ; 1 \mathrm{mM} \mathrm{MgCl} 2 ; 5 \mathrm{mM}$ HEPES (pH 7,5) 


\subsection{Präparation von Xenopus-Embryonalstadien}

Zur Präparation von Testis wurde ein adultes Xenopus Männchen zunächst betäubt, dekapitiert und ventral aufgeschnitten. Nach Öffnen der Bauchhöhle wurden dem Tier die Hoden entnommen und in eiskalten $1 \times$ MBSH-Puffer überführt. Nach Zugabe von Penicillin/Streptomycin konnten sie bei $4^{\circ} \mathrm{C}$ bis zu einer Woche gelagert werden. (Penicillin/Streptomycin: $10.000 \mathrm{U} / \mathrm{ml}$ Penicillin, $10 \mathrm{mg} / \mathrm{ml}$ Streptomycin (Sigma), Verdünnung 1:1.000). Um die Eiablage für den folgenden Morgen zu stimulieren, wurden einem Weibchen Nachmittags 50-100 U humanes Gonadotropin (500 U/ml) und um $22 \mathrm{Uhr}$ je nach Größe des Weibchens 300-600 U (1.000 U/ml) mit einer $1 \mathrm{ml}$-Spritze mit G27-Kanüle in die dorsalen Lymphsäcke injiziert. Zur meist spontanen Eiablage wurden die Weibchen über eine leere Petrischale gehalten. Die Gelege wurden mit Spermien aus frisch präparierten Hoden befruchtet. Um die Spermien freizusetzen, wurde ca. 1/5 eines Hodens mit einer Mikroschere in $100 \mu 11 \times$ MBSH mazeriert. Unmittelbar vor der Befruchtung wurden die in

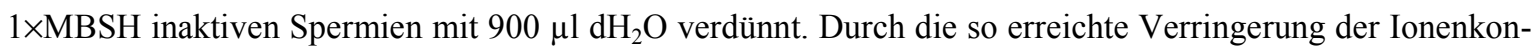
zentration erlangten die Spermien ihre volle Motilität. Mit einer abgeschnittenen gelben Pipettenspitze wurden die Spermien anschließend auf den Gelegen verteilt. Nach dem Ausbreiten der Gelege zu einer Einzelschicht wurden sie 2 Minuten inkubiert und dann mit $1 \times \mathrm{MBSH}$ überschichtet. $1 \mathrm{~h}$ nach der Befruchtung wurden die Embryonen durch 3-5 minütige Inkubation in $2 \%$ Cystein (pH 7.8) unter Schütteln von ihrer Gallerthülle befreit und fünfmal mit $0.1 \times \mathrm{MBSH}$ gespült. Die Embryonen wurden auf einer Temperierplatte bei $14-20^{\circ} \mathrm{C}$ bis zu den gewünschten Stadien herangezogen. Um die Feinstrukturen von Albinoembryonen besser erkennen zu können, wurden diese mit dem Vitalfarbstoff Nilblau angefärbt werden.

2\% Cystein-HCl: 2\% (w/v) L-Cystein-HCl, $\mathrm{pH}$ mit $\mathrm{NaOH}$ auf 7.8 einstellen

Nilblau-Färbelösung: $0.01 \%(\mathrm{w} / \mathrm{v})$ Nilblau in $0.1 \times \mathrm{MBSH}$, vor Gebrauch filtrieren

\subsection{Nachweis von RNA-Transkripten durch die whole mount in situ-Hybridisierung}

Um die räumliche und zeitliche Expression von Genen zu analysieren bzw. um die Verteilung einer RNA in Xenopus Oozyten zu analysieren, wurde die endogene RNA in situ mit komplementären, digoxygenin- oder fluoreszinmarkierten antisense RNA-Sonden hybridisiert und in einer antikörpervermittelten Färbereaktion detektiert. Zur Kontrolle der Spezifität können markierte sense RNA-Sonden eingesetzt werden.

\subsubsection{Fixierung von Xenopus Oozyten und Embryonen}

Waren die Oozyten oder Embryonen für whole mount in situ-Färbungen bestimmt, wurden sie in $5 \mathrm{ml}$ Schraubdeckelglasröhrchen auf einer Wippe für eine Stunde in 1×MEMFA fixiert und anschließend in $100 \%$ Ethanol bei $-20^{\circ} \mathrm{C}$ gelagert.

MEM (10 $\times)$ : 1 M MOPS, $20 \mathrm{mM}$ EGTA, $10 \mathrm{mM} \mathrm{MgSO}_{4}$

MEMFA (1×): $1 \times$ MEM, 3,7 \% Formaldehydlösung

\subsubsection{Rehydrieren der Oozyten und Embryonen}

Soweit nicht anders erwähnt, wurde bei jedem Schritt $5 \mathrm{ml}$ Lösung verwendet. Pro $5 \mathrm{ml}$ Schraubdeckelröhrchen wurden nicht mehr als 20 Embryonen gleichzeitig behandelt.

\begin{tabular}{|l|l|l|l|l|}
\hline & Ethanol (\%) & Puffer (\%) & Dauer (min) & Anzahl \\
\hline 1. & Ethanol 100\% & & 5 & $1 \times @$ \\
\hline 2. & Ethanol 75\% & $\mathrm{dH}_{2} \mathrm{O} \mathrm{25 \%}$ & 5 & $1 \times @$ \\
\hline 3. & Ethanol 50\% & $\mathrm{dH}_{2} \mathrm{O} 50 \%$ & 5 & $1 \times @$ \\
\hline 4. & Ethanol 25\% & PTw 75\% & 5 & $1 \times @$ \\
\hline 5. & & PTw 100\% & 5 & $4 \times @$ \\
\hline
\end{tabular}

@ $=$ kopfüber (Drehrad), PTw: 1×PBS; 0,1 \% (v/v) Tween-20 


\subsubsection{Permeabilisieren der Oozyten und Embryonen durch Proteinase K- Behandlung}

Um die Oozyten und Embryonen durchlässiger für die RNA-Hybridisierungssonden zu machen, wurden sie bis zu 25 min bei RT in $1 \mathrm{ml}$ PTw-Puffer inkubiert, dem $0.5 \mu 1$ Proteinase K-Lösung (Merck, $20 \mathrm{mg} / \mathrm{ml}$ ) zugegeben wurde (Endkonzentration $10 \mu \mathrm{g} / \mathrm{ml}$ ).

\subsubsection{Refixierung}

Die durch Proteinase K-Behandlung fragilen Oozyten und Embryonen wurden durch Azetylierung und Inkubation in PTw/Formaldehydlösung refixiert. Die Embryonen wurden in $0.1 \mathrm{M}$ Triethanolamin-Lösung (pH 7.5) umgepuffert, durch zweimalige Zugabe von Azetanhydrid azetyliert und anschließend in PTw $+4 \%$ FA refixiert.

\begin{tabular}{|l|l|l|l|l|}
\hline & Puffer & Zugabe von & Dauer (min) & Anzahl \\
\hline 1. & 0,1 M Triethanolamin & & 5 & $2 \times @$ \\
\hline 2. & 0.1 M Triethanolamin & $12.5 \mu$ l Azetanhydrid & 5 & $1 \times @$ \\
\hline 3. & & $12.5 \mu 1$ Azetanhydrid & 5 & $1 \times @$ \\
\hline 4. & PTw & & 5 & $2 \times @$ \\
\hline 5. & PTw + 4\% FA & & 20 & $1 \times @$ \\
\hline 6. & PTw & & 5 & $5 \times @$ \\
\hline
\end{tabular}

Anschließend wurde der PTw-Puffer bis auf $1 \mathrm{ml}$ entfernt und $250 \mu$ l Hybridisierungs-Lösung zugegeben. Nach dem Absinken der Oozyten und Embryonen in die Hybridisierungslösung wurde der Überstand abgenommen, durch $500 \mu \mathrm{l}$ Hybridierungslösung ersetzt und $10 \mathrm{~min}$ bei $60^{\circ} \mathrm{C}$ im Wasserbad inkubiert.

Hybridisierungslösung: 50\% (v/v) Formamid; 5×SSC; $1 \mathrm{mg} / \mathrm{ml}$ Torula RNA (Sigma); $100 \mu \mathrm{g} / \mathrm{ml}$ Heparin (Sigma); 1×Denhards; 0,1 \% (v/v) Tween-20; 0,1\% (w/v)CHAPS (Sigma)

100×Denhards: $2 \%$ (w/v) BSA (Serva, Fraktion V); $2 \%$ (w/v) Polyvinyl Pyrrolidone (Sigma); $2 \%$ (w/v); 2 $\%(w / v)$ Ficoll 400 in DEPC-behandeltem $\mathrm{H}_{2} \mathrm{O}$

\subsubsection{Hybridisierung mit markierten antisense RNA-Sonden}

Die Hybridisierungslösung wurde erneut ausgetauscht und die Oozyten und Embryonen für mindestens $6 \mathrm{~h}$ bei $60^{\circ} \mathrm{C}$ prähybridisiert. Nach dem Abnehmen des Überstands und Zugabe der digoxygenin- oder fluoreszinmarkierten RNA-Sonde (Endkonzentration ca.1 $\mu \mathrm{g} / \mathrm{ml}$ ) in $500 \mu \mathrm{l}$ Hybridisierungslösung wurde über Nacht unter leichtem Schütteln bei $60^{\circ} \mathrm{C}$ hybridisiert.

\subsubsection{Waschen}

Um nicht gebundene, einzelsträngig vorliegende Sonden-RNA zu entfernen, wurden die Oozyten und Embryonen unter stringenten Bedingungen gewaschen und mit $10 \mu \mathrm{g} / \mathrm{ml}$ RNase A und $10 \mathrm{U} / \mathrm{ml}$ RNase T1 behandelt. Die Sonden-RNA konnte bei $-20^{\circ} \mathrm{C}$ gelagert und mehrfach verwendet werden.

\begin{tabular}{|l|l|l|l|l|}
\hline & Puffer & Temperatur $\left({ }^{\circ} \mathrm{C}\right)$ & Dauer $(\min )$ & Anzahl \\
\hline 1. & Hyb-puffer $(500 \mu \mathrm{l})$ & 60 & 10 & $1 \times$ \\
\hline 2. & $2 \times$ SSC & 60 & 20 & $3 \times$ \\
\hline 3. & $2 \times$ SSC mit RNasen & 37 & 30 & $2 \times$ \\
\hline 4. & $2 \times$ SSC & RT & 10 & $1 \times$ \\
\hline 5. & $0.2 \times$ SSC & 60 & 30 & $2 \times$ \\
\hline 6. & MAB & RT & 15 & $2 \times$ \\
\hline
\end{tabular}

RNasen: $20 \mu \mathrm{g} / \mathrm{ml}$ RNase A, $10 \mathrm{U} / \mathrm{ml}$ RNase T1 


\subsubsection{Antikörper-Inkubation}

Die Hybride aus digoxigeninmarkierter Sonden-RNA und endogener mRNA konnten mit einem Digoxigenin- bzw. Fluoreszin-spezifischen Antikörper, an den alkalische Phosphatase gekoppelt war, nachgewiesen werden. Zur Blockieren unspezifischer Bindungsstellen wurden die Oozyten und Embryonen vor Zugabe des Detektions-Antikörpers in 2\% Boehringer Mannheim Blockierungs-Reagenz und 20\% hitzeinaktiviertem Pferdeserum (Biochrom KG, Berlin) inkubiert.

\begin{tabular}{|l|l|l|l|l|}
\hline & Puffer & Temperatur $\left({ }^{\circ} \mathrm{C}\right)$ & Dauer $(\mathrm{min})$ & Anzahl \\
\hline 1. & MAB $+2 \%$ BMB & RT & 60 & $1 \times-$ \\
\hline 2. & $\begin{array}{l}\text { MAB }+2 \% \text { BMB } \\
20 \% \text { Serum }\end{array}$ & RT & 60 & $1 \times-$ \\
\hline 3. & $\begin{array}{l}\text { MAB }+2 \% \text { BMB } \\
20 \% \text { Serum }+ \text { AK } \\
(1: 5.000)\end{array}$ & RT & 240 & $1 \times-$ \\
\hline 4. & MAB (Waschen) & RT & & \\
\hline 5. & MAB (Waschen) & 4 & 30 & $2 \times-$ \\
\hline
\end{tabular}

$-=$ horizontale Wippe

MAB (Maleinsäure-Puffer): 100 mM Maleinsäure; 150 mM NaCl; pH 7,5

\subsubsection{Farbentwicklung}

Alkalische Phosphatase setzt die Substrate NBT/BCIP zu einem dunkelvioletten Farbstoff um. Die Färbereaktion wurde im Dunkeln durchgeführt bis der gewünschte Kontrast einer hohen Signalintensität bei schwacher Hintergrundfärbung erreicht wurde.

\begin{tabular}{|l|l|l|l|l|}
\hline & Puffer & Temperatur $\left({ }^{\circ} \mathrm{C}\right)$ & Dauer $(\mathrm{min})$ & Anzahl \\
\hline 1. & MAB & RT & 60 & $1 \mathrm{x}$ \\
\hline 2. & APB & RT & 5 & $2 \mathrm{x}$ \\
\hline 3. & APB + NBT/BCIP & RT & $5 \mathrm{~min}-24 \mathrm{~h}$ & $1 \mathrm{x}$ \\
\hline
\end{tabular}

Alkaline Phosphatase Buffer (APB): $100 \mathrm{mM}$ Tris- $\mathrm{HCl}(\mathrm{pH} 9.5), 50 \mathrm{mM} \mathrm{MgCl}, 100 \mathrm{mM} \mathrm{NaCl}, 0.1 \%$ Tween-20

Färbelösung NBT/BCIP: Pro ml APB wurden $1.75 \mu 1$ NBT (Boehringer, $100 \mathrm{mg} / \mathrm{ml}$ in 70\% Dimethylformamid) und $3.5 \mu \mathrm{l}$ BCIP (Boehringer, $50 \mathrm{mg} / \mathrm{ml}$ in 100\% Dimethylformamid) eingesetzt.

\subsubsection{Abstoppen der Färbereaktion, Auswertung und Konservierung der Präparate}

Nach dem Erreichen der gewünschten Farbintensität wurde die Färbereaktion durch Spülen mit $\mathrm{dH}_{2} \mathrm{O}$ abgestoppt. Durch Inkubation in Methanol konnte die Hintergrundfärbung unter optischer Kontrolle reduziert werden. Anschließend wurden die Oozyten und Embryonen in einer absteigenden Methanolreihe rehydriert und in $1 \times$ MEMFA fixiert. In $1 \times$ MEM-Puffer konnten sie bei $4^{\circ} \mathrm{C}$ gelagert werden.

\begin{tabular}{|l|l|l|l|l|}
\hline & Lösung & Temperatur $\left({ }^{\circ} \mathrm{C}\right)$ & Dauer $(\mathrm{min})$ & Anzahl \\
\hline 1. & $\mathrm{dH}_{2} \mathrm{O}$ & RT & 1 & $1 \mathrm{x}$ \\
\hline 2. & Methanol $100 \%$ & RT & $1-5$ & $1 \mathrm{x}$ \\
\hline 3. & Methanol $75 \%$ & RT & 1 & $1 \mathrm{x}$ \\
\hline 4. & Methanol $50 \%$ & RT & 1 & $1 \mathrm{x}$ \\
\hline 5. & Methanol 25\% & RT & 1 & $1 \mathrm{x}$ \\
\hline 6. & $\mathrm{dH}_{2} \mathrm{O}$ & RT & 1 & $1 \mathrm{x}$ \\
\hline 7. & MEMFA & RT & über Nacht & $1 \mathrm{x}$ \\
\hline
\end{tabular}


Mit Hilfe eines Stereomikroskops (Stemi SV6, Zeiss) mit Kameraaufsatz wurden die Ergebnisse auf Ektachrome 64T Kunstlichtdiafilmen (Kodak) oder unter Verwendung eines digitalen Videodokumentationssystems dokumentiert.

\subsubsection{Vibratomschnitte}

Der Embryo wurde zunächst in Gelatine/Albumin Einbettungmedium ca. 10 min äquilibriert. In einem Wägeschälchen wurde auf Eis $2 \mathrm{ml}$ Einbettungsmedium mit $150 \mu \mathrm{l} 25 \%$ Glutaraldehyd-Lösung (Sigma) vermischt und möglichst luftblasenfrei in eine Silikonform gegossen. Nach dem Verfestigen wurden die Oozyten auf diesen Sockel gebettet und wie gewünscht positioniert. Erneut wurden $2 \mathrm{ml}$ Einbettungsmedium und $150 \mu 125 \%$ Glutaraldehyd-Lösung gemischt und die Oozyten sofort mit der Mischung überschichtet. Nach 10 min wurde der verfestigte Block aus der Form gelöst und mit einer Rasierklinge getrimmt. Das Objekt wurde mit Sekundenkleber in der entsprechenden Orientierung auf einen Metallblock aufgeklebt. Der Objekthalter mit dem Präparat wurde in ein Vibratom (Typ 1000, Pelco International) eingespannt und submers in $\mathrm{dH}_{2} \mathrm{O}$ 10-30 $\mu$ m dicke Schnitte angefertigt, die mit Hilfe eines feinen Pinsels auf mit Seife gespülte Objektträger überführt wurden. Nach kurzem Trocknen wurden die Schnitte in Moviol-Lösung eingebettet.

Gelatine/Albumin Einbettungsmedium: $1 \times \mathrm{PBS}, 4.88 \mathrm{mg} / \mathrm{ml}$ Gelatine, $0.3 \mathrm{~g} / \mathrm{ml}$ Albumin, $0.2 \mathrm{mg} / \mathrm{ml} \mathrm{Su}-$ crose. Zunächst wurde die Gelatine durch Erhitzen auf ca. $60^{\circ} \mathrm{C}$ gelöst und nach dem Abkühlen Albumin und Sucrose zugefügt. Die Lösung wurde filtriert $(0.45 \mu \mathrm{m})$ und aliquotiert bei $-20^{\circ} \mathrm{C}$ gelagert.

Moviol-Lösung: $9.6 \mathrm{~g}$ Moviol in $19.35 \mathrm{ml}$ 100\% Propantriol lösen, $1 \mathrm{~h}$ Rühren. Zugabe von $24 \mathrm{ml} \mathrm{dH}_{2} \mathrm{O}, 2 \mathrm{~h}$ Rühren. Zugabe von $48 \mathrm{ml} 0.2 \mathrm{M}$ Tris- $\mathrm{HCl}(\mathrm{pH} 8.5), 10 \mathrm{~min}$ Erhitzen auf $50^{\circ} \mathrm{C}, 15 \mathrm{~min}$ bei $5.000 \mathrm{Rpm}$ abzentrifugieren. Überstand aliquotiert bei $-20^{\circ} \mathrm{C}$ lagern.

\subsection{Isolierung von RNA-Lokalisationselementen in Mikroinjektionsexperimenten}

\subsubsection{Kultivierung von Xenopus Oozyten}

Die Kultivierung von Oozyten erfolgte nach Kloc und Etkin, 1999. Verschiedene Stadien vereinzelter Oozyten wurden in $1 \times \mathrm{MBSH}$ bei $18^{\circ} \mathrm{C}$ aufbewahrt. Die Kultivierung von Oozyten in $1 \times \mathrm{MBSH}$ fördert nicht deren Reifung und Wachstum sowie eine effiziente Lokalisation von endogenen und injizierter RNAs. Daher wurden die Oozyten nach Injektion von exogenen RNAs zur Analyse von Lokalisationselementen in das komplexe, mit Vitellogenin angereicherte OCM (Oozyten Kulturmedium) verbracht.

Oozyten Kulturmedium: 50 \% Leibovitz L15-Kulturmedium (Gibco); $1 \mathrm{mM} \mathrm{L-Glutamin} \mathrm{(Gibco);} 1 \mu \mathrm{g} / \mathrm{ml}$ Schweine-Insulin (Sigma); $15 \mathrm{mM}$ Hepes/NaOH, pH 7,5; $100 \mu \mathrm{g} / \mathrm{ml}$ Gentamycin (Gibco); $50 \mu \mathrm{g} / \mathrm{ml}$ Tetracyclin; $50 \mathrm{U} / \mathrm{ml}$ Nystatin (Gibco); $5 \mathrm{mg} / \mathrm{ml}$ Vitellogenin

\subsubsection{Präparation von Vitellogenin aus Froschserum}

Die Präparation von Vitellogenin aus Froschserum wurde wie in Kloc und Etkin, 1999 beschrieben, durchgeführt. Zur Präparation von Vitellogenin wurde das Serum 20 weiblicher Frösche verwendet. Zur Anregung der Vitellogenin-Synthese wurde den Fröschen jeweils zehn und sieben Tage vor Blutentnahme 1,5 mg 17- $\beta$ Östradiol (Sigma) in die dorsalen Lymphgefäße injiziert. Vor dem Ausbluten der Frösche wurden diese in 0,25 \% 3-Aminobenzoesäureethylesther anästhesiert. Mit einem dreieckigen Einschnitt wurde dann das Sternum und die Rippen entfernt und das schlagende Herz herausgehoben. Danach wurde ein kleiner Einschnitt in den Herzbeutel eingeführt und das austretende Blut in einem $50 \mathrm{ml}$ Falcon-Gefäß mit $50 \%$ Dulbeccos Kalzium-freier Saline (Gibco) mit 0,07 M Natriumzitrat (pH 7,6) gesammelt. Es wurde so jeweils $1 \mathrm{ml}$ Saline zum Blut von zwei Fröschen gegeben und auf Eis aufbewahrt. Anschließend wurden feste Bestandteile des Blutes durch Zentrifugation bei $2500 \mathrm{~g}$ für 15 min abgetrennt. Zur Ausfällung des Vitellogenins wurden jeweils $5 \mathrm{ml}$ Serum mit $20 \mathrm{ml} 20 \mathrm{mM}$ EDTA und 1,6 $\mathrm{ml} 0,5 \mathrm{M} \mathrm{MgCl}_{2}$ versetzt, durchmischt und für $15 \mathrm{~min}$ im GSA-Rotor bei 5000 rpm zentrifugiert. Nach der Zentrifugation wurde der Überstand entfernt und das leuch- 
tend grüne Vitellogenin-Pellet in $3 \mathrm{ml}$ Puffer A gelöst. Um Magnesiumionen zu entfernen wurde das Vitellogenin über Nacht im Kühlraum gegen $4 \times 1$-Liter- Wechsel $50 \mathrm{mM}$ Tris/HCl, $\mathrm{pH}$ 7,5 in Dialysierrahmen (Slide-A-Lyzer, Pierce) dialysiert. Anschließend wurden die Präparationen zur Mengenabschätzung bei 280 $\mathrm{nm}$ im Photometer 1:20 in $50 \mathrm{mM}$ Tris/ $\mathrm{HCl}, \mathrm{pH} 7,5$ verdünnt gemessen und in $1 \mathrm{ml}$ Aliquots bei $-20^{\circ} \mathrm{C}$ eingefroren und gelagert. Die Vitellogenkonzentration der Präparationen konnten über deren Extinktion bei 280 $\mathrm{nm}$ multipliziert mit Verdünnungsfaktor und dividiert durch den Koeffizienten $0,75 \mathrm{in} \mathrm{mg} / \mathrm{ml}$ ermittelt werden. Zu diesem Wert wurde anschließend der Korrekturfaktor von $2,3 \mathrm{mg} / \mathrm{ml}$ addiert. Üblicherweise konnten so Vitellogeninkonzentrationen von $40-60 \mathrm{mg} / \mathrm{ml}$ ermittelt werden. Es wurden so ca.40 $\mathrm{ml}$ gereinigtes Vitellogenin aus dem Serum von 20 Fröschen gewonnen.

Puffer A: $1 \mathrm{M} \mathrm{NaCl} ; 50 \mathrm{mM}$ Tris/HCl, $\mathrm{pH} 7,5$

\subsubsection{Injektion und Detektion von lacZ-RNA-Fusionen in Xenopus Oozyten}

Um die cis-agierenden Elemente einer lokalisierten RNA nachzuweisen, können Subfragmente derselben fusioniert an einen RNA-tag, in die Nuklei von Stadium II-IV Oozyten injiziert werden und nach zwei- bis dreitägiger Kultivierung in Oozyten Kulturmedium in der whole mount in situ-Hybridisierung mit einer digoxygeninmarkierten Sonde nachgewiesen werden, die gegen den Fusionsanteil der injizierten RNA gerichtet ist. Entsprechende cDNA-Fragmente der in vivo lokalisierten RNAs wurden dazu hinter einen kurzen lacZReporter kloniert und davon in vitro transkribierte, Monomethylguanosin-Cap-enthaltene RNAs in die Nuklei von Xenopus Oozyten injiziert.

Zur Mikroinjektion von RNA in Xenopus Oozyten wurde die RNA mit einer langen Plastikpipettenspitze (Mikroloader von Eppendorf) in eine mit einem Nadelziehgerät ausgezogene Glaskapillare (GC100F-16, Clark Electromedical Instruments, Reading, England) pipettiert. Unter dem Binokular wurde dann mit einer Uhrmacherpinzette die Spitze der Kapillare abgebrochen und diese so geöffnet. Die Injektionsnadel wurde dann in eine Luftdruckregulierte Mikromanipulationsapparatur (Mikroinjektor 5242, Eppendorf) eingespannt. Unter Variation des Injektionsdrucks (1000-2000 hPa) sowie der Injektionszeit (0,1-0,2 sec.) wurden so 0,5 $\mathrm{nl}(\mathrm{ca} .0,1 \mu \mathrm{g} / \mu \mathrm{l})$ in die Zellkerne der Xenopus Oozyten injiziert. Dazu wurden die Oozyten in MBSH-Puffer auf einem in eine Zellkulturschale eingeklebten, Nylonsiebgewebe $(0,2-0,6 \mathrm{~cm})$ ausgerichtet. Nach Injektion wurden die Oozyten in Oozytenkulturmedium überführt und bei $18^{\circ} \mathrm{C}$ für zwei bis vier Tage kultiviert. Zur Detektion der injizierten RNAs wurden die Oozyten zunächst für $1 \mathrm{~h}$ in MEMFA fixiert und dann in die whole mount in situ-Hybridisierung eingesetzt.

\subsection{Analyse von RNA-Protein-Wechselwirkungen}

\subsubsection{UV-Quervernetzungsversuche}

Mit der Methode der UV-Quervernetzung können RNA-Protein-Interaktionen durch Einfügung einer kovalenten Bindung zwischen im RNA-Proteinkomplex direkt in Kontakt stehenden Basen- oder Aminosäurereste. Aufgrund der differentiellen Absorption von RNA und Proteinen bei einer Wellenlänge von $254 \mathrm{~nm}$ können RNA-Protein-Quervernetzungen in den Komplex eingefügt werden, die Ausbildung von intra-Protein-Quervernetzungen sowie die Degradation von RNA oder Protein jedoch weitgehend vermieden werden. Durch die Anregung interkalierender $\pi$-Elektronensysteme von Uracil- oder aromatischen Aminosäureresten kommt es dabei zur Aubildung einer kovalenten, intermolekularen $\sigma$-Bindung. An die Behandlung des RNA-Proteinkomplexes mit UV-Licht schließt sich die Analyse der miteinander vernetzten Komponenten durch RNAse-Behandlung, SDS-PAGE und Auswertung im Phosphoimager an.

Üblicherweise wurden zum Nachweis von RNA-Protein-Interaktionen durch UV-Quervernetzung 2,5 $\mu 1 \mathrm{Xe}$ nopus-Oozyten S100-Extrakt (10 mg/ml Proteingehalt) mit 5×UV-Quervernetzungsmix, Kompetitor-RNA und DEPC-behandeltem Wasser in einem Volumen von $9 \mu \mathrm{l}$ in einem Eppendorfreaktionsgefäß zusammengefügt und zehn Minuten bei RT inkubiert. Danach wurde $1 \mu 1$ einer mit $\alpha^{32}$ P-UTP während der in vitro- 
Transkriptionsreaktion markierten RNA hinzugegeben und weitere 10 min Bei RT inkubiert. Anschließend erfolgte eine zehnminütige Behandlung des Reaktionansatzes mit UV-Licht einer Wellenlänge von 254nm im Stratalinker (Stratagene). Der Abstand zwischen Probe und UV-Lichtröhre betrug dabei $5 \mathrm{~cm}$. Zur Entfernung der nicht-quervernetzten RNA-Proben aus dem Reaktionsansatz, wurde dieser mit $2 \mu 1$ RNase A $(5 \mathrm{mg} / \mathrm{ml})$ versetzt und für $15 \mathrm{~min}$ Bei $37^{\circ} \mathrm{C}$ inkubiert. Zur weiteren Analyse wurden die Proben zusammen mit einem radioaktiv markiertem Molekulargewichtstandard über SDS-PAGE aufgetrennt, das Gel in Methanol-Essigsäure fixiert, getrocknet und mit dem Phosphoimager ausgewertet.

Bindungs-Bedingungen für den UV-Quervernetzungsversuch: $5 \mathrm{mg} / \mathrm{ml}$ Heparin; 1\% (v/v) Propantriol; 50 mM KCl; 10 mM DTT; 5,2 mM HEPES (pH 7,9); 1,5 mM ATP; 1 mM MgCl2; 0,1 mM EDTA; $40 \mu \mathrm{g} / \mathrm{ml}$ tRNA. Die Komponenten wurdem dem in vitro Bindungsansatz als $5 \times$ Mix zugefügt.

\subsubsection{Koimmunopräzipitation von RNA}

Zur Untersuchung von RNA-Protein-Wechselwirkungen wurde die Methode der Koimmunopräzipitation radioaktiv markierter RNAs mit in vitro translatierten, myc-Epitop-markierten und immobilisierten Proteinen verwendet. Dafür wurden zunächst die zu untersuchenden Proteine in Retikulozytenlysat, nicht radioaktiv, translatiert. Anschließend wurde dem Ansatz die zu untersuchende in vitro transkribierte und radioaktiv markierte RNA zugesetzt (ca. 200000-400000 cpm) und für $1 \mathrm{~h}$ bei RT inkubiert. Dem in vitro Bindungsansatz wurde zusätzlich noch die entsprechende Menge des in 2.24.1 angegebenen 5×Bindungsmixes zugegeben. Danach wurden die Reaktionsansätze in $500 \mu$ l NET-2-Puffer auf ein $\alpha$-myc-Immunopellet gegeben und für $1,5 \mathrm{~h}$ bei $8^{\circ} \mathrm{C}$ auf einem Drehrad rotiert. Anschließend wurden $200 \mu \mathrm{l}$ des Überstandes mit der ungebundenen RNA abgenommen und Phenol/Chloroform-extrahiert. Die Immunopellets wurden $3 \times$ mit $800 \mu$ l NET-2Puffer gewaschen um nichtgebundene RNAs aus dem Ansatz zu entfernen. Das Pellet wurde anschließend in $200 \mu 1$ Net-2 mit $20 \mu 1 \quad 10 \%$ SDS und Fällungs-tRNA versetzt und die RNA aus dem Ansatz Phenol/Chloroform extrahiert und Ethanol-gefällt. Die RNA-Pellets wurden anschließend in $10 \mu 1$ HarnstoffRNA-Auftragspuffer aufgenommen und auf einem $8 \%$ Harnstoff-Polyacrylamidgel aufgetrennt und mit dem Phosphoimager ausgewertet.

NET-2-Puffer: $50 \mathrm{mM}$ Tris/ $\mathrm{HCl}$ (pH 7,4); $150 \mathrm{mM} \mathrm{NaCl} ; 0,05 \% \mathrm{NP}$ 40; eventuell wurden vor Anwendung $1 \mathrm{mM}$ PMSF und Proteaseinhibitor-Tabletten (Pharmacia) zugefügt.

\subsubsection{Herstellung von $\alpha$-myc-Immunopellets}

Zur Herstellung von Immunopellets wurden anti-Myc-Antikörper (9E10; Santa Cruz Biotechnology) an eine Sepharosematrix gebunden. Pro Pellet wurden dabei $15 \mu$ Protein-G-Sepharose und $10 \mu 1$ Antikörperlösung eingesetzt. Die Sepharosematrix wurde vorangehend dreimal mit NET-2-Puffer gewaschen und anschließend für $1 \mathrm{~h}$ bei RT mit dem Antikörper inkubiert. Um nichtgebundene Antikörper zu entfernen wurde das Sepharosepellet wiederum dreimal mit NET-2-Puffer gewaschen und anschließend in Eppendorf-Reaktionsgefäße aliquotiert. Bis zur weiteren Verwendung wurden die Immunopellets bei $4^{\circ} \mathrm{C}$ gelagert.

\subsection{Mikroinjektion von Xenopus Embryonen}

Zur Überexpression von Proteinen wurde beim Erreichen des 2- Zell-Stadiums synthetische Cap-mRNA in einzelne Blastomere von Xenopus Embryonen injiziert. Die Injektion erfolgte dabei ebenso wie unter 2.23.3 für Oozyten Injektionen beschrieben wurde. Vor der Injektion wurden die zu injizierenden Embryonen in Injektionspuffer überführt und auf mit Repell-Silan beschichtete Objektträger aufgebracht. Nach $1 \mathrm{~h}$ Inkubation in Plastikkulturschalen (Greiner) wurden die Embryonen in Post-Injektionspuffer überführt, der nach ca. 30 min gegen $0.1 \times \mathrm{MBSH}$ ausgetauscht werden konnte. Zur Fixierung wurden die Embryonen bei RT $1 \mathrm{~h}$ in $1 \times$ MEMFA inkubiert und anschließend in $1 \times$ MEM bei $4^{\circ} \mathrm{C}$ gelagert. 
Die photografische Dokumentation von phänotypischen Effekten der Injektion auf die Embryonalentwicklung erfolgte mit Hilfe eines Stereomikroskops (Stemi SV 6, Zeiss) mit Kameraaufsatz (Zeiss) und Kunstlichtdiafilmen (Ektachrome 64T, Kodak).

Injektionspuffer: $1 \%$ Ficoll, $1 \times \mathrm{MBSH}$

Post-Injektionspuffer: $0.5 \%$ Ficoll, $0.1 \times \mathrm{MBSH}$

\subsection{Klonierungen}

MC118: Dieses pBK-CMV-Plasmid enthält die cDNA der 6E RNA, die in der PCR-vermittelten Durchmusterung der Stadium V/VI Oozyten cDNA-Bibliothek isoliert werden konnte. Linearisierung des Vektors mit BamHI zur Gewinnung von antisense Transkripten (T7-Polymerase) für die in situ-Hybridisierung.

MC207 und MC208: Diese Plasmide enthalten die kürzeren Spleißvarianten der 6E-cDNA, die in der whole mount in situ-Hybridisierungs-basierten Durchmusterung der Kortex cDNA-Bibliothek identifiziert werden konnten.

MC119: Dieses pBK-CMV-Plasmid enthält die cDNA der B2B-10B RNA (XNIF), die in der PCRvermittelten Durchmusterung der Stadium V/VI Oozyten cDNA-Bibliothek isoliert werden konnte. Linearisierung des Vektors mit BamHI zur Gewinnung von antisense Transkripten (T7-Polymerase) für die in situHybridisierung.

MC135: Dieses Plasmid enthält die zusammengesetzte cDNA der B2B-9D-RNA (DEADSouth-Isoform). Ein PCR-Fragment das mit den Oligonukleotiden CMV-F (ACAGGAAACAGCTATGACCTTG) und B2B-9DLOW (CAGACCGAAATAACTGTTGCTAAA) aus einer positiven Phagenfraktion der Stadium V/VI Oozyten cDNA-Bibliothek gewonnen wurde, wurde in den pGEM-T-Vektor ligiert. Da diesem Plasmid aufgrung der Verwendung eines internen 3'-Oligonukleotides in der PCR Bereiche des 3'-UTRs fehlten, wurde ein NsiI/NsiI-Fragment dieses Plasmides gegen dasjenige des primär isolierten pTriplEx2-Klons ausgetauscht. Linearisierung des Vektors mit NcoI zur Gewinnung von antisense Transkripten (Sp6-Polymerase) für die in situ-Hybridisierung.

MC186: Dieses pBK-CMV-Plasmid enthält die cDNA der A3A-11C RNA (XPTB), die in der PCRvermittelten Durchmusterung der Stadium V/VI Oozyten cDNA-Bibliothek isoliert werden konnte. Linearisierung des Vektors mit BamHI zur Gewinnung von antisense Transkripten (T7-Polymerase) für die in situHybridisierung.

MC187: Dieses Plasmid enthält die partielle cDNA-Sequenz des in der in situ Hybridisierung als äquatorial lokalisiert identifizierten B2B-2B-Klons. Ein SmaI/NotI-Fragment des primären pTriplEx2-Klons wurde dazu in die ScaI/NotI-Schnittstellen des MC161-Vektors ligiert. Dieses Plasmid enthält also auch die kurze lacZ-Sequenz, die die Detektion der hiervon generierten RNA nach Injektion in Xenopus Oozyten ermöglicht. Zur Gewinnung von sense-Transkripten (T3-Polymerase) wurde das Plasmid mit KpnI oder NotI linearisiert. Zur Erstellung von antisense Transkripten (T7-Polymerase) für die in situ-Hybridisierung kann das Plasmid mit BamHI linearisiert werden.

\subsubsection{Kontroll-Konstrukte}

MC161: Dieses Plasmid enthält ein 320 bp Fragment des kodierenden Bereiches des lacZ-Gens. Es wurde als Kontrolle in Injektionsexperimenten und UV-Quervernetzungsexperimenten eingesetzt. Zu seiner Erstellung wurde ein Fragment aus dem lacZ-Gen des pAX4a-Vektors mit den Oligonukleotiden

pAX4a-BssHII-up: TTGGCGCGCATGATTACGGATTCACTGGCCG

pAX4a-BamHI-low: CGGGATCCGACCGTAATGGGATAGGTTACG

amplifiziert. Über die PCR wurden diesem Fragment BssHII und BamHI-Schnittstellen angefügt, über die dieses dann in den ebenfalls mit BssHII und BamHI geschnittenen pBK-CMV-Vektor ligiert wurde.

MC153: Dieses Plasmid enthält den das Lokalisationselement umfassenden Bereich des Vg1 3'-UTRs. Daszu wurde ein EcoRI/XbaI-Fragment aus dem Vg1-Sequenzen enthaltenden pTriplEx2-Plasmid (wurde bei der 
Durchmusterung der Kortex-Bibliothek isoliert) in den EcoRI/XbaI-geschnittenen pBK-CMV ligiert. Die kurze lacZ-Sequenz wurde wie für den MC161-Vektor beschrieben eingefügt.

\subsubsection{Subklonierung von Fragmenten der 6E-cDNA}

MC158: Dieses Plasmid enthält die 6E cDNA 3' hinter der lacZ-Sequenz und kann zur Generierung einer Fusions-RNA zur Injektion in Oozyten benutzt werden. Zur Erstellung dieses Plasmides wurde wie schon für das Plasmid MC161 beschrieben wurde, ein in der PCR-amplifiziertes lacZ-Fragment in die BssHII und BamHI-Schnittstellen des MC118-Plasmides inseriert.

MC159: Dieses Plasmid enthält die kodierende Region der 6E cDNA hinter den kurzen lacZ-tag fusioniert. Zu seiner Erstellung wurde zunächst über die PCR unter Verwendung der folgenden Oligonukleotide

6E-cod-up: $\quad$ CGGGATCCGTTGTGCTTTGAATGAAC

6E-cod-low: GCTCTAGATTACAGTTTGCCATTCAG

die kodierende Region und das kurze 5'-UTR der 6E cDNA aus dem Plasmid MC118 herausamplifiziert. Über die Oligonukleotide wurden BamHI- und XbaI-Schnittstellen in das Fragment eingefügt und dieses nach restriktionsenzymatischer Spaltung in den ebenfalls BamHI- und XbaI-geschnittenen pBK-CMV-Vektor ligiert. In die BssHII und BamHI-Schnittstellen des Vektors wurde wie für das Plasmid MC161 beschrieben, das lacZ-Fragment inseriert.

MC160: Dieses Plasmid enthält das 3'-UTR der 6E cDNA hinter den kurzen lacZ-tag fusioniert. Zu seiner Erstellung wurde zunächst über die PCR unter Verwendung der folgenden Oligonukleotide

6E-3'utr-up:

CGGGATCCAGTGTATATATCTCTCTT

T7-primer:

GTAATACGACTCACTATAGGGC

der 3'-nichtkodierende Bereich der 6E cDNA aus dem Plasmid MC118 herausamplifiziert. Über die Oligonukleotide wurden BamHI- und $X b a \mathrm{I}-S c h n i t t s t e l l e n$ in das Fragment eingefügt und dieses nach restriktionsenzymatischer Spaltung in den ebenfalls BamHI- und XbaI-geschnittenen pBK-CMV-Vektor ligiert. In die BssHII und BamHI-Schnittstellen des Vektors wurde wie für das Plasmid MC161 beschrieben, das lacZ-Fragment inseriert.

Die anfolgend genannten Plasmide enthalten jeweils Fragmente des 3'-UTRs der 6E-cDNA, die 3 ' hinter den kurzen lacZ-Fusionsanteil ligiert wurden. Die Fragmente wurden mit spezifischen Oligonukleotiden, über die BamHI- und XhoI-Schnittstellen in die Fragmente eingefügt wurden, aus der 6E-cDNA herausamplifiziert und anschließend in den ebenfalls mit BamHI und XhoI geschnittenen MC160-Vektor ligiert. Angegeben sind anfolgend die für die Erstellung der jeweiligen Konstrukte verwendeten Oligonukleotide.

MC168: Nukleotide 2369-2462 der 6E-cDNA

6E-utr-up-1:

CGGGATCCAGTGTATATATCTCTATT

6E-utr-low-1:

CCGCTCGAGTGAGTGGGTAGGTAGGAC

MC169: Nukleotide 2441-2543 der 6E-cDNA

6E-utr-up-2:

CGGGATCCAGGGGTCCTACCTACCCAC

6E-utr-low-2:

CCGCTCGAGTGCCTGTTTCAAAACTATTT

MC170: Nukleotide 2516-2638 der 6E-cDNA

6E-utr-up-3:

CGGGATCCAGGAGGCTAAATAGTTTTG

6E-utr-low-3: CCGCTCGAGATACAATGTTAAGAGTGC

MC171b: Nukleotide 2592-2704 der 6E-cDNA

6E-utr-up-4:

CGGGATCCATATTGAAATAGCACATG

6E-utr-low-4:

CCGCTCGAGTAAGTACATTATTTGCAG

MC179: Nukleotide 2628-2666 der 6E-cDNA

6E-utr-4a-up:

6E-utr-4b-low: CCGCTCGAGTGCTAGTACATTGTGGAC 
MC180: Nukleotide 2592-2647 der 6E-cDNA

6E-utr-up-4: CGGGATCCATATTGAAATAGCACATG

6E-utr-4a-low: CCGCTCGAGACAGTGCTATATACAATG

MC181: Nukleotide 2592-2666 der 6E-cDNA

6E-utr-up-4:

CGGGATCCATATTGAAATAGCACATG

6E-utr-4b-low:

CCGCTCGAGTGCTAGTACATTGTGGAC

MC182: Nukleotide 2629-2704 der 6E-cDNA

6E-utr-4a-up:

CGGGATCCAACATTGTATATAGCACTG

6E-utr-low-4: CCGCTCGAGTAAGTACATTATTTGCAG

\subsubsection{Subklonierung von Fragmenten der 9D (DEADSouth)-cDNA}

MC149: Dieses Plasmid enthält die Volllängen cDNA des B2B-9D-Klons (DEADSouth-Isoform), die hinter einen kurzen lacZ-tag fusioniert wurde. Zu seiner Erstellung wurde ein 320 bp Fragment aus dem lacZ-Gen des pAX4a-Vektors mit den Oligonukleotiden

pAX4a-ApaI-up:

AATTGGGCCCATGATTACGGATTCACTGGCCG

PAX4a-NcoI-low: CATGCCATGGGACCGTAATGGGATAGGTTACG

herausamplifiziert. Über die Oligonukleotide wurden ApaI- und NcoI-Schnittstellen in das Fragment eingefügt und dieses nach restriktionsenzymatischer Spaltung in das ebenfalls mit ApaI und NcoI geschnittene MC 135-Plasmid ligiert.

MC150: Dieses Plasmid enthält den kodierenden Bereich sowie das kurze 5'-UTR der B2B-9D cDNA hinter einen kurzen lacZ-tag fusioniert. Dazu wurde zunächst in der PCR unter Verwendung der Oligonukleotide

T7-primer:

GTAATACGACTCACTATAGGGC

9D-cod-low:

GCTCTAGATTACTTCCATATTTTCCC

das entsprechende Fragment aus der B2B-9D cDNA herausamplifiziert. Dieses Fragment wurde mit EcoRI und $X b a \mathrm{I}$ geschnitten und in das ebenfalls mit EcoRI und $X b a \mathrm{I}$ geöffnete MC135 Plasmid ligiert. Zusätzlich wurde über die ApaI- und NcoI- Schnittstellen des Vektors ein kurzes lacZ-Fragment angefügt, wie auch für das MC149-Plasmid beschrieben wurde.

MC151: Dieses Plasmid enthält den 3'-untranslatierten Bereich der B2B-9D cDNA hinter den kurzen lacZtag fusioniert. Dazu wurde zunächst in der PCR unter Verwendung der Oligonukleotide

9D-3'utr-up: $\quad$ CGGAATCAGTGATGAGTCGGCATGAT

Sp6-primer: $\quad$ TTAGGTGACACTATAGAATAC

das entsprechende Fragment aus der B2B-9D cDNA herausamplifiziert. Dieses Fragment wurde mit EcoRI und XhoI geschnitten und in das ebenfalls mit EcoRI und XhoI geöffnete MC135 Plasmid ligiert. Zusätzlich wurde über die ApaI- und NcoI- Schnittstellen des Vektors ein kurzes lacZ-Fragment angefügt, wie auch für das MC149-Plasmid beschrieben wurde.

Die anfolgend beschriebenen Plasmide enthalten Fragmente des 3'-UTRs der DEADSouth-cDNA 3' hinter den kurzen lacZ-Reporter fusioniert. Dazu wurden entsprechende Fragmente aus der DEADSouth-cDNA herausamplifiziert und über die angefügten BamHI- und XhoI-Schnittstellen in den ebenfalls mit BamHI und XhoI geschnittenen MC161-Vektor ligiert.

MC197: Nukleotide 1432-1731 der DEADSouth-cDNA

9D-utr-up-1:

CGGGATCCAGTGATGAGTCGGCATGATC

9D-utr-low1:

CCGCTCGAGGTCAAGCCTAAAACTCCAAA

MC198: Nukleotide DEADSouth-1682-1980

9D-utr-up-2:

CGGGATCCATTCTATTAATAATGTGTTGC

9D-utr-low-2:

CCGCTCGAGTGGGCGATTCTACACAATTTG

MC199: Nukleotide 1932-2270 der DEADSouth-cDNA

9D-utr-up-3:

CGGGATCCACTATATTTTATTGCATGTA

9D-utr-low-3: CCGCTCGAGCTTAAATGCTACTTTTAAAC 
MC200: Nukleotide 2181-2490 der DEADSouth-cDNA

9D-utr-up-4:

CGGGATCCGGCTTTTAGCAACAGTTATT

9D-utr-low-4:

CCGCTCGAGATCAGAGCATCACAAAACC

MC201: Nukleotide 2441-2730 der DEADSouth-cDNA

9D-utr-up-5:

CGGGATCCTACTATCCTGAGCATGCTCC

9D-utr-low-5: $\quad$ CCGCTCGAGCCGATAAGCTTTTTCTGTG

MC202: Nukleotide 2681-3010 der DEADSouth-cDNA

9D-utr-up-6:

CGGGATCCCACATTAAACAGAAATTAACG

9D-utr-low-6: CCGCTCGAGCCTCTTTAATGACCTTTTTA

MC203: Nukleotide 1682-1771 der DEADSouth-cDNA

9D-utr-up-2:

CGGGATCCATTCTATTAATAATGTGTTGC

9D-utr-low-2-1: CCGCTCGAGGTTTTCTAGTGATGTATG

MC204: Nukleotide 1737-1838 der DEADSouth-cDNA

9D-utr-up-2-2: CGGGATCCTCACATGAGCACTTTTTC

9D-utr-low-2-2: $\quad$ CCGCTCGAGGTGCAAGAACACATTTTG

MC205: Nukleotide 1803-1902 der DEADSouth-cDNA

9D-utr-up-2-3: CGGGATCCGAAGGTCTTGGTTATTTG

9D-utr-low-2-3: $\quad$ CCGCTCGAGAAACTCTGTAATACATGC

MC206: Nukleotide 1882-1980 der DEADSouth-cDNA

9D-utr-up-2-4: $\quad$ CGGGATCCAATGCATGTATTACAGAG

9D-utr-low-2: $\quad$ CCGCTCGAGTGGGCGATTCTACACAATTTG

\subsubsection{Subklonierung von Fragmenten der 10B (XNIF)-cDNA}

MC154: Dieses Plasmid enthält die Volllängen B2B-10B (XNIF) cDNA hinter den kurzen lacZ-tag fusioniert. Zur Erstellung dieses Plasmides wurde wie schon für das Plasmid MC161 beschrieben wurde, ein in der PCR-amplifiziertes lacZ-Fragment des pAX4-Vektors in die BssHII und BamHI-Schnittstellen des MC119-Plasmides inseriert.

MC156: Dieses Plasmid enthält den 5'-untranslatierten Bereich der B2B-10B cDNA, der hinter die kurze lacZ-Reportersequenz fusioniert wurde. Zu seiner Erstellung wurde zunächst über die PCR unter Verwendung der folgenden Oligonukleotide

10B-5'utr-up: $\quad$ CGGGATCCTCCGACCTTAGACTCGAC

10B-5'utr-low: $\quad$ CCGCTCGAGGGAAACGAATTGGCTGTTG

das entsprechende Fragment der B2B-10B cDNA amplifiziert. Über die Oligonukleotide wurden BamHIund XhoI-Schnittstellen in das Fragment eingefügt und dieses nach restriktionsenzymatischer Spaltung in den ebenfalls mit BamHI und XhoI geschnittenen MC119-Vektor ligiert. Das lacZ-Fragment wurde wie für das MC161-Plasmid beschrieben über die BssHII und BamHI-Schnittstellen eingefügt.

MC152: Dieses Plasmid enthält den kodierenden Bereich der B2B-10B cDNA, der hinter die kurze lacZReportersequenz fusioniert wurde. Zu seiner Erstellung wurde zunächst über die PCR unter Verwendung der folgenden Oligonukleotide

10B-5'utr-up: $\quad$ CGGGATCCTCCGACCTTAGACTCGAC

10B-cod-low: $\quad$ CCGCTCGAGCTACCTGTTACATAACTT

aus der B2B-10B cDNA herausamplifiziert. Dieses Fragment wurde in die BamHI- und XhoI-Schnittstellen des MC119-Vektor ligiert. Das den kodierenden Bereich enthaltene NcoI/XhoI-Fragment dieses Plasmides wurde dann in die NcoI/XhoI-Schnittstellen des MC135-Vektors ligiert (pGEM-T-Derivat). Der kurze lacZtag wurde wie für das Plasmid MC149 beschrieben wurde in die ApaI- und NcoI-Schnittstellen des Vektors eingefügt. 
MC157: Dieses Plasmid enthält den 3'-untranslatierten Bereich der B2B-10B cDNA, der hinter die kurze lacZ-Reportersequenz fusioniert wurde. Zu seiner Erstellung wurde zunächst über die PCR unter Verwendung der folgenden Oligonukleotide

10B-3'utr-up:

CGGGATCCCCCTGGCCAAGCTCTCCG

T7-primer:

GTAATACGACTCACTATAGGGC

das entsprechende Fragment der B2B-10B cDNA amplifiziert. Über die Oligonukleotide wurden BamHIund XhoI-Schnittstellen in das Fragment eingefügt und dieses nach restriktionsenzymatischer Spaltung in den ebenfalls mit BamHI und XhoI geschnittenen MC119-Vektor ligiert. Das lacZ-Fragment wurde wie für das MC161-Plasmid beschrieben über die BssHII und BamHI-Schnittstellen eingefügt.

Die anfolgend beschriebenen Konstrukte beinhalten jeweils Fragmente des $5^{\prime}$-UTRs der B2B-10B-cDNA, die 3' hinter die lacZ-Reportersequenz fusioniert wurden. Dazu wurden die Fragmente über spezifische Oligonukleotide aus der B2B-10B-cDNA herausamplifiziert und in den mit BamHI- und XhoI-geschnittenen MC156-Vektor ligiert.

MC172: Nukleotide 1-300 der B2B-10B-cDNA

10B-utr-up-1:

CGGGATCCTCCGACCTTAGACTCGAC

10B-utr-low-1:

CCGCTCGAGGCCGTGTATAGAAATGGC

MC173: Nukleotide 252-551 der B2B-10B-cDNA

10B-utr-up-2:

CGGGATCCATTCCCCTCACACACACAC

10B-utr-low-2: $\quad$ CCGCTCGAGTATACTGAGCTGCAAGGG

MC174: Nukleotide 501-802 der B2B-10B-cDNA

10B-utr-up-3: CGGGATCCATCTACACACACATATATAC

10B-utr-low-3: $\quad$ CCGCTCGAGCTGCTCTATACTTTGCGG

MC175: Nukleotide 752-1052 der B2B-10B-cDNA

10B-utr-up-4: CGGGATCCACCGTACAGCGTTCTTTAC

10B-utr-low-4: $\quad$ CCGCTCGAGTGGAGGCAGTTCTGGCTC

MC176: Nukleotide 1002-1308 der B2B-10B-cDNA

10B-utr-up-5: $\quad$ CGGGATCCATACTTTGCACACTCTTCTTC

10B-utr-low-5: $\quad$ CCGCTCGAGGGAAACGAATTGGCTGTTG

MC177: Nukleotide 415-551 der B2B-10B-cDNA

10B-utr-2b-up: CGGGATCCAGCCTCTATACACCTATTAC

10B-utr-low-2: $\quad$ CCGCTCGAGTATACTGAGCTGCAAGGG

MC178b: Nukleotide 252-381 der B2B-10B-cDNA

10B-utr-up-2: $\quad$ CGGGATCCATTCCCCTCACACACACAC

10B-utr-2a-low: $\quad$ CCGCTCGAGTGGTGTAGGAGGGGGAGA

\subsubsection{Sonstige Konstrukte}

MC183: Dieses Bluescript-Plasmid enthält das 6E-Lokalisationselement (Nukleotide 2592-2704). Ein Bam$\mathrm{HI} / X h o \mathrm{I}-F r a g m e n t$ aus dem MC171b-Konstrukt wurde hierzu in den BamHI/XhoI-geschnittenen pBluescript$\mathrm{KS}+$ ligiert.

MC185: Um Vektor-Sequenzen aus dem MC183-Konstrukt zu entfernen, wurde dieses mit SacI und SpeI restriktionsenzymatisch gespalten und die überhängenden DNA-Enden durch Behandlung mit Klenow- und T7-Polymerase geglättet. Danach erfolgte die Religation des Vektors.

MC189: Dieses pBS-KS $+\Delta$ SacI/SpeI-Plasmid enthält das B2B-10B-Lokalisationselement-1 (Nukleotide 252-551). Ein BamHI/XhoI-Fragment aus dem MC173-Plasmid wurde dazu gegen dasjenige des MC185Plasmides ausgetauscht. 
MC191: Dieses pBS-KS $+\Delta$ SacI/SpeI-Plasmid enthält das Lokalisationselement der Vg1-RNA. Dazu wurde dieses mit den folgenden Oligonukleotiden

Vg1-LE-up-BamHI: CGGGATCCTATTTCTACTTTATTTCTACACTG

Vg1-LE-low-Xhol: CCGCTCGAGCAAGTCATATGGACTATTATATAT

aus dem MC153-Plasmid herausamplifiziert und in die BamHI/XhoI-Schnittstellen des MC185-Plasmides ligiert.

MC195: Um eine immunpräzipitierbare Form des Vg1RBPs zu generieren, wurde ein NcoI/XhoI-Fragment aus dem Vektor Vg1RBP-his pET21a(+) (Havin et al., 1998) in den NcoI/XhoI-geschnittenen pCS2+MTVektor ligiert. Das entsprechende Protein erhält dadurch am N-Terminus sechs myc-Epitope und läßt sich im gekoppelten $\mathrm{T}_{\mathrm{N}} \mathrm{T}$-System in vitro translatieren.

MC140: Dieses pCS2+MT-Plasmid enthält den kodierenden Bereich der B2B-9D (DEADSouth-Isoform) cDNA. Zur Erstellung dieses Konstruktes wurde ein mit den unten angegebenen Oligonukleotiden generiertes PCR-Produkt der kodierenden Region der cDNA mit den Enzymen NcoI und XhoI geschnitten und in die entsprechenden Positionen des pCS2+MT-Vektors ligiert.

9Dup-f.pCS:

CATGCCATGGCCGCTAAGTTTTTAC

9Dlow-f.pCS:

CTAGTCTAGATTACTTCCATATTTTCCC

MC142: „DEADSouth E233Q“. Unter Verwendung des Quick-Change-Systems von Stratagene, sowie den angeführten Oligonukleotiden wurden spezifische Basenaustausche in die codierende Sequenz der DEADSouth cDNA eingefügt. Diese Basenaustausche haben den Austausch der Aminosäure Glutamat an Position 233 gegen die Aminosäure Glutamin zur Folge. Als template diente das ebenfalls beschriebene MC140Plasmid.

E233Q-up: GTGTTTGTGTTAGATCAGGCTGATGTTATG

E233Q-low: CATAACATCAGCCTGATCTAACACAAACAC 


\section{Experimentelle Ergebnisse}

\subsection{Identifizierung lokalisierter RNAs mittels whole mount in situ-Hybridisierung}

Zur Anreicherung vegetal lokalisierter RNAs wurden in früheren Arbeiten verschiedener Gruppen unterschiedliche technische Ansätze gewählt. So konnten unter Anwendung eines Replikafilterscreenings mit radioaktiv markierten cDNA-Sonden aus RNA-Präparationen animaler und vegetaler Bereiche der Oozyte differentiell angereicherte Transkripte wie zum Beispiel Vg1 identifiziert werden (Rebagliati et al., 1985). Am vegetalen Pol der Xenopus Oozyte angereicherte RNAs zeichnen sich im Gegensatz zu der Population primär animaler RNAs, durch eine stabile Assoziation mit dem Zytoskelettsystem des Oozyten Kortex aus (Pondel und King, 1988; Yisraeli et al., 1990). Aufgrund dieser Beobachtung konnten so auch mehrere vegetal angereicherte Transkripte aus einer cDNA-Bibliothek isoliert werden, die aus einer RNA-Präparation der Detergenz-unlöslichen, zytoskelettassoziierten RNA-Fraktion erstellt wurde (Forristall et al., 1995; King, 1995; Mosquera et al., 1993). Ein charakteristisches Merkmal der früh lokalisierten RNAs wie Xcat2 und Xwnt11 ist ihre Assoziation mit der Struktur der migrierenden mitochondrialen Wolke in Stadium I Oozyten. Mit dem Ziel, spezifisch früh lokalisierte und Keimplasma-assoziierte RNAs zu isolieren, wurden von Chan et al, (1999) daher zunächst mitochondriale Wolken präparativ angereichert und diese als Ausgangsmaterial zur Erstellung einer cDNAPhagenbibliothek verwandt. In einer whole mount in situ-Hybridisierungs-Durchmusterung konnten hier zwei vegetal angereicherte Transkripte aus einer Population von 150 analysierten Klonen der cDNA-Bibliothek identifiziert werden.

In der vorliegenden Arbeit sollte ebenfalls eine cDNA-Bibliothek erstellt werden, die primär vegetal und kortikal angereicherte Transkripte der Xenopus Oozyte repräsentiert. Dazu wurden zunächst vegetale Kortizes aus Stadium VI Oozyten manuell präpariert und aus diesen Gesamt-RNA gewonnen (modifiziert nach Zhang und King, 1999). Diese RNAPräparation wurde in einer RT-PCR-Reaktion amplifiziert und diente als Ausgangsmaterial zur parallelen Erstellung zweier cDNA-Phagenbibliotheken unter Verwendung des SMART cDNA Library Construction Systems der Firma Clontech. Die primären $\lambda$ TriplEx2-Phagenbibliotheken weisen einen Umfang von $4,5 \times 10^{6}$ Klonen sowie einen Phagentiter von $9030 \mathrm{pfu} / \mu \mathrm{l}$ (cDNA-Bank A3) bzw. 3,2×10 $0^{6}$ Klone und $6560 \mathrm{pfu} / \mu 1$ (cDNA-Bank B2) auf. Die durchschnittliche Größe der inserierten cDNAs liegt bei ca. 1100 bp (cDNA-Bank A3) bzw. ca. 800 bp (cDNA-Bank B2). Aufgrund der Qualität der RNA-Präparation bzw. des PCR-Amplifikationsschrittes bei der cDNA-Bibliothekerstellung konnten vermutlich in vielen Fällen nicht die Volllängen-cDNAs der Transkripte kloniert werden. Um Zugriff auf die entsprechenden vollständigen cDNAs zu haben, wurde aus diesem Grunde eine weitere cDNA-Bank aus Gesamt-Oozyten des Stadiums V-VI unter Verwendung des $\lambda$ ZAP Express cDNA-Synthese Systems der Firma Stratagene er- 
stellt, die mit einer ermittelten durchschnittlichen Insertgröße von ca. 1700 bp hauptsächlich Volllängen-Klone repräsentieren sollte.

Zur Durchmusterung der $\lambda$ TriplEx2-Phagen-cDNA-Bank nach vegetal lokalisierten Transkripten wurde diese zunächst im großen Maßstab exzisiert, die inserierten Fragmente einzelner Bakterienklone der cDNA-Bibliothek in einer PCR-Reaktion amplifiziert und als Matrize für die Generierung fluoreszinmarkierter antisense RNA-Sonden eingesetzt. In der in situ-Hybridisierung konnten diese antisense RNA-Sonden zur Analyse der Verteilung der korrespondierenden endogenen Transkripte in der Oozyte verwendet werden. Nach der Durchmusterung von 400 Einzelklonen konnte für acht dieser Transkripte eine eindeutige subzelluläre Lokalisation nachgewiesen werden. Diese acht RNAs lassen sich aufgrund ihres charakteristischen Verteilungsmusters in drei unterschiedliche Gruppen einteilen (Tab. 3.1).

Fünf der Transkripte sind entsprechend dem für Vg1 und andere spät lokalisierende RNAs beschriebenen Verteilungsweg am Kortex der gesamten vegetalen Hemisphäre der Oozyten angereichert. Nach Ansequenzierung der entsprechenden cDNA-Inserts konnten so auch die bereits als vegetal lokalisiert beschriebenen Transkripte Vg1 und VegT, sowie drei weitere bisher unbekannte Transkripte identifiziert werden. Im Falle von Vg1 enthielt der entsprechende Klon ein cDNA-Insert einer Länge von ca. 1,3 kb, das dem 3'untranslatierten Bereich des Transkriptes zuzuordnen ist. Das cDNA-Fragment des VegTKlons weist eine Länge von ca. 800 Nukleotiden auf und entstammt ebenfalls dem 3'untranslatierten Bereich der RNA. Nach der Sequenzanalyse der drei weiteren identifizierten RNAs dieses Verteilungstyps wurde festgestellt, daß die Klone B2B-6E und A3A-3A unterschiedliche, partiell überlappende Sequenzabschnitte derselben mRNA enthalten. Zusätzlich konnte auch noch eine zu diesen Klonen alternative Spleißvariante aus der Gesamt-Oozyten cDNA-Bibliothek isoliert werden (6E; siehe 3.2.1. Der Klon der zunächst A3A-11C genannten nach dem späten Verteilungsweg lokalisierten RNA enthielt ebenfalls ein unvollständiges cDNA-Fragment einer bisher unbekannten RNA.

\begin{tabular}{l||l|l} 
Verteilungsmuster & isolierte bekannte Transkripte & neu identifizierte Transkripte \\
\hline \hline spät lokalisiert & Vg1 & B2B-6E \\
& VegT & A3A-3A \\
& & A3A-11C \\
\hline früh lokalisiert & & B2B-10B \\
& & B2B-9D \\
\hline äquatorial lokalisiert & & B2B-2B
\end{tabular}

Tabelle 3.1 Die in der whole mount in situ-Hybridisierung identifizierten lokalisierten RNAs lassen sich drei verschiedenen Lokalisationstypen zuordnen.

Von 400 in der in situ-Hybridisierung analysierten cDNA-Klonen zeigen acht eine subzelluläre Lokalisation, die sich aufgrund ihres charakteristischen Verteilungsmusters in Stadium IV-VI Oozyten in drei voneinander unterscheidbare Gruppen einteilen lassen. 
Zwei der identifizierten RNAs weisen das für früh lokalisierte RNAs typische Verteilungsmuster auf. Die RNAs sind in diesem Fall auf eine relativ kleine Region am Apex des vegetalen Pols der Oozyte begrenzt. Einer dieser entsprechenden Klone (B2B-9D) enthielt dabei die unvollständige cDNA einer im Laufe der Anfertigung dieser Arbeit von MacArthur et al., (2000) beschriebenen Variante einer vermutlichen RNA-Helikase aus Xenopus laevis. Die Autoren konnten hier ebenfalls die vegetale Lokalisation des Transkriptes in Xenopus Oozyten nachweisen. Der zweite Klon dieser Gruppe der früh lokalisierenden RNAs (B2B-10B) enthielt ein partielles cDNA-Fragment eines bisher unbekannten Transkriptes.

Die dritte Gruppe der lokalisierten RNAs zeichnet sich durch ein neuartiges, bislang nicht beschriebenes Verteilungsmuster aus. Das zu dieser Gruppe zugehörige Transkript (B2B2B) ist hauptsächlich auf einen ringförmigen Bereich am Äquator der Oozyte beschränkt und zeigt in der in situ-Hybridisierung im Bereich der vegetalen Hemisphäre nur ein recht schwaches Signal.

\subsection{Neu identifizierte lokalisierte RNAs weisen charakteristische Verteilungs- und Expressionsmuster in Xenopus Oozyten und Embryonenstadien auf}

Zur genaueren Charakterisierung der neu identifizierten, lokalisierten RNAs sollte deren Verteilung während der verschiedenen Stadien der Oogenese sowie deren Expression während der Xenopus-Embryogenese und in adulten Geweben analysiert werden. Da in allen Fällen aus der Kortex-cDNA-Bibliothek nur unvollständige cDNA-Fragmente isoliert werden konnten, erfolgte daraufhin die PCR-vermittelte Durchmusterung der fraktionierten Gesamt-Oozyten cDNA-Bibliothek und anfolgende Anreicherung und Isolierung der entsprechenden Volllängen-Klone. Die von diesen kodierten hypothetischen Proteinprodukte wurden unter Anwendung von Sequenzvergleichprogrammen auf die Anwesenheit von Homologien zu Proteinen derselben oder anderer Spezies sowie konservierter Aminosäuremotive hin untersucht.

\subsubsection{Das 6E-Transkript ist eine spät lokalisierte RNA und kodiert für ein Protein bisher unbekannter Identität}

Zur detaillierteren Analyse des Verteilungsweges der spät lokalisierten 6E-RNA wurden in situ-Hybridisierungen mit verschiedenen Stadien von Albino Oozyten durchgeführt. In Albino Oozyten sind die vegetale und animale Hemisphäre äußerlich nicht mehr aufgrund ihrer Pigmentierung sondern nur noch durch die differentielle Verteilung des Dottermaterials in den beiden Hälften zu unterscheiden. Nach der Fixierung der Oozyten in einer Formaldehydhaltigen Salzlösung, die der in situ-Hybridisierung vorangeht, kommt es jedoch aufgrund der Beschaffenheit des Oozyten Kortex der animalen Hälfte und des 
darunterbefindlichen relativ Dotterfreien Zytoplasmas dort zu einer charakteristischen Einbuchtung, die somit vielfach als Orientierung dienen kann.

In prävitellogenen Stadium I Oozyten liegt das endogene Transkript dieses 6E-Klons über das ganze Zytoplasma verteilt vor, wobei jedoch die Struktur der migrierenden mitochondrialen Wolke ausgespart bleibt Abb. 3.1 A). Beginnend mit dem Stadium III der Oogenese akkumuliert das Transkript zunächst in einem relativ begrenzten Bereich des vegetalen Pols der Oozyte und kann in späteren Stadien charakteristischer Weise über den Kortex der gesamten vegetalen Hemisphäre verteilt nachgewiesen werden Abb. 3.1 B und C). Der Verteilungsweg dieser RNA entspricht also dem der spät lokalisierten RNAs wie z.B. Vg1, VegT und XBic-C.

A

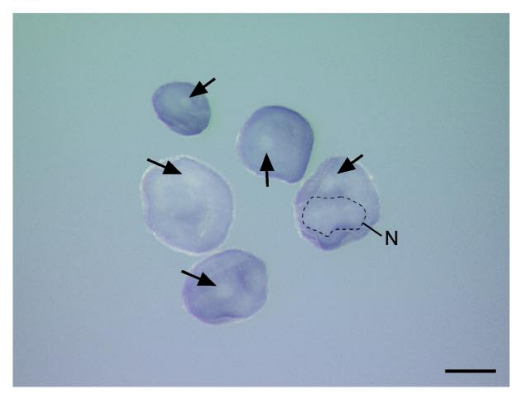

B

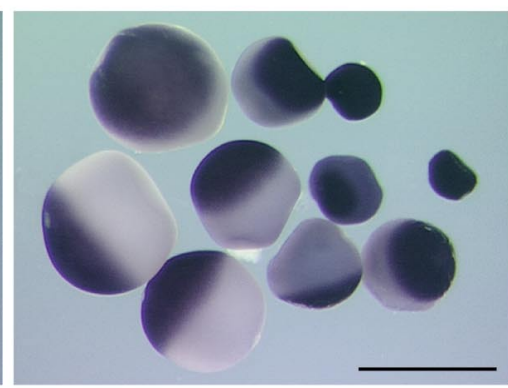

C

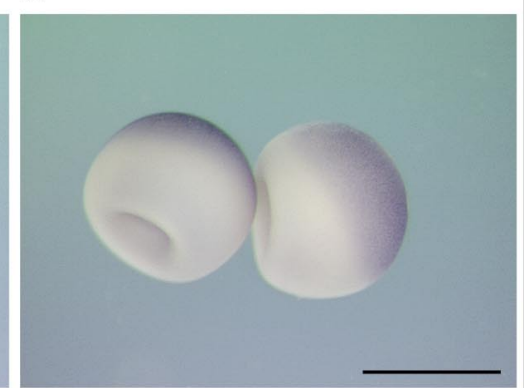

Abb. 3.1 Das 6E-Transkript wird während der Xenopus Oogenese entsprechend dem späten Lokalisationsweg verteilt. Verschiedene Oozytenstadien wurden in der in situ-Hybridisierung unter Verwendung der antisense RNA-Probe der 6E-Volllängen-cDNA (MC118; siehe Abb. 3.2 auf die Verteilung des endogenen Transkriptes hin untersucht. A. Im Stadium I (100-300 $\mu \mathrm{m}$ im Durchmesser) liegt die RNA unter Aussparung der mitochondrialen Wolke (Pfeile) homogen im Zytoplasma verteilt vor. Der Zellnukleus ist in einer Oozyte durch eine offene Umrandung gekennzeichnet. N, Nukleus. B. Stadium II Oozyten (oben rechts; 300-450 $\mu \mathrm{m}$ im Durchmesser) weisen eine homogene zytoplasmatische Verteilung des Transkriptes auf. Mit Beginn des Stadiums III (450-600 $\mu \mathrm{m}$ im Durchmesser) der Oogenese akkumuliert das Transkript an der Spitze des vegetalen Kortex und wird von dort aus über den Kortex der gesamten vegetalen Hemisphäre verteilt (Stadien IV-V; 600 bis ca. $1000 \mu \mathrm{m}$ im Durchmesser). C. Vegetal-kortikale Lokalisation der 6E-RNA in Stadium VI Oozyten (1000-1200 $\mu \mathrm{m}$ im Durchmesser). Nach Auswertung der Präparate unter Verwendung eines digitalen Kamerasystems konnte die Bestimmung des Größenmaßstabes in dieser Abbildung, sowie allen weiter folgend gezeigten, nur ungefähr vorgenommen werden. Der Maßstabsbalken entspricht ca. $100 \mu \mathrm{m}$ in (A) sowie ca. $1 \mathrm{~mm}$ in (B und $\mathrm{C}$ ).

Nach der partiellen Sequenzanalyse der entsprechenden Plasmid-DNAs konnte nachgewiesen werden, daß die Klone B2B-6E und A3A-3A partiell überlappende cDNA-Fragmente enthalten. Während das Insert des B2B-6E-Klons eine Länge von 965 Nukleotiden aufweist, enthält der A3A-6E-Klon noch zusätzlich 400 weitere Nukleotide im 3'untranslatierten Bereich (siehe Anhang 7.1. Beide Transkripte weisen denselben offenen Leserahmen von 807 Nukleotiden Länge auf, der für ein 269 Aminosäuren umfassendes hypothetisches Protein einer relativen Molekülmasse von 30,7 kDa kodiert. Die Definition des Startkodons an Position 28 der cDNA wurde aufgrund der Tatsache erstellt, daß sich weiter 5' im selben Leserahmen des Transkriptes ein Stopkodon nachweisen läßt. Das po- 
stulierte Startkodon ist jedoch nicht in eine von Kozak beschriebene Konsensussequenz (5'A/G-X-X-A-U-G-G) für effiziente Translationsinitiation eingebunden (Kozak, 1989).

Da die RT-PCR-Expressionsanalyse dieses Gens (siehe Abschnitt 3.2.2 Hinweise auf die Existenz mehrerer alternativer Transkripte oder alternativer Spleißvarianten der Transkripte dieses Genlocus lieferte, wurde eine fraktionierte cDNA-Bibliothek, die aus der GesamtRNA von Stadium V/VI Oozyten erstellt worden war (siehe Abschnitt 3.1), dahingehend durchsucht. Hierzu wurden Oligonukleotide ausgewählt, die im 5'-untranslatierten sowie im kodierenden Bereich der cDNA hybridisieren und nach der Amplifikations-Reaktion ein Produkt einer Größe von 429 bp ergeben (in Abb. 3.2 schematisch dargestellt). Verschiedene Phagen-Fraktionen der Bibliothek wurden mittels der PCR-Reaktion auf die Anwesenheit des gesuchten Fragmentes hin untersucht, die als positiv identifizierten Fraktionen ausverdünnt und in mehreren Anreicherungsschritten eingegrenzt. Nach Plattieren der so angereicherten Phagenfraktion konnte ein positiver Klon identifiziert werden (anfolgend 6E genannt), bei dem nach Exzision ein Phagemid mit einem Insert von 2704 bp nachzuweisen war. Nach der Sequenzierung der cDNA konnte ein offener Leserahmen mit einer Länge von 2239 Nukleotiden nachgewiesen werden (siehe Anhang 7.2. Weiterhin enthält die cDNA einen 3'-untranslatierten Bereich einer Länge von 346 Nukleotiden. Der offene Leserahmen der cDNA kodiert für ein Protein von 779 Aminosäuren und einer rechnerisch ermittelten relativen Molekülmasse von 102,5 kDa. Nach der vergleichenden Sequenzanalyse des aus der Oozyten cDNA-Bank angereicherten 6E-Klons und der beiden vorher identifizierten kürzeren cDNA Klone (A3A-3A und B2B-6E) konnte festgestellt werden, daß es sich bei diesen um alternative Spleiß-Produkte derselben mRNA handelt, die aufgrund eines durch die unterschiedliche Prozessierung der Transkripte bedingten Wechsels des offenen Leserahmens für unterschiedliche Proteine kodieren (vergl. Anhang 7.1 und 7.2. Die beiden alternativen Proteinprodukte weisen bis zur Position 214 dieselbe $\mathrm{N}$-terminale Aminosäureabfolge auf, weichen jedoch in Länge und Aminosäuresequenz ihrer C-Termini voneinander ab. Die drei unterschiedlichen Varianten weisen auch im 3'untranslatierten Bereich eine identische Nukleotidsequenzabfolge auf, unterscheiden sich jedoch in der relativen Länge desselben (in Abb. 3.2 schematisch dargestellt). Bei der Datenbanksuche nach homologen Nukleotid- bzw. Proteinsequenzen zu diesen Klonen konnte die Nukleotidsequenz des Xenopus Polycomb1-Proteins (XPc1), als partiell mit den Sequenzen der 6E-, A3A-3A und B2B-6E-Transkripte überlappend, identifiziert werden (Strouboulis et al., 1999). Wie sich in weiteren Sequenzvergleichen herausstellte, scheinen sich $6 \mathrm{E}$ und XPc1 einen genomischen Locus zu teilen, werden jedoch von unterschiedlichen Strängen der DNA transkribiert. So überlappt der sehr lange 3'-untranslatierte Bereich der XPc1-cDNA partiell mit kodierenden Regionen und 3'-untranslatierten Bereichen der 6E-cDNA bzw. ihren alternativen Spleißvarianten (siehe Abb. 3.2. Unter Verwendung von Sequenzvergleichprogrammen konnten keine Homologien der von der 
6E-RNA bzw. ihrer alternativen Spleißvarianten kodierten hypothetischen Proteinprodukte zu bereits bekannten Proteinen identifiziert werden. Auch konnten keine charakteristischen Aminosäuremotive nachgewiesen werden, die Auskunft über eine mögliche Funktion des Proteins geben könnten.

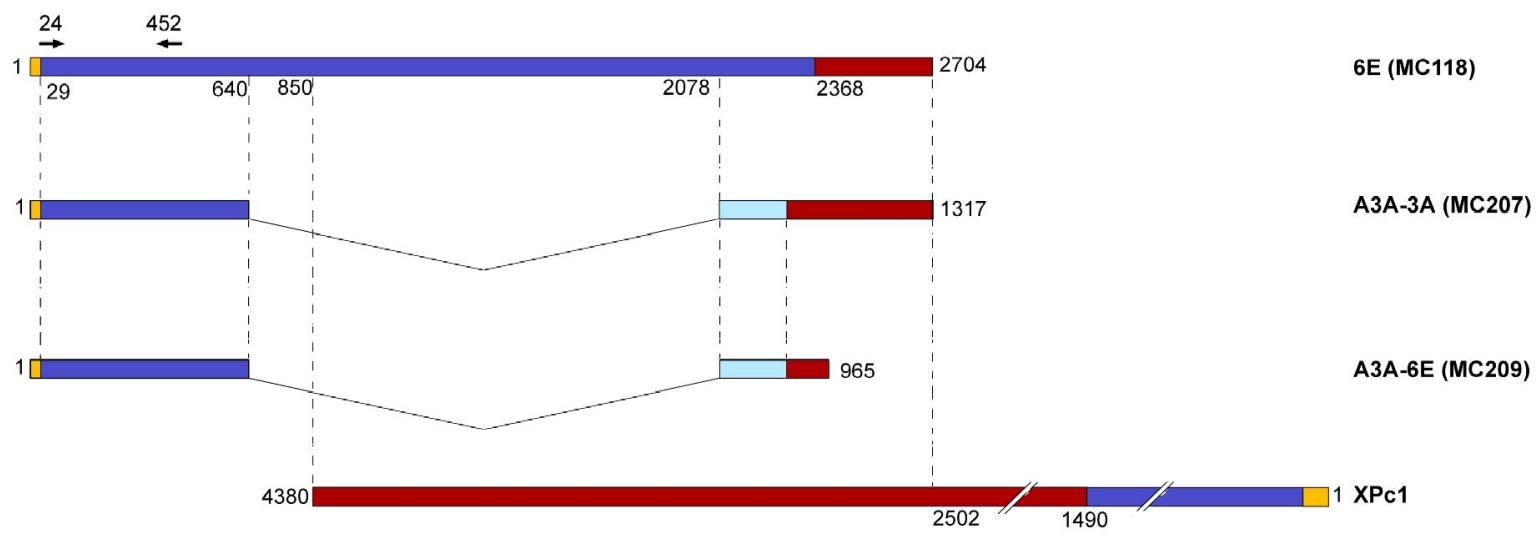

Abb. 3.2 Schematische Darstellung der 6E-cDNA sowie alternativer Spleißprodukte. Dargestellt sind die aus der Stadium V/VI Oozyten cDNA-Bibliothek isolierte 6E-cDNA (Plasmid MC118) sowie die beiden in der whole mount in situ-Hybridisierungs-Durchmusterung der Kortex-cDNA-Bibliothek identifizierten alternativen Spleißprodukte A3A-3A (Plasmid MC207) und B2B-6E (Plasmid MC209). Unten in der Abbildung ist die für das XPc1-Protein kodierende cDNA dargestellt (Gendatenbank Zugangsnummer AF101438). Angegeben sind jeweils die Nukleotidsequenzpositionen in den entsprechenden cDNAs, die den Abgrenzungen der untranslatierten und kodierenden Bereiche bzw. Positionen alternativer Spleiß-Ereignisse entsprechen. Gelbe Bereiche stehen für 5'- untranslatierte Bereiche; blaue für kodierende Bereiche der cDNAs. Hellblau steht für Bereiche des alternativen offenen Leserasters der verkürzten Spleißvarianten A3A-3A und B2B-6E; 3'-untranslatierte Bereiche sind durch eine rote Farbgebung kenntlich gemacht. Oberhalb der 6E-cDNA sind die Positionen der Oligonukleotide angegeben, die in der RT-PCR-Expressionsanalyse (siehe Abb. 3.3 B) sowie in der PCR-vermittelten Durchmusterung der Gesamt-Oozyten cDNA-Bibliothek verwendet wurden.

\subsubsection{Räumlich-zeitliche Expressionsanalyse von 6E und Expression in adulten Ge- weben}

Um das Expressionsverhalten der 6E-RNA während der Embryogenese zu ermitteln, wurden whole mount in situ-Hybridisierungen an fixierten Embryonen verschiedener Stadien durchgeführt. Während die RNA in Stadium VI Oozyten sehr deutlich am Kortex der vegetalen Hemisphäre zu detektieren ist (siehe Abb. 3.1, weisen Embryonen des 2- und 8-ZellStadiums keine Anreicherung des Transkriptes in vegetalen Bereichen auf. Die RNA kann in frühen Embryonalstadien sowohl in vegetalen als auch in animalen Blastomeren nachgewiesen werden Abb. 3.3 A). Eine schwächere Färbung ist in der ehemals äquatorialen Region nachzuweisen. Möglicherweise erfolgt mit der Reifung und Fertilisierung des Eis die Ablösung der RNA vom vegetalen Kortex und Neuverteilung auf unterschiedliche Bereiche des Embryos. In späteren Entwicklungsstadien wie Neurula- und frühes Kaulquappenstadium läßt sich das Transkript in der in situ-Hybridisierung nicht mehr nachweisen (nicht gezeigt). 
A

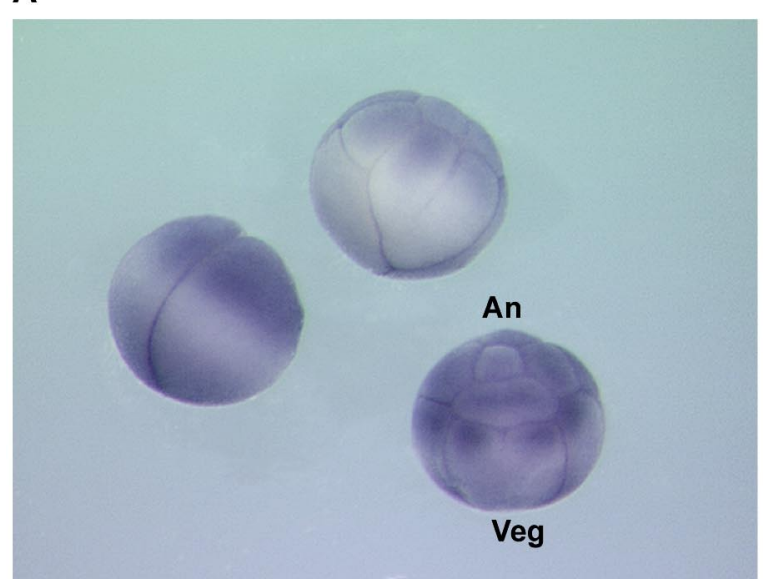

B
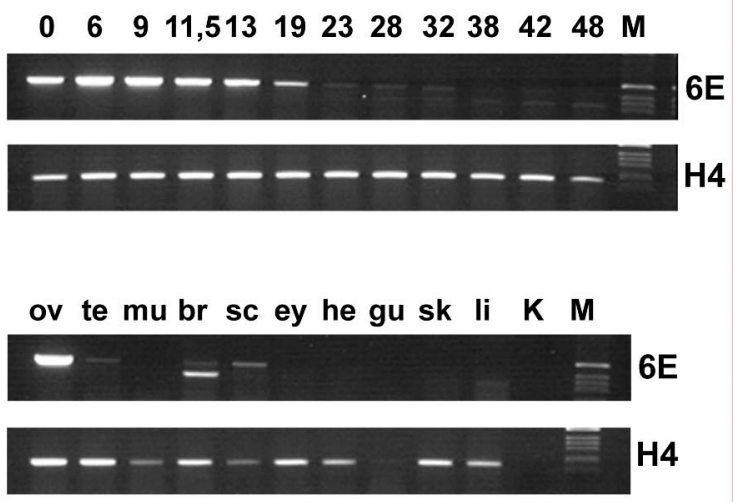

Abb. 3.3 Expression des 6E-Transkriptes in Embryonalstadien und adulten Geweben. Endogene 6E-Transkripte wurden mittels digoxygeninmarkierter antisense RNA-Sonden in Albino Embryonen verschiedener Stadien nachgewiesen. A. Stadium 2 (links); Stadium 5 (oben und rechts). Animale (An) und vegetale (Veg) Bereiche des Embryos sind exemplarisch gekennzeichnet. B. Zur Analyse des Expressionsniveaus in verschiedenen Embryonalstadien und Geweben des adulten Tieres wurden die Transkripte über nichtradioaktive RT-PCR in entsprechenden RNA-Präparationen nachgewiesen. In der Beschriftung über den DNA-Banden sind die Stadien der untersuchten Embryonen (Nieuwkoop und Faber, 1967) bzw. Gewebe des adulten Tieres angegeben (ov, Ovar; te, Testis; mu, Skelettmuskel; br, Gehirn; sc, Rückenmark; ey, Auge; he, Herz; gu, Darm; sk, Haut; li, Leber; $\mathrm{K}, \mathrm{H}_{2} \mathrm{O}-$ Kontrollreaktion; M, Molekulargewichtsstandard, 1 kb-Leiter). Die zu erwartende PCR-Produktlänge für 6E-Transkripte beträgt 429 bp. Zur Kontrolle der eingesetzen RNA-Menge wurde ebenfalls die gleichmäßig und ubiquitär exprimierte Histon H4 RNA in der RT-PCR nachgewiesen (Produktlänge $200 \mathrm{bp})$.

Zur Analyse der Expression des 6E-Transkriptes während der frühen Embryogenese sowie in verschiedenen Geweben des adulten Tieres, wurden semi-quantitative, nichtradioaktive RT-PCRs auf Gesamt-RNA aus verschiedenen Embryonalstadien oder Geweben des adulten Frosches durchgeführt Abb. 3.3 B). Die in der RT-PCR eingesetzten Oligonukleotide hybridisieren im 5 '-untranslatierten Bereich sowie im kodierenden Bereich aller alternativen 6E-Transkripte. Der amplifizierte Bereich von 429 Nukleotiden überlappt nicht mit Sequenzen des vom Gegenstrang kodierten XPc1-Transkriptes (siehe auch Abb. 3.2. In Northern-Blot-Analysen kann XPc1 in Oozyten, fertilisierten Eiern und Gastrula-Stadien nachgewiesen werden. Die Expression ist in Neurula-Stadien kaum nachweisbar und nimmt mit erst mit Einsetzen des Schwanzknospenstadiums wieder zu (Strouboulis et al., 1999). Das Expressionsmuster von XPc1 ist also deutlich von dem der 6E-RNA zu unterscheiden. Die RT-PCR-Expressionsanalyse von $6 \mathrm{E}$ zeigt, daß das Transkript im Ei stark repräsentiert ist. Das Expressionsniveau scheint im Stadium 6 leicht anzusteigen und bleibt bis zum Stadium 11,5 (Gastrula-Stadium) relativ konstant. Mit Fortschreiten der Gastrulation und Einsetzen der Neurulation (Stadium 13 und 19) sind nur mehr abnehmende Mengen der RNA nachzuweisen; in späteren Embryonalstadien (nach Stadium 32) können in der RT-PCR keine Fragmente der entsprechenden Größe mehr detektiert werden. Die 6E-RNA wird also nur während der Oogenese sowie in frühen Embryonalstadien exprimiert. Auffällig ist, daß ab dem Stadium 38 geringe Mengen eines RT-PCR-Produktes 
abweichender Größe nachgewiesen werden können (ca. 300 bp), das möglicherweise einer zusätzlich zu den hier identifizierten, bisher nicht identifizierten alternativen Spleißvariante des Transkriptes zuzuordnen ist. Die Analyse der gewebespezifischen Expression der 6ERNA zeigt, daß das Transkript in großen Mengen im Ovar (ov) des adulten Tieres nachzuweisen ist, jedoch nur geringe Mengen der RNA in den männlichen Testis (te) zu detektieren sind. Während in den Geweben Muskel (mu), Herz (he), Auge (ey), Haut (sk) und Leber (li) keine Expression nachgewiesen werden kann, wird die RNA im Rückenmark (sc) schwach exprimiert. In der RNA-Präparation des Gehirns wird in der RT-PCR ein kürzeres Fragment amplifiziert, das möglicherweise einer zusätzlichen alternativen Spleißvariante des Transkriptes zuzuordnen ist (s. o.).

\subsubsection{Das XPTB (A3A-11C)-Transkript ist eine spät lokalisierte RNA und kodiert für ein Protein mit einer konservierten Phosphotyrosin-Bindungsdomäne}

In der auf der whole mount in situ-Hybridisierung basierenden Durchmusterung der Kortex-cDNA-Bibliothek konnte das zum A3A-11C-Klon zugehörige Transkript der Population spät lokalisierender RNAs zugeordnet werden. Während der frühen Oogenese (Stadium I-II) liegt diese RNA zunächst über das gesamte Zytoplasma der Oozyte verteilt vor Abb. 3.4 A). Interessanterweise ist hier weder eine deutliche Aussparung der mitochondrialen Wolke, wie sie für spät lokalisierte RNAs beschrieben wurde, noch eine Anreicherung des Transkriptes in dieser Struktur, wie sie für früh lokalisierte Transkripte nachgewiesen werden konnte, zu erkennen.

A

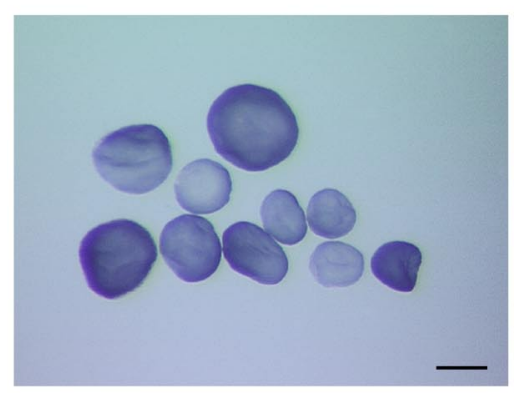

B

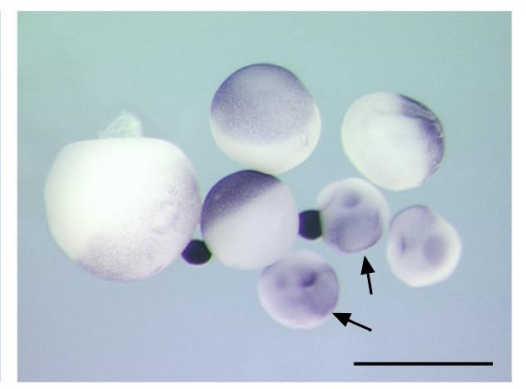

C

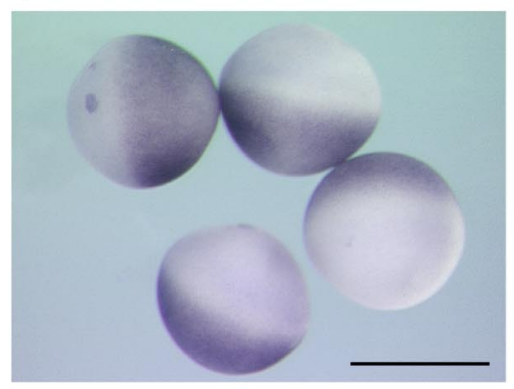

Abb. 3.4 Lokalisation des XPTB (A3A-11C)-Transkriptes im Verlauf der Xenopus Oogenese. A. In Stadium I Oozyten (100-300 $\mu \mathrm{m}$ imDurchmesser) liegt die RNA homogen im Zytoplasma verteilt vor. B. Mit Beginn des Stadiums III der Oogenese (450-600 $\mu \mathrm{m}$ im Durchmesser) akkumuliert das Transkript an der Spitze des vegetalen Kortex in einer ringförmigen Region (Pfeile) und wird dann über den Kortex der gesamten vegetalen Hemisphäre späterer Oozytenstadien verteilt (Stadien IV-V; 600-1000 $\mu \mathrm{m}$ im Durchmesser). Zusätzlich sind in der Abbildung auch noch zwei sehr stark gefärbte Oozyten des Stadium I zu sehen. C. Vegetal-kortikale Lokalisation der A3A-11C-RNA in Stadium VVI Oozyten (1000-1200 $\mu \mathrm{m}$ im Durchmesser). Der Maßstabsbalken entspricht ca.100 $\mu \mathrm{m}$ in (A) sowie ca. $1 \mathrm{~mm}$ in (B und $\mathrm{C}$ ). 
In frühen Stadium III Oozyten akkumuliert das Transkript am Pol des vegetalen Kortex wobei eine ringförmige Anreicherung der RNA am äußeren Rand des kreisförmigen Lokalisationsbereiches zu beobachten ist (Pfeile in Abb. 3.4B). Mit Fortschreiten der Oogenese nimmt die RNA einen weiteren Bereich der vegetalen Hemisphäre ein und liegt schließlich in Stadium V/VI Oozyten bis zum Äquator des vegetalen Kortex verteilt vor (Abb. 3.4C). Der Lokalisationsweg der A3A-11C-RNA weist also viele Charakteristika des späten Verteilungsweges, wie er für $\mathrm{Vg} 1$ beschrieben wurde, auf.

Der zu dieser lokalisierten RNA isolierte pTriplEx2-Plasmidklon enthält ein Insert einer Größe von ca. 1000 bp. Nach Ansequenzierung des Plasmides konnte kein offener Leserahmen bestimmt werden, d.h. nur Sequenzen des 3'-untranslatierten Bereiches konnten in der reversen Transkription in cDNA umgeschrieben werden. Um die entsprechende Volllängen cDNA zu isolieren, wurden innerhalb der bekannten Sequenz spezifische Oligonukleotide ausgewählt, mit denen mittels der PCR die Stadium V/VI GesamtOozyten Phagenbibliothek nach dem entsprechenden Fragment durchmustert wurde (in Abb. 3.5 eingezeichnet). Nach zahlreichen sukzessiven Amplifikations- und Verdünnungsreihen konnte ein Einzelphage isoliert werden, bei dem nach Exzision des Plasmides ein cDNA-Insert von 3127 bp nachgewiesen werden konnte (Anhang 7.3. Nach der anfolgenden Sequenzierung des Klons konnte ein offener Leserahmen von 924 Nukleotiden Länge identifiziert werden, der jedoch kein Startkodon beinhaltet. Die cDNA enthält weiterhin einen 3'-untranslatierten Bereich von 2202 Nukleotiden Länge (Nukleotide 924-3127 der cDNA) (in Abb. 3.5 schematisch dargestellt).

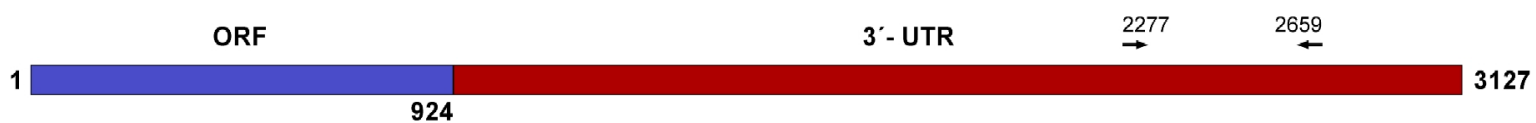

Abb. 3.5 Schematische Darstellung des XPTB (A3A-11C) cDNA-Klons. Gezeigt ist die aus der Stadium V/VI Oozyten Bibliothek isolierte A3A-11C cDNA (Plasmid MC186). Angegeben sind jeweils die Nukleotidsequenzpositionen, die den Abgrenzungen des kodierenden (ORF; offener Leserahmen; in blau unterlegt) und des 3'- untranslatierten Bereiches (3'- UTR; in rot unterlegt) entsprechen. Die Positionen der in der PCR-vermittelten Durchmusterung der Gesamt-Oozyten cDNA-Bibliothek und in der RT-PCR-Expressionsanalyse verwendeten Oligonukleotide (siehe Abb. 3.8 C) sind oberhalb in der schematischen Darstellung angegeben.

In der Datenbanksuche konnten mehrere kurze Xenopus EST-Klone identifiziert werden, die der isolierten A3A-11C cDNA entsprechen. Bei der genaueren Sequenzanalyse dieser Klone konnte nachgewiesen werden, daß diese vermutlich auch das vollständige 5 '-UTR der entsprechenden mRNA, welches das Startmethionin des offenen Leserahmens sowie ein weiteres 5 'gelegenes Stopkodon desselben Leserahmens enthält, aufweisen (Nukleotidsequenzen der EST-Klone sind in der Sequenz im Anhang 7.3 durch Fettdruck hervorgehoben). Somit konnte angenommen werden, daß dem aus der Oozyten Phagenbibliothek isolierten cDNA-Klon vom Bereich der translatierten Sequenz lediglich das für Methionin kodierende Startkodon fehlt. Das aus dem offenen Leserahmen abgeleitete Pro- 
tein weist eine Länge von 310 Aminosäuren und eine rechnerisch ermittelte relative Molekülmasse von $34 \mathrm{kDa}$ auf. In der Datenbanksuche konnte unter Verwendung der CDSearch(Conserved Domain)-Option des BLAST-Datenbankservers nachgewiesen werden, daß dieses Protein eine konservierte Phosphotyrosin-Bindungsdomäme (PTB-Domäne) aufweist und wurde deshalb XPTB genannt (siehe graue Unterlegung der PTB-Domänen in Abb. 3.6. PTB-Domänen wurden zunächst als modulare Domänen in Proteinen wie dem SHC (SH2, collagen homology)-Adaptorprotein oder dem IRS-1 (insulin receptor substrate-1) beschrieben, die bestimmte Phosphotyrosinhaltige Peptidmotive in ihren Interaktionspartnern erkennen. Späterhin konnten noch weitere Proteine identifiziert werden, die eine PTB-Domäne enthalten, ihre Zielproteine jedoch auch in nichtphosphorylierter Form binden können. Darunter sind zum Beispiel die Proteine X11, Fe65 und Disabled (Dab), die mit einem Tyrosinhaltigen $\beta$ Amyloidvorläuferprotein (APP)-Peptid interagieren, sowie das in Mammaliern in vier differentiell exprimierten Isoformen vorkommende Numb-Protein (Übersicht in Forman-Kay und Pawson, 1999). In der Proteinsequenzdatenbank konnte ein hypothetisches Protein aus dem Menschen identifiziert werden, das sehr große Homologien zu dem isolierten PTB-Protein aus Xenopus aufweist Abb. 3.6. Basierend auf einem nach der Clustal-Methode durchgeführten Sequenzvergleich (MegAlign des DNAStar-Software-Pakets) konnte eine Sequenzidentität von $68,6 \%$ für die beiden Proteine ermittelt werden. Bezogen auf die PTB-Domäne beträgt diese sogar 90,8 \%.

\begin{tabular}{|c|c|c|c|c|}
\hline XРТВ & $\mathrm{X} .1$. & 1 & MDALKSAGRAIIRSPSIAKQSWG & 23 \\
\hline hyp-P & H.S. & 1 & TRPPERA---- - - - - - L- - - - - L- - - - - & 30 \\
\hline ХРTB & X.1. & 24 & GG.KHKKLPENWTDTRETLLEGMLFHLKYLGMTLVEQPKGEELSATAVKRIVATAKASGK & 82 \\
\hline hyp-P & H.S. & 31 & - - GR-R----- - - - - - - - - - - S - - - - - - - - - - - - - - A - I ---------- & 90 \\
\hline XРTB & X.1. & 83 & KLQKVILKVSPRGI ILYDSTSNQLIENVS IYRISYCTADKMHDKVFAYIAQSQQNETLEC & 142 \\
\hline hyp-P & H.s. & 91 & 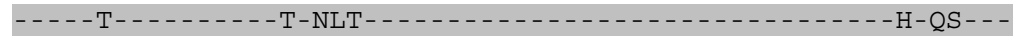 & 150 \\
\hline XPTB & $\mathrm{x} .1$. & 143 & HAFLCTKRKMAQAVTLTVAQAFKVAFEFWQVSRDKTEKREKSGSGGEGASSSQSDGSSSI & 202 \\
\hline hyp-P & H.S. & 151 & - - - - - - - - - - - - - - - - KEEK- - D-ASQE-GDVLGARQ-CTPPL & 210 \\
\hline XPTB & $\mathrm{x} .1$. & 203 & TSLKASASANLLDLEDCTKA. FDVLNASDNHIEDLFRQNASNENNNIVWELDDGLDEAFA & 262 \\
\hline hyp-P & H.S. & 211 & K- - VATG- - - - - . TA-PLST-S-NTT-MD-VPRP-AL-GSS . .V- - - - - - - - S & 266 \\
\hline XPTB & $\mathrm{x} .1$. & 263 & RLAESRTNPQVLDIGLTANDLQSEECLSPSSWDKLELNPAEADELFMF & 310 \\
\hline hyp-P & H.s. & 271 & $---\mathrm{Q}---------\mathrm{T}----\mathrm{Q}-\mathrm{MHYAQ}----\mathrm{VD}---\mathrm{PDSSGT}-\mathrm{Q}-\mathrm{D}--\mathrm{S}-$ & 314 \\
\hline
\end{tabular}

Abb. 3.6 Proteinsequenzvergleich des hypothetischen Xenopus PTB-Proteins (A3A-11C) mit dem homologen hypothetischen Protein aus dem Menschen. Hypothetisches Proteinprodukt aus dem Menschen (Proteindatenbank-Zugangsnummer: T17340). Zu dem Xenopus PTB-Protein identische Aminosäuren sind als Striche, fehlende Aminosäuren als Punkte dargestellt. Die Aminosäurepositionen der Proteine sind am linken bzw. rechten Rand der Sequenzen angeführt. Die in der Datenbanksuche identifizierte konservierte PTB-Domäne der Proteine ist in grau unterlegt.

Zusätzlich zu dem humanen homologen Protein aus der Proteinsequenzdatenbank konnten weitere (zum Teil vorhergesagte) Proteine verschiedener Spezies ermittelt werden, deren 
PTB-Domänen Ähnlichkeiten zu der des in dieser Arbeit isolierten XPTB-Proteins aufweisen. Die Ähnlichkeiten sind in diesen Fällen fast ausschließlich auf die PTB-Domäne beschränkt (Vergleich dargestellt in Abb. 3.7. In diesen Fällen konnten folgende Sequenzidentitäten bezogen auf die PTB-Domäne des Xenopus PTB-Proteins ermittelt werden: hypothetisches humanes Protein, 90,8\%; humanes Numb4, 28,0 \%; murines Numb, 28,0 $\%$; Numb aus G. gallus, 27,3 \%. Untereinander weisen die PTB-Domänen der NumbProteine aus dem Menschen, der Maus und dem Hühnchen sogar Sequenzidentitäten von 97\% bis $99 \%$ auf. Die Sequenzvergleiche lassen also vermuten, daß das aus Xenopus isolierte PTB-Protein zusammen mit dem in der Datenbanksuche identifizierten hypothetischen humanen Homologen einer weiter divergierten Subklasse von PTBDomänen-Proteinen zuzuordnen ist.

\begin{tabular}{|c|c|c|c|c|}
\hline XPTB & X.1. & 17 & PENWTDTRETLLEGM . LFHLKYLGMTLVEQPKGEELSATAVKRIV . . . . & 74 \\
\hline hyp-P & H.s. & 23 &,$-------------S----------------A-I----\ldots$ & 3 \\
\hline Numb4 & H.S. & 12 & -HQ-QTDE-GVRT-KCS-PV----HVE-DESR-MHICED----L . . . . & 55 \\
\hline mNumb & M.m. & 12 & -HQ-QTDE-GVRT-KCS-PV----HVE-DESR-MHICED--- - L . & 65 \\
\hline Numb & G.g. & 12 & -HQ-QTDE-GVRT-KCS-PV-- - -HVE-DESR-MHICED-V--L . . . . & 65 \\
\hline XРTB & X.1. & 75 & . . ATAKASGKKLQKVILKVSPRGI ILYDSTSNQLIENVS IYRISYCTADKMHDKVFAYIA & 32 \\
\hline hyp-p & H.S. & 83 & 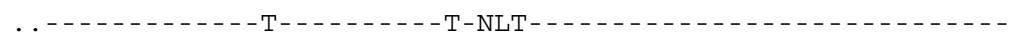 & 40 \\
\hline Numb4 & H.S. & 66 & $\ldots \ldots--\mathrm{T}---\mathrm{AV}-\mathrm{AV}-\mathrm{W}--\mathrm{AD}-\mathrm{LRVV}-\mathrm{EKTKD}-\mathrm{VDQT}-\mathrm{EKV}-\mathrm{F}-\mathrm{AP}-\mathrm{RNF}-\mathrm{RA}-\mathrm{S}--\mathrm{C}$ & 120 \\
\hline mNumb & M.m. & 66 & $\ldots \ldots--\mathrm{T}---\mathrm{AV}-\mathrm{AV}-\mathrm{W}--\mathrm{AD}-\mathrm{LRVV}-\mathrm{EKTKD}-\mathrm{VDQT}-\mathrm{EKV}-\mathrm{F}-\mathrm{APDRNF}-\mathrm{RA}-\mathrm{S}--\mathrm{C}$ & 120 \\
\hline Numb & G.g. & 66 & $\ldots .-\mathrm{ST}---\mathrm{AV}-\mathrm{AV}-\mathrm{W}--\mathrm{AD}-\mathrm{LRVV}-\mathrm{EKTKD}-\mathrm{VDQT}-\mathrm{EKV}-\mathrm{F}-\mathrm{APDRNF}-\mathrm{RAFS}-\mathrm{C}$ & 120 \\
\hline XPTB & X.1. & 133 & QSQQNET . . LECHAFL . . . . . . . . . . . . . . . . CTKRKMAQAVTLTVAQAF . . K & 165 \\
\hline hyp-P & H.s. & 141 & 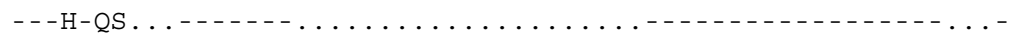 & 173 \\
\hline Numb4 & H.s. & 121 & RDGTTRR . . .WI--C-MAVKDTGE . RLSHAVGC . AFAA-LE--QKREKECGVTATFDASR & 175 \\
\hline mNumb & M.m. & 121 & RDGTTRR. . . WI--C-MAVKDTGE . RLSHAVGC.AFAA-LE--QKREKECGVTATFDASR & 175 \\
\hline Numb & $\mathrm{G} \cdot \mathrm{g} \cdot$ & 121 & RDGTTRR . . WI - - C-MAVKDTGE . RLSHAVGC . AFAA-LE--QKREKECGVTATFDASR & 175 \\
\hline XPTB & $\mathrm{X} .1$. & 166 & VAFE . . . FW . . . . . . . . QVVSRDK & 177 \\
\hline hyp-P & H.S. & 174 & $---\ldots \ldots F W \ldots \ldots \ldots \ldots \ldots--\mathrm{KEE}$ & 185 \\
\hline Numb4 & H.s. & 176 & TT-TREGS - RVTTATEQAEREEIMK-MQDA- & 206 \\
\hline mNumb & M.m. & 176 & TT-TREGS-RVTTATEQAEREEIMK-LQDA- & 206 \\
\hline Numb & $\mathrm{G} \cdot \mathrm{g}$. & 176 & TT-TREGS - RVTTATEQAEREEVMR - MPDA- & 20 \\
\hline
\end{tabular}

Abb. 3.7 Sequenz- und Strukturvergleich der PTB-Domäne des vorhergesagten XPTB-Proteins mit homologen Proteinen anderer Spezies. Dargestellt sind die Aminosäuresequenz des vorhergesagten PTB-Domänen-Proteins aus Xenopus, sowie die zu diesem homologe Proteine anderer Spezies. Zur Sequenz des XPTB-Proteins identische Aminosäuren sind durch einen Querstrich gekennzeichnet, fehlende Aminosäuren oder größere Lücken in der durchgehenden Sequenz sind durch Punkte markiert. Die Aminosäurepositionen der Proteine sind am linken bzw. rechten Rand der Sequenzen angeführt. Dargestellt sind die homologen Proteine aus dem Menschen (hypothetisches Proteinprodukt und Numb4-Homologes (T17340 und AF171941), mNumb aus der Maus (U70674) sowie die Aminosäuresequenz des homologen Numb-Proteins aus dem Hühnchen (AF176086). Die PTBDomäne des Xenopus PTB-Proteins ist in grau unterlegt. Die Datenbank-Zugangsnummern der Proteine sind in Klammern angegeben. 


\subsubsection{Räumlich-zeitliche Expressionsanalyse von XPTB (A3A-11C) und RT-PCR- Analyse der Expression in Embryonalstadien und adulten Geweben}

Zur weiteren Charakterisierung des XPTB (A3A-11C)-Klons sollte das Expressionsverhalten der endogenen RNA in whole mount in situ-Hybridisierungen mit verschiedenen Embryonalstadien, sowie in der RT-PCR-Analyse verschiedener Embryonalstadien und Gewebe des adulten Tieres untersucht werden. Obgleich das Transkript in Oozyten sehr deutlich am Kortex der vegetalen Hemisphäre nachzuweisen ist (vergl. Abb. 3.4), scheint es in 2-Zell-Stadien sowie Embryonen des Stadiums 5 zu einer Neuverteilung der RNA zu kommen. Das Transkript ist nun ähnlich wie die in Abschnitt 3.2.2 beschriebene 6E-RNA auch in animalen Blastomeren des sich entwickelnden Embryos nachzuweisen Abb. 3.8 A).

A

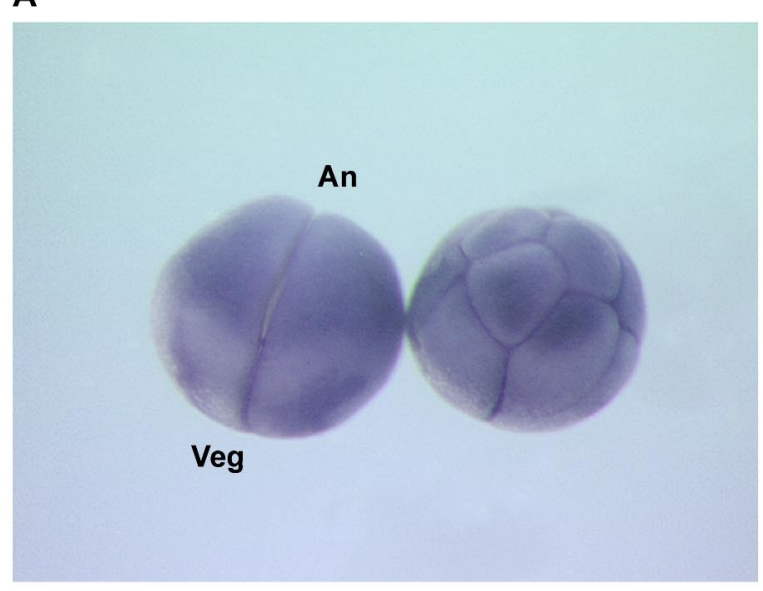

B

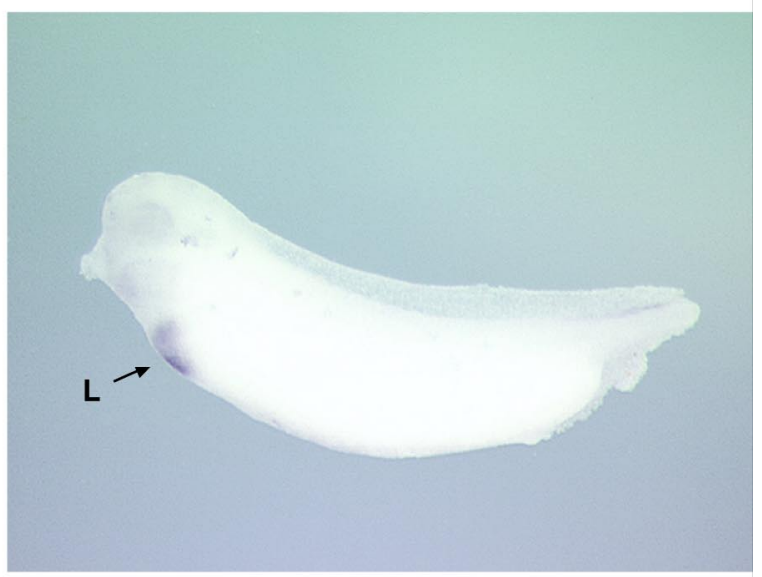

C

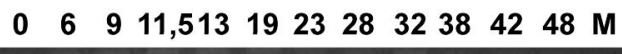
XPTB
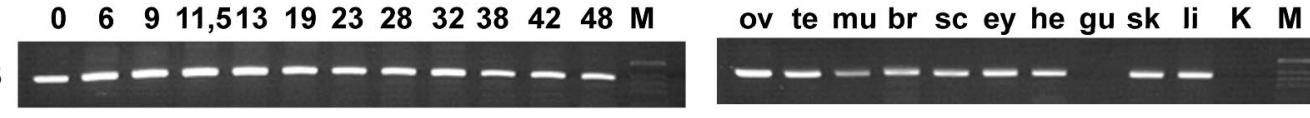

H4

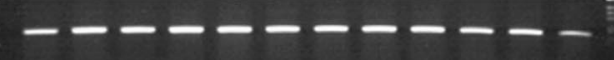

$-$

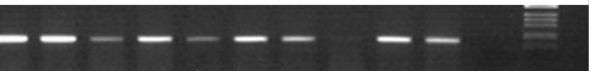

Abb. 3.8 Expression von XPTB (A3A-11C) in Embryonalstadien und adulten Geweben. Endogene XPTB-Transkripte wurden mittels digoxygeninmarkierter antisense RNA-Sonden in Embryonen verschiedener Stadien nachgewiesen (Volllängen cDNA-Probe MC186). A. 2- und 16-Zellstadien; animale (An) und vegetale (Veg) Bereiche des Embryos sind exemplarisch gekennzeichnet. B. Stadium 32; L, Leberanlage. C. In der RT-PCR wurde die Expression der XPTB-RNA in verschiedenen Embryonalstadien und Geweben ermittelt. In der Beschriftung über den DNA-Banden sind die Stadien der untersuchten Embryonen (Nieuwkoop und Faber, 1967) bzw. Gewebe des adulten Tieres angegeben (ov, Ovar; te, Testis; mu, Skelettmuskel; br, Gehirn; sc, Rückenmark; ey, Auge; he, Herz; gu, Darm; sk, Haut; li, Leber; $\mathrm{K}, \mathrm{H}_{2} \mathrm{O}$-Kontrollreaktion; M, Molekulargewichtsstandard 1 kb-Leiter). Die zu erwartende PCR-Produktlänge für XPTB-Transkripte beträgt 378 bp. Zur Kontrolle der eingesetzen RNA-Menge wurde ebenfalls die gleichmäßig und ubiquitär exprimierte Histon H4 RNA in der RT-PCR nachgewiesen (Produktlänge 200 bp). 
Während der sehr frühen Embryogenese (Gastrulation und Neurulation) ist die RNA in der in situ-Hybridisierung nicht detektierbar (nicht gezeigt). Im Stadium 32 ist der Beginn einer gewebespezifischen Expression des Gens in der Leberanlage nachzuweisen Abb. 3.8 B). Bei der Analyse der stadien- und gewebespezifischen Expression zeigt sich, daß XPTB in allen untersuchten Embryonalstadien sowie adulten Geweben exprimiert wird und in der RT-PCR nachzuweisen ist (Abb. 3.8C).

\subsubsection{Das B2B-9D-Transkript ist eine früh lokalisierte RNA und kodiert für eine keimzellspezifisch exprimierte DEADSouth-Isoform}

Das endogene Transkript des aus der Kortex cDNA-Bibliothek isolierten B2B-9D-Klons ist in frühen prävitellogenen Stadium I Oozyten in der in situ-Hybridisierung in Assoziation mit der mitochondrialen Wolke nachzuweisen (Abb. 3.9 A). In späteren Stadium II Oozyten migriert das Transkript, vermutlich zusammen mit Komponenten der mitochondrialen Wolke, zum vegetalen Kortex der Oozyte, der ab dem späten Stadium II erreicht wird Abb. 3.9 B). Die Lokalisation des früh lokalisierten DEADSouth-Transkriptes bleibt im Gegensatz zu der Gruppe der spät lokalisierten RNAs auch in späteren Oozytenstadien (Stadium IV-VI) auf die äußerste vegetale Region des Kortex beschränkt und weist dort eine punktförmige, granuläre Verteilung auf Abb. 3.9 B und C).

A

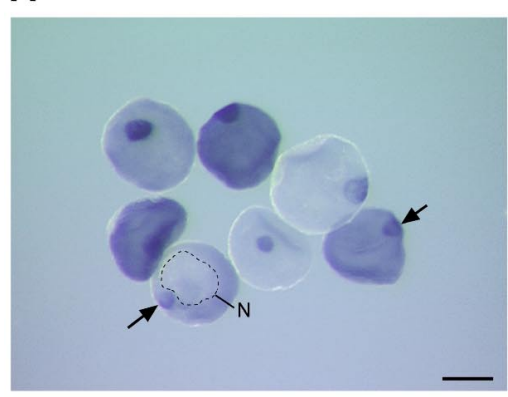

B

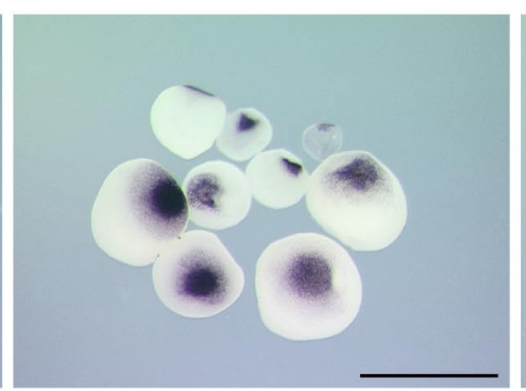

C

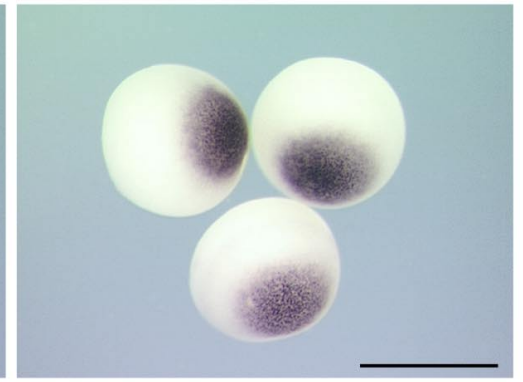

Abb. 3.9 Lokalisation der DEADSouth-RNA während der Oogenese. Die Verteilung endogener B2B-9D (DEADSouth)-Transkripte in Oozyten verschiedener Entwicklungsstadien wurde in der whole mount in situ-Hybridisierung mittels einer spezifischen antisense RNA-Sonde und anfolgender Färbereaktion nachgewiesen. A. Im Stadium I (100-300 $\mu \mathrm{m}$ im Durchmesser) ist die Assoziation der RNA mit der mitochondrialen Wolke nachweisbar (Pfeil). Der Zellnukleus ist in einer Oozyte durch eine offene Umrandung gekennzeichnet. N, Nukleus; B. In Stadium II Oozyten (300-450 $\mu \mathrm{m}$ im Durchmesser; oben in der Abbildung) beginnt die Akkumulation des Transkriptes am vegetalen Kortex, wo es auch in Stadium III-IV Oozyten (450-900 $\mu \mathrm{m}$ im Durchmesser) auf einen relativ kleinen Bereich begrenzt vorliegt; C. Punktförmig-granuläre Verteilung der RNA am vegetalen Kortex von Stadium V-VI Oozyten (1000-1200 $\mu \mathrm{m}$ im Durchmesser). Der Maßstabsbalken entspricht ca. $100 \mu \mathrm{m}$ in (A) sowie ca. $1 \mathrm{~mm}$ in (B und $\mathrm{C}$ ).

Zur genaueren Analyse der subzellulären Verteilung der B2B-9D-RNA in frühen Oozytenstadien wurden zusätzlich Vibratom-Schnitte der whole mount in situ-Präparate angefertigt. In Schnitten von Stadium I Oozyten ist die Lokalisation des Transkriptes in der mitochondrialen Wolke sehr deutlich zu erkennen Abb. 3.10A). Die vor allem im kortika- 
len Zytoplasma detektierbare Färbung repräsentiert möglicherweise zu diesem Zeitpunkt nach dem nukleären Export noch frei vorliegende RNA, die anfolgend in die Struktur der mitochondrialen Wolke rekrutiert wird. In späten Stadium II Oozyten ist das Transkript in einer keilförmigen Region, die sich unterhalb des Zellnukleus bis zum Oozytenkortex erstreckt, zu detektieren Abb. 3.10 B). Die RNA scheint sich dort während des Transportes in granulären Strukturen zu befinden, bevor sie in einer schmalen Region am Kortex der vegetalen Hemisphäre akkumuliert. Das Transkript ist in späten Stadium II Oozyten in einer halbmondförmigen Region unterhalb des Zellkerns angereichert. Diese Struktur wurde in früheren Arbeiten in Verbindung mit dem vermutlich ER- und mikrotubuliabhängigen Transport spät- oder intermediär lokalisierender Transkripte wie Vg1 und fatvg gebracht (Chan et al., 1999). Eine deutliche Anreicherung der RNA in der als METRObeschriebenen Region der mitochondrialen Wolke konnte nicht beobachtet werden.
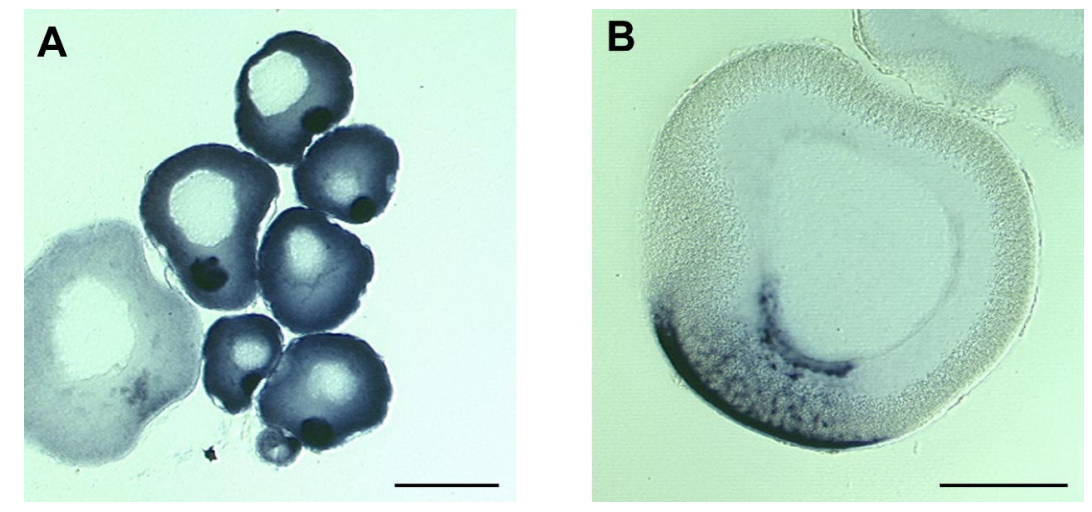

Abb. 3.10 Verteilung der DEADSouth-mRNA in Vibratomgeschnittenen whole mount in situHybridisierungs-Präparaten. Die in der whole mount in situ-Hybridisierung mit der DEADSouthantisense RNA-Sonde behandelten Oozyten wurden nach Fixierung eingebettet und im Vibratom geschnitten. A. Stadium I; B. Stadium II. Die Maßstabsbalken entprechen jeweils ca. $100 \mu \mathrm{m}$.

Das cDNA-Insert des zu dieser lokalisierten RNA zugehörigen pTriplEx2-Klons der Kortex-cDNA-Bibliothek weist eine Größe von ca. 1100 bp auf. Nach der Sequenzierung der cDNA konnte kein offener Leserahmen identifiziert werden, so daß auch im Hinblick auf die relativ geringe Größe des Inserts angenommen wurde, daß es sich um ein cDNAFragment des 3'-untranslatierten Bereiches handelt. Um einen Phagen-Klon der Volllängen-cDNA-Sequenz anzureichern, wurde ebenfalls die schon beschriebene Strategie der PCR-vermittelten Durchmusterung einer fraktionierten Stadium V/VI Oozyten cDNABibliothek angewendet. Da auch nach einer Vielzahl von Anreicherungs- und Verdünnungsschritten kein Einzelphage isoliert werden konnte, wurde versucht, das cDNAFragment aus einer positiven Phagenfraktion mittels der PCR unter Verwendung eines Insert- sowie eines Vektor-spezifischen Oligonukleotides herauszuamplifizieren. Das erhaltene PCR-Produkt der Länge von ca. 2,6 kb wurde zunächst in den pGEM-T-Vektor ligiert. Nach Sequenzanalyse des Inserts konnte festgestellt werden, daß es sich in der Tat um ein längeres Fragment der gesuchten cDNA handelt. Um diese, aufgrund der Verwen- 
dung eines insertspezifischen Oligonukleotides während der Amplifikationsreaktion am 3'Ende verkürzte cDNA, zu vervollständigen, wurde ein NsiI/Nsil-Fragment dieses Klons gegen dasjenige aus dem vorhergehend isolierten pTriplEx2-Plasmid ausgetauscht. Die so erhaltene cDNA weist einen Umfang von 3010 Nukleotiden auf, in der ein 1404 Nukleotide umfassender offener Leserahmen (Nukleotide 26-1429 der cDNA) sowie ein 3'untranslatierter Bereich von 1581 Nukleotiden Länge (Nukleotide 1430-3010 der cDNA) identifiziert werden konnte (Sequenz in Anhang 7.4 und in Abb. 3.11 schematisch dargestellt). Es konnten keine 5'- zu dem identifizierten Startkodon gelegene Stopkodons im selben Leserahmen nachgewiesen werden. Aufgrund der Tatsache, daß das postulierte Startkodon jedoch eine Kozak-Konsensussequenz aufweist, sowie aufgrund von aus Datenbanksuchen erhaltenen Sequenzinformationen homologer Proteine, kann angenommen werden, daß es sich hierbei tatsächlich um das Startkodon der cDNA handelt.

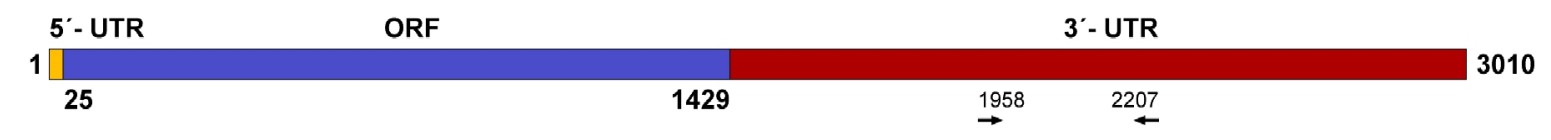

Abb. 3.11 Schematische Darstellung des B2B-9D (DEADSouth-Isoform)-Klons. Angegeben sind jeweils die Nukleotidsequenzpositionen die den Abgrenzungen des kodierenden Bereiches (ORF; offener Leserahmen; in blau unterlegt) sowie der 5' - (5'- UTR; in gelb unterlegt) und 3'- (3'- UTR; in rot unterlegt) untranslatierten Bereiche entsprechen. Zusätzlich sind die Positionen der in der RTPCR-Expressionsanalyse verwendeten Oligonukleotide unterhalb der schematischen Darstellung angegeben (siehe Abb. 3.13 C).

Der offene Leserahmen der cDNA kodiert für ein Protein mit 468 Aminosäuren und einer vorhergesagten relativen Molekülmasse von 52,8 kDa. Bei der Suche nach bekannten Proteinmotiven mittels der CD (Conserved Domain)-Suche des BLAST-Datenbankservers, konnte eine signifikante Ähnlichkeit des vorhergesagten Proteines mit mutmaßlichen RNA-Helikasen des DEAD-Box-Typs festgestellt werden Abb. 3.12. Das Protein weist alle acht voneinander getrennten konservierten Sequenzmotive auf, die den Proteinen der DEAD-Box-Familie gemein sind. Benannt ist diese Protein-Familie nach der kurzen Aminosäuresequenzabfolge DEAD (Aspartat-Glutamat-Alanin-Aspartat), die für die RNAHelikase-Aktivität essentiell zu sein scheint (de la Cruz et al., 1999; Linder und Daugeron, 2000; Luking et al., 1998; Tanner und Linder, 2001). Neben den in der Datenbanksuche identifizierten homologen DEAD-Box-Proteinen aus der Maus, dem Menschen, der Fruchtfliege sowie der Bäckerhefe, wurde während der experimentellen Phase dieser Promotionsarbeit von MacArthur et al., (2000) auch das Expressionsmuster einer vermutlichen Variante oder Isoform dieses Xenopus DEAD-Box-Proteins publiziert (GendatenbankEingangsnummer AF190623). Dieses Protein, das aufgrund des konservierten RNAHelikase-Motivs DEADSouth (vormals Xcat3) genannt wurde, konnte ebenfalls während der Suche nach vegetal lokalisierten, zytoskelett-assoziierten maternalen RNAs in Xenopus Oozyten identifiziert werden (Elinson et al., 1993). DEADSouth weist auf DNA-Ebene 30 Nukleotidaustausche bzw. Einzelnukleotiddeletionen oder Insertionen $\mathrm{zu}$ dem in dieser 
Arbeit beschriebenen cDNA-Klon auf, die vornehmlich im 3'-untranslatierten Bereich der cDNAs lokalisiert sind. Da der hier vorliegende Klon aus cDNA-Sequenzen zusammengesetzt ist, die bei der Erstellung der Kortex-cDNA-Bibliothek bzw. bei der Anreicherung von Fragmenten aus der Stadium V-VI Oozyten cDNA-Bibliothek über PCR angereichert wurden, ist nicht auszuschließen, daß diese geringen Unterschiede in der Nukleotidsequenz eventuell auch auf einer fehlerhaften Polymerase-vermittelten Amplifikationsreaktion basieren. Auffällig ist jedoch das Fehlen einer zusätzlichen Sequenz die fünfzehn Aminosäuren im N-terminalen Bereich des in dieser Arbeit identifizierten DEAD-Box Proteins umfaßt.

\begin{tabular}{|c|c|c|c|}
\hline & & & \\
\hline So & $\mathrm{x} .1$ & 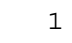 & 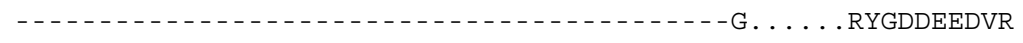 \\
\hline P5 & M.m. & & . . MATDSW-LAV-EQEAA-KSMSS-QIKEEKA-SDTN . . . .VIKTSTTAEKTE \\
\hline $3 \mathrm{P} 5$ & H.s. & 1 & . . . . . . . MATDSW-LAV-EQEAAAESLSN-HLKEEKI - PDTN . . GAVVKTNANAEKTD \\
\hline p5 & S.c. & & . . . . MSDTKRDPADL-ASLKIDNEKEDTSEVSTKE-V-SQPEKTADS IKPAEKLVPKV \\
\hline So- & x.1. & & . . EDLANHSLLNKLLRRTLVDSPHNVEVLQRDPTSPLFSVKSFEELHLI \\
\hline So & .1 & & RGHI - - - - - \\
\hline BP5 & M. m. & 49 & EEK- -R-AQ- - - - - I -SN-- -NTNQ- - - - - -S- - Y- - - - - -R- - PQ- - Q-V- - \\
\hline $3 \mathrm{P} 5$ & H.s. & 5 & EEK- -R-AQ- - - - - I -SN-- -NTNQ- - - - - -N- - Y- - - - - - R- - PQ- - Q-V- - \\
\hline bp5 & S.C. & 5 & EKKTKQEDSN-ISSEYEVKV. . . . KLADI -A - -N-- -Y-A---D--G-AP- - - K-I- - \\
\hline So-Iso & x.1. & 00 & MGFNRPSKIQENALPMMLADPPQNLIAQSQSGTGKTAAFVLAMLSRVDANKKYPQCICLS \\
\hline So & $\mathrm{x} .1$. & 5 & $\begin{array}{l}\text { - } \\
\end{array}$ \\
\hline BP5 & . m. & 9 & - - - - \\
\hline BP5 & H.s. & 10 & 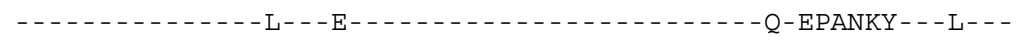 \\
\hline bp5 & S.c. & 0 & 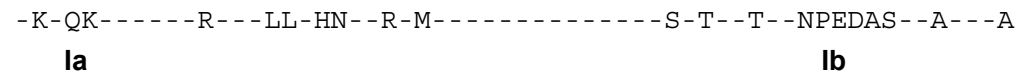 \\
\hline So-Iso & $\mathrm{x} .1$. & 60 & PTFELALQTGKVVEEMGKFCAGIEVIYALRGNRPGKGSRLEAQIVIGTPGTVLDWCFKLR \\
\hline So & .1 . & 5 & $\begin{array}{l} \\
\end{array}$ \\
\hline BP5 & M.m. & 9 & 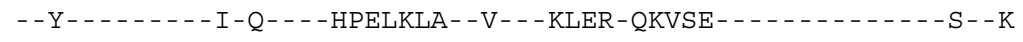 \\
\hline BP5 & H.s. & 70 & 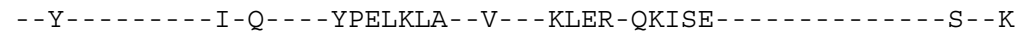 \\
\hline bop5 & S.c. & 70 & 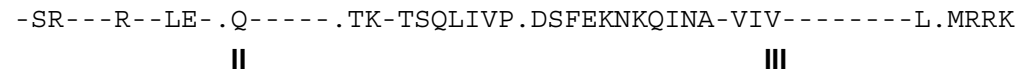 \\
\hline So-Iso & x.1. & 0 & ITVENISVFVLDEADVMINVQGRSDHSVRVKRSMPKSCQMLLFSATFEDSVWAFAERIV \\
\hline So & $\mathrm{x} .1$. & & - - - \\
\hline BP5 & M.m. & 29 & '-DPKK-K---- - - - - AT- - HQ - Q- I - IQ - IV-RN--- - - - - - - - K- - QKV- \\
\hline $3 P 5$ & H.s. & & 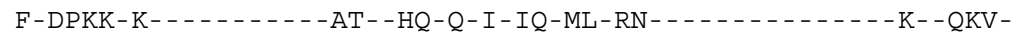 \\
\hline Dbp5 & S.C. & 30 & $\begin{array}{c}\text { MQLQKIKI - - - - - N-LDQ- - LG-QCI-V--FL-KDT-LV-- - }-\mathrm{A}-\mathrm{A}-\mathrm{RQY}-\mathrm{KK}-- \\
\text { IV }\end{array}$ \\
\hline So- & 1. & & DPNI IKLKKEELTLKNIQQFYDQCENKEQKYSALCNLYGVITIAQAIVFCQTRKIASWL \\
\hline So & .1 . & & 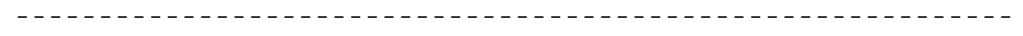 \\
\hline BP5 & M. m. & 89 & - - - - - - -R- -E- -DT-K-Y-VL-N-R-E-FQ-- - - -A- - - - -MI - - H- - - T- - - \\
\hline 5 & H.s. & 290 & 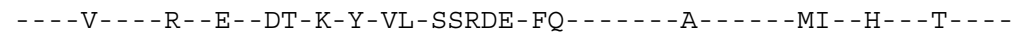 \\
\hline Dop5 & S.c. & 90 & $\begin{array}{c}-\mathrm{NA}-\mathrm{TLE}-\mathrm{QTN}-\mathrm{VNVDA}-\mathrm{K}-\mathrm{L}-\mathrm{MD}-\mathrm{K}-\mathrm{EAD}-\mathrm{FDV}-\mathrm{TE}--\mathrm{LM}-\mathrm{-GSS}-\mathrm{I}-\mathrm{VA}-\mathrm{K}-\mathrm{T}-\mathrm{NV}- \\
\mathbf{V}\end{array}$ \\
\hline $50-$ & & & QKLSDDGHQVALLSGELPIYDRADMIQRFREGREKVLVTTNVCARGIDVEQVSIVVNFD \\
\hline $\mathrm{DSC}$ & $\mathrm{x} .1$ & & 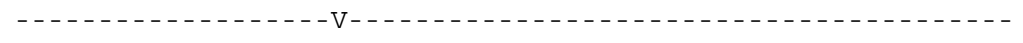 \\
\hline $\mathrm{BP}$ & m. & & 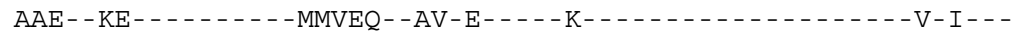 \\
\hline & H.S. & & AAE- -KE- - - - - - - -MMVEQ - -AV-E-- - - K- - - - - - - - - - - - - -V-I - - \\
\hline p 5 & S.C. & 350 & G- -KSE- -E-SI-H-D-QTQE-DRL-DD-- - -S- - - I- - - -L- - - - IPT- -M- - -Y- \\
\hline
\end{tabular}


VI

\begin{tabular}{|c|c|c|c|}
\hline DSo-Iso & x.1. & 400 & LPVNVDGSVDFETYLHRIGRTGRFGKKGIAVSLIEN . FFVYMLKEIEDHF . NTKITKLNS \\
\hline DSo & X.1. & 415 & 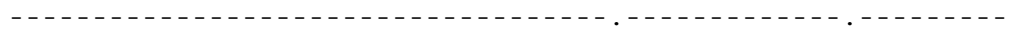 \\
\hline DBP5 & M. m. & 409 & 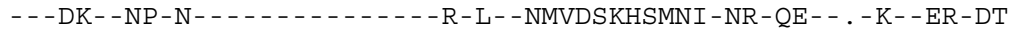 \\
\hline DBP5 & H.S. & 410 & -- -DK- -NP-N------- \\
\hline Dbp5 & S.C. & 410 & - - TLAN-QA-PA- - I- - - - - - - RK-V-ISFVHDKNSFNI-SA-QKY - GDIEMTRVPT \\
\hline Do-Iso & X.1. & 458 & MDMDEMGKIWK \\
\hline DSo & X.1. & 473 & $-\ldots-n-1$ \\
\hline BP5 & M.m. & 468 & $\mathrm{D}-\mathrm{L}-\mathrm{-IE}-\mathrm{AN}$ \\
\hline BP5 & H.s. & 469 & $D-L--I E-A N$ \\
\hline Dbp5 & S.C. & 470 & D-W--VE--V-KVLKD \\
\hline
\end{tabular}

Abb. 3.12 Sequenz- und Strukturvergleich der XDEADSouth-Isoform (B2B-9D) mit homologen DEAD-Box Proteinen anderer Spezies. Im Aminosäuresequenzvergleich sind die Sequenzen des Xenopus DEADSouth-Proteins (DSo) und die in dieser Arbeit isolierte Isoform (DSo-Iso), sowie homologe DEAD-Box Proteine anderer Spezies dargestellt. DEADSouth (AF190623); murines DBP5 (L25125); humanes DBP5 (NM_007242 bzw. NP_009173); DBP5 aus der Hefe (NC_001147 bzw. NP_014689). Die Datenbank-Zugangsnummern der Proteine sind in Klammern angegeben. Zur Sequenz der DEADSouth-Isoform identische Aminosäuren sind durch einen Querstrich gekennzeichnet. Fehlende Aminosäuren oder größere Lücken in der durchgehenden Sequenz sind durch Punkte markiert. Die Aminosäurepositionen der Proteine sind am linken bzw. rechten Rand der Sequenzen angeführt. Die acht charakteristischen Sequenzmotive der DEAD-Box RNA-Helikasen sind in der Aminosäuresequenz der in dieser Arbeit isolierten 9D-DEADSouth-Isoform gekennzeichnet und farbig unterlegt. Eigenschaften und vermutete Funktion der konservierten Motive: I, NTPBindungsmotiv; Ia, Substratbindung über Zucker-Phosphat-Rückgrat; Ib, Substratbindung; II, NTPBindungsmotiv; III, bindet $\gamma$-Phosphat und verbindet NTP-Hydrolyse mit der Entwindungsaktivität der Helikase; IV, Substratbindung; V, Substratbindung; Bindung von $\gamma$-Phosphat (nach Tanner und Linder, 2001).

Basierend auf einem nach der Clustal-Methode durchgeführten Sequenzvergleich (MegAlign) konnten folgende Sequenzidentitäten der hier isolierten DEADSouth-Isoform zu den in der Datenbanksuche identifizierten homologen Proteinen ermittelt werden: DEADSouth (AF190623), 98,5 \%; murines DBP5 (L25125), 61,5 \%; humanes DBP5 (NM_007242 bzw. NP_009173), 61 \%; Dbp5 aus der Hefe (NC_001147 bzw. NP_014689), 41,4\%.

\subsubsection{Expressionsanalyse der DEADSouth-Isoform in Embryonalstadien und adul- ten Geweben}

Um das Expressionsverhalten der DEADSouth-Isoform (B2B-9D) während der Xenopus Embryogenese zu ermitteln, wurden whole mount in situ-Hybridisierungen an fixierten Albino Embryonen verschiedener Entwicklungsstadien durchgeführt. In 2- und 4-ZellStadien ist die DEADSouth-RNA in punkt- oder inselförmigen Strukturen am Kortex der vegetalen Blastomeren nachweisbar Abb. 3.13 A). Die charakteristische Assoziation von RNAs mit dem dort befindlichen Keimplasma konnte neben DEADSouth auch schon für andere früh lokalisierende RNAs beschrieben werden (Chan et al., 2001; Houston et al., 1998; Kloc et al., 2000; MacArthur et al., 2000; Zhou und King, 1996). Während der Gastrulation invaginieren die Keimplasma- und DEADSouth-RNA-enthaltenden Zellmassen 
und können nur noch in Spuren am Dotterpfropf des Embryos nachgewiesen werden (nicht gezeigt). Im Stadium 31 ist die gewebespezifische Expression in den migrierenden primordialen Keimzellen des Embryos sehr deutlich zu erkennen (Pfeile in Abb. 3.13 B). Die Analyse der stadienpezifischen Expression der DEADSouth-Isoform mittels der RT-PCR zeigt, daß das Expressionsniveau von Stadium 0 (Ei) bis zum Embryonalstadium 38 konstant bleibt, während in Stadium 42 nur noch geringere Mengen RNA detektiert werden können Abb. 3.13 C). In Stadium 48 Embryonen ist keine Expression von DEADSouth mehr nachzuweisen. Bei der Analyse der Expression in adulten Geweben zeigt sich, daß DEADSouth sowohl in Ovar und Testis, als auch in der Leber stark exprimiert wird. Eine etwas schwächere Expression ist im adulten Gehirn und Rückenmark nachzuweisen. Die Gewebe Skelettmuskel und Haut weisen keine Expression des Transkriptes auf.

A

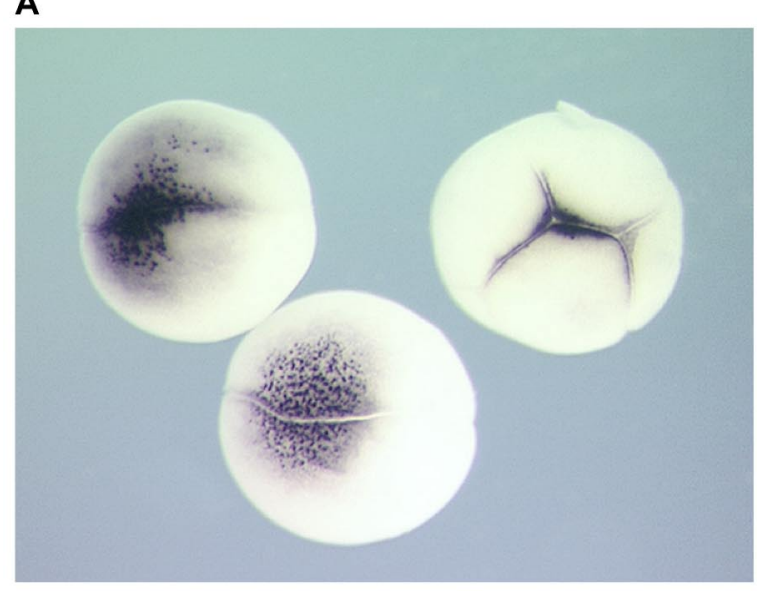

B

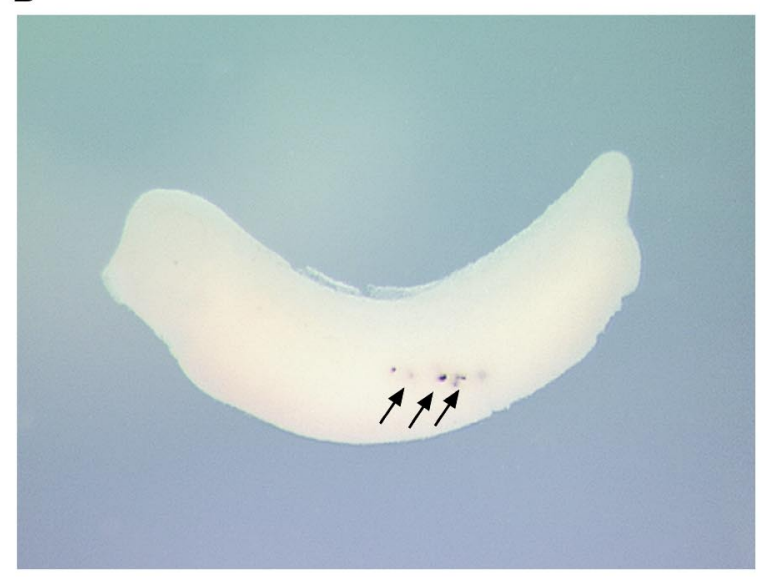

C $\begin{array}{lllllllllll}0 & 6 & 9 & 11,513 & 19 & 23 & 28 & 32 & 38 & 42 & 48 \\ \mathrm{M}\end{array}$ DEADSouth

H4

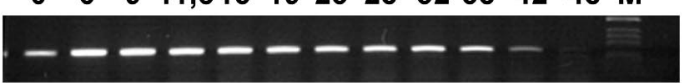

ov te mu br sc ey he gu sk li $\mathrm{K} \mathrm{M}$

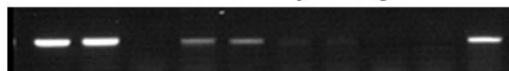

$------$

Abb. 3.13 Expression von DEADSouth in Embryonalstadien und adulten Geweben. Die Expression von DEADSouth und Lokalisation der RNA in verschiedenen Embryonenstadien wurde in der in situ-Hybridisierung unter Verwendung einer digoxygeninmarkierten antisense RNA-Sonde nachgewiesen (Volllängen cDNA-Probe MC135). A. vegetale Bereiche von 2- und 4-Zell-Stadien; B. Stadium 32; primordiale Keimzellen sind mit Pfeilen gekennzeichnet; C. Der Nachweis des DEADSouth-Transkriptes in RNA-Präparationen verschiedener Embryonalstadien und adulter Gewebe erfolgte in der RT-PCR. In der Beschriftung über den DNA-Banden sind die Stadien der untersuchten Embryonen (Nieuwkoop und Faber, 1967) bzw. Gewebe des adulten Tieres angegeben (ov, Ovar; te, Testis; mu, Skelettmuskel; br, Gehirn; sc, Rückenmark; ey, Auge; he, Herz; gu, Darm; sk, Haut; li, Leber; K, $\mathrm{H}_{2} \mathrm{O}$-Kontrollreaktion; M, Molekulargewichtsstandard 1 kb-Leiter). Die zu erwartende PCR-Produktlänge für DEADSouth-Transkripte beträgt 251 bp (Mit den verwendeten Oligonukleotiden werden beide DEADSouth-Isoformen amplifiziert). Zur Kontrolle der eingesetzen RNA-Menge wurde ebenfalls die gleichmäßig und ubiquitär exprimierte Histon H4 RNA in der RT-PCR nachgewiesen (Produktlänge 200 bp). 


\subsubsection{Das XNIF (B2B-10B)-Transkript ist eine früh lokalisierte RNA, die für ein hypothetisches Protein einer konservierten Proteinfamilie kodiert}

Zur detaillierteren Analyse des Verteilungsweges der früh lokalisierten B2B-10B-RNA wurden in situ-Hybridisierungen mit verschiedenen Stadien von Albino Oozyten durchgeführt. In Stadium I Oozyten ist dieses Transkript in Assoziation mit der mitochondrialen Wolke nachzuweisen Abb. 3.14 A, Pfeile). Mit dem Fortschreiten der Oogenese erreicht die RNA ab dem späten Stadium II den vegetalen Kortex der Oozyte und ist hier auf einen relativ kleinen kreisförmigen Bereich beschränkt, bis zum Stadium VI der Oogenese in der in situ-Hybridisierung nachweisbar Abb. 3.14 B. und C.).

A

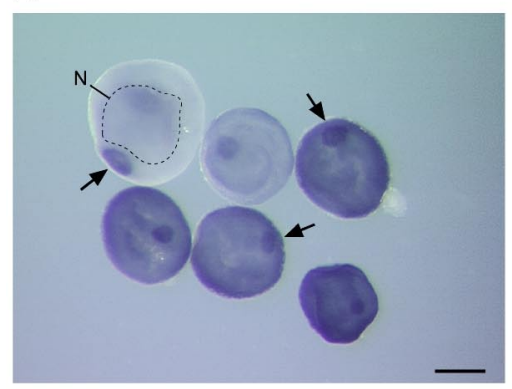

B

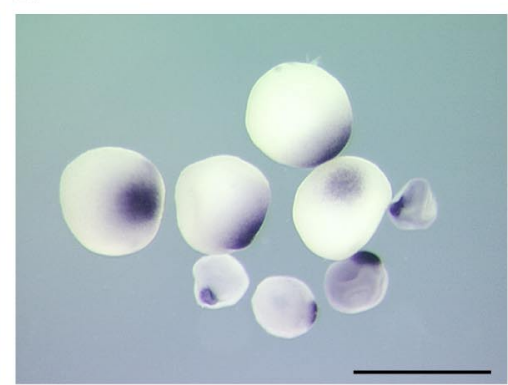

C

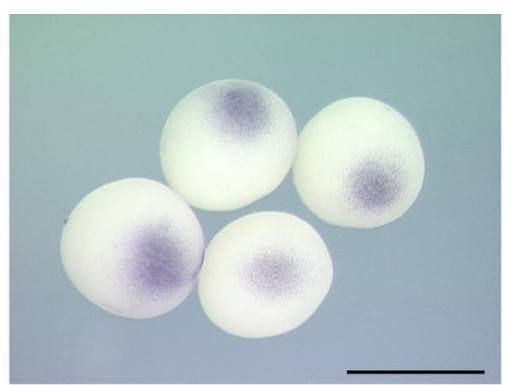

Abb. 3.14 Lokalisation des XNIF (B2B-10B)-Transkriptes während der Oogenese. Endogene B2B-10B-Transkripte wurden in der whole mount in situ-Hybridisierung unter Verwendung einer spezifischen, digoxygeninmarkierten antisense RNA-Sonde nachgewiesen (Volllängen cDNA-Probe MC119). A. Im Stadium I (100-300 $\mu \mathrm{m}$ im Durchmesser) ist die Assoziation der RNA mit der mitochondrialen Wolke nachweisbar (Pfeile). Der Zellnukleus ist in der Oozyte durch eine offene Umrandung exemplarisch gekennzeichnet. N, Nukleus; B. In Stadium II Oozyten $(300-450 \mu \mathrm{m}$ im Durchmesser; unten in der Abbildung) beginnt die Akkumulation des Transkriptes am vegetalen Kortex. Die RNA ist in Stadium III-IV Oozyten vegetal-kortikal lokalisiert $(450-900 \mu \mathrm{m}$ im Durchmesser, oben in der Abbildung); C. Lokalisation der B2B-10B-RNA am vegetalen Kortex von Stadium V-VI Oozyten (1000-1200 $\mu \mathrm{m}$ im Durchmesser). Der Maßstabsbalken entspricht ca. $100 \mu \mathrm{m}$ in (A) sowie ca. $1 \mathrm{~mm}$ in (B und $\mathrm{C}$ ).

Zur genaueren Analyse der subzellulären Verteilung der XNIF (B2B-10B)-RNA in frühen Oozytenstadien wurden Vibratom-Schnitte der whole mount in situ-Präparate angefertigt. Hier ist in Stadium I Oozyten sehr deutlich die für früh lokalisierte RNAs typische Assoziation des Transkriptes mit der mitochondrialen Wolke zu erkennen, eine Anreicherung in der als METRO beschriebenen Region ist jedoch nicht zu detektieren Abb. 3.15. A). Geringe Mengen des Transkriptes scheinen in diesem Stadium noch nicht lokalisiert zu sein, sondern liegen frei im Zytoplasma vor (vergl. DEADSouth-Lokalisation in Abb. 3.10 A). In späten Stadium II Oozyten ist das Transkript, wie dies vorangehend auch für DEADSouth gezeigt werden konnte, in einer keilförmigen Region, die sich vom Zellnukleus bis zum Oozytenkortex erstreckt, zu detektieren (Abb. 3.15 B). Auch die XNIF (B2B-10B)RNA scheint sich während des Transportes in granulären Strukturen zu befinden, in denen 
sie zur vegetalen Hemisphäre transportiert wird und dort in einer schmalen Region am Kortex akkumuliert.
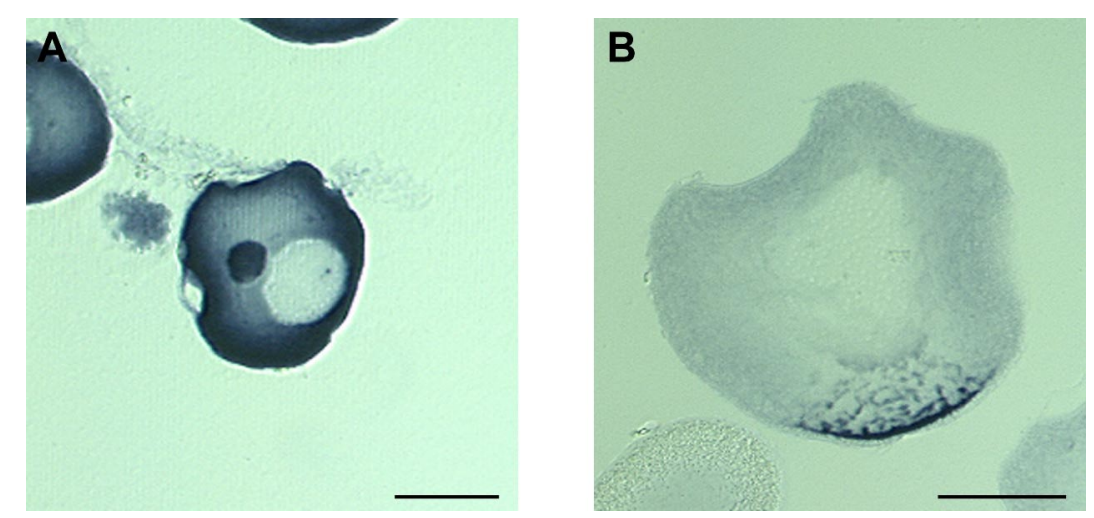

Abb. 3.15 Analyse der XNIF (B2B-10B)-Lokalisation in Schnitten von whole mount in situOozyten Präparaten. Oozyten verschiedener Stadien bei denen das 10B-Transkript in der whole mount in situ-Hybridisierung nachgewisen werden konnte, wurden in Gelatine/Albumin eingebettet und im Mikrotom geschnitten. A. Stadium I Oozyten; B. Stadium II Oozyten. Die Maßstabsbalken entprechen jeweils ca. $100 \mu \mathrm{m}$.

Der in der in situ-Hybridisierung als vegetal lokalisiert identifizierte primäre pTriplEx2Klon enthält ein Insert einer Größe von ca. 900 bp, welches nach Ansequenzierung als nur unvollständig kloniertes cDNA-Fragment identifiziert werden konnte. Bei der PCRvermittelten Durchmusterung der Gesamt Oozyten cDNA-Bibliothek konnte jedoch ein positiver Klon identifiziert werden, der ein cDNA-Insert von 2600 bp enthält. Nach Sequenzierung der cDNA konnte ein außergewöhnlich langer 5'-untranslatierter Bereich von 1308 Nukleotiden (Nukleotide 1-1308), ein offener Leserahmen von 828 Nukleotiden (Nukleotide 1309-2136 der cDNA) sowie ein 3'-untranslatierter Bereich von 466 Nukleotiden (Nukleotide 2137-2601) identifiziert werden (schematisch dargestellt in Abb. 3.16. siehe auch Anhang 7.5). Die Lokalisierung des Startkodons an Position 1309 der cDNA basiert auf der Tatsache, daß 5'zu diesem Startkodon mehrere Stopkodons im gleichen Leseraster des Transkriptes zu finden sind. Eine Übereinstimmung mit der von Kozak postulierten Konsensus-Sequenz für optimale Translationsinitiationssequenzen kann jedoch nicht nachgewiesen werden.

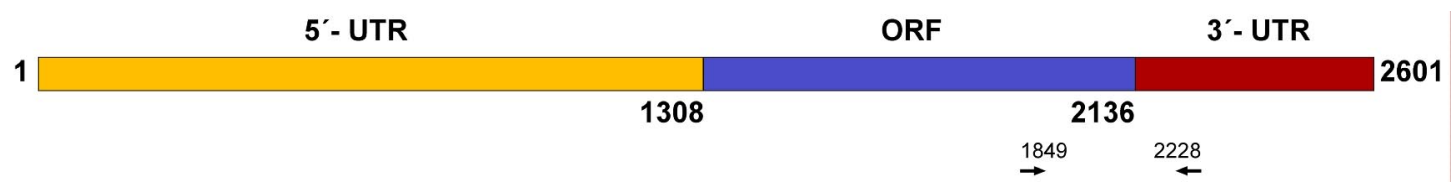

Abb. 3.16 Schematische Darstellung des XNIF (B2B-10B)-Klons. Angegeben sind jeweils die Nukleotidsequenzpositionen die den Abgrenzungen des kodierenden Bereiches (ORF; offener Leserahmen; in blau unterlegt) sowie der 5'- (5'- UTR; in gelb unterlegt) und 3'- (3'- UTR; in rot unterlegt) untranslatierten Bereiche entsprechen. Zusätzlich sind in der schematischen Darstellung die Positionen der in der RT-PCR-Expressionsanalyse (siehe Abb. 3.18 C), sowie in der PCR-vermittelten Durchmusterung der Gesamt-Oozyten cDNA-Bibliothek verwendeten Oligonukleotide angegeben. 
Der offene Leserahmen der isolierten cDNA kodiert für ein 276 Aminosäuren umfassendes Protein einer rechnerisch kalkulierten relativen Molekülmasse von 97,3 kDa.

Bei der Suche nach homologen Proteinen anderer Spezies in der Proteindatenbank konnten zahlreiche hypothetische Genprodukte aus dem Hühnchen, der Maus, dem Menschen, aus der Fruchtfliege, der Bäckerhefe sowie das kürzlich beschriebene Os4-Protein aus Xenopus identifiziert werden, die eine sehr hohe Sequenzähnlichkeit zu dem vorhergesagten Genprodukt des B2B-10B-Transkriptes aufweisen (Aminosäuresequenzvergleich der Proteine in Abb. 3.17. Basierend auf dem nach der Clustal-Methode durchgeführten Sequenzvergleich (MegAlign) konnten folgende Sequenzidentitäten des vorhergesagten B2B-10BProteins zu den in der Datenbanksuche identifizierten homologen zum Teil hypothetischen Proteinen ermittelt werden: NIF-Isoform T1 aus dem Huhn (AF189773), 86,5 \%; NIFähnliches Protein aus der Maus (AJ344340), 78,3 \%; hypothetisches Protein Hya22 aus dem Menschen (NM_005808), 76,2 \% sowie das Xenopus XOs4 (AF441288), 57,6 \% Identität. Sehr hoch konserviert ist in dieser Proteinfamilie vor allem der Bereich der NIFDomäne (in Abb. 3.17 in grau unterlegt). Aufgrund dieser konservierten Domäne wurde das Protein anfolgend XNIF genannt. Das NIF-Proteinmotiv ist nach dem homologen Protein aus dem Hühnchen benannt, für welches eine Proteininteraktion mit dem nukleären Lim-interagierenden Faktor (NLI) beschrieben wurde (AF189773). Hierin enthalten ist auch das sehr kurze konservierte Proteinmotiv (DXDET/V) (in Abb. 3.17 umrandet) einer Gruppe von Proteinphosphatasen, wie zum Beispiel der RNA-Polymerase II Phosphatase (Fcp1) aus Xenopus.

\begin{tabular}{|c|c|}
\hline $\mathrm{XNIF}$ & X.1. \\
\hline NIF & G. g. \\
\hline NIF-I & M.m. \\
\hline Hya 22 & H.S. \\
\hline OS4 & X.1. \\
\hline XNIF & X.1. \\
\hline NIF & G. g. \\
\hline$N I F-1$ & M.m. \\
\hline Hya 22 & H.S. \\
\hline OS4 & X.1. \\
\hline XNIF & X.1. \\
\hline NIF & G.. \\
\hline NIF-1 & M.m. \\
\hline Hya 22 & H.S. \\
\hline OS4 & X.1. \\
\hline $\mathrm{XNIF}$ & X.1. \\
\hline NIF & G.g. \\
\hline NIF-1 & M.m. \\
\hline Hya 22 & H.S. \\
\hline OS4 & X.1. \\
\hline
\end{tabular}

MLTRRRPLQPSGGGDGG.SWGAGPGRLSRSAG . . . . PGGG.ERPTAPR MVTRRRPLEPSGGGRRELGRGPGPPLPERGAGRRARPGSGCERPPAPR

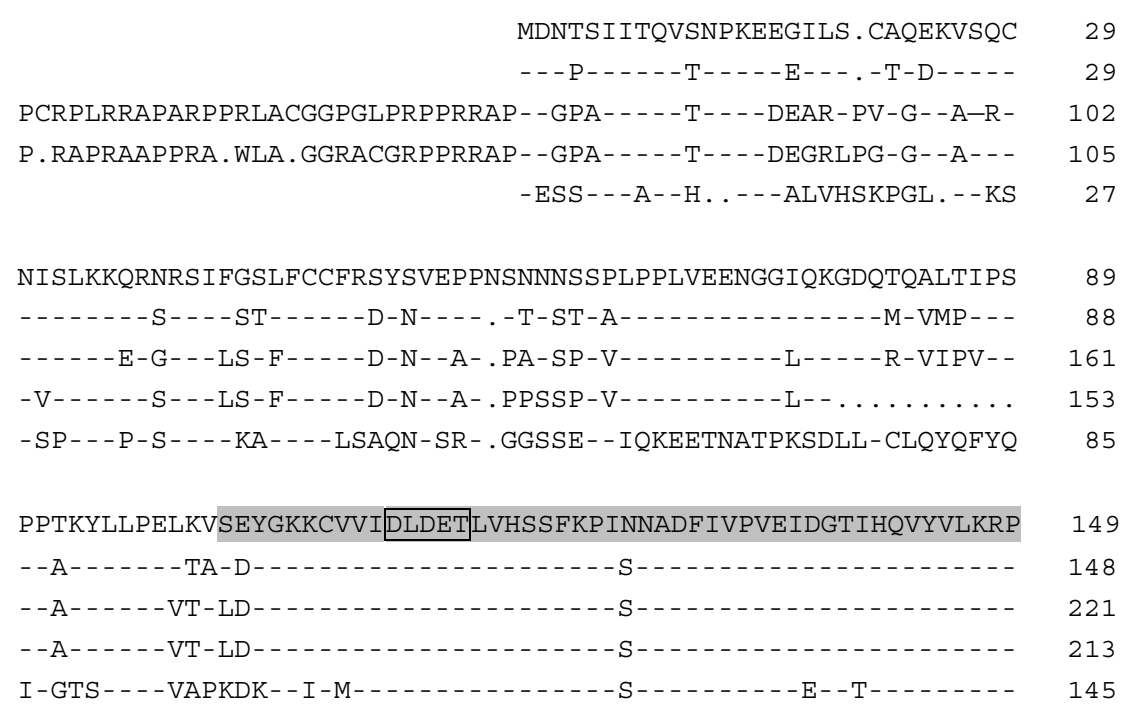




\begin{tabular}{|c|c|c|c|c|}
\hline $\mathrm{XNIF}$ & X.1. & 150 & HVDEFLQKMGEMFECVLFTASLAKYADPVADLLDRWGVFNARLFRESCVFHRGNYVKDLS & 209 \\
\hline NIF & G.g. & 149 & - - - - - -R-- - L- - - - - - - - - - - - - - - - - - - - - R - - - - - - - - - - - - - - - - & 208 \\
\hline NIF-1 & M.m. & 222 & 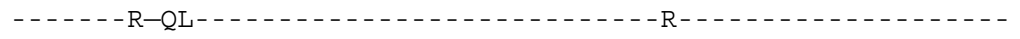 & 281 \\
\hline Hya22 & H.S. & 214 & - - - - - - R-QLL- - - - - - - - - - - - - - - - - - - - - - - R- - - - - - - - - - - - - - - - - & 273 \\
\hline OS4 & $\mathrm{X} .1$. & 146 & Y-- - - ER- - QLY - - - - - - - - - - - T- - - KS - - -RS - - - - A - - - HQ - C- - - - & 205 \\
\hline $\mathrm{XNIF}$ & X.1. & 210 & RLGRELSKVI I IDNSPASYIFHPENAVPVMSWFDDMADTELLDLLPFFEGLSKEENVYNM & 269 \\
\hline NIF & G.g. & 209 & $-----------V-----------------\mathrm{Q}------\mathrm{T}-------\mathrm{I}----------\mathrm{E}--\mathrm{S}-$ & 268 \\
\hline NIF-1 & M.m. & 282 & 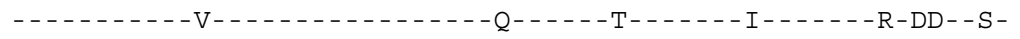 & 341 \\
\hline Hya22 & H.s. & 274 & ---------- V - - - - - - - - - - - - - Q & 333 \\
\hline OS4 & $\mathrm{X} .1$ & 206 & $----\mathrm{D}-\mathrm{K}-\mathrm{TV}-\mathrm{L}-----------\mathrm{Q}----\mathrm{S}----\mathrm{S}-\mathrm{I}-\mathrm{I}--\mathrm{EF}-\mathrm{YS}-\mathrm{DI}-\mathrm{TS}$ & 265 \\
\hline XNIF & X.1. & 270 & LNKLCNR & 276 \\
\hline NIF & G.g. & 269 & $-\mathrm{H}-----$ & 275 \\
\hline$N I F-1$ & M.m. & 342 & $-\mathrm{HR}----$ & 348 \\
\hline Hya22 & H.s. & 334 & -HR--- - & 340 \\
\hline OS4 & X.1. & 266 & -GQ-KAP & 272 \\
\hline
\end{tabular}

Abb. 3.17 Sequenz und Strukturvergleich von XNIF (B2B-10B) mit NIF-ähnlichen Proteinen verschiedener Spezies. Dargestellt ist die aus dem offenen Leserahmen der XNIF-cDNA abgeleitete Aminosäuresequenz, sowie zu diesem in der Datenbank identifizierte homologe, hypothetische Proteinprodukte anderer Spezies. Zur Sequenz des XNIF-Proteins identische Aminosäuren sind durch einen Querstrich gekennzeichnet, fehlende Aminosäuren oder größere Lücken in der durchgehenden Sequenz sind durch Punkte markiert. Die Aminosäurepositionen der Proteine sind am linken bzw. rechten Rand der Sequenzen angeführt. In den hier gezeigten Aminosäurevergleich mit einbezogen wurden die homologen, zum Teil hypothetischen Proteine folgender Spezies: Gallus gallus (NIF Isoform T1; AF189773), Mus musculus (NIF-like protein; AJ344340), Homo sapiens (Hya22; NM_005808) sowie Xenopus (XOs4; AF441288). Angegeben sind jeweils auch die DatenbankZugangsnummern der Proteine. Der konservierte Bereich des NIF-Motifs ist in grau unterlegt, das kurze Proteinphosphatase-Motiv durch Umrahmung gekennzeichnet.

\subsubsection{Räumlich-zeitliche Expressionsanalyse von XNIF (B2B-10B) und Expression in Embryonalstadien und adulten Geweben}

Während das XNIF-Transkript in der in situ Hybridisierung sehr deutlich am vegetalen Kortex der Oozyte zu detektieren ist (vergl. Abb. 3.14, kann die RNA im 2- und 16Zellstadium sowohl in animalen wie auch in vegetalen Bereichen bzw. Blastomeren des sich entwickelnden Embryos nachgewiesen werden (Abb. 3.18 A). Während der Gastrulation kann in der in situ-Hybridisierung nur noch eine schwache und diffuse Expression der RNA detektiert werden (nicht gezeigt). Mit Beginn der Neurulation setzt jedoch die zygotische Expression der XNIF-RNA in den sich ausbildenden Somiten des Embryos ein (nicht gezeigt). Dieses gewebespezifische Expressionsmuster ist auch im Stadium 32 sehr deutlich erkennbar Abb. 3.18 B). Die Analyse der stadien- und gewebespezifischen Expression ergibt konstante Expressionsniveaus der RNA sowohl in den untersuchten Embryonalstadien als auch in den verschiedenen untersuchten Geweben des adulten Tieres Abb. 3.18C). 
A

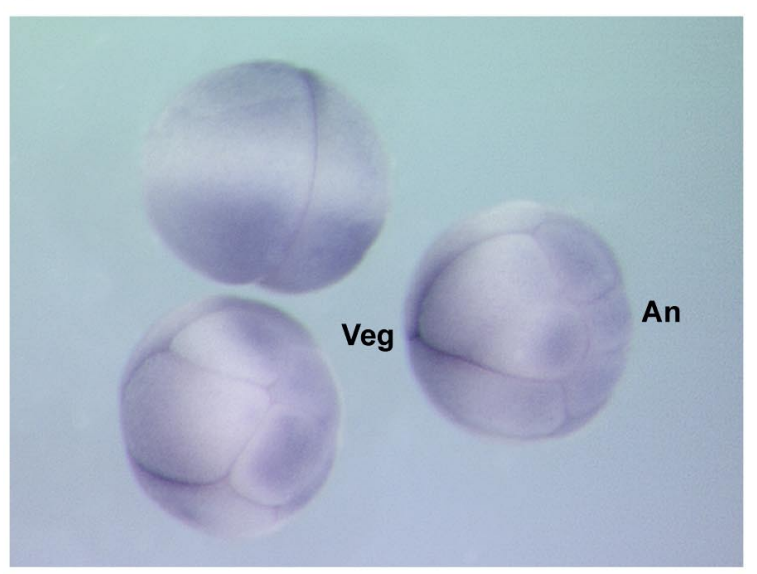

B

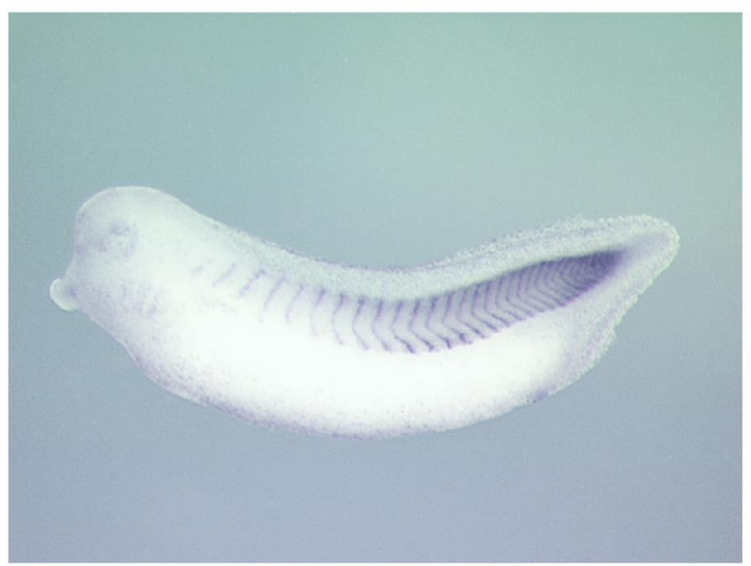

C

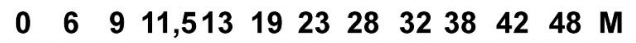
ov te mu br sc ey he gu sk li $\mathrm{K} M$ XNIF

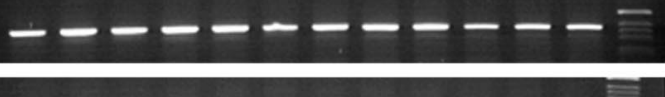

H4
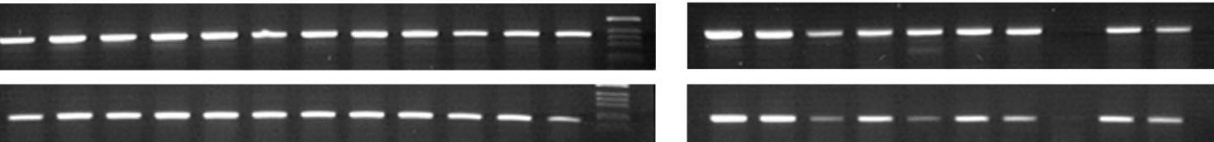

Abb. 3.18

Expression und Lokalisation von XNIF (B2B-10B) in verschiedenen Embryonalstadien und adulten Geweben. Gezeigt sind die in der in situ-Hybridisierung detektierten Lokalisationsund Expressionsmuster von der XNIF-RNA (Volllängen cDNA-Probe MC 119). A. 2- und 16Zellstadien; Animale (An) und vegetale (Veg) Bereiche des Embryos sind exemplarisch gekennzeichnet. B. Stadium 32. C. Der Nachweis des XNIF-Transkriptes in RNA-Präparationen verschiedener Embryonalstadien und adulter Gewebe erfolgte unter Verwendung spezifischer Oligonukleotide in der RT-PCR. In der Beschriftung über den DNA-Banden sind die Stadien der untersuchten Embryonen (Nieuwkoop und Faber, 1967) bzw. Gewebe des adulten Tieres angegeben (ov, Ovar; te, Testis; mu, Skelettmuskel; br, Gehirn; sc, Rückenmark; ey, Auge; he, Herz; gu, Darm; sk, Haut; li, Leber; K, $\mathrm{H}_{2} \mathrm{O}$-Kontrollreaktion; M, Molekulargewichtsstandard 1 kb-Leiter). Die zu erwartende PCRProduktlänge für XNIF-Transkripte beträgt $380 \mathrm{bp}$. Zur Kontrolle der eingesetzen RNA-Menge wurde ebenfalls die gleichmäßig und ubiquitär exprimierte Histon H4 RNA in der RT-PCR nachgewiesen (Produktlänge 200 bp).

\subsubsection{Die B2B-2B-RNA wird über einen neuartigen Lokalisationsweg am äquatoria- len Kortex der Oozyte angereichert}

Für die RNA des B2B-2B-Klons konnte in der in situ-Hybridisierung ein neuartiges, bisher nicht beschriebenes Lokalisationsmuster nachgewiesen werden. So ist das Transkript in Stadium V/VI Oozyten in einem äquatorialem Ring angereichert und nur als schwaches Farbsignal am vegetalen Kortex der Oozyte nachweisbar. Zur detaillierteren Analyse des Verteilungsweges der RNA wurden in situ-Hybridisierungen mit verschiedenen Stadien von Albino Oozyten durchgeführt. Während der frühen Oogenese kann dieses Transkript homogen im Zytoplasma verteilt nachgewiesen werden. Wie auch für das in dieser Arbeit isolierte spät lokalisierende Transkript 6E beschriebenen wurde, bleibt jedoch die mitochondriale Wolke in diesem Stadium von der Färbung ausgespart (Pfeile in Abb. 3.19 A). $\mathrm{Ab}$ dem Stadium II ist das Transkript in einem ringförmigen Bereich am Kortex der Oozyte nachzuweisen Abb. 3.19 B). Ein ähnliches Lokalisationsmuster konnte in frühen 
Oozytenstadien auch für die XPTB (A3A-11C)-RNA beschrieben werden (siehe Abb. 3.4 B). Während die XPTB-RNA jedoch in späteren Stadien über den Kortex der gesamten vegetalen Hemisphäre verteilt vorliegt, bleibt die B2B-2B-RNA bis zum Stadium VI der Oogenese in einer ringförmigen Region am Äquator der Oozyte nachweisbar und zeigt nur ein schwaches Farbsignal im Bereich des vegetalen Kortex (Abb. 3.19 C). Die B2B-2BRNA weist somit ein bisher unbekanntes Lokalisationsmuster auf und ist einem neuartigen, bisher nicht beschriebenem RNA-Verteilungsweg der Xenopus Oozyte zuzuordnen.

A

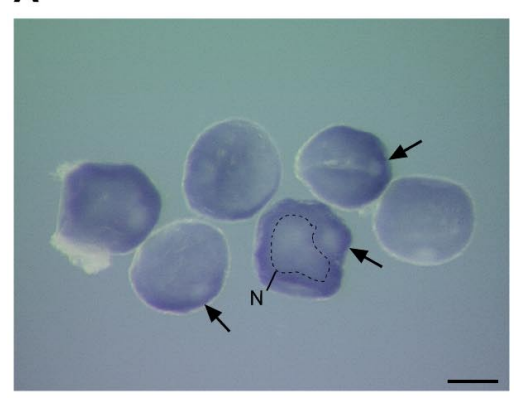

B

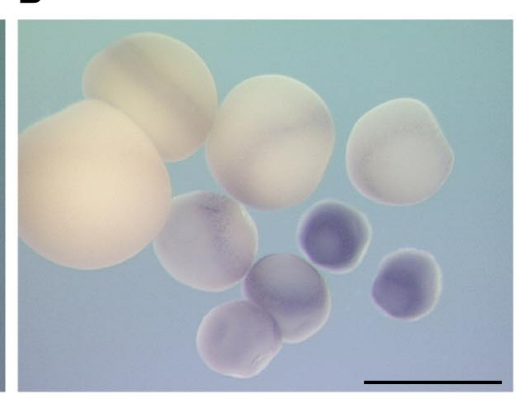

C

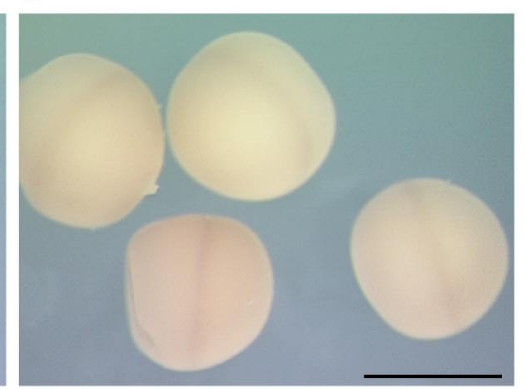

Abb. 3.19 Lokalisation der B2B-2B-RNA im Verlauf der Xenopus-Oogenese. Die Verteilung des endogenen B2B-2B-Transkriptes wurde in der whole mount in situ-Hybridisierung mit einer digoxygeninmarkierten, spezifischen antisense RNA-Sonde nachgewiesen (als Matrize diente der cDNAKlon MC 187). A. Zytoplasmatische Lokalisation der RNA in Stadium I Oozyten $(100-300 \mu \mathrm{m}$ im Durchmesser). Die Struktur der mitochondrialen Wolke bleibt von der Färbung ausgespart (Pfeile). Der Zellnukleus ist in einer Oozyte durch eine offene Umrandung exemplarisch gekennzeichnet. N, Nukleus; B. In Stadium II Oozyten (300-450 $\mu \mathrm{m}$ im Durchmesser; unten in der Abbildung) beginnt die Akkumulation des Transkriptes in einer ringförmigen Region des Kortex. Äquatorial-kortikale Lokalisation des Transkriptes in Stadium III-IV Oozyten (450-900 $\mu \mathrm{m}$ im Durchmesser, oberer Teil der Abbildung); C. Äquatoriale Lokalisation der B2B-2B-RNA in Stadium V-VI Oozyten (1000-1200 $\mu \mathrm{m}$ im Durchmesser). Der Maßstabsbalken entspricht ca. $100 \mu \mathrm{m}$ in (A) sowie ca. $1 \mathrm{~mm}$ in (B und C).

Der zu dieser äquatorial lokalisierten RNA zugehörige pTriplEx2-Plasmid-Klon trägt ein Insert von 1950 Nukleotiden Länge. In der Sequenzanalyse konnte kein offener Leserahmen identifiziert werden, so daß angenommen wurde, daß es sich um ein unvollständiges cDNA-Insert handelt. Mit der Methode der PCR-basierten Durchmusterung der Stadium V/VI Oozyten cDNA-Bibliothek konnte bislang kein längeres Fragment dieser cDNA identifiziert und isoliert werden. In der Datenbanksuche konnten keine homologen Nukleotidsequenzen oder längere EST-Klone identifiziert werden.

\subsubsection{Expression von B2B-2B in Embryonalstadien und adulten Geweben}

Mit der Fertilisierung des Eis und dem Einsetzen der ersten Zellteilungen des Embryos scheint es zu einer Neuverteilung der in der Oozyte ehemals äquatorial lokalisierten B2B2B-RNA zu kommen. Die kortikale Assoziation des Transkriptes scheint aufgehoben zu werden und eine schwache Expression des Transkriptes ist in der in situ-Hybridisierung nur mehr in den animalen Blastomeren des sich entwickelnden Embryos nachzuweisen 
Abb. 3.20 A). In Gastrula- und Neurula-Stadien ist die RNA in der in situ Hybridisierung nicht detektierbar (nicht gezeigt). Im Stadium 32 läßt sich eine sehr schwache Expression in neuralem Gewebe wie dem Auge, Gehirn sowie dem Rückenmark und den Somiten, nicht jedoch in Geweben endodermalen Ursprungs, beschreiben (Abb. 3.20 B). Die Analyse der stadien- und gewebespezifischen Expression ergibt konstante Expressionsniveaus der RNA sowohl in den untersuchten Embryonalstadien als auch in den verschiedenen untersuchten Geweben des adulten Tieres Abb. 3.20 C).

A

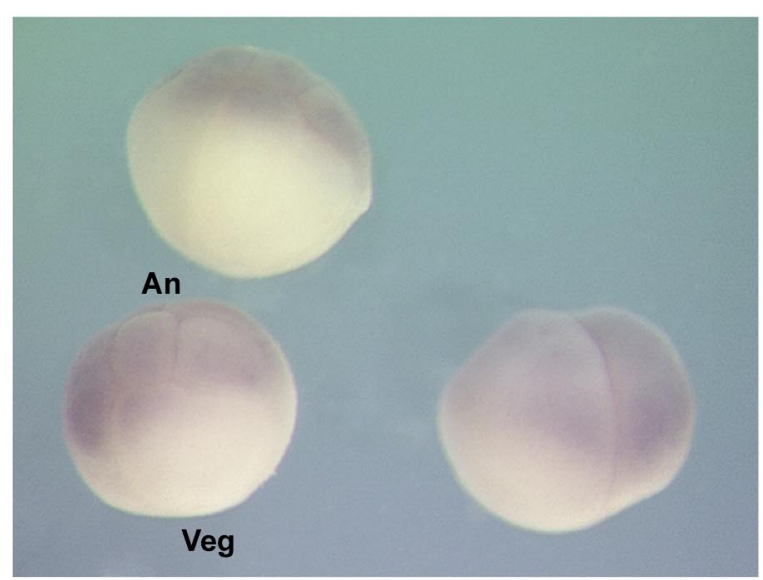

B

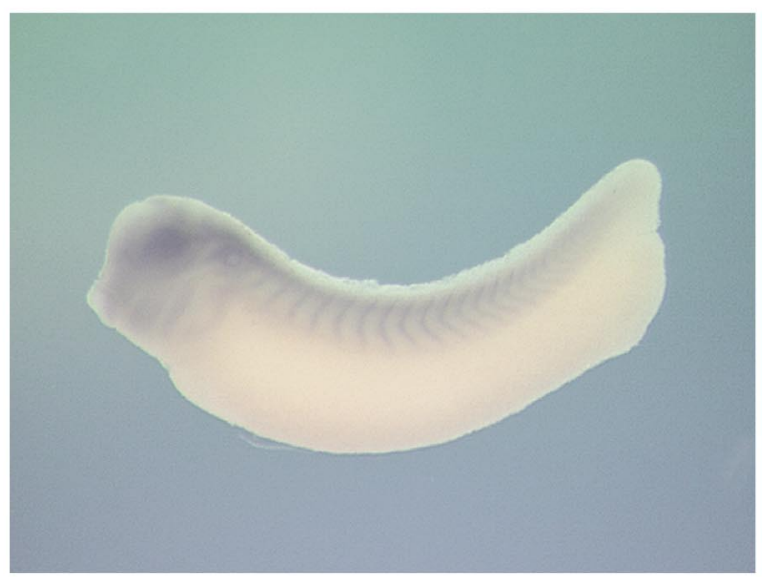

C

B2B-2B
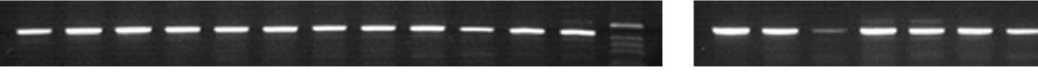

H4
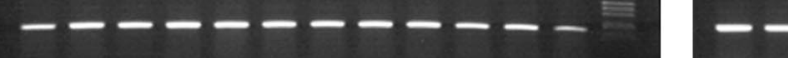

Abb. 3.20

Expression der 2B-RNA in Embryonalstadien und Analyse der stadien- und gewebespezifischen Expression. Endogene 2B-Transkripte wurden mittels digoxygeninmarkierter antisense RNA-Sonden in Embryonen verschiedener Stadien nachgewiesen. A. 2- und 16-Zellstadien; animale (An) und vegetale (Veg) Bereiche des Embryos sind exemplarisch gekennzeichnet. B. Expression der RNA im Embryonalstadium 32. C. Der Nachweis des B2B-2B-Transkriptes in RNA-Präparationen verschiedener Embryonalstadien und adulter Gewebe erfolgte unter Verwendung spezifischer Oligonukleotide in der RT-PCR. In der Beschriftung über den DNA-Banden sind die Stadien der untersuchten Embryonen (Nieuwkoop und Faber, 1967) bzw. Gewebe des adulten Tieres angegeben (ov, Ovar; te, Testis; mu, Skelettmuskel; br, Gehirn; sc, Rückenmark; ey, Auge; he, Herz; gu, Darm; sk, Haut; li, Leber; K, $\mathrm{H}_{2} \mathrm{O}$-Kontrollreaktion; M, Molekulargewichtsstandard 1 kb-Leiter). Die zu erwartende PCR-Produktlänge für B2B-2B-Transkripte beträgt 437 bp. Die in der RT-PCR verwendeten Oligonukleotide sind in der partiellen Nukleotidsequenz des Klons im Anhang 7.6 eingezeichnet. Zur Kontrolle der eingesetzen RNA-Mengen wurde ebenfalls die gleichmäßig und ubiquitär exprimierte Histon H4 RNA in der RT-PCR nachgewiesen (Produktlänge 200 bp). 


\subsection{In Mikroinjektionsexperimenten können die RNA-Lokalisationselemente in den untranslatierten Bereichen der Transkripte nachgewiesen werden}

In Injektionsexperimenten oder bei der Analyse von Deletionsmutanten konnten bisher für eine Vielzahl von lokalisierten RNAs verschiedener Spezies Sequenzen identifiziert und eingegrenzt werden, die für eine subzelluläre Lokalisation dieser Transkripte nötig und/oder hinreichend sind. Zur Untersuchung einzelner Subfragmente in vivo lokalisierter RNAs kann in Xenopus Oozyten das gekoppelte System der Injektion in vitro transkribierter, artifizieller mRNAs und der in vitro Kultur der Oozyten in angereichertem Medium angewandt werden. Hierzu können die injizierten Transkripte entweder unter Verwendung modifizierter Nukleotide (zumeist fluoreszin- oder digoxygeninmarkierte rUTPs) markiert und direkt über floureszenz- oder immunhistochemische Methoden nachgewiesen werden. Alternativ können die RNAs auch mit einer kurzen Reportersequenz versehen werden, über die dann in einer anschließenden in situ-Hybridisierungsreaktion die subzelluläre Lokalisation des injizierten RNA-Konstruktes indirekt nachgewiesen wird. Versuche der Lokalisation digoxygeninmarkierter injizierter RNA-Subfragmente waren im Rahmen dieser Arbeit nicht erfolgreich. Vermutlich beeinträchtigt die chemische Modifikation der RNAs die Ausbildung korrekter Sekundärstrukturen und somit auch die Interaktion mit Proteinen, die an der Lokalisation von RNAs beteiligt sind. Ähnliche Beobachtungen wurden auch von anderen Arbeitsgruppen beschrieben (Bullock und Ish-Horowicz, 2001; Wilkie und Davis, 2001 und J. Deshler, pers. Mitteilung). Zur Identifizierung der Lokalisationselemente der im Rahmen dieser Arbeit identifizierten neuen lokalisierten RNAs wurden stattdessen Subfragmente der entsprechenden cDNAs hinter ein 320 bp Fragment des offenen Leserahmens des bakteriellen lacZ-Gens kloniert. Diese Konstrukte dienten dann als Matrizen zur in vitro Synthese Monomethylguanosin-Capstruktur-enthaltender Transkripte, die anschließend in die Nuklei von Stadium II- bis IV Oozyten injiziert wurden. Wie in anderen Arbeiten beschriebene Mikroinjektionsversuche mit Xenopus Oozyten vermuten lassen, haben die Cap-Struktur der RNA und die mit ihr assoziierten Proteine eine den Export der RNAs stimulierende Funktion (Huang und Carmichael, 2001). Capenthaltende RNAs werden im Zellkern vom „Cap-Binding Complex“ CBC, welcher sich aus den beiden Proteinen CBP80 und CBP20 zusammensetzt, gebunden und nach Reifung des Ribonukleoproteinpartikels aktiv ins Zytoplasma der Zelle transportiert. Nach einer zwei- bis viertägigen Kultivierung der mit dem RNA-Fusionskonstrukt injizierten Oozyten in L15-Medium, das mit aufgereinigtem Frosch-Vitellogenin angereichert wurde, kann das Transkript dann unter Verwendung einer digoxygeninmarkierten lacZ-antisense RNASonde in der whole mount in situ-Hybridisierung detektiert werden. So kann zum Beispiel gezeigt werden, daß der 3'-untranslatierte Bereich der Vg1-mRNA die vegetale Lokalisation der lacZ-Reporter-RNA vermitteln kann, während der RNA-Fusionsanteil alleine nach Injektion homogen in der Oozyte verteilt vorliegt (Abb. 3.21 A und B). 

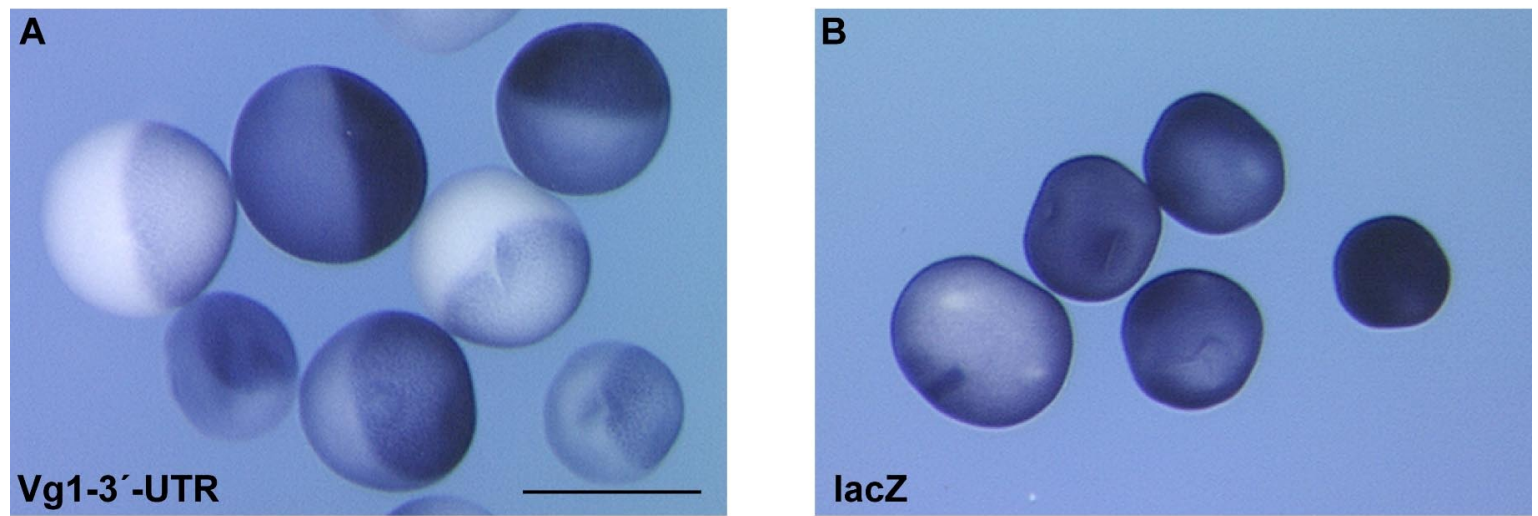

Abb. 3.21 Der 3'-untranslatierte Bereich der Vg1-mRNA vermittelt die vegetale Lokalisation eines lacZ-RNA-Reporters. M7G-Capstruktur-enthaltende in vitro generierte Transkripte der LacZSequenz sowie des lacZ-Vg1-3'- UTR-Fusionskonstruktes wurden in Zellkerne von Stadium III-IV Oozyten injiziert. Nach drei Tagen Inkubation, in mit Vitellogenin angereichertem L15-Medium, erfolgte die Detektion der injizierten Transkripte in der whole mount in situ-Hybridisierung mit einer digoxygeninmarkierten lacZ antisense RNA-Sonde. Der angegebene Maßstabsbalken entspricht ca. $600 \mu \mathrm{m}$.

\subsubsection{Das 3'-UTR des spät lokalisierten 6E Transkriptes enthält ein 75 Nukleotide langes RNA-Lokalisationselement}

Um das RNA-Lokalisationselement der spät lokalisierten 6E-RNA zu identifizieren und funktionell einzugrenzen, wurden zunächst RNA-Konstrukte injiziert, die entweder die Volllängen-RNA, den offenen Leserahmen (dieses Konstrukt enthält auch den sehr kurzen 5 '-untranslatierten Bereich) oder die 3'-nichtkodierenden Sequenzen, fusioniert an den lacZ-RNA-tag, enthielten (schematisch dargestellt in Abb. 3.22 unten). Wie nach Detektion der RNAs mittels der in situ-Hybridisierung zu erkennen ist, wird die Volllängen-RNA zum vegetalen Pol der Oozyte transportiert und dort, entsprechend der endogenen RNA, am Kortex der gesamten vegetalen Hemisphäre angereichert (vergl. Abb. 3.1. Die 6EVolllängen-RNA enthält also ein Lokalisationssignal, das auch die vegetale Lokalisation einer synthetischen RNA vermitteln kann (Abb. 3.22A). Wird nur der offene Leserahmen der RNA injiziert, so kann keine Lokalisation des Transkriptes nachgewiesen werden (Abb. 3.22 B). Der translatierte Bereich der RNA trägt also keine Sequenzen, die die subzelluläre Anreicherung des Transkriptes vermitteln können. Wird der 346 Nukleotide umfassende 3'-untranslatierte Bereich injiziert, so kann eine effiziente Akkumulation des Transkriptes an der vegetalen Hemisphäre der Oozyte identifiziert werden Abb. 3.22 C). Das Verteilungsmuster entspricht hierbei ebenfalls demjenigen, daß auch für das endogen vorliegende Transkript oder nach Injektion der synthetischen Volllängen-RNA nachgewiesen werden kann. Der 3'-nichtkodierende Bereich enthält also diejenigen Sequenzelemente, die vermutlich auch die vegetale Lokalisation der endogenen 6E-RNAs vermitteln. 

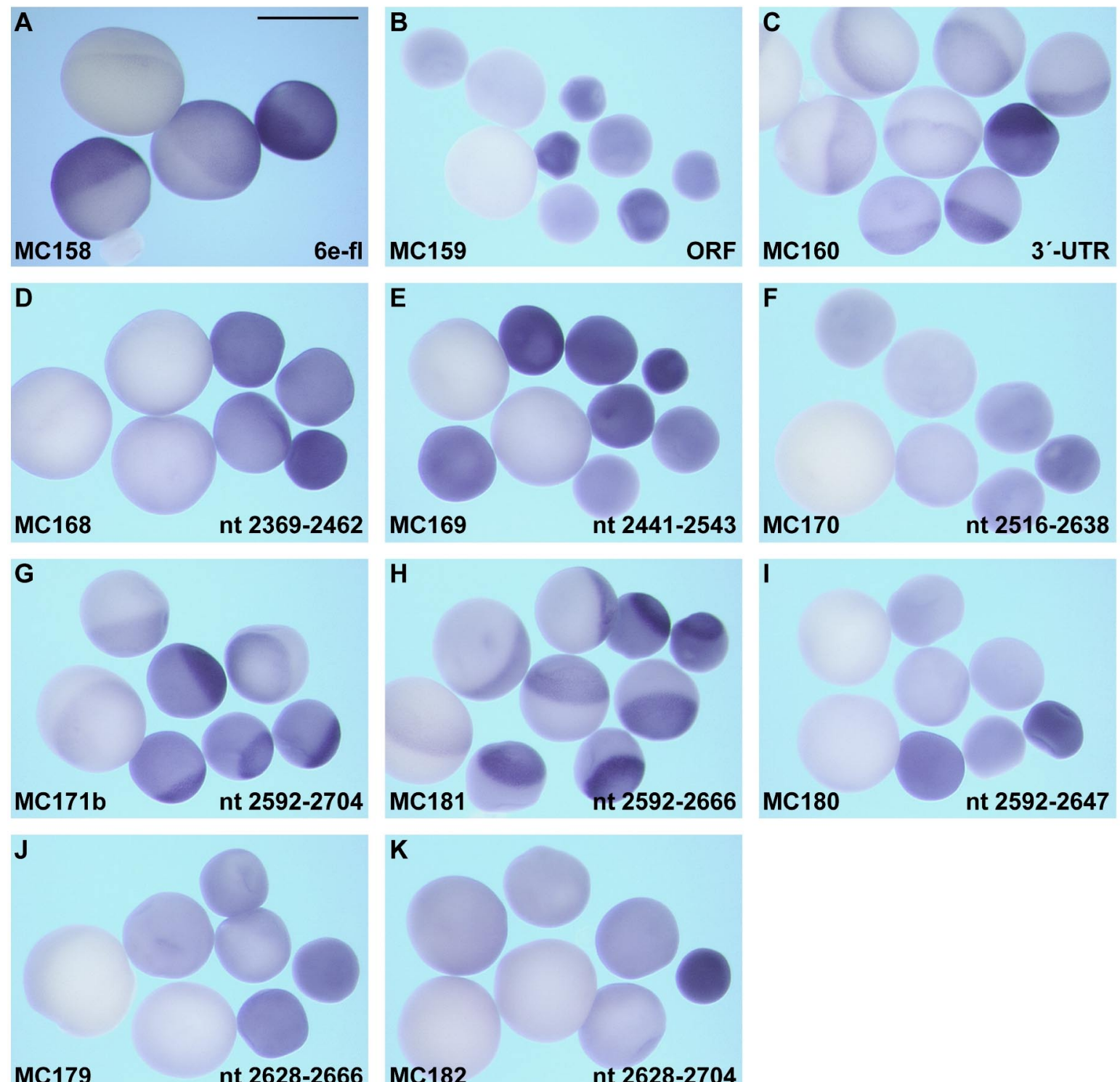

\section{MC179}

nt 2628-2666

MC182

nt 2628-2704

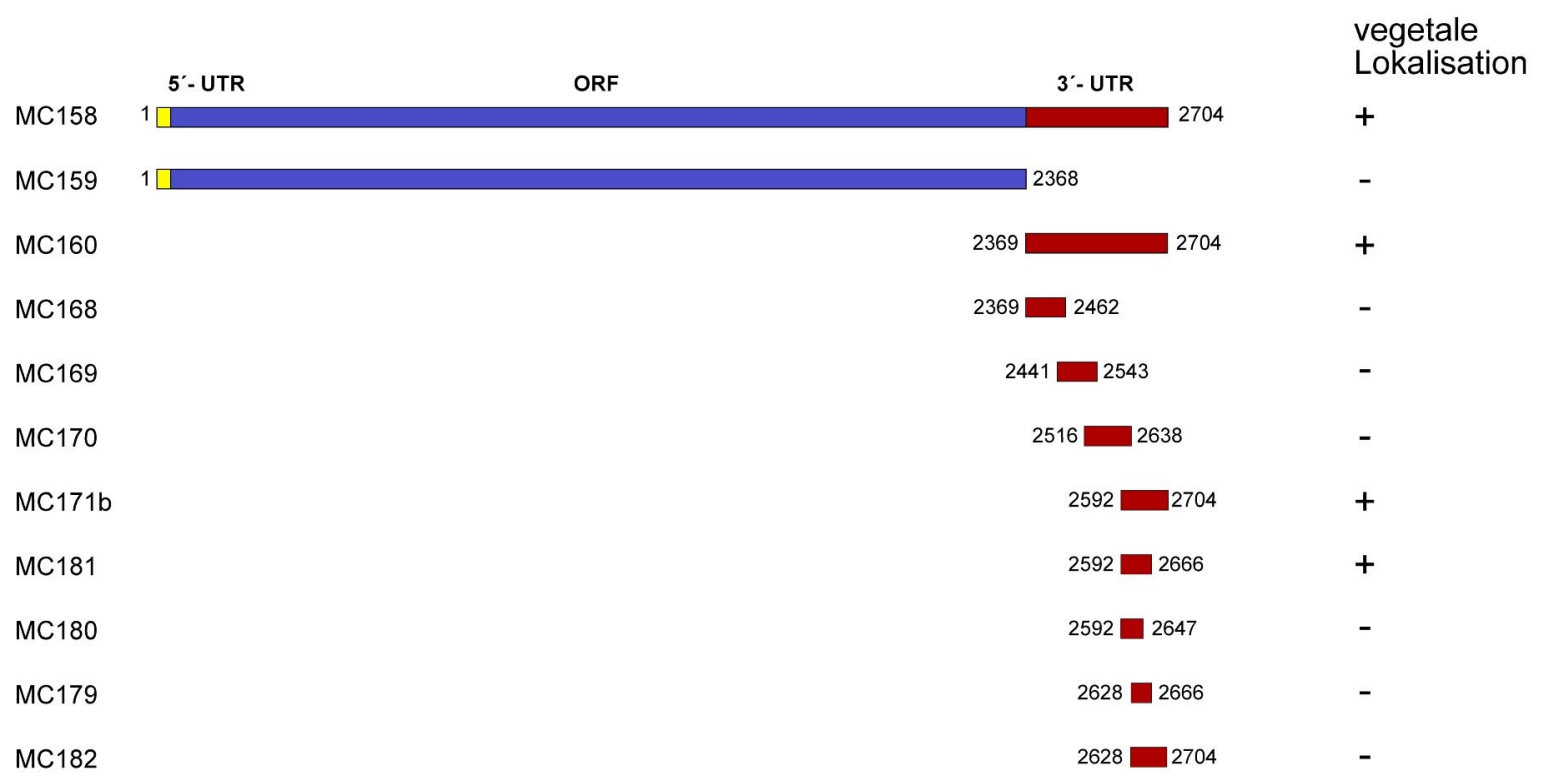


Abb. 3.22 Die 6E-RNA enthält ein 75 Nukleotide umfassendes Lokalisationselement im 3'untranslatierten Bereich. Subfragmente der 6E-cDNA wurden an den einen lacZ-Reporteranteil fusioniert und zur Analyse der Lokalisationssequenzen davon in vitro generierte Transkripte in Kerne von Stadium II-IV Oozyten injiziert. Nach dreitägiger Inkubation wurde die Verteilung dieser RNAs durch in situ-Hybridisierung mit einer lacZ-spezifischen, digoxygeninmarkierten antisense RNASonde detektiert. Angegeben sind die systematischen Namen der Fusionskonstrukte und die beinhaltenden Nukleotide der cDNA-Sequenz. Der in der Abbildung angegebene Maßstabsbalken entspricht ca. $500 \mu \mathrm{m}$. Unten in der Abbildung sind die Ergebnisse der Injektionsexperimente schematisch zusammengefaßt. Der 5'-untranslatierte Bereich (gelb), die kodierende Region (blau) sowie der 3'untranslatierte Bereich (rot) der 6E-RNA sind durch unterschiedliche Farbgebung gekennzeichnet. Die jeweiligen Fragmentgrößen der RNAs, die an den lacZ-Reporter fusioniert wurden, ergeben sich aus den angegebenen Nukleotidpositionen der cDNA-Sequenz. Zusätzlich sind die systematischen Namen der entsprechenden Fusionskonstrukte angegeben. Die Fähigkeit der RNA-Anteile die vegetale Akkumulation der lacZ-Reporter-RNA zu vermitteln ist mit einem + bzw. - angegeben.

Um die genauere Position des Lokalisationselements der 3'-untranslatierten Sequenz zu bestimmen, wurden zunächst vier überlappende Subfragmente derselben generiert und an den lacZ-tag fusioniert (Abb. 3.22 unten). Nach Injektion der entsprechenden in vitro transkribierten RNAs kann gezeigt werden, daß nur das am äußersten 3'-Ende des Transkriptes gelegene Fragment Abb. 3.22 G; nt 2592-2704) eine vegetale Lokalisation vermittelt, während RNA-Fusionen die weiter 5' gelegene Bereiche des 3'-UTRs enthalten, homogen über die Oozyte verteilt vorliegen Abb. 3.22 D, E und F). Werden weitere 38 Nukleotide am 3'-Ende des eingegrenzten Fragmentes deletiert, so ist das resultierende 75 Nukleotide lange RNA-Fragment Abb. 3.22 H; nt 2592-2666) immer noch in der Lage eine Anreicherung der Reporter-RNA am vegetalen Kortex zu vermitteln.

Unter Verwendung des von M. Zuker entwickelten computerbasierten Analyseprogramm Mfold (Mathews et al., 1999; Zuker et al., 1999) kann für dieses 75 Nukleotide lange RNA-Fragment die Ausbildung einer zwei Haarnadelstrukturen enthaltenden Sekundärstruktur vorhergesagt werden Abb. 3.23. Weiterhin konnten auch in vorläufigen enzymatischen Strukturanalyseexperimenten Hinweise auf die Ausbildung von RNADoppelsträngen, die den vorhergesagten Haarnadelstrukturen entsprechen könnten, gewonnen werden (nicht gezeigt). Die funktionelle Bedeutung der beiden vorhergesagten Haarnadelstrukturen des 75 Nukleotide langen RNA-Lokalisationselementes der 6E-RNA sollte deshalb auch in weiteren Deletionsexperimenten untersucht werden. Nach Deletion von 19 Nukleotiden am 3'-Ende des Lokalisationselementes wird dieses zerstört und das Transkript kann nach Injektion nicht mehr vegetal lokalisiert werden sondern liegt homogen über das Zytoplasma der Oozyte verteilt vor Abb. 3.22 I; nt 2592-2647). Diese Deletion betrifft auch die von den Nukleotiden 2630-2659 ausgebildete, vorhergesagte Haarnadelschleife des RNA-Elementes Abb. 3.23. Um auch die 5' gelegene Grenze des Lokalisationselementes nachzuweisen, wurde weiterhin ein Konstrukt kloniert, bei dem 36 Nukleotide am 5' -Ende des Lokalisationselementes deletiert wurden Abb. 3.22 J; nt 26282666). Mit dieser Deletion wird auch die kurze, von den Nukleotiden 2619-2628 ausgebildete, Haarnadelschleife des RNA-Elementes entfernt Abb. 3.23. Nach Injektion des 
entsprechenden Transkriptes kann nun keine vegetale Lokalisation der RNA mehr nachgewiesen werden. Ebenso wird auch das die Nukleotide 2628-2704 enthaltende Konstrukt, bei dem diese vorhergesagte Haarnadelstruktur ebenfalls deletiert wurde, nicht mehr lokalisiert, sondern liegt homogen über die Oozyte verteilt vor Abb. 3.22 K).

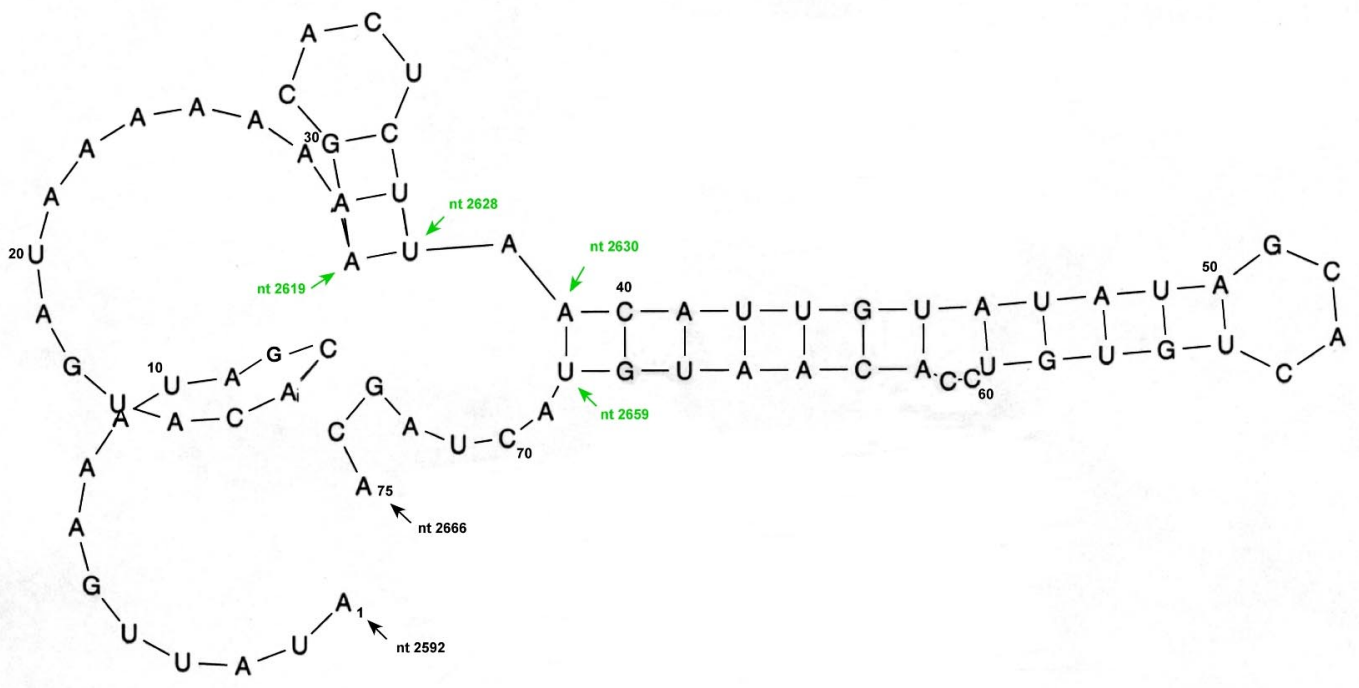

Abb. 3.23 Darstellung der hypothetischen Sekundärstruktur des 6E-RNA-Lokalisationselementes. Die 75 Nukleotide lange Sequenz des in Injektionsexperimenten ermittelten 6E-RNALokalisationselementes wurde mit dem von M.Zuker entwickelten computerbasierten Analyseprogramm Mfold auf die Ausbildung möglicher RNA-Sekundärstrukturen hin untersucht und unter Verwendung des RNAdraw-Programms bearbeitet und dargestellt. Angegeben sind die Positionen des 75 Nukleotide langen RNA-Lokalisationselementes. Nukleotidpositionen, die den Anfangs- und Endpunkten der hypothetischen Haarnadelstrukturen entsprechen, sind in grün angegeben. Für die 5 ' - und 3'-Bereiche des RNA-Elementes konnten keine Sekundärstrukturen vorhergesagt werden.

Das RNA-Lokalisationselement, welches hinreichend ist um den vegetalen Transport einer artifiziellen, injizierten Reporter-RNA zu vermitteln, konnte somit auf ein 75 Nukleotide umfassendes Fragment (nt 2592-2666) eingegrenzt werden. Vermutlich bildet dieses charakteristische Sekundärstrukturen aus, die für den Lokalisationsprozeß essentiell zu sein scheinen. Die Ergebnisse der Injektionsexperimente sind zusammenfassend in Abb. 3.22 unten dargestellt.

\subsubsection{Die früh lokalisierende XNIF-RNA enthält zwei funktionelle RNA- Lokalisationselemente im 5'-untranslatierten Bereich}

Zur ersten Eingrenzung der Lage des RNA-Lokalisationssignals der XNIF-RNA wurden auch in diesem Fall die Volllängen cDNA sowie Subfragmente derselben, die entweder nur den 5'-untranslatierten Bereich, den offenen Leserahmen, oder den 3 '-untranslatierten Bereich enthalten, an das lacZ-Fragment fusioniert. Nach Injektion der entsprechenden in vitro transkribierten RNAs kann nachgewiesen werden, daß die Volllängen-RNA, sowie 
das Transkript, welches den 5'-untranslatierten Bereich enthält, effizient zum vegetalen Pol der Oozyte transportiert werden Abb. 3.24 A und B). Die Lokalisation der Transkripte ist in den meisten Fällen (in Stadium II und frühen Stadium III Oozyten) auf die Spitze der vegetalen Hemisphäre beschränkt und entspricht somit derjenigen, die auch für die endogen vorliegende mRNA nachgewiesen werden konnte (vergl. Abb. 3.14. Es kann also angenommen werden, daß der 5'-untranslatierte Bereich das Lokalisationssignal der mRNA enthält. Nach Injektion in spätere Stadium III und frühe Stadium IV Oozyten ist die Lokalisation des Transkriptes nicht mehr nur auf die äußere Spitze des vegetalen Kortex beschränkt, sondern scheint hier, ähnlich wie RNAs vom spät lokalisierten Typ, einen weiteren Bereich der vegetalen Hemisphäre einzunehmen. RNA-Konstrukte, die den offenen Leserahmen oder den 3'-untranslatierten Bereich fusioniert an den RNA-tag enthalten, werden nicht lokalisiert und liegen homogen über die Oozyte verteilt vor Abb. 3.24C und D). Zur weiteren Eingrenzung des im 5'-UTR gelegenen Lokalisationselementes wurden fünf überlappende Subfragmente mit einer jeweiligen Größe von ca. 300 Nukleotiden generiert und auf ihre Fähigkeit die vegetale Lokalisation der Reporter-RNA zu vermitteln hin untersucht. Es zeigt sich, daß sowohl das die Nukleotide 252-551 der cDNA enthaltende Fragment, als auch das die Nukleotide 1002-1308 umfassende Fragment, nach Injektion am vegetalen Pol der Oozyte nachgewiesen werden können Abb. 3.24 F und I; LE-1 und LE-2). Letzteres vermittelt jedoch einen weniger effizienten Transport, da die Lokalisation dieser Transkripte nicht auf die vegetale Hälfte der Oozyte beschränkt ist, sondern dieses zu einem gewissen Anteil auch ubiquitär im Zytoplasma vorliegt. Alle anderen untersuchten Fragmente des 5'-UTRs vermitteln keine Lokalisation (Abb. 3.24 E, G und H). Da das 5 '-gelegene Lokalisationselement mit 300 Nukleotiden noch einen relativ großen Bereich der cDNA umfaßt, wurde versucht, die bezüglich der Lokalisation des Transkriptes hinreichenden Sequenzen weiter einzugrenzen. Es wurden zwei Subfragmente des Fragmentes kloniert und im Injektionsexperiment untersucht. Während das die Nukleotide 415-551 enthaltende RNA-Fragment homogen über den gesamten Kortex der Oozyte verteilt vorliegt, wird das 130 Nukleotide lange 5'-Subfragment, das die Nukleotide 252-381 umfaßt, zum vegetalen Kortex transportiert (vergl. J und K in Abb. 3.24. Dieses schien in den Injektionsexperimenten jedoch einen etwas weniger effektiven Transport zu vermitteln, als das die Nukleotide 252-551 umfassende Element. Auch hier ist zu beobachten, daß die Lokalisation des Transkriptes nach Injektion in spätere Oozytenstadien einen weiteren Bereich des vegetalen Kortex umspannt als dies nach Injektion in frühere Oozytenstadien oder bei der Detektion endogener XNIF-Transkripte der Fall ist. Mit den hier beschriebenen Injektionsexperimenten konnte nachgewiesen werden, daß die früh lokalisierende XNIF-RNA zwei Subelemente besitzt (Nukleotide 252-381 bzw. 1002-1308 der cDNA) die hinreichend sind, um den vegetalen Transport und die kortikale Lokalisation einer chimären Reporter-RNA zu vermitteln. Die Ergebnisse der Injektionsexperimente sind in der unteren Hälfte der Abb. 3.24 schematisch zusammengefaßt. 
A

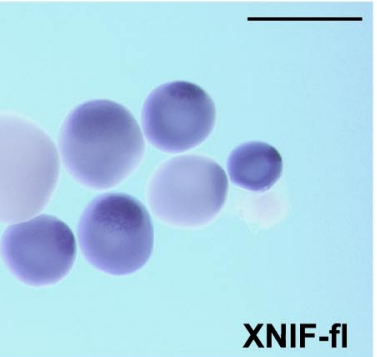

MC154

D

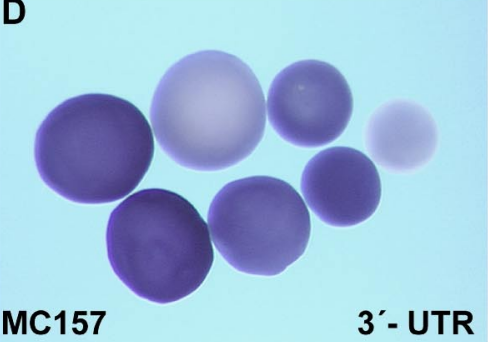

G

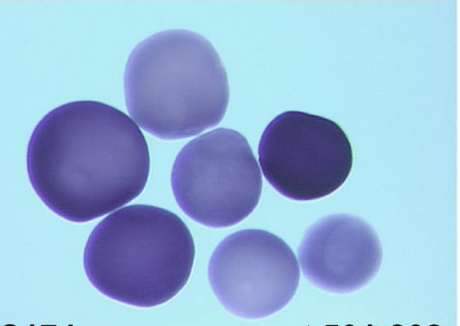

MC174

nt 501-802

J
B

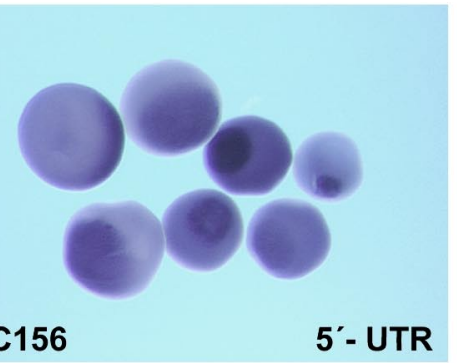

E

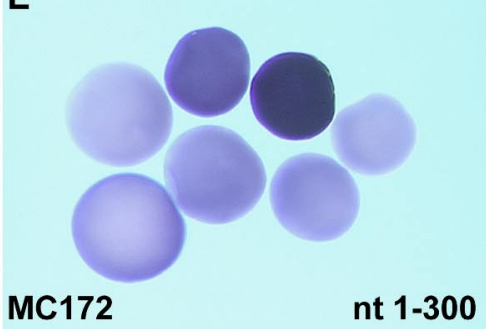

H

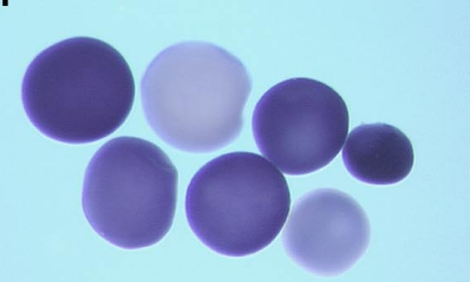

MC175

nt 752-1052

K

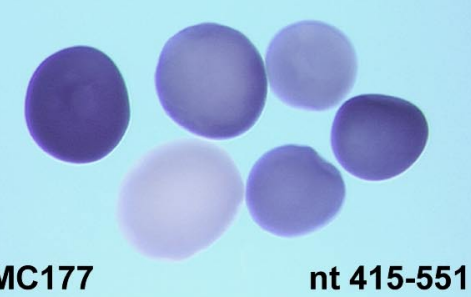

nt $415-551$
C

MC152 ORF

$F$

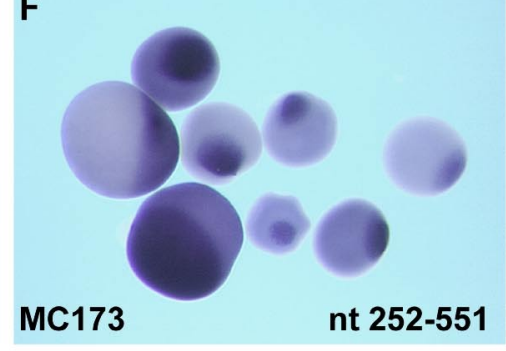

I

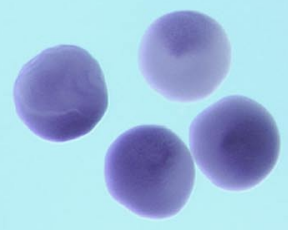

MC176

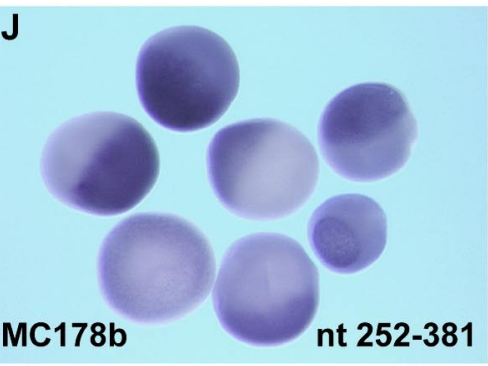

vegetale

Lokalisation

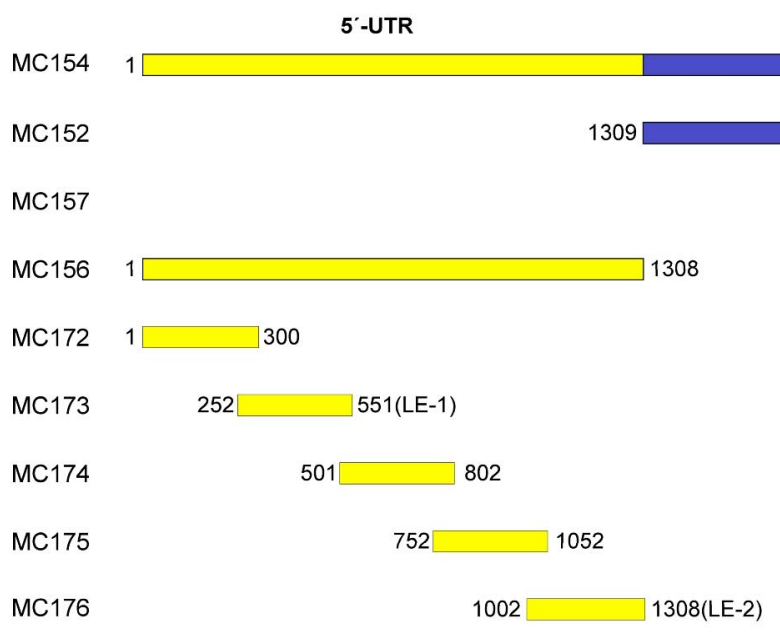

3'-UTR

ORF

2601

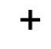

2136

2137

2601

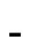

$+$

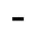

$+$

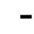

$(+)$

MC178b $\quad 252 \square 381$

MC177

$415 \square 551$ 
Abb. 3.24 Der 5'-untranslatierte Bereich der XNIF (B2B-10B)-RNA enthält zwei RNALokalisationselemente. Die Volllängen XNIF cDNA bzw. die angegebenen Subfragmente derselben wurden an den lacZ-Fusionsanteil kloniert und davon in vitro transkribierte chimäre Transkripte in Stadium II-IV Oozyten injiziert. Nach drei Tagen Inkubation in Oozyten Kulturmedium wurde die Verteilung der RNAs dann in der in situ-Hybridisierung unter Verwendung einer digoxygeninmarkierten lacZ-antisense RNA-Probe nachgewiesen. Angegeben sind die systematischen Namen der Fusionskonstrukte und die beinhalteten Nukleotide der cDNA-Sequenz. Der angegebene Maßstabsbalken entspricht ca. $500 \mu \mathrm{m}$. Eine schematische Übersicht über die injizierten XNIF-Fragmente und deren Lokalisationsfähigkeit ist in der unteren Hälfte der Abbildung angegeben. 5'- (gelb) bzw. 3'untranslatierter Bereich (blau) sowie der offene Leserahmen (rot) der 10B-RNA sind durch unterschiedliche Farbgebung kenntlich gemacht. Angegeben sind der jeweilige Konstruktname sowie die entsprechenden Nukleotidsequenzen der cDNA, die an die lacZ-Reportersequenz fusioniert wurden. Die Lokalisationsfähigkeit der RNA-Fragmente ist durch ein + bzw. - gekennzeichnet; eine weniger effiziente Lokalisationsfähigkeit ist durch ein $(+)$ vermerkt.

\subsubsection{Das 3'-UTR der früh lokalisierten DEAD-South mRNA enthält zwei Lokalisa- tionselemente}

Um das RNA-Lokalisationselement der in dieser Arbeit isolierten früh lokalisierenden DEADSouth-Isoform (B2B-9D) einzugrenzen, wurden zunächst ebenfalls jeweils die Volllängen cDNA, der offene Leserahmen, sowie der 3'-untranslatierte Bereich an den lacZReporter fusioniert und davon in vitro generierte, synthetische RNAs in die Kerne von Stadium II-IV Oozyten injiziert. Sowohl das Volllängenkonstrukt, als auch der 3'untranslatierte Bereich der RNA werden am vegetalen Pol der Oozyte lokalisiert Abb. 3.25 A und C), wohingegen das Transkript, das nur den offenen Leserahmen enthält, nach Injektion homogen über die gesamte Oozyte verteilt vorliegt (Abb. 3.25B). Das Lokalisationssignal der DEADSouth-RNA befindet sich also im 3'-untranslatierten Bereich des Transkriptes. Ähnlich wie dies auch schon bei der Analyse der ebenfalls früh lokalisierten XNIF-RNA beobachtet werden konnte, ist die Lokalisation des endogenen Transkriptes nur nach Injektion in Stadium II Oozyten nachzustellen; wird die Reporter-RNA in spätere Stadium III Oozyten injiziert, so wird diese, ähnlich der spät lokalisierenden RNAs, auf einen weiteren Bereich des vegetalen Kortex verteilt (vergl. Abb. 3.9 und Abb. 3.24. Interessanterweise stellte sich auch in mehrfach wiederholten Injektionsexperimenten heraus, daß die Volllängen RNA weit weniger effizient transportiert und lokalisiert wird als der, in parallel durchgeführten Injektionsexperimenten untersuchte, 3'-untranslatierte Bereich oder Subfragmente desselben. Zur weiteren Eingrenzung des im 3'-untranslatierten Bereich gelegenen Transportsignals wurden wiederum sechs überlappende Fragmente desselben subkloniert und die entsprechenden in vitro transkribierten RNAs auf ihre subzelluläre Verteilung hin untersucht. Hierbei zeigt sich, daß zwei der fünf generierten Fragmente die vegetale Lokalisation der Reporter-RNA vermitteln können Abb. 3.25 E und G). Diese Fragmente umfassen jeweils die Nukleotide 1682-1980 und 2181-2490 der cDNA-Sequenz (siehe auch Abb. 3.25 II). Alle anderen RNA-Subfragmente enthalten keine Lokalisationssequenzen und werden nach Injektion nicht am vegetalen Pol angereichert, sondern liegen homogen über die Oozyte verteilt vor Abb. 3.25 D, F, H und I). 
I.
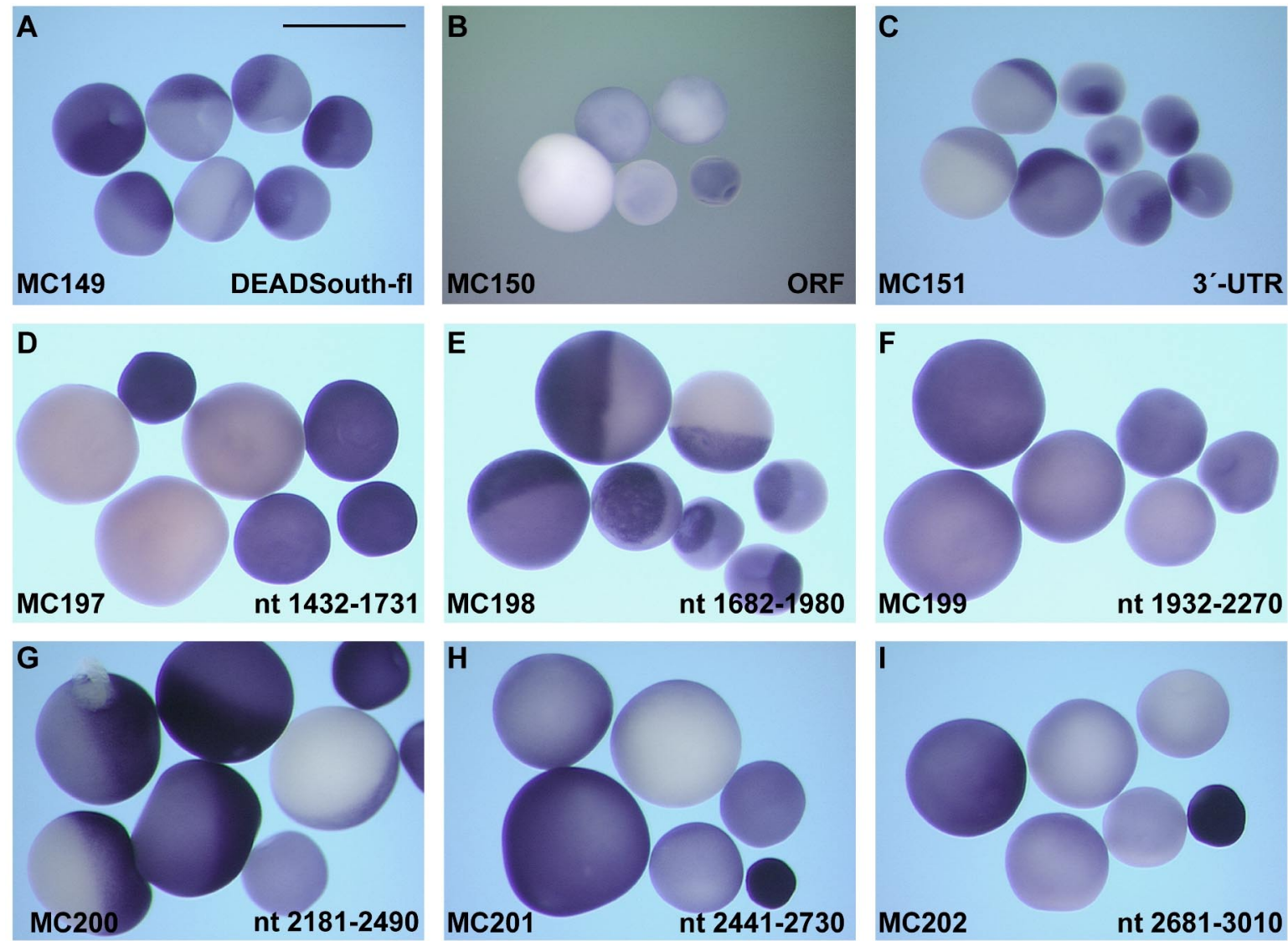

MC199

nt 1932-2270
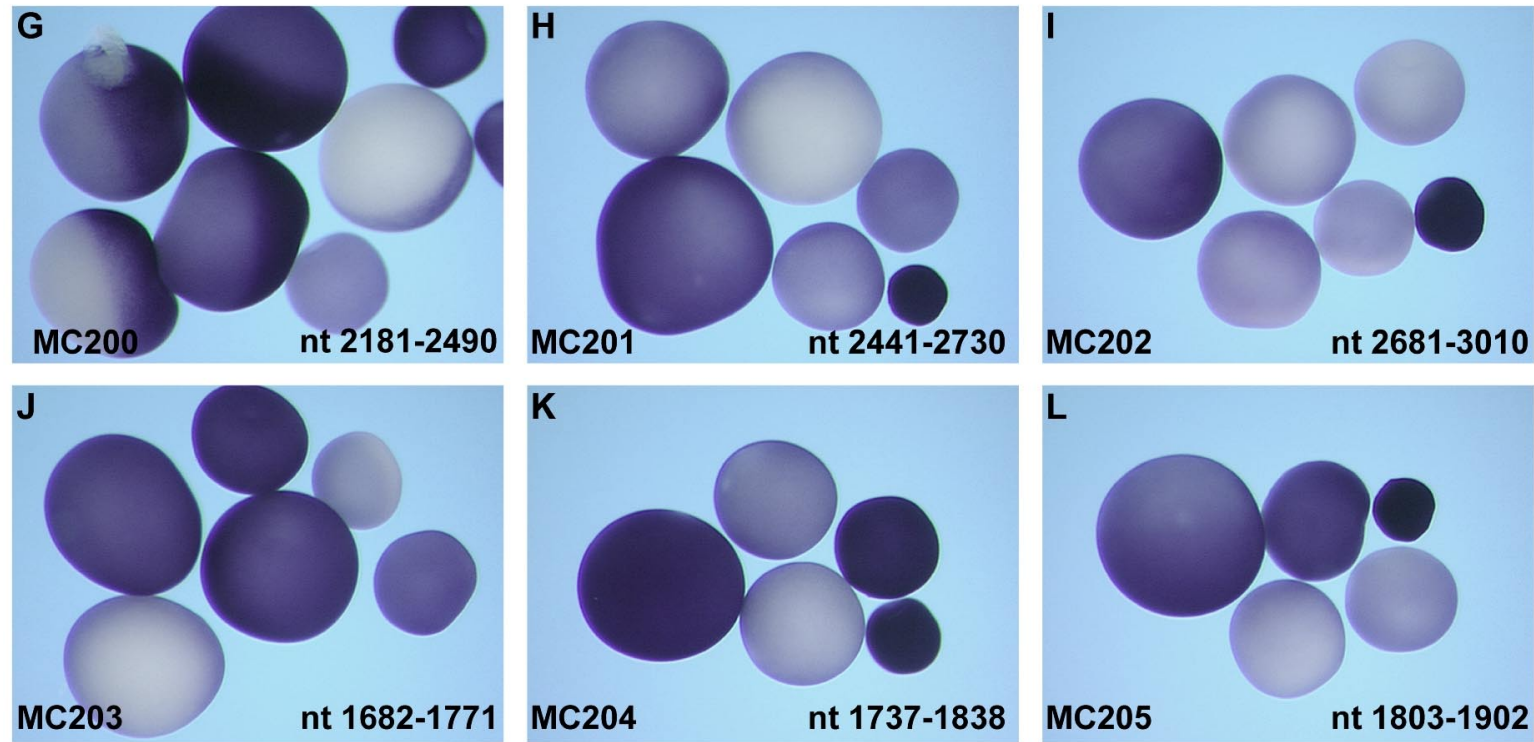

M
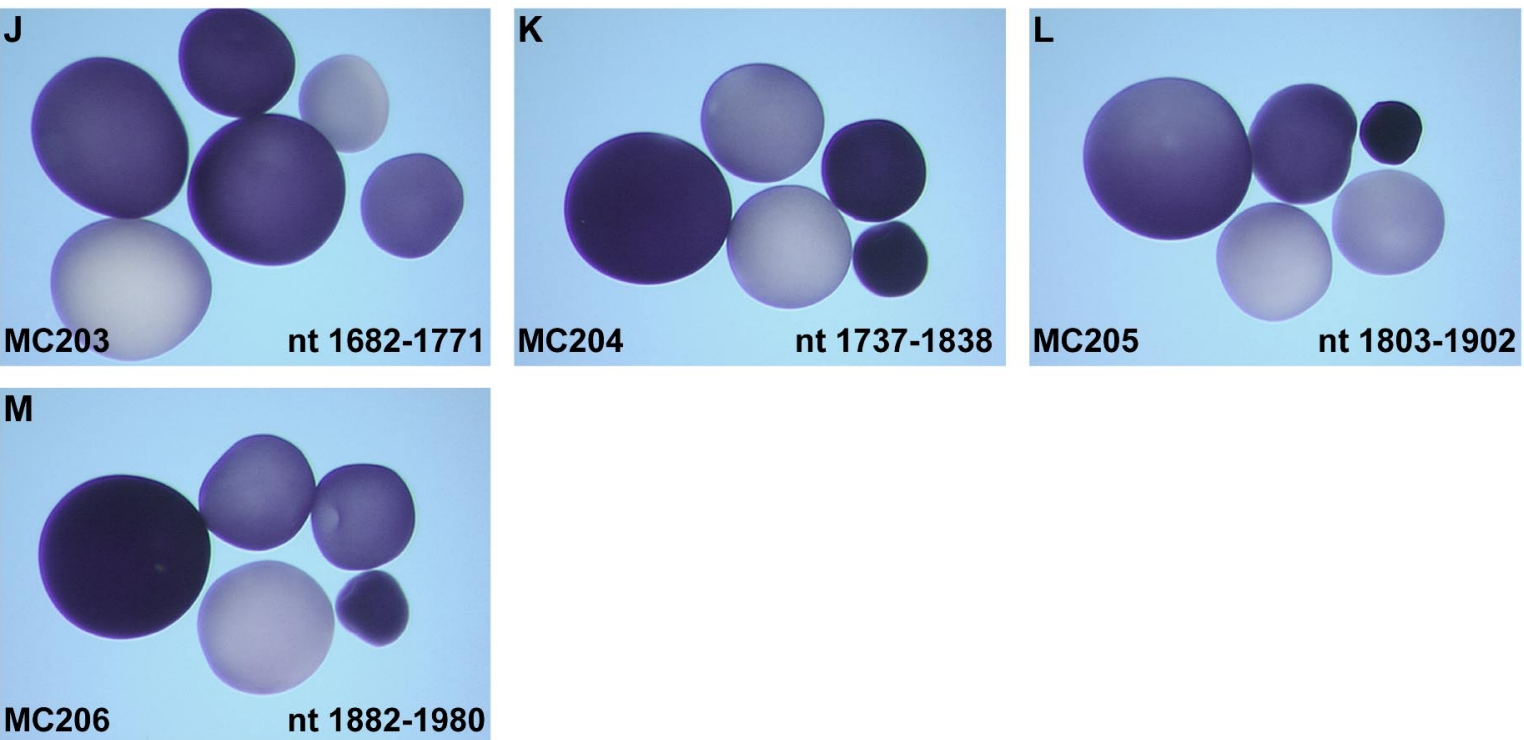

nt $\mathbf{1 8 8 2 - 1 9 8 0}$ 
II.

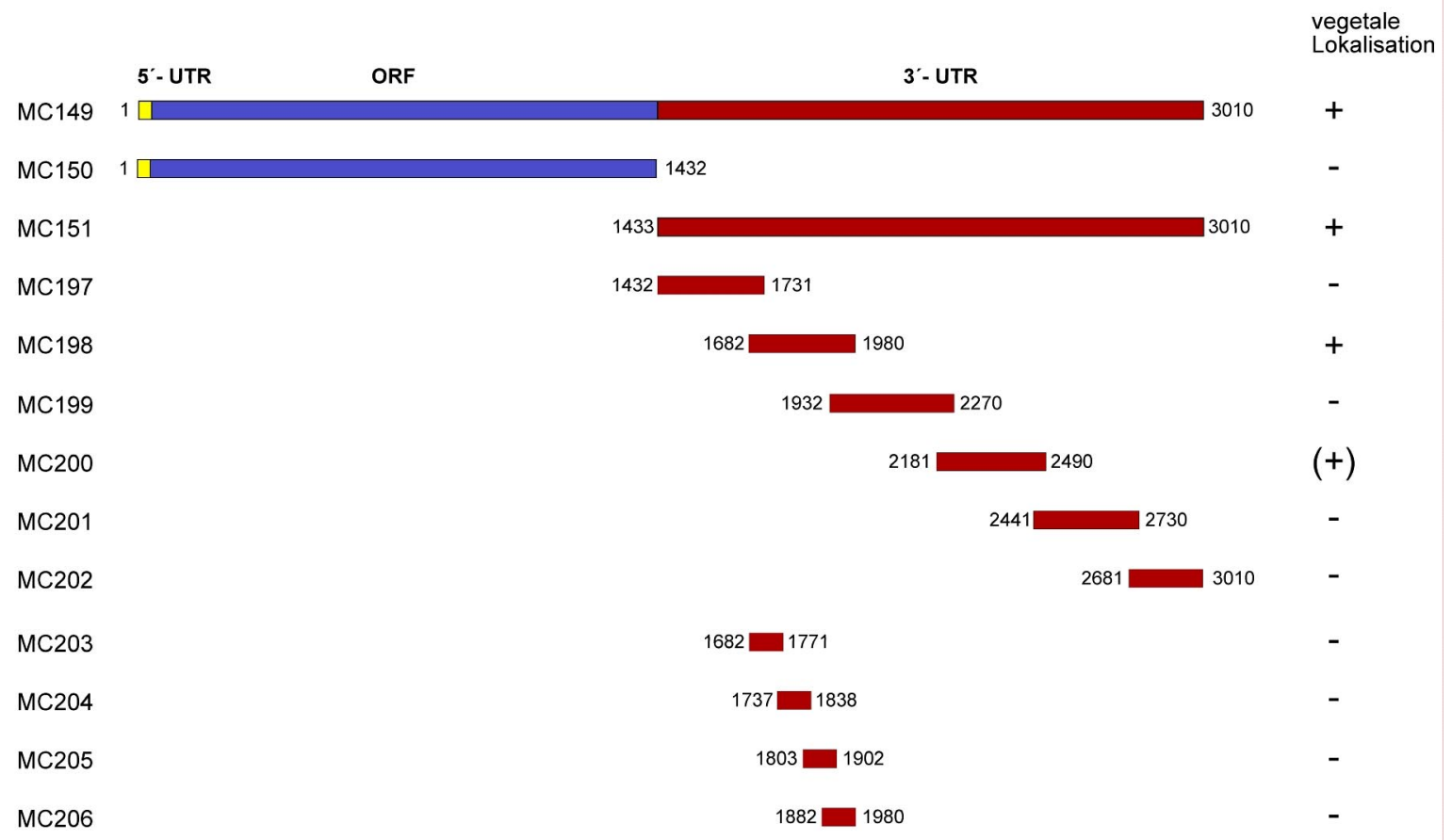

Abb. 3.25 Das 3'-UTR der DEADSouth-RNA enthält zwei Lokalisationselemente. I. Die Volllängen DEADSouth (B2B-9D) cDNA, der kodierende Bereich sowie der 3'-untranslatierte Bereich und Subfragmente desselben wurden an den lacZ-Reporter fusioniert und davon in vitro generierte Transkripte in Stadium II-IV Oozyten injiziert. Nach drei Tagen Inkubation in vitellogeninhaltigem Kulturmedium wurde die Verteilung der Transkripte in der whole mount in situ-Hybridisierung nachgewiesen. Angegeben sind die systematischen Namen der Fusionskonstrukte und die beinhalteten Nukleotide der cDNA-Sequenz. Der angegebene Maßstabsbalken entspricht ca. $500 \mu \mathrm{m}$. II. Zusammenfassung der Ergebnisse der DEADSouth-Injektionsexperimente. Angegeben sind jeweils der Name des lacZ-Fusionskonstruktes und die aus der Volllängen cDNA-Sequenz abgeleitete Anfangsund Endnukleotidposition der Fragmente. 5'-UTR(gelb), kodierender Bereich (blau) und 3'untranslatierter Bereich (rot) sind durch unterschiedliche Farbgebung in der schematischen Darstellung der Konstrukte hervorgehoben. Die Lokalisationsfähigkeit der RNA-Fragmente ist durch ein + bzw. - gekennzeichnet; eine weniger effiziente Lokalisationsfähigkeit, bzw. die Lokalisation des RNA-Konstruktes ausschließlich nach dem Verteilungsweg spät lokalisierender RNAs, durch ein (+) vermerkt.

Auffällig ist, daß das Transkript MC200 (Nukleotide 2181-2490) nur die für spät lokalisierende RNAs typische Verteilung über die gesamte vegetale Hemisphäre in Oozyten eines späteren Stadiums (III-IV) vermittelt. Wird das Transkript in die Nuklei von Stadium II Oozyten injiziert, so wird die RNA nicht vegetal angereichert, sondern liegt homogen über die Oozyte verteilt vor. Das erste Lokalisationssignal der RNA (Nukleotide 1682-1980) sollte durch die Generierung von vier überlappenden Subfragmenten von jeweils ca. 100 Nukleotiden Länge weitergehend in Injektionsexperimenten untersucht und eingegrenzt werden. Es stellte sich hierbei heraus, daß keines dieser so generierten Fragmente ein intaktes Lokalisationselement enthält Abb. 3.25 J, K, L und M). Wie in den hier gezeigten Injektionsexperimenten nachgewiesen werden konnte, besitzt die DEADSouth mRNA also zwei Lokalisationselemente im 3'-untranslatierten Bereich. Zum einen das die Nukleotide 1682-1980 umfassende Element, welches in früheren Oozytenstadien eine der endogenen 
früh lokalisierenden RNA entsprechende Lokalisation der Transkripte vermittelt. Zum anderen das die Nukleotide 2181-2490 umfassende Element, das eine Verteilung der injizierten RNA vermittelt, die eher charakteristisch für spät lokalisierte RNAs wie zum Beispiel Vg1 oder das in dieser Arbeit untersuchte Transkript 6E ist. Im Teil II der Abb. 3.25 sind die Ergebnisse dieser DEADSouth-RNA-Injektionsexperimende nochmals zusammenfassend dargestellt.

\subsubsection{Die Lokalisationselemente der XNIF- und DEADSouth-RNAs vermitteln nach Injektion in Stadium I Oozyten die Anreicherung des Transkriptes in der mi- tochondrialen Wolke}

Früh lokalisierende Transkripte werden in Stadium I Oozyten in charakteristischer Weise in der Struktur der mitochondrialen Wolke angereichert. In Injektionsexperimenten konnte so gezeigt werden, daß ein 227 Nukleotide umfassender Bereich des Xcat2 3'-UTRs hinreichend ist, die Akkumulation des Transkriptes in der mitochondrialen Wolke zu vermitteln (Zhou und King, 1996). Nach Injektion in Stadium IV Oozyten konnte gezeigt werden, daß dieses MC (,mitochondrial cloud“)-Lokalisationselement auch die Sequenzen umfaßt, die hinreichend sind die Lokalisation der RNA entsprechend des späten Transportweges zu vermitteln (Zhou und King, 1996). Umgekehrt scheinen aber eingegrenzte RNA-Elemente früh lokalisierter RNAs, die den Transport entlang des späten Verteilungsweges vermitteln nicht in der Lage zu sein, nach Injektion in Stadium I Oozyten in der mitochondrialen Wolke angereichert zu werden (Chan et al., 1999; Zhou und King, 1996).

In den in Abschnitten 3.3.2 und 3.3.3 gezeigten Injektionsexperimenten zur Eingrenzung der Lokalisationselemente der früh lokalisierten RNAs XNIF und DEADSouth konnte so auch beobachtet werden, daß die Transkripte nach Injektion in spätere Oozytenstadien entsprechend des späten Verteilungsweges am Kortex der gesamten vegetalen Hemisphäre lokalisiert werden. Um zu überprüfen, ob die eingegrenzten RNA-Sequenzen (LE-1 der XNIF- und das LE-1 der DEADSouth-RNA) bzw. das Volllängen-DEADSouthReporterkonstrukt tatsächlich den Transport entsprechend des frühen Verteilungsweges, d.h. auch die charakteristische Akkumulation des Transkriptes in der mitochondrialen Wolke, vermitteln können, wurden diese daher auch in Zellkerne von Stadium I Oozyten injiziert und ihre Verteilung nach zwei Tagen Inkubation in der in situ-Hybridisierung analysiert (Abb. 3.26). So konnte gezeigt werden, daß sowohl das Lokalisationselement-1 der XNIF-RNA, als auch die Volllängen DEADSouth-RNA und das darin enthaltene Lokalisationselement-1 die Anreicherung der Transkripte in der mitochondrialen Wolke vermitteln Abb. 3.26A, B und C). 

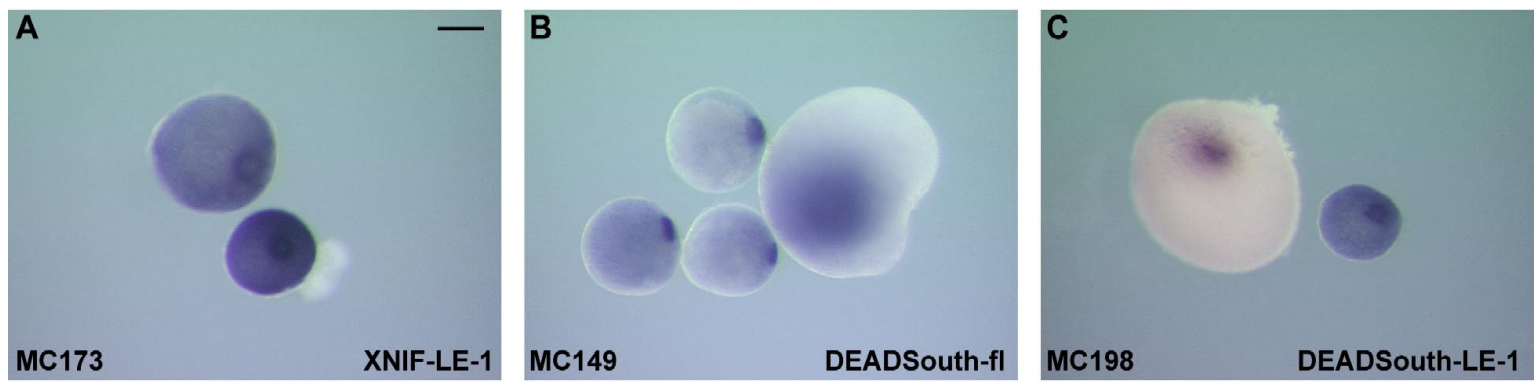

Abb. 3.26

Akkumulation der XNIF- und DEADSouth-LE-RNA-Konstrukte in der mitochondrialen Wolke nach Injektion in Stadium I Oozyten. Das Lokalisationselement-1 der früh lokalisierten XNIF-RNA, sowie die Volllängen-RNA und das Lokalisationselement-1 der DEADSouth-Isoform wurden in Stadium I und frühe Stadium II Oozyten injiziert. Nach zwei Tagen Inkubation in vitellogeninhaltigem Kulturmedium wurde die Verteilung der Transkripte in der whole mount in situ-Hybridisierung nachgewiesen. A. Lokalisationselement-1 der XNIF-RNA, mittleres (unten) und spätes (oben) Oozyten Stadium I. B. Volllängen-DEADSouth-RNA nach Injektion in Stadium I (links) und Stadium II (rechts) Oozyten. C. Lokalisationselement-1 der DEADSouth-RNA nach Injektion in Stadium I (rechts) und Stadium II (links) Oozyten. In der Abbildung sind die systematischen Namen der Fusionskonstrukte angegeben. Der in der Abbildung gezeigte Maßstabsbalken entspricht ca. $100 \mu \mathrm{m}$.

Somit konnte bestätigt werden, daß es sich bei den eingegrenzten Lokalisationselementen1 der XNIF und DEADSouth-RNAs um Signalsequenzen handelt, die auch die für früh lokalisierte RNAs typische Akkumulation in der mitochondrialen Wolke vermitteln. (Die in Abb. 3.26 gezeigten Injektionsexperimente in Stadium I Oozyten entstammen einer nur einmal durchgeführten Injektionsreihe; das parallel injizierte nichtlokalisierende lacZRNA-Fragment zeigte in keinem Fall eine Anreicherung in der mitochondrialen Wolke.)

\subsubsection{Der nichtkodierende Bereich des B2B-2B-Transkriptes vermittelt eine schwa- che äquatoriale Lokalisation}

Wie schon in Abschnitt 3.2.9 beschrieben wurde konnte die Volllängen cDNA des äquatorial angereicherten $\mathrm{B} 2 \mathrm{~B}-2 \mathrm{~B}-$ Transkriptes bisher nicht isoliert werden. Daher sollte zunächst getestet werden, ob das vorliegende, vermutlich dem 3'-untranslatierten Bereich der entsprechenden RNA zugehörige cDNA-Fragment des primär isolierten pTriplEx2Klons, die Akkumulation einer Reporter-RNA am Äquator der Oozyte vermitteln kann. Das vorhandene cDNA-Fragment wurde somit ebenfalls hinter die lacZ-Sequenz kloniert und das davon in vitro generierte Transkript in Oozyten injiziert. In drei separat durchgeführten Injektionsexperimenten konnte nur in einer Serie eine verstärkte Färbung im äquatorialen Bereich der Oozyte nachgewiesen werden Abb. 3.27. In den meisten Fällen wird die RNA nach Injektion nicht lokalisiert, sondern liegt über die gesamte Oozyte verteilt vor. Hierin könnte die Tatsache wiedergespiegelt sein, daß nur eine Teilsequenz der cDNA injiziert wurde und für eine effektive Lokalisation der Transkripte zusätzlich noch weiter 5' in der RNA gelegene Sequenzen oder Elemente erforderlich sind. 


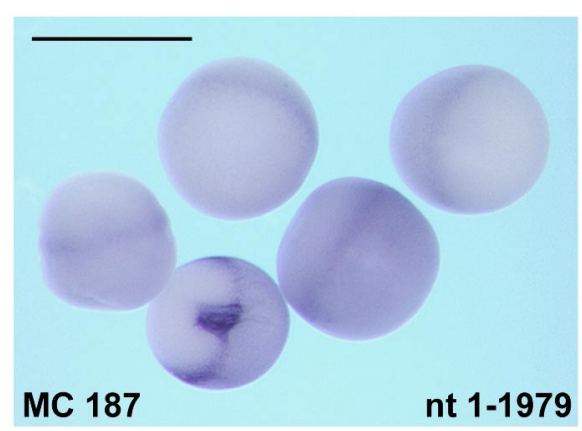

Abb. 3.27 Eine äquatoriale RNA-Lokalisation kann durch den nichtkodierenden Bereich des B2B-2B-Transkriptes vermittelt werden. Die vermutlich unvollständige 1950 bp umfassende cDNA-Sequenz des 2B Klons wurde an den lacZ-Reporter fusioniert und von diesem in vitro transkribierte synthetische RNA in die Nuklei von Stadium III Oozyten injiziert. Die subzelluläre Verteilung des Transkriptes wurde nach drei Tagen Inkubation in der in situ-Hybridisierung detektiert. Angegeben ist der systematische Name des injizierten Fusionskonstruktes sowie die darin beinhalteten Nukleotidsequenzen der B2B-2B-RNA. Der in der Abbildung gezeigte Maßstabsbalken entspricht ca. $500 \mu \mathrm{m}$.

Möglicherweise ist dieser neu identifizierte Verteilungsweg, der die Lokalisation einer mRNA an der äquatorialen Region der Oozyte vermittelt, in Injektionsexperimenten aber auch sehr schwer nachzustellen und wird durch die in vitro Bedingungen, mit denen die Oozyten für mehrere Tage in Kultur gehalten werden, nur unzureichend unterstützt.

\subsection{Nachweis der Protein-Bindung an RNA-Lokalisationselemente in UV-Querver- netzungsversuchen}

Nach der Identifizierung und Eingrenzung der cis-agierenden Sequenzen der vegetal lokalisierten RNAs sollten anschließend mit diesen interagierende Proteine in in vitro Studien untersucht werden. Eine Möglichkeit des Nachweises spezifischer RNA-Proteininteraktionen bietet die Methode der UV-induzierten Quervernetzung. Dabei werden entweder aufgereinigte Proteinpräparationen oder (evtl. fraktionierte) Zellextrake zusammen mit einer radioaktiv markierten RNA inkubiert und durch eine kurze Bestrahlung mit energiereichem UV-Licht eine Quervernetzung zwischen üblicherweise $\alpha-{ }^{32} \mathrm{P}$-markierten Uridinen der RNA mit aromatischen Aminosäuren des spezifisch mit der RNA interagierenden Proteines induziert. Anschließend wird der Bindungsansatz mit RNasen behandelt, um nichtgebundene RNAs sowie nicht vernetzte Anteile einer gebundenen RNA aus dem aufzutrennenden Komplex zu entfernen. Dieser kann dann in der SDS-PAGE analysiert werden, wobei die mit dem Radionuklid kovalent vernetzten spezifisch interagierenden Proteine als radioaktive Bande im Gel identifiziert werden können.

Für die hier beschriebenen Quervernetzungsversuche wurde ein aus Xenopus Oozyten (Stadien I-VI) gewonnener S100-Extrakt eingesetzt, dem während der Präparation durch mehrere Zentrifugationsschritte membranöse Zellbestandteile sowie ein Großteil der Dot- 
terproteine entzogen wurden. In Vorversuchen konnte nachgewiesen werden, daß keine Unterschiede in der RNA-Stabilität zwischen Monomethylguanosin-Cap enthaltender oder Cap-freier RNAs im S100-Extrakt bestehen. Ebenso sind keine unterschiedlichen Proteinbindungsmuster nach Quervernetzung von Cap-haltiger und Cap-freier RNA zu beobachten (nicht gezeigt).

Viele der in den in vitro Quervernetzungsstudien untersuchten RNA-Konstrukte enthalten aufgrund ihrer vorherigen Verwendung in Injektionsexperimenten einen lacZ-Fusionsanteil. Daher sollte zunächst untersucht werden ob auch diese nichtlokalisierende RNA von zellulären Proteinen gebunden werden kann und wie sich das erhaltene Bindungsmuster von demjenigen einer lokalisierten RNA unterscheidet. Betrachtet man das im UVQuervernetzungsversuch für die lacZ-RNA erhaltene Bindungsmuster, so ist zu erkennen, daß dieses von einer Protein-Doppelbande mit einer relativen Molekülmasse von ca. 54 und $56 \mathrm{kDa}$ dominiert wird (Abb. 3.28 Spur 1). Diese beiden Proteine die auch in den UVQuervernetzungsstudien anderer Arbeiten nachgewiesen werden konnten, entsprechen wahrscheinlich den in der Oozyte sehr abundanten, nicht sequenzspezifisch RNAbindenden masking- oder FRGY-Proteinen, welche vermutlich eine Rolle bei der Aufrechterhaltung eines translationsinaktiven Status maternaler RNAs spielen (Bouvet et al., 1995; Bouvet und Wolffe, 1994; Darnbrough und Ford, 1981; Ladomery und Sommerville, 1994; Ladomery et al., 1997; Matsumoto et al., 1996; Murray, 1994; Tafuri und Wolffe, 1993; Wolffe et al., 1992). Darüberhinaus konnte ebenso die Bindung dreier weiterer Proteine der relativen Molekülmasse von ca. 97, 69 und $40 \mathrm{kDa}$ nachgewiesen werden. Diese entsprechen vermutlich ebenfalls abundanten, sequenzunspezifisch RNA-bindenden Proteinen der Xenopus-Oozyte. Die Bindung der Proteine der relativen Molekülmassen von 69 $\mathrm{kDa}, 54 \mathrm{kDa}, 56 \mathrm{kDa}$ und $40 \mathrm{kDa}$ läßt durch einen Überschuß an nicht-markierter lacZRNA, nicht jedoch durch Zugabe eines großen Überschuß an tRNA kompetieren (vergl. Spur 2 und 3 in Abb. 3.28. Molekülmassen der Proteine sind in blau links in der Abbildung angegeben). Das Bindungsmuster der RNA, die zusätzlich zum lacZ-tag noch den Sequenzabschnitt des 6E-RNA-Lokalisationselementes enthält, weist zusätzlich zu den vorangehend beschriebenen noch sechs weitere Proteinbanden einer Größe von ca. $33 \mathrm{kDa}$, $38 \mathrm{kDa}, 42 \mathrm{kDa}, 45 \mathrm{kDa}, 75 \mathrm{kDa}$ und $78 \mathrm{kDa}$ auf Abb. 3.28 mit Sternchen an Spur 6 markiert; die relativen Molekülmassen sind in rot am rechten Rand der Abbildung angegeben). Diese Proteinbindung ist nicht durch einen Überschuß an tRNA oder unmarkierter lacZtag-RNA zu kompetieren Abb. 3.28 Spur 5 und 6). Wird die Bindungsreaktion jedoch in Anwesenheit eines Überschusses nicht-markierter lacZ-6E-LE-RNA durchgeführt, so kann die RNA-Protein-Interaktion spezifisch kompetiert werden Abb. 3.28 Spur 7). Es handelt sich bei diesen Proteinen also um spezifisch mit dem Lokalisationselement der 6E-RNA interagierende Proteine. 
32P-RNA

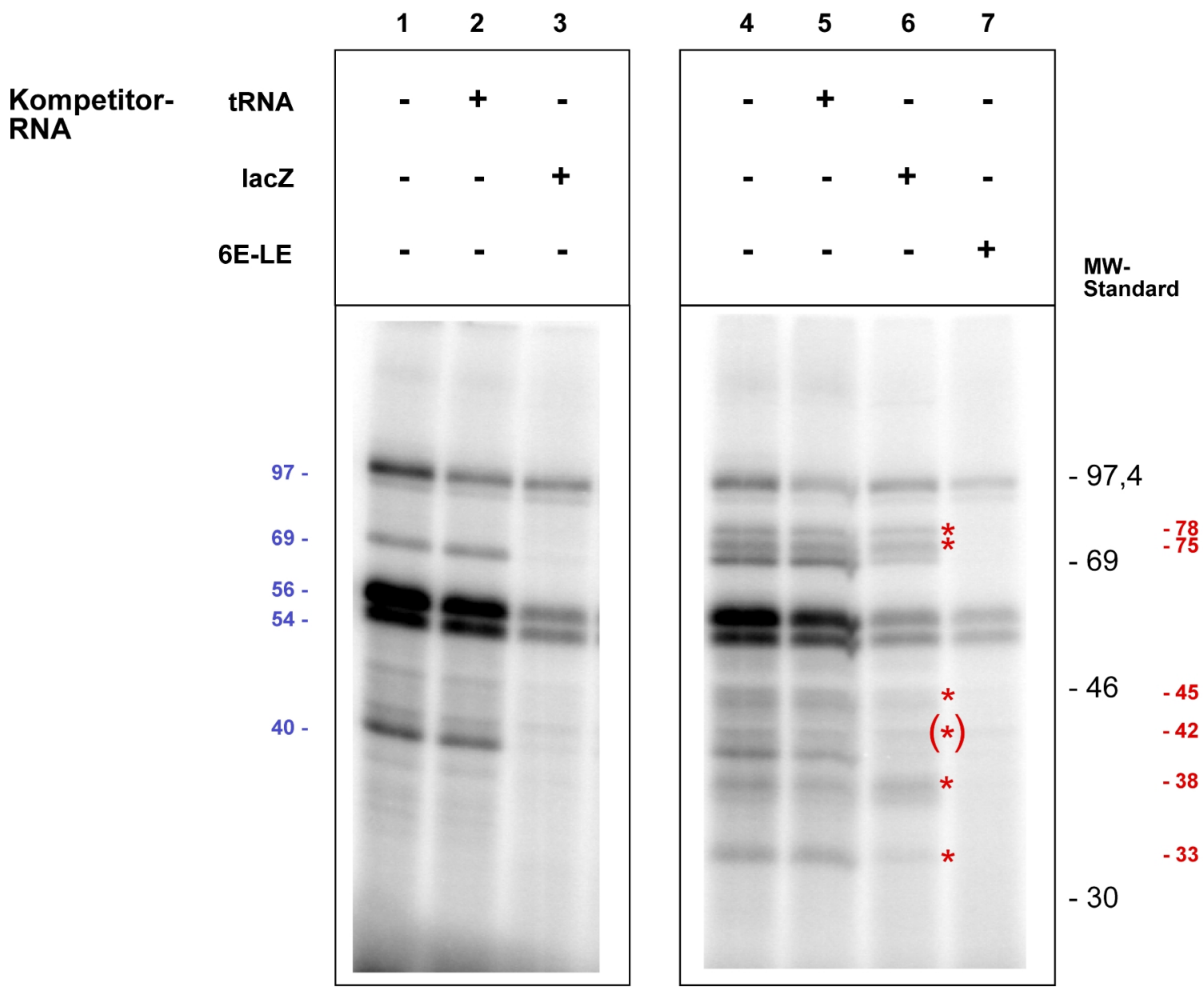

Abb. 3.28 Das Lokalisationselement der 6E-RNA interagiert spezifisch mit Proteinen des Xenopus Oozyten S100-Extraktes. Die in einer in vitro-Transkriptionsreaktion mit ${ }^{32} \mathrm{P}$-UTP markierten lacZ- bzw. lacZ+6E-LE RNAs (Konstrukte MC161 und MC171b) wurden in Anwesenheit verschiedener Kompetitor RNAs in Oozyten S100-Proteinextrakt inkubiert. Nach einer zehnminütigen UVinduzierten Quervernetzungsreaktion wurden die Proben mit RNase A behandelt, in der SDS-PAGE aufgetrennt und das Proteinbindungsmuster anschließend mit dem Phosphoimager ausgewertet. Als Kompetitor-RNAs wurden jeweils $5 \mu \mathrm{g}$ E. coli tRNA (Spuren 2 und 5) bzw. 2,2 $\mu \mathrm{g}$ in vitro transkribierte lacZ-RNA (Spuren 3 und 6) bzw. lacZ+6E-LE-RNA (Spur 7) eingesetzt. An der linken Seite sind die relativen Molekülmassen der sequenzunspezifisch RNA-bindenden Proteine, die auch mit der nichtlokalisierenden lacZ-RNA quervernetzt werden, in blau angegeben. An der rechten Seite der Abbildung sind die relativen Molekülmassen der spezifisch mit dem Lokalisationselement der 6E-RNA interagierenden Proteine in rot, sowie die relativen Molekülmassen eines mitaufgetragenen ${ }^{14} \mathrm{C}$ markierten Proteinstandards angegeben (MW-Standard). Die spezifisch mit dem Lokalisationselement der 6E-RNA interagierenden Proteine sind zusätzlich mit roten Sternchen an Spur 6 markiert. Schwächere Interaktionen sind durch Klammern gekennzeichnet.

Um die spezifischen Bindungsmuster der verschiedenen im Rahmen dieser Arbeit identifizierten und funktionell eingegrenzten RNA-Lokalisationselemente sowohl untereinander als auch mit demjenigen des Vg1-Lokalisationselementes zu vergleichen, wurden Quervernetzungsversuche mit den genannten RNA-Elementen durchgeführt und die Ansätze parallel auf einem SDS-PA-Gel aufgetrennt Abb. 3.29). In Spur 1 ist das schon vorangehend beschriebene Muster der ubiquitären und nicht sequenzspezifisch RNA-bindenden 
Proteine zu erkennen (ca. 97, 69, 56, 54 und $40 \mathrm{kDa}$; nur die spezifisch mit den Lokalisationselementen interagierenden Proteine sind in Abb. 3.29 in rot gekennzeichnet). An das Lokalisationselement der spät lokalisierten Vg1-mRNA werden darüberhinaus noch zusätzlich die Proteine der Größen von 33, 38, 42 (dieses scheint mit geringerer Effizienz auch die lacZ-RNA zu binden), 45, 75 und $78 \mathrm{kDa}$ gebunden (Abb. 3.29 Spur 2).

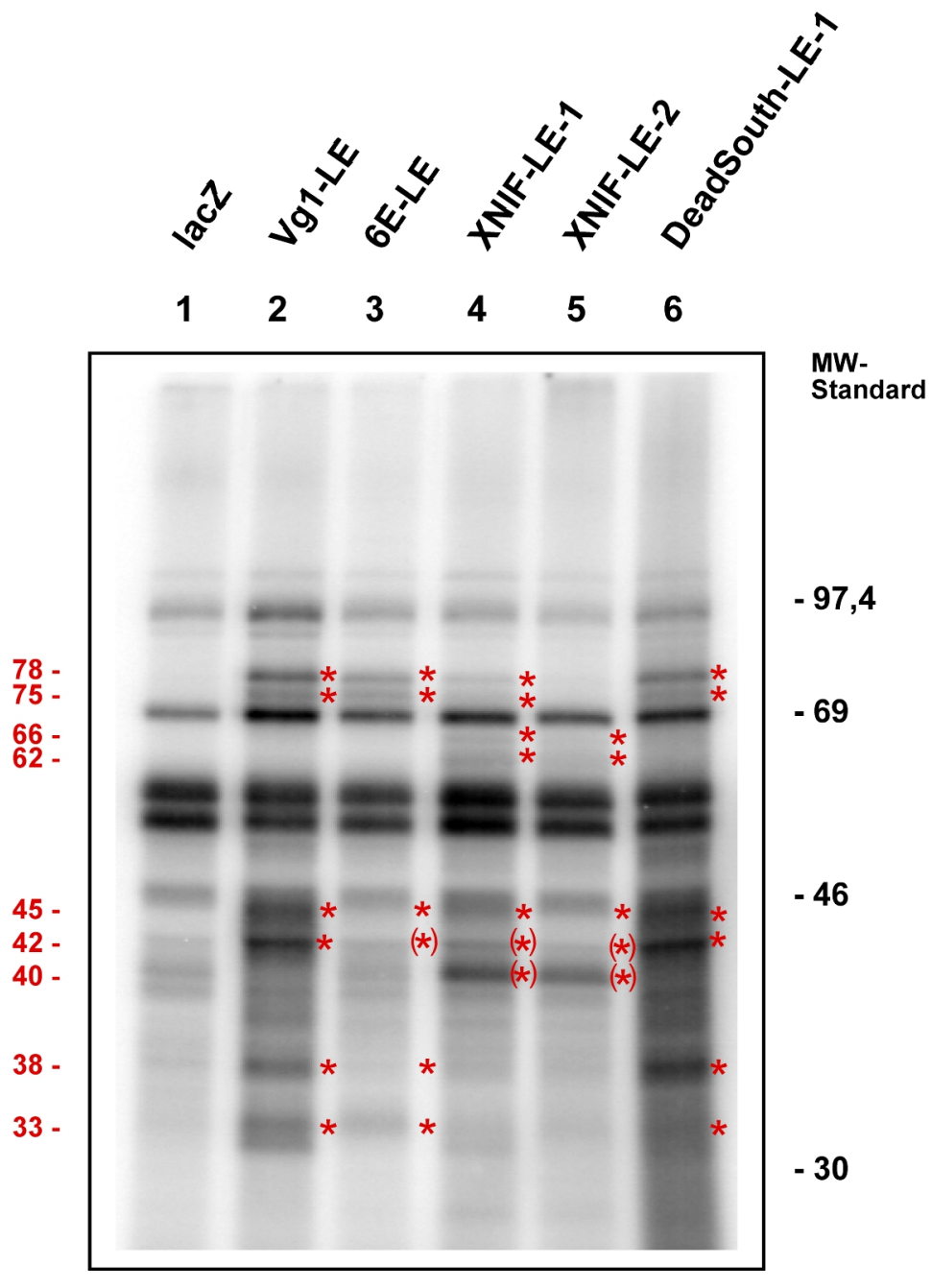

Abb. 3.29 Nachweis der Protein-Bindung an verschiedene RNA-Lokalisationselemente im UVQuervernetzungsversuch. Die RNAs lacZ (MC161; Spur 1), Vg1-LE (MC191; Spur 2), 6E-LE+lacZ (MC171b; Spur 3), XNIF-LE-1+lacZ (MC173; Spur 4), XNIF-LE-2+lacZ (MC176; Spur 5) sowie das DEADSouth-LE-1+lacZ (MC198; Spur 6) wurden in einer in vitro Reaktion transkribiert und mit ${ }^{32} \mathrm{P}$ UTP radioaktiv markiert. Nach Inkubation in Oozyten S100-Extrakt und UV-induzierter Quervernetzung wurden die Proben mit RNase A behandelt und auf einem SDS-Gel aufgetrennt. Anschließend wurden die spezifischen Bindungsmuster im Phosphoimager ausgewertet. An der linken Seite der Abbildung sind die relativen Molekülmassen der spezifisch mit den Lokalisationselementen interagierenden Proteine in rot angegeben. Zusätzlich sind diese auch durch rote Sternchen an der rechten Seite der entsprechenden Spuren des Gels markiert. Proteine, die nur schwächer oder die zu einem gewissen Anteil auch mit der lacZ-RNA zu interagieren scheinen, sind in Klammern gesetzt. An der rechten Seite des Gels sind die relativen Molekülmassen eines ${ }^{14} \mathrm{C}$-markierten Proteinstandards angegeben (MW-Standard).

Ein ähnliches Bindungsmuster kann ebenfalls für das Lokalisationselement der spät lokalisierenden 6E-RNA erhalten werden, wobei hier jedoch eine etwas geringere Bindungseffizienz für die Proteine kleinerer Molekülmassen beobachtet werden kann Abb. 3.29 
Spur 3, siehe auch Abb. 3.28. Wird hingegen das Lokalisationselement-1 der früh lokalisierten XNIF-mRNA in den UV-Quervernetzungsversuch eingesetzt, so wird ein von den vorangehend beschriebenen Mustern verschiedenes erhalten Abb. 3.29 Spur 4). In diesem Fall kann nahezu keine Interaktion mit den Proteinen der Größen 33 und 38 kDa nachgewiesen werden. Die beiden 78 und $75 \mathrm{kDa}$ großen Proteine, binden nicht nur die Lokalisationselemente der spät lokalisierenden RNAs Vg1 und 6E sondern etwas schwächer auch das LE-1 der früh lokalisierten XNIF-RNA. Zusätzlich ist hier die spezifische Interaktion des RNA-Elementes mit zwei Proteinen einer Größe von ca. 62 und 66 kDa nachzuweisen. Diese beiden Proteine scheinen ebenfalls, wenn auch mit geringerer Effizienz, mit dem zweiten Lokalisationselement der XNIF-RNA zu interagieren Abb. 3.29 Spur 5). Eine spezifische Interaktion mit den Proteinen der Größen 75 und $78 \mathrm{kDa}$ kann hier jedoch nicht nachgewiesen werden. Dies spiegelt vermutlich die geringere Effizienz des XNIF-LE-2 wieder, mit der dieses zum vegetalen Pol der Oozyte transportiert wird (siehe Abb. 3.24 I). Weiterhin binden die Proteine der Größen 40, 42 und $45 \mathrm{kDa}$ in der UV-Quervernetzung an die Lokalisationselemente der XNIF-RNA, diese scheinen jedoch zum Teil auch sequenzunspezifische Bindungsaktivität aufzuweisen.

Obwohl es sich bei der DEADSouth-RNA um eine früh lokalisierende RNA handelt, ist im UV-Quervernetzungsexperiment mit dem Lokalisationselement-1 derselben ein Proteinbindungsmuster zu erhalten, das auffällig demjenigen der spät lokalisierten RNAs Vg1 und 6E gleicht Abb. 3.29 Spur 6). Auch in diesem Fall ist die Bindung von Proteinen der Größen 33, 38, 42, 45, 75 und $78 \mathrm{kDa}$ nachzuweisen. Eine Bindung der spezifisch mit den beiden Lokalisationselementen der früh lokalisierenden XNIF-RNA interagierenden Proteine der Größen 62 und $66 \mathrm{kDa}$ ist nicht $\mathrm{zu}$ beobachten. Die Ergebnisse der UVQuervernetzungsexperimente sind in Tabelle 3.2 zusammengefaßt.

\begin{tabular}{|c|c|c|c|c|c|c|c|c|c|c|}
\hline \multicolumn{2}{|c|}{ spez. interagierende Proteine $(\mathrm{kDa})$} & 78 & 75 & 66 & 62 & 45 & 42 & 40 & 38 & 33 \\
\hline (spät) & LEE & + & + & & & + & + & & + & + \\
\hline (spät) & LE & + & + & & & $(+)$ & $(+)$ & & + & + \\
\hline \multirow[t]{2}{*}{ XNIF } & LE-1 & + & + & + & + & + & $(+)$ & $(+)$ & & \\
\hline & LE-2 & & & + & + & + & $(+)$ & $(+)$ & & \\
\hline DEADSouth (früh) & $\begin{array}{l}\text { 3'-UTR bzw. } \\
\text { LE-1 }\end{array}$ & + & + & & & + & + & & + & + \\
\hline
\end{tabular}

Tab. 3.2 Übersicht der im UV-Quervernetzungsversuch spezifisch an Lokalisationselemente spät bzw. früh lokalisierender RNAs bindenden Proteine: In der Tabelle angegeben sind die untersuchten Lokalisationselemente der spät (Vg1 und 6E) sowie früh lokalisierenden (XNIF und DEADSouth) RNAs sowie die spezifisch mit diesen interagierenden Proteine. Die vermutlich sequenzunspezifisch RNA-bindenden Proteine der Größen p97; p69 und p54/56 die auch mit der nichtlokalisierenden lacZRNA quervernetzt werden, sind nicht in der Tabelle angegeben. Eine im UVQuervernetzungsexperiment ermittelte Proteinbindung ist durch ein + vermerkt. Schwächere Interaktionen oder die Bindung des p40 an XNIF-Lokalisationselemente, die auch mit der lacZ-RNA kompetiert werden kann, sind durch Klammern gekennzeichnet. In der Tabelle zusammengefaßt wurden die Ergebnisse der in den Abb. 3.28 Abb. 3.29 und Abb. 3.30 dargestellten Experimente. 
In der in Tabelle 3.2 zusammenfassend dargestellten Übersicht über die in den UV-Quervernetzungsexperimenten erhaltenen Bindungsmuster der verschiedenen Lokalisationselemente ist $\mathrm{zu}$ erkennen, daß die spezifisch interagierenden Proteine und RNAs aufgrund ihres Bindungsverhaltens in verschiedene Gruppen eingeteilt werden können. So binden die $42 \mathrm{kDa}$ und $45 \mathrm{kDa}$ großen Proteine im UV-Quervernetzungsversuch sowohl an Lokalisationselemente spät wie auch früh lokalisierter RNAs. Die $33 \mathrm{kDa}$ und $38 \mathrm{kDa}$ großen Proteine binden an die Lokalisationselemente der spät lokalisierten Vg1- und 6E-RNA, aber auch an das der früh lokalisierten DEADSouth-RNA. Die beiden 75 und 78 kDa groBen Proteine interagieren mit den Signalsequenzen der spät lokalisierten Vg1- und 6ERNA sowie mit dem Lokalisationselement-1 der früh lokalisierten XNIF-RNA und dem Lokalisationselement der DEADSouth-RNA. Die Proteine der Größen 40 kDa, 62 kDa und $66 \mathrm{kDa}$ scheinen präferentiell an die beiden Lokalisationselemente der früh lokalisierten XNIF-RNA zu binden. Aufgrund der in den UV-Quervernetzungsversuchen erhaltenen Daten kann also angenommen werden, daß sich die Lokalisationselemente von mRNAs unterschiedlicher Sortierungswege (früh bzw. spät lokalisierte RNAs) in ihrem Bindungsverhalten an Oozyten Proteine bedingt unterscheiden lassen. Die spät lokalisierten RNAs Vg1 und 6E werden von einer bestimmten, vermutlich identischen Population von Proteinen gebunden. Interessanterweise ähnelt dieses Bindungsmuster jedoch auch demjenigen der früh lokalisierten DEADSouth RNA.

Um zu untersuchen, ob es sich bei den interagierenden Proteinen tatsächlich um dieselben oder um von diesen verschiedene Proteine einer ähnlichen relativen Molekülmasse handelt, wurden anfolgend Kreuzkompetitionsversuche durchgeführt. Handelt es sich um die gleichen interagierenden Proteine, sollten diese nicht nur mit dem entsprechend untersuchten RNA-Element kompetiert werden können, sondern auch mit demjenigen, das in den Quervernetzungsversuchen ein ähnliches Bindungsverhalten aufweist.

Das 6E-Lokalisationselement bindet spezifisch an Proteine der Größen 78, 75, 45, 42, 38 und $33 \mathrm{kDa}$ (Sternchen an Spur 4 der Abb. 3.30. Diese können sowohl durch Zugabe eines Überschusses an unmarkierter 6E-LE-RNA als auch durch einen Überschuß an nicht markierter lacZ-DEADSouth-3'-UTR-RNA kompetiert werden (Spur 5 und 6 der Abb. 3.30, es handelt sich also um dieselben interagierenden Proteine. Die Bindung der 33, 38 und 42 kDa Proteine kann mit dem DEADSouth-3'-UTR jedoch nur in abgeschwächter Form kompetiert werden (vergl. Banden mit grünem Sternchen in Spur 4 mit dem Bindungsmuster in Spur 6). Zur Untersuchung der Proteinbindung an die beiden Lokalisationselemente der früh lokalisierten XNIF-RNA wurden in diesem Fall die jeweiligen Elemente zur spezifischen- bzw. Kreuzkompetition eingesetzt. Die Bindung der mit dem LE-1 dieser RNA spezifisch interagierender Proteine (78, 75, 66, 62, 45, 42 und $40 \mathrm{kDa}$ ) kann durch einen Überschuß an nichtmarkierter RNA desselben Lokalisationselementes kompetiert werden (vergl. rote Sternchen an Spur 8 mit Bindungsmuster in Spur 9 der Abb. 3.30. Wird ein Überschuß nichtmarkierter Lokalisationselement-2-RNA eingesetzt, so ist zu erkennen, daß dieses um die Bindung der 66, 62, 45, 42 und 40 kDa großen Proteine kreuzkompetiert 
(Spur 10 in Abb. 3.30. Die Proteine der Größen 75 und 78 kDa werden von diesem Element hingegen nicht gebunden und bleiben somit auch im Kreuzkompetitionsexperiment als radioaktiv markierte Banden im Gel sichtbar (vergl. grüne Sternchen an Spur 8 mit Spur 10 der Abb. 3.30. Im UV-Quervernetzungsversuch ist die Bindung der Proteine der Größen 40, 42, 45, 62 und $66 \mathrm{kDa}$ an das Lokalisationselement-2 der früh lokalisierten XNIF-RNA nachzuweisen (rote Sternchen an Spur 12 der Abb. 3.30. Diese können sowohl spezifisch durch Einsatz desselben nicht markierten Elementes, sowie durch Zugabe eines Überschusses an nicht markierter XNIF-LE-1-RNA kreuzkompetiert werden, es handelt sich also um die gleichen Proteine, die mit diesen beiden Elementen interagieren können (vergl. Spur 12 mit Spur 13 und 14 der Abb. 3.30.

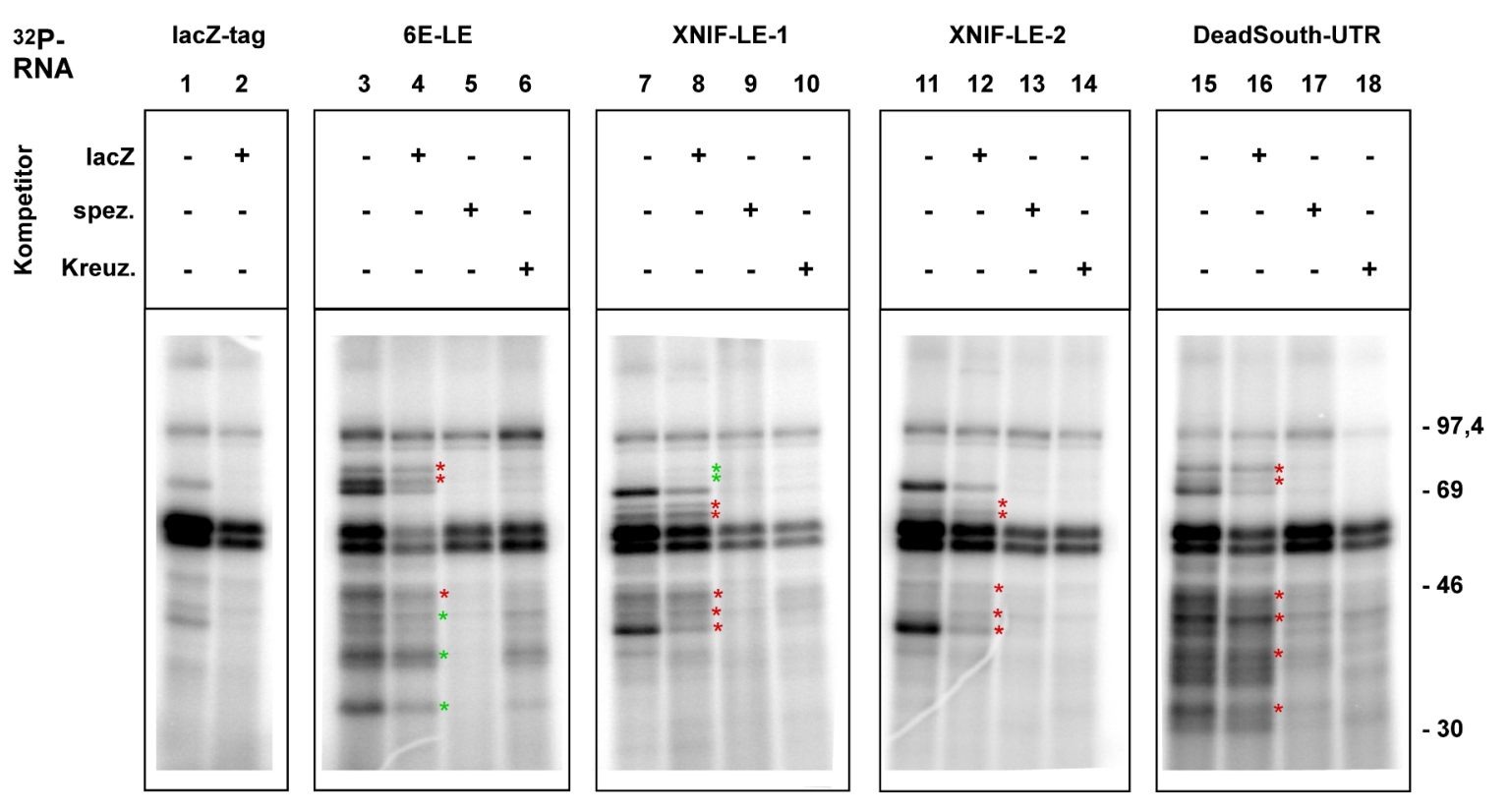

Abb. 3.30 Kreuzkompetitionen der Bindung von Oozyten Proteinen an RNA-Lokalisationselemente im UV-Quervernetzungsversuch. Die folgenden RNAs wurden in einer in vitro Reaktion transkribiert, mit ${ }^{32} \mathrm{P}-\mathrm{UTP}$ radioaktiv markiert und in der UV-Quervernetzung untersucht: lacZ-tag (MC161), 6E-LE (MC185), lacZ-XNIF-LE-1 (MC173), lacZ-XNIF-LE-2 (MC176), lacZDEADSouth-3'-UTR (MC151). An der linken Seite der Abbildung sind die in der Bindungsreaktionen eingesetzten Kompetitor RNAs angegeben. Spezifisch kompetiert wurde jeweils mit einem Überschuß derselben, nichtmarkierten RNA. Als Kreuzkompetitoren wurden folgende nichtmarkierte RNAs eingesetzt: 6E-LE: DEADSouth-3'-UTR; XNIF-LE-1: XNIF-LE-2; XNIF-LE-2: XNIF-LE-1; DEADSouth-3'-UTR: 6E-LE. An der rechten Seite der Abbildung sind die relativen Molekülmassen der Proteine des ${ }^{14} \mathrm{C}$-Proteinstandards angegeben. Proteine, die spezifisch binden und durch den Kreuzkompetitor kompetiert werden können sind durch rote Sternchen markiert; Proteine, die sich nicht oder nur schwach kreuzkompetieren lassen, sind mit grünen Sternchen gekennzeichnet.

Die 3'-untranslatierte Region der früh lokalisierten DEADSouth mRNA, die deren Lokalisationselemente enthält, wird vermutlich von denselben Proteinen gebunden, die auch mit den Lokalisationselementen der Vg1- oder 6E-RNA interagieren können (siehe auch Abb. 3.29. Dieses Bindungsverhalten kann auch in dem hier gezeigten Kreuzkompetitionsexperiment bestätigt werden. Die Bindung der Proteine der Größen 33, 38, 42, 45, 75 sowie 78 kDa kann nicht nur durch die Zugabe des spezifischen Kompetitors DEADSouth-UTR 
kompetiert werden, sondern auch bei Einsatz des 6E-Lokalisationselementes in der Kreuzkompetition (vergl. Spur 16, 17 und 18 der Abb. 3.30. Das DEADSouthLokalisationselement wird also tatsächlich (zumindest in vitro) von Proteinen gebunden deren Interaktion sonst eher mit Elementen spät lokalisierender RNAs nachgewiesen werden konnte.

Bisher konnten drei Proteine isoliert werden, die an das Lokalisationselement der spät lokalisierten Vg1-mRNA binden und vermutlich auch an deren vegetalem Transport in der Xenopus Oozyte beteiligt sind (Vg1-RBP, VgRBP60 und Prrp)(Cote et al., 1999; Deshler et al., 1998; Havin et al., 1998; Zhao et al., 2001). Es ist daher von Interesse, ob diese möglicherweise auch mit den hier untersuchten Transportelementen interagieren und als Banden der entsprechenden relativen Molekülmasse im UV-Quervernetzungsversuch nachgewiesen werden können. Das Vg1-RBP oder auch VERA genannte Protein besitzt eine relative Molekülmasse von $69 \mathrm{kDa}$, scheint aber in SDS-Polyacrylamidgelen auch einer Größe von 75 kDa entsprechend zu migrieren (Deshler et al., 1998; Havin et al., 1998). Ein Protein der Größe von $69 \mathrm{kDa}$ bindet in den hier gezeigten Quervernetzungsexperimenten sowohl an die RNA-Lokalisationselemente, als auch an die lacZ-RNA und wurde daher als nichtsequenzspezifisch-interagierendes Protein eingestuft. Ein Protein von 75 kDa relativer Molekülmasse, bei dem es sich um das Vg1-RBP handeln könnte, bindet hier spezifisch an die Lokalisationselemente der spät lokalisierten Vg1- und 6E-RNA, sowie an das Lokalisationselement -1 der XNIF- und das Lokalisationselement der DEADSouthRNA. Das VgRBP60 weist eine Größe von 60 kDa auf. Eine eventuelle Bindung eines Proteins dieser Größe an die hier untersuchten RNA-Elemente ist im UVQuervernetzungsversuch nicht nachzuweisen, da dieser Bereich durch die sehr abundanten FGRY-Proteine überlagert wird. Das kürzlich identifizierte Prrp besitzt eine relative Molekülmasse von $39 \mathrm{kDa}$. In den hier durchgeführten Quervernetzungsversuchen konnten zwei Proteine einer Größe von 38 und $40 \mathrm{kDa}$ identifiziert werden, die an die Lokalisationselemente der 6E-, Vg1- und DEADSouth-RNA (38 kDa-Protein), bzw. die beiden Lokalisationselemente der XNIF-RNA (40 kDa-Protein) binden und bei denen es sich möglicherweise um das Prrp handeln könnte.

\subsection{Vg1-RBP und Prrp weisen ein differentielles Bindungsverhalten für Lokalisati- onselemente früh bzw. spät lokalisierter RNAs auf}

In den vorangehend beschriebenen UV-Quervernetzungs- und Kreuzkompetitionsexperimenten konnte eine bedingte differentielle Proteinbindung der Lokalisationselemente der RNAs des früh bzw. spät lokalisierenden Typs nachgewiesen werden. Da RNAquervernetzte Proteine im SDS-Gel andere Wanderungseigenschaften aufweisen als aufgrund ihrer eigentlichen relativen Molekülmasse vorausgesagt werden kann, ist eine 
Zuordnung der gebundenen Proteine anhand ihrer abgeschätzten Größen zu den bisher charakterisierten Vg1-mRNA-bindenden Proteine wie Vg1-RBP, VgRBP60 und Prrp nur eingeschränkt möglich.

Koimmunopräzipitationsexperimente bieten eine andere Möglichkeit, RNA-ProteinInteraktionen in vitro nachzuweisen. Die radioaktiv markierte RNA wird dazu in einem Ansatz mit dem interessierenden in vitro translatierten Protein inkubiert und kann anschließend nach erfolgter Bindung im Komplex mit diesem koimmunopräzipitiert werden. In den anfolgend beschriebenen Experimenten sollte so die Interaktion der in dieser Arbeit eingegrenzten Lokalisationselemente, sowie dem Lokalisationselement der Vg1-mRNA mit den bereits beschriebenen Proteinen Vg1-RBP und Prrp untersucht werden. Diese wurden hierzu mit einem Myc-Epitop versehen, über den das Protein bzw. der RNAProteinkomplex unter Verwendung eines anti-myc-Antikörpers immunopräzipitiert werden kann. Als Negativkontrolle wurde die auch in den Injektionsexperimenten eingesetzte kurze lacZ-RNA verwendet, die mit spezifisch interagierenden RNA-bindenden Proteinen nicht koimmunopräzipitiert werden sollte. Keines der eingesetzten Elemente wird von dem 5S rRNA-bindenden ribosomalen Protein L5 gebunden (nicht gezeigt).

Protein

Vg1-RBP

Prrp

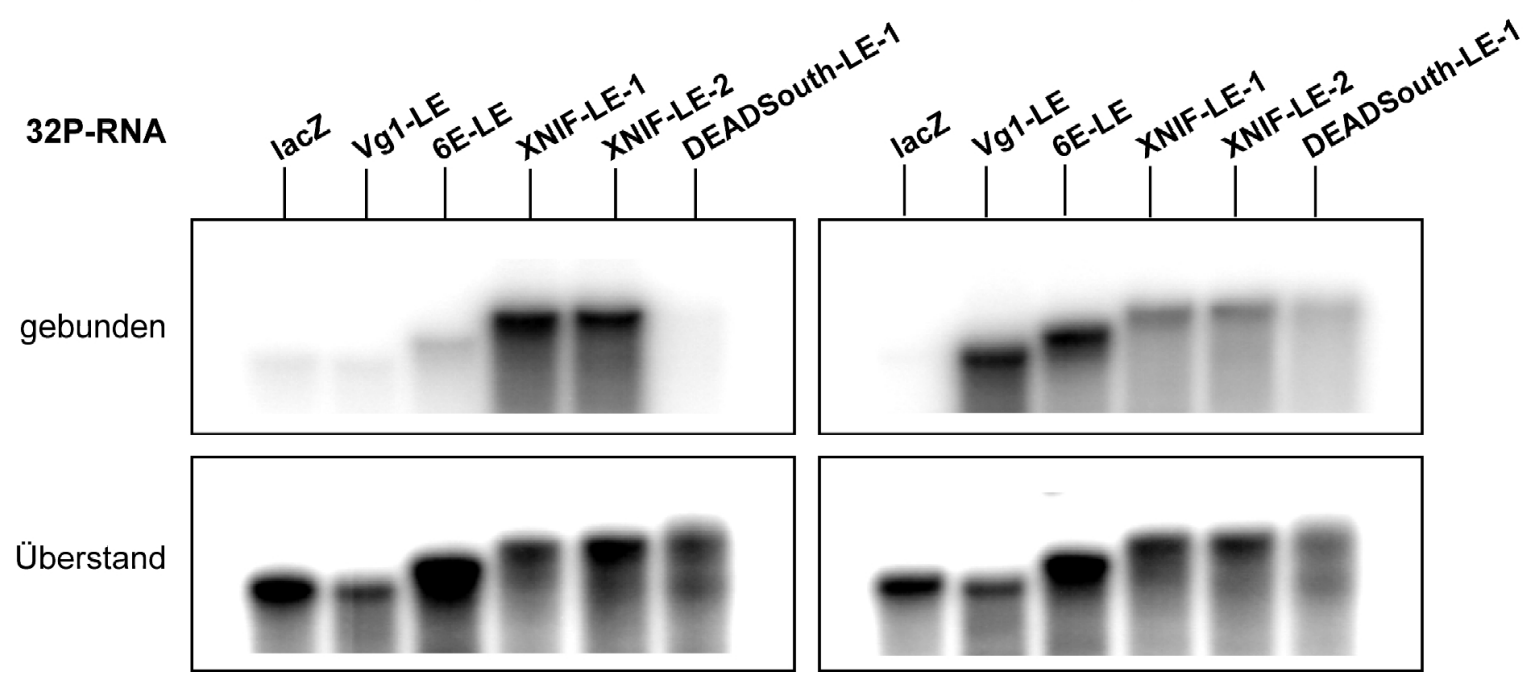

Abb. 3.31 Differentielle Bindung von Vg1-RBP und Prrp an Lokalisationselemente früh- bzw. spät lokalisierender RNAs im Koimmunopräzipitationsexperiment. Die folgenden RNAElemente wurden in einer in vitro Reaktion transkribiert und mit ${ }^{32} \mathrm{P}-\mathrm{UTP}$ radioaktiv markiert: lacZtag (MC161), Vg1-LE (MC191), lacZ-6E-LE (MC171b), lacZ-XNIF-LE-1 (MC173), lacZ-XNIF-LE2 (MC176), lacZ-DEADSouth-LE-1 (MC198). Die RNAs wurden anschließend zusammen mit in vitro translatierten poly-myc-getagten Vg1-RBP bzw. Prrp in Retikulozytenlysat inkubiert und anschließend mit anti-myc-Immunopellets koimmunopräzipitiert. Die gebundenen RNAs, sowie die im Überstand befindlichen nichtgebundenen RNAs, wurden mit Phenol/Chloroform extrahiert, in Ethanol gefällt und auf einem denaturierenden Harnstoff PA-Gel aufgetrennt. Die Auswertung des Bindungsexperimentes erfolgte mit dem Phosphoimager. 
Die als Negativkontrolle eingesetzte nicht-lokalisierende lacZ-RNA wird in der Koimmunopräzipitation nicht von Vg1-RBP und Prrp gebunden Abb. 3.31. Die beiden Lokalisationselemente der spät lokalisierenden RNAs Vg1 und 6E interagieren in diesem in vitro Bindungsexperiment nur sehr schwach mit dem Vg1-RBP. Eine sehr starke Bindung des Proteins ist hingegen an die beiden Lokalisationselemente der früh lokalisierten XNIF-RNA nachzuweisen. Das RNA-Lokalisationselement der ebenfalls früh lokalisierten DEADSouth-RNA kann nicht von Vg1-RBP gebunden werden. Das Prrp zeigt in den in vitro Koimmunopräzipitationsexperimenten hingegen eine präferentielle Bindungsaktivität für die RNA-Lokalisationselemente der spät lokalisierenden Vg1- und 6E-RNAs. Die Lokalisationselemente der früh lokalisierten RNAs XNIF und DEADSouth werden von diesem nur mit geringerer Effizienz gebunden.

Anders als es zu erwarten gewesen wäre, bindet das Vg1-RBP im Koimmunopräzipitationsexperiment nur schwach an das Vg1-Lokalisationselement bzw. an das Lokalisationselement der ebenfalls spät lokalisierten 6E-RNA. Eine sehr starke Interaktion ist hier jedoch mit Elementen der früh lokalisierten XNIF-RNA nachzuweisen. Das DEADSouth-Lokalisationselement, das in seinem Bindungsverhalten ja auch in den UVQuervernetzungsversuchen eher demjenigen der spät lokalisierenden RNAs gleicht, wird ebenfalls nicht vom Vg1-RBP gebunden. Eine eindeutige Korrelation $\mathrm{zu}$ den UVQuervernetzungsversuchen ist nicht zu beobachten, da dort keine Proteine der Größe des Vg1-RBPs identifiziert werden konnten, die präferentiell nur an die Lokalisationselemente der früh lokalisierten XNIF-RNA binden.

Prrp bindet im Koimmunopräzipitationsexperiment präferentiell an die Lokalisationselemente der Vg1- und 6E-RNA. In den UV-Quervernetzungsversuchen konnte ebenfalls ein Protein der relativen Molekülmasse von ca. $38 \mathrm{kDa}$, das mit den Lokalisationselementen der Vg1- und 6E-RNA, nicht jedoch mit denen der XNIF-RNA interagiert und welches somit dem Prrp entsprechen könnte. Allerdings kann dieses auch mit dem DEADSouth-Lokalisationselement quervernetzt werden.

\subsection{Eine mögliche Funktion von DEADSouth bei der Entwicklung der primordialen Keimzellen}

Die Entwicklung der primordialen Keimzellen ist in vielen Organismen durch die selektive Vererbung des sogenannten Keimplasmas, das neben einer Anhäufung von Mitochondrien und den elektronenmikroskopisch dichten Keimgranula auch spezifisch angereicherte RNAs enthält, charakterisiert (Houston und King, 2000b; Matova und Cooley, 2001). Auch in Xenopus Oozyten kann die Aggregation der Keimplasmakomponenten und mit ihr assoziierte RNAs wie Xpat, Xdazl u. a. am vegetalen Pol der Oozyte nachgewiesen werden. Diese vegetal lokalisierten RNAs segregieren nach der Fertilisierung des Eis und in 
den sich anschließenden Zellteilungen zusammen mit dem Keimplasma in die vegetalen Blastomeren des Embryos, deren Abkömmlinge während späterer Stadien der Entwicklung die primordialen Keimzellen bilden und spielen möglicherweise eine Rolle bei der Determination und Spezifizierung der Keimbahnzellen in Xenopus (Houston und King, 2000b; Kloc et al., 2001). Während der Gastrulation und Neurulation in Xenopus werden die primordialen Keimzellen im posterioren Endoderm positioniert, wo sie bis zum Beginn der Migrationsbewegungen im frühen Kaulquappenstadium verbleiben. Im Stadium 32/33 migrieren die primordialen Keimzellen dorsal durch das laterale Endoderm und akkumulieren im Stadium 40 in der Dorsalleiste des posterioren Endoderms und werden anschließend in das laterale Plattenmesoderm, das die dorsalen Mesenterien bildet und anschließend in die paarigen Gonadenleisten verbracht.

Obwohl schon seit langem zahlreiche im Keimplasma lokalisierte RNAs in Xenopus identifiziert werden konnten, wurde erst kürzlich die Rolle dieser bei der Spezifizierung der primordialen Keimzellen in funktionellen Studien untersucht (Houston und King, 2000a). Die in dieser Arbeit identifizierte DEADSouth-Isoform (B2B-9D)-RNA liegt so auch in Stadium VI Oozyten in granulären Strukturen, vermutlich in Assoziation mit dem Keimplasma, am vegetalen Pol der Oozyte vor. (Kürzlich konnte auch in elektronenmikroskopischen Analysen die Lokalisation der DEADSouth-mRNA in der Matrix des Keimplasmas nachgewiesen werden (Kloc et al., 2002). DEADSouth kodiert für eine vermutliche RNA-Helikase des eIF4 $\alpha$-Typs, die alle acht charakteristischen Sequenzmotive dieser Klasse der sogenannten DEAD-Box Proteine aufweist Abb. 3.32 oben). Funktionell sind die Mitglieder der Familie der RNA-Helikasen in Prozesse wie der Transkriptionsinitiation, der RNA-Prozessierung sowie dem nukleären Export von mRNAs und der Translationsinitiation beteiligt (de la Cruz et al., 1999; Linder und Stutz, 2001; Luking et al., 1998; Tanner und Linder, 2001). Möglicherweise ist also auch DEADSouth, deren mRNA mit dem Keimplasma und den primordialen Keimzellen assoziiert vorliegt, in derartige Prozesse bei der Regulation von Keimzell-spezifisch exprimierten Faktoren involviert. Um diese mögliche Funktion von DEADSouth bei der Entwicklung primordialer Keimzellen in Xenopus zu untersuchen, wurde zunächst eine DEADSouth-Mutante generiert, die an Position 233 des Proteins im Motiv der sogenannten DEAD-Box, einen Austausch der Aminosäure Glutamat (E) gegen Glutamin (Q) aufweist Abb. 3.32 oben). In früheren Arbeiten konnte gezeigt werden, daß ein solcher Aminosäureaustausch die Zerstörung der ATPase- und Entwindungs-Aktivität der Helikase zur Folge hat (Schmitt et al., 1999). Diese Mutante sollte also noch Bindungseigenschaft für ihre zellulären Substrate, nicht jedoch die von der ATPase-Aktivität abhängigen Funktion aufweisen und somit im zellulären Kontext dominant negativ fungieren. Diese DEADSouth-E233Q genannte Mutante wurde in vitro transkribiert und die RNA zur Misexpression in beide Blastomeren sich entwickelnder Albino Embryonen des Zwei-Zell-Stadiums injiziert. Nach Erreichen des 
Stadiums 34 wurden dann die primordialen Keimzellen durch Verwendung der keimzellspezifischen digoxygeninmarkierten Xpat antisense RNA-Probe in der in situHybridisierung nachgewiesen (Abb. 3.32 unten).

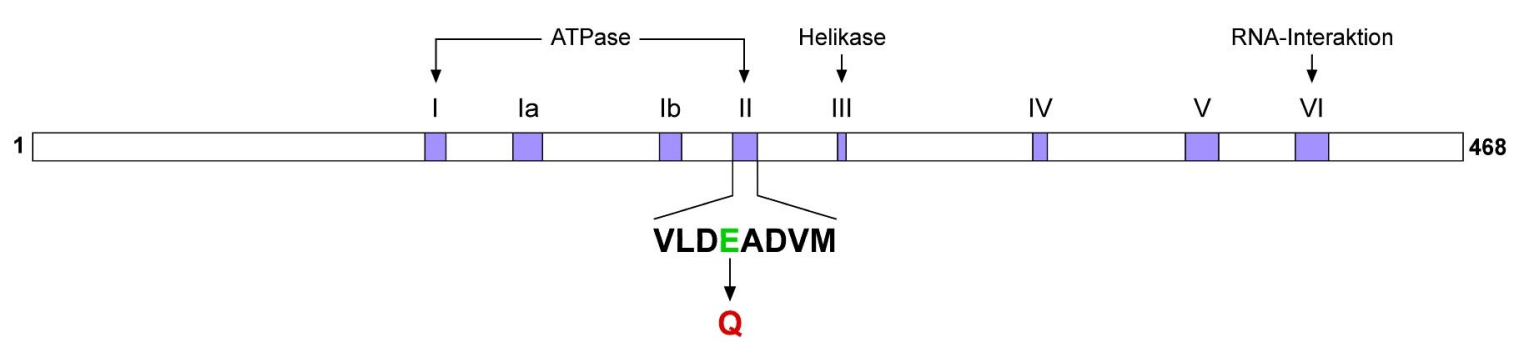

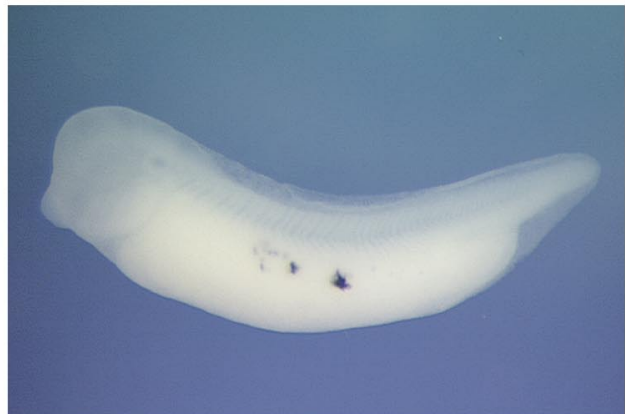

E233Q-inj.

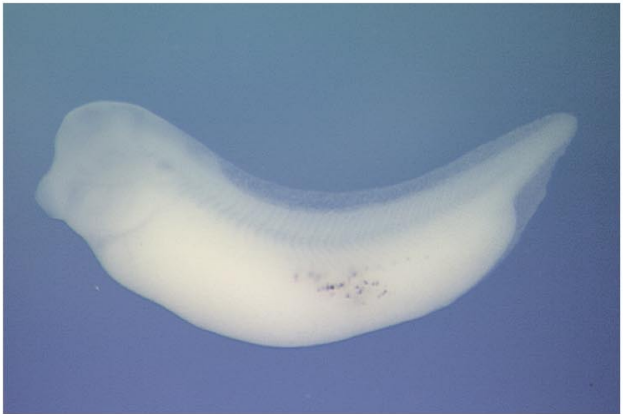

Kontrolle

Abb. 3.32 Überexpression einer DEAD-Box-Mutante. Albino Embryonen wurden vegetal mit DEADSouthE233Q (100 pg/ Embryo) bzw. der äquivalenten Menge $\mathrm{H}_{2} \mathrm{O}$ in beide Blastomeren des 2Zell-Stadiums injiziert und bis zum Stadium 34 heranwachsen gelassen. Anschließend wurden die primordialen Keimzellen mit einer für diese spezifischen Xpat antisense RNA-Probe in der in situHybridisierung nachgewiesen.

Nach Injektion und Misexpression der vermutlich dominant-negativ wirkenden DEADSouth-Mutante konnte in Embryonen des Stadiums 34 in der in situ-Hybridisierung die Zusammenlagerung der primordialen Keimzellen in größere Aggregate beobachtet werden. Kontrollinjizierte Embryonen weisen hingegen eine punktuelle Verteilung der primordialen Keimzellen auf. Das hier gezeigte Injektionsexperiment lieferte somit einen Hinweis auf eine mögliche Beteiligung von DEADSouth am Prozeß der Migration primordialer Keimzellen im Xenopus Embryo. Um den Effekt der DEADSouth-Mutante zu bestätigen, müssen in weiteren Untersuchungen jedoch auch statistische Auswertungen der Anzahl und Verteilung der primordialen Keimzellen in injizierten und nichtinjizierten Embryonen herangezogen werden sowie versucht werden diesen Effekt durch die gleichzeitige Überexpression des Wildtyp-Proteins wieder aufzuheben. 


\section{Diskussion}

Die zytoplasmatische Lokalisation von mRNAs am vegetalen Kortex stellt einen wichtigen Mechanismus der Restriktion maternaler Determinanten auf bestimmte Bereiche der Oozyte und des sich entwickelnden Embryos dar. Für einzelne dieser lokalisierten RNAs wurden so auch Funktionen bei der frühen Embryonalentwicklung und der Determination der primordialen Keimzellen nachgewiesen.

Mit dem Ziel, neue bisher nicht identifizierte RNA-Moleküle zu isolieren, wurde in der vorliegenden Arbeit eine cDNA-Bibliothek erstellt, die angereichert vegetal-kortikal lokalisierte RNAs enthält. Diese wurde in einer whole mount in situ-Hybridisierungs-basierten Durchmusterung auf vegetal lokalisierte Transkripte durchsucht. Neben der Reisolierung bereits bekannter lokalisierter Transkripte wie Vg1 und VegT konnten fünf neue lokalisierte RNAs identifiziert werden, die sich aufgrund ihres charakteristischen Verteilungsmusters den frühen und späten Sortierungswegen sowie einem neuartigen äquatorialen Lokalisationstyp zuordnen lassen.

Die RNA-Sequenzen, die den vegetalen Transport dieser RNAs vermitteln, konnten in Mikroinjektionsexperimenten in den 5'- und 3'-untranslatierten Bereichen der Transkripte identifiziert und eingegrenzt werden. In UV-Quervernetzungs- und Koimmunopräzipitatationsexperimenten konnten differentielle Bindungsaktivitäten der Lokalisationselemente des früh bzw. spät lokalisierenden Typs für Proteine des Oozytenextraktes sowie für bekannte Lokalisationselement-bindende Proteine (Vg1-RBP und Prrp) nachgewiesen werden.

Aufgrund ihrer Kosegregation mit dem Keimplasma wurden für RNAs des frühen Verteilungsweges Funktionen bei der Entwicklung der primordialen Keimzellen postuliert und so konnte auch in dieser Arbeit durch die Misexpression einer dominant-negativen Mutante Hinweise auf die mögliche Beteiligung der früh lokalisierten DEADSouth-RNA an der Migration der primordialen Keimzellen gewonnen werden.

\subsection{Die 6E- und XPTB-Transkripte sind spät lokalisierte RNAs}

In der in situ-Hybridisierung ist das endogene 6E-Transkript in Stadium I Oozyten im Zytoplasma der Oozyte lokalisiert nachzuweisen und ist von der Struktur der mitochondrialen Wolke ausgeschlossen, wie vorangehend auch für die spät lokalisierte Vg1 mRNA gezeigt wurde (Forristall et al., 1995; Kloc und Etkin, 1995). Auch die weiteren Charakteristika spät lokalisierter RNAs, wie die Akkumulation an der Spitze des vegetalen Kortex im frühen Stadium III und die darauffolgende Verteilung über den Kortex der gesamten vegetalen Hemisphäre werden von dieser erfüllt Abb. 3.1. Aufgrund ihres räumlichen und zeitlichen Verteilungsmusters ist das 6E-Transkript also der Gruppe der spät lokalisierenden RNAs zuzuordnen. 
Während die XPTB (A3A-11C)-RNA während der Stadien IV-VI der Oogenese ebenfalls die für spät lokalisierte Transkripte typische Verteilung über den Kortex der gesamten vegetalen Hemisphäre aufweist, scheint ihre Verteilung in frühen Oozytenstadien von dieser abzuweichen Abb. 3.4. So ist in Stadium I Oozyten keine klare Aussparung der mitochondrialen Wolke durch die RNA zu erkennen, sondern diese scheint homogen über das ganze Zytoplasma verteilt vorzuliegen. Zu Beginn der Akkumulation des Transkriptes am vegetalen Kortex in frühen Stadium III Oozyten kann die dortige Anreicherung der RNA in einem ringförmigen Bereich beobachtet werden, der bisher nicht für Vg1 oder andere spät lokalisierte RNAs beschrieben wurde. Eine ähnliche Lokalisation in diesem Stadium konnte allerdings auch für die im Rahmen dieser Arbeit identifizierten, äquatorial lokalisierten B2B-2B-RNA nachgewiesen werden, die jedoch bis zum Stadium VI der Oogenese auf den äquatorialen Bereich beschränkt bleibt (s.u.). Möglicherweise akkumulieren spät lokalisierende RNAs nach Erreichen des vegetalen Kortex zunächst in dieser Region, bevor ihre weitere Verteilung über den Kortex der vegetalen Hemisphäre eingeleitet wird. Die subzelluläre Verteilung spät lokalisierender Transkripte wurde bisher am eingehendsten für die schon sehr früh entdeckte Vg1-RNA untersucht. Da die Klassifizierung der anderen Mitglieder der Gruppe der spät lokalisierten RNAs primär anhand deren charakteristischer Verteilung in Stadium VI Oozyten vorgenommen wurde, ist es möglich, daß auch noch andere spät lokalisierte RNAs in frühen Stadien der Oogenese ein von Vg1 unterschiedliches, bisher aber nicht beschriebenes Lokalisationsverhalten aufweisen. Viele der lokalisierten RNAs werden während der frühen Oogenese schon sehr stark exprimiert, was die Analyse von deren Verteilung in der whole mount in situ-Hybridisierung erschwert und so eine Aussparung der mitochondrialen Wolke oder die dortige Akkumulation, wie auch die lokale Anreicherung von Transkripten in der hier für die XPTB-RNA gezeigten ringförmigen Struktur am vegetalen Kortex, möglicherweise deshalb nicht zu detektieren ist.

\subsection{XNIF und DEADSouth lassen sich dem Transportweg früh lokalisierter RNAs zuordnen}

Sowohl die XNIF (B2B-10B)-RNA, als auch das Transkript der im Rahmen dieser Arbeit isolierten DEADSouth-Isoform, können aufgrund ihres Verteilungsmusters der Gruppe der früh lokalisierten RNAs zugeordnet werden Abb. 3.9 und Abb. 3.14. In Stadium I Oozyten ist für beide Transkripte die charakteristische Anreicherung in der mitochondrialen Wolke zu beobachten. Die Akkumulation am vegetalen Kortex erfolgt hier schon während des Stadiums II der Oogenese und bleibt dort bis zum Stadium VI auf einen relativ engen Bereich am Apex des vegetalen Kortex beschränkt. In Schnitten von Stadium II Oozyten, in denen die Transkripte zuvor durch die whole mount in situ-Hybridisierung detektiert wurden, kann die Lokalisation der RNAs in einem keilförmigen Bereich, der sich vom Zellnukleus bis zum vegetalen Kortex erstreckt, sowie deren Akkumulation in einem 
halbmondförmigen Bereich unterhalb des Zellkerns, nachgewiesen werden in dem sich auch die Komponenten der mitochondrialen Wolke nach deren Deassemblierung befinden Abb. 3.10 und Abb. 3.15. In anderen Arbeiten wurde eine derartige Verteilung und Anreicherung den RNAs des späten (Vg1) oder intermediären Verteilungsweges (fatvg) in Stadium III Oozyten zugeordnet (Chan et al., 1999). Einem Modell von Kloc und Etkin, (1995) zufolge werden die RNAs des frühen Transportweges in der dem vegetalen Kortex der Oozyte zugewandten METRO-Region der mitochondrialen Wolke angereichert und zusammen mit dieser zum vegetalen Kortex transportiert, bevor spät lokalisierende RNAs wie Vg1 in der keilförmigen Region nachzuweisen sind. Die in dieser Arbeit gezeigte Anreicherung von früh lokalisierten RNAs in der keilförmigen Region konnte in ähnlicher Weise auch schon von anderen Arbeitsgruppen für früh lokalisierte RNAs wie Xwnt11, Xotx1 und Xdazl beobachtet werden und so ist denkbar, daß der Transport von früh lokalisierenden RNAs nicht ausschließlich von der METRO-Region vermittelt wird, sondern auch über die keilförmige Region nach der Deassemblierung der mitochondrialen Wolke (King et al., 1999; Pannese et al., 2000). Vorangehend konnte gezeigt werden, daß früh lokalisierte RNAs in unterschiedliche Bereiche der METRO-Region der mitochondrialen Wolke verteilt werden und daß dort eine differentielle Verteilung in unterschiedliche Kompartimente des Keimplasmas, die in granulär-fibrilläres Material (GFM), Keimgranula und Matrix unterschieden werden, in Stadium I Oozyten aufweisen (Kloc et al., 2002; Kloc und Etkin, 1995). Die METRO-Region der mitochondrialen Wolke könnte also als eine Art Sortierungsort für Keimplasma-spezifische RNAs dienen, der vegetale Transport jedoch auch unabhängig von dieser erfolgen.

Ein Argument für eine partielle Überlappung des frühen und späten Transportweges lieferte so auch die Beobachtung, daß die fatvg-RNA ein intermediäres Lokalisationsverhalten aufweist. Diese akkumuliert erst in späten Stadium I Oozyten in der mitochondrialen Wolke, kann aber im Stadium III, wie Vg1, auch in den halbmond- und keilförmigen Regionen unterhalb des Zellnukleus nachgewiesen werden und ist dann wie spät lokalisierende RNAs auch über den Kortex der gesamten vegetalen Hälfte verteilt nachzuweisen (Chan et al., 1999).

Aufgrund der in dieser Arbeit beobachteten Anreicherung der früh lokalisierten DEADSouth- und XNIF-RNA in der keilförmigen Region und der halbmondförmigen Struktur unterhalb des Zellnukleus in Stadium II Oozyten kann postuliert werden, daß die beiden unterschiedlichen Verteilungswege also nicht klar voneinander abgrenzbar sind, sondern teilweise überlappen. Die METRO-Region der mitochondrialen Wolke könnte als Ort dienen, an dem früh lokalisierte RNAs mit Faktoren assemblieren, die ihre spätere Verteilung auf den Apex des vegetalen Kortex beschränken, der vegetale Transport jedoch auch durch Komponenten der keilförmigen Region erfolgt, über die dann zum späteren Zeitpunkt der Oogenese auch die Sortierung der spät lokalisierenden RNAs vermittelt wird. Hinweise auf die Überlappung der Transportprozesse liefert so auch die Beobachtung, daß früh lokali- 
sierte RNAs auch nach Injektion in spätere Stadien vegetal lokalisiert werden, da sie dann vermutlich jedoch nicht mit Komponenten der mitochondrialen Wolke assemblieren konnten, in der für spät lokalisierende RNAs typischen Weise, über den Kortex der gesamten vegetalen Hemisphäre verteilt werden Abb. 3.24 und Abb. 3.25.

\section{3 Äquatorial lokalisierte RNAs-ein neuer Transportweg?}

Neben Transkripten, die hauptsächlich Charakteristika der frühen und späten vegetalen Transportwege in Xenopus Oozyten aufweisen, konnte in dieser Arbeit eine RNA identifiziert werden, die in einer bisher nicht beschriebenen Weise am Äquator der Oozyte angereichert wird. Der Beginn dieses Transportprozesses scheint zeitlich parallel mit demjenigen der spät lokalisierenden RNAs einherzugehen. So ist die RNA dieses Transportweges (B2B-2B) in den Stadien II-III der Oogenese am vegetalen Pol der Oozyte nachzuweisen, liegt dort jedoch auf einen ringförmigen Bereich beschränkt vor Abb. 3.14. Mit Fortschreiten der Oogenese scheint dieser kortikale Ring vom vegetalen Pol in Richtung der animalen Hemisphäre bis zum Äquator der Oozyte zu migrieren, wo die RNA dann bis zum Stadium VI zu detektieren ist. Interessanterweise kann auch das ansonsten Charakteristika der spät lokalisierenden RNAs aufweisende XPTB-Transkript in Stadium III Oozyten in diesem ringförmigen Bereich des vegetalen Kortex nachgewiesen werden Abb. 3.4. Möglicherweise überlappt also der Transportweg der äquatorialen RNA partiell mit demjenigen der spät lokalisierten RNAs. Die äquatoriale RNA wird jedoch während des kortikalen Transports nicht über den ganzen Bereich der vegetalen Hemisphäre verteilt, sondern wird bis zum Äquator transportiert und nur dort verankert. Alternativ könnte das B2B-2B-Transkript auch als eine Art Initiator oder Organisator für den kortikalen Transport spät lokalisierter RNAs dienen, indem es den Bereich des Kortex markiert, an dem entlang diese Transkripte verteilt und verankert werden. In Doppel-in situHybridisierungen mit antisense RNA-Proben verschiedener RNAs des späten Transportweges gekoppelt mit der B2B-2B-Probe könnte nachgewiesen werden, inwieweit diese beiden Verteilungswege möglicherweise überlappen oder räumlich voneinander getrennt ablaufen. Denkbar ist auch, daß die B2B-2B-RNA am Äquator eine Art Barrierefunktion einnimmt, und die Migration von RNAs in weiter animal gelegene Bereiche des Kortex verhindert. Strukturelle Funktionen bei der Verankerung lokalisierter RNAs am vegetalen Pol konnten so auch schon für andere RNAs wie die nichtkodierenden Xlsirts oder das VegT-Transkript nachgewiesen werden (Heasman et al., 2001; Kloc und Etkin, 1994). Interessant wäre es, in diesem Zusammenhang $\mathrm{zu}$ untersuchen, ob sich das Lokalisationsmuster der spät lokalisierten RNAs nach Depletion der B2B-2B-RNA (oder des möglicherweise von diesem kodierten Proteins) verändert und sich in weiter animal gelegene Bereiche des Kortex ausbreitet. 


\subsection{Analyse der Transportsignalsequenzen lokalisierter RNAs}

Dem gängigen Modell zufolge wird der gerichtete zytoplasmatische Transport von RNAs von Signalsequenzen vermittelt, die sich typischerweise im 3'-untranslatierten Bereich der Transkripte befinden. So konnten bisher auch die RNA-Lokalisationselemente einiger weniger vegetal lokalisierter RNAs aus Xenopus Oozyten identifiziert werden, die jedoch keine augenscheinliche Konsensus-Sequenz oder Struktur aufweisen (siehe 1.4). Um auch die Lokakalisationssequenzen der im Rahmen dieser Arbeit identifizierten vegetal lokalisierten RNAs einzugrenzen, wurde das System der Mikroinjektion von RNAFusionskonstrukten verwendet und so konnten für drei der untersuchten RNAs die jenigen RNA-Sequenzbereiche identifiziert und eingegrenzt werden, die hinreichend sind, den vegetalen Transport einer Reporter-RNA zum vegetalen Kortex zu vermitteln.

Das Transportsignal der spät lokalisierten 6E-RNA konnte im 3'-untranslatierten Bereich nachgewiesen und bis auf einen 75 Nukleotide umfassenden Bereich eingegrenzt werden Abb. 3.22 und schematisch dargestellt in Abb. 4.1). In dieser Sequenz scheinen sich keine augenfälligen charakteristischen RNA-Elemente, wie zum Beispiel wiederholte Nukleotidsequenzabfolgen, zu befinden. Im Lokalisationselement der ebenfalls spät lokalisierten Vg1-mRNA konnten mehrere repetitive Elemente identifiziert werden, von denen die sogenannten E2- und VM1-Elemente eine zentrale Rolle beim vegetalen Transport der RNA und der Bindung an zelluläre Faktoren zu spielen scheinen (Deshler et al., 1998; Deshler et al., 1997; Gautreau et al., 1997; Havin et al., 1998). Zwei dieser E2-Elemente lassen sich auch im kodierenden Bereich der 6E-RNA nachweisen, stehen hier jedoch nicht in funktionellem Zusammenhang mit dem vegetalen Transport, da sich in Injektktionsexperimenten diesem Bereich keine Transportaktivität zuordnen läßt. Der Transport der spät lokalisierten 6E-RNA erfolgt also unabhängig von E2- oder VM1Elementen.

Für viele der in verschiedenen Spezies und RNAs identifizierten Lokalisationselemente können unter Verwendung von computerbasierten Strukturanalyseprogrammen die Ausbildung von zum Teil komplexen Sekundärstrukturen, die charakteristische Haarnadelschleifen beinhalten, vorhergesagt werden und deren funktionelle Relevanz in einigen Fällen auch experimentell bestätigt werden konnte (Ainger et al., 1997; Chartrand et al., 1999; Gonzalez et al., 1999; MacDonald, 1990; Seeger und Kaufman, 1990; Serano und Cohen, 1995). Auch für das Lokalisationselement der 6E-RNA kann aufgrund computerbasierter Strukturvorhersagen und vorläufiger enzymatischer Strukturanalysen die Ausbildung von Haarnadelstrukturen postuliert werden Abb. 3.23. Hinweise auf deren Funktion beim RNA-Transport konnten in dieser Arbeit durch Injektionen von Deletionskonstrukten gewonnen werden, in denen diese entfernt wurden. Weitergehende Analysen des Transportsignals, die gezielte stem-loop-zerstörende und erhaltende Muta- 
tionen, sowie Nukleotidaustausche im Bereich der einzelsträngigen RNA-Schleifen und enzymatische oder chemische Strukturanalysen beinhalten sollten, könnten hierbei detailliertere Information über die Ausbildung von RNA-Sekundärstrukturen des 6ELokalisationselementes und deren funktionelle Bedeutung beim vegetalen Transport geben. Überdies könnten diese RNAs in Proteinbindungsexperimenten auf ihre spezifische Interaktion mit bekannten Proteinen (Vg1-RBP, VgRBP60 und Prrp) oder auch Proteinen des Oozytenextraktes hin untersucht werden.

Neben dem Transportsignal der spät lokalisierten 6E-RNA wurden in Injektionsexperimenten auch die RNA-Lokalisationselemente der früh lokalisierten XNIF- und DEADSouthRNA eingegrenzt. In der XNIF-RNA konnten zwei unterschiedlich effiziente Lokalisationselemente im 5'-untranslatierten Bereich der mRNA nachgewiesen werden Abb. 3.24 und Abb. 4.1). Die ungewöhnliche Lokalisation von Transportelementen im 5'-UTR stellt eine Besonderheit dar und wurde bisher nur für die gurken- und yemanuclein-alpha-RNAs in Drosophila beschrieben (Capri et al., 1997; Saunders und Cohen, 1999; Thio et al., 2000). Die Existenz des ungewöhnlich langen 5'-untranslatierten Bereiches in der XNIFRNA läßt vermuten, daß dieser bei der Translationsregulation der RNA eine wichtige Rolle spielen könnte und daß diese Funktion möglicherweise mit dem Lokalisationsprozeß gekoppelt ist.

Im 3'-untranslatierten Bereich der DEADSouth-RNA konnten ebenfalls zwei Elemente identifiziert werden, die jedoch vermutlich den Transport entlang verschiedener Lokalisationswege vermitteln. Die funktionelle Redundanz von Lokalisationselementen, das heißt die Existenz mehrerer Signalsequenzen in der zu lokalisierenden mRNA, konnte vorangehend auch schon für andere RNAs wie zum Beispiel der fatvg-RNA aus Xenopus oder der Ash1-mRNA aus der Hefe nachgewiesen werden (Chan et al., 1999; Chartrand et al., 1999; Gonzalez et al., 1999). Möglicherweise dient die Anwesenheit mehrerer Lokalisationssequenzen der Gewährleistung der effizienten subzellulären Anreicherung der RNA.

In den Injektionsexperimenten konnte beobachtet werden, daß die beiden Elemente der XNIF-RNA sich in ihrer Transportaktivität unterschieden lassen. Während das LE-1Reporterfusionskonstrukt nach Injektion sehr deutlich am vegetalen Pol lokalisiert ist, kann für die RNA der LE-2-Fusion hier nur eine schwache Anreicherung beobachtet werden Abb. 3.24. Möglicherweise wurden bei der Generierung der Subfragmente des 5'-UTRs Teilsequenzen dieses Lokalisationselementes entfernt, die für einen effizienten Transport benötigt werden. Nach weiterem Eingrenzen der Minimalsequenzen des LE-1 auf einen 130 Nukleotide umfassenden Bereich ist so ebenfalls eine leichte Abnahme der Lokalisationseffizienz nachzuweisen, d. h. das auch noch weiter 3'-gelegene Sequenzen für eine effektivere Lokalisation benötigt werden könnten.

Da die Lokalisationssignalsequenzen auf zwei Bereiche im 5'-untranslatierten Bereich der RNA eingegrenzt werden konnten, die zwar E2-Elemente und das LE-1 auch noch ein VM1-Element besitzt, andere nicht lokalisierende Fragmente aber auch diese Elemente 
enthalten, konnte hier keine direkte Korrelation zwischen der Anwesenheit dieser Elemente und der Transportaktivität nachgewiesen werden. Darüberhinaus weisen die Lokalisationselemente der XNIF-RNA weder untereinander augenscheinliche Sequenzähnlichkeiten auf, noch können Ähnlichkeiten $\mathrm{zu}$ den bereits bekannten Lokalisationselementen früh oder spät lokalisierter RNAs nachgewiesen werden.

* E2-Element UUCAC

\# VM1-Element UUUCUA
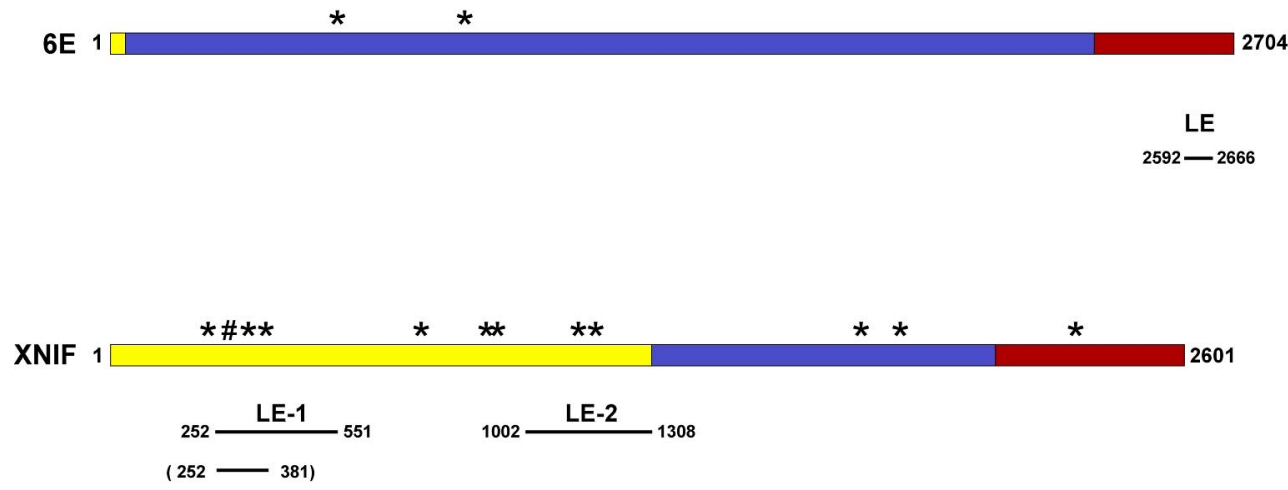

** $* \#$ \#

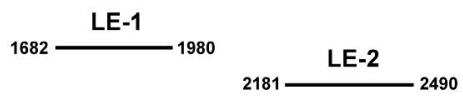

Abb. 4.1 Schematische Übersicht über die in Injektionsexperimenten eingegrenzten Signalsequenzen vegetal lokalisierter RNAs Die spät (6E) bzw. früh lokalisierten (XNIF und DEADSouth) RNAs sind schematisch dargestellt. Gelbe Bereiche stehen für 5'-untranslatierte Sequenzen, blaue für Bereiche der offenen Leserahmens und rote für 3'-untranslatierte Bereiche. Angegeben sind ebenfalls die diesen Bereichen entsprechenden Nukleotidpositionen der cDNAs. Die in den Injektionsexperimenten identifizierten und eingegrenzten Lokalisationselemente sind jeweils unterhalb der entsprechenden schematisch dargestellten RNA eingezeichnet und deren Nukleotidpositionen angegeben. Das 130 Nukleotide enthaltende Fragment der XNIF-RNA, das eine etwas abgeschwächte Lokalisationsfähigkeit aufweist, ist in Klammern dargestellt. Ebenfalls sind die Positionen der RNAs markiert, in denen VM1(Raute)- und E2(Sternchen)-Elemente identifiziert werden konnten.

Nach Injektion der Reporterkonstrukte der Lokalisationselemente-1 der XNIF- sowie der DEADSouth-RNA in Stadium I Oozyten konnte deren Anreicherung in der mitochondrialen Wolke nachgewiesen werden, was darauf hinweist, daß diese Lokalisationselemente beide Funktionen früh lokalisierter RNAs, nämlich die Anreicherung in der mitochondrialen Wolke im Stadium I sowie die Vermittlung des vegetalen Transports in Stadium II-III Oozyten, aufweisen (siehe Abb. 3.26. Da, wie unter 4.2 beschrieben wurde, eine gewisse Überlappung zwischen den Transportprozessen früh lokalisierender und spät lokalisierender RNAs zu bestehen scheint, zeigen auch die XNIF- und DEADSouth-RNA, bzw. deren Lokalisationselemente, nach Injektion in spätere Oozytenstadien eine für spät lokalisierte 
RNAs charakteristische Verteilung über den gesamten vegetalen Cortex. Dies konnte so vorangehend auch schon für einige andere RNAs des frühen Transportweges gezeigt werden (Hudson und Woodland, 1998; Kloc et al., 1993; Zhou und King, 1996). Sequenzen, die diesen späten Transport vermitteln, überlappen in der Xcat2-RNA mit denjenigen, die die Akkumulation in der mitochondrialen Wolke vermitteln, sind aber umgekehrt nicht hinreichend, um eine solche für früh lokalisierte RNAs charakteristische Anreicherung zu vermitteln (Zhou und King, 1996; Zhou und King, 1996). In den XNIF- und DEADSouthTranskripten scheinen jedoch zumindestens die ersten Lokalisationselemente der RNAs alle drei Transportaktivitäten (Akkumulation in der mitochondrialen Wolke, Lokalisation am vegetalen Pol in Stadium II Oozyten sowie die Verteilung entsprechend dem späten Transportweg in Stadium III-IV Oozyten) ineinander zu vereinen.

Im Gegensatz zum Lokalisationselement-1-Konstrukt vermittelt das Lokalisationselement2 der DEADSouth-RNA ausschließlich die Lokalisation und Verteilung des Transkriptes entsprechend dem späten Transportweg (siehe Abb. 3.25). Möglicherweise überlappen hier also wie bei Xcat2 die Signalsequenzen, die für eine Lokalisation entlang des frühen Transportweges benötigt werden, partiell mit denen des späten Verteilungsweges. Die für die Akkumulation in der mitochondrialen Wolke nötigen Teilsequenzen könnten also in dem Lokalisationselement-2-Konstrukt deletiert worden sein und die RNA vermittelt somit nur noch die Verteilung entlang des späten Transportweges.

Aufgrund der visuellen Identifizierung von VM1-Elementen in RNAs des früh lokalisierenden Typs wurde deren Lokalisationsfähigkeit entsprechend dem späten Verteilungsweg erklärt, jedoch nicht experimentell erwiesen (Havin et al., 1998; Kloc et al., 2001; Kloc et al., 1993; Yaniv und Yisraeli, 2001; Zhou und King, 1996). Ein VM1-Element kann nur im Lokalisationselement-1 der XNIF-RNA, nicht jedoch in denen der DEADSouth-RNA, nachgewiesen werden, und somit konnte diese Hypothese einer Korrelation zwischen der Anwesenheit von VM1-Elementen und der Lokalisationsfähigkeit früh lokalisierter Transkripte entlang des späten Transportweges in dieser Arbeit widerlegt werden (vergl. Abb. 4.1).

Die Identifizierung von Lokalisationselementen unterschiedlicher Lokalisierungstypen im RNA-Injektionsexperiment und die Beobachtung, daß RNA-Elemente, die in Stadien injiziert werden, in denen die endogene RNA bereits lokalisiert vorliegt, ein von diesen verschiedenes Lokalisationsverhalten aufweisen, wirft die Frage nach deren funktioneller Bedeutung im Kontext der Lokalisation der endogenen RNA auf. Möglicherweise gewährleistet die Fähigkeit von RNA-Lokalisationselementen des früh lokalisierenden Typs, auch diejenige des spät lokalisierenden Typs vermitteln zu können, deren Lokalisation am vegetalen Kortex auch dann, wenn diese möglicherweise verzögert exprimiert wurden oder zum Zeitpunkt des frühen Lokalisationsweges nicht in der mitochondriale Wolke angereichert wurden. Weiterhin unklar bleibt die Frage, inwieweit die beiden Lokalisationsprozesse 
früh lokalisierter RNAs, Akkumulation in der mitochondrialen Wolke im Stadium I und Transport zum vegetalen Kortex im Stadium II der Oogenese, miteinander verknüpft sind, und ob letzterer ausschließlich über die METRO-Region der mitochondrialen Wolke vermittelt wird, oder partiell auch durch die in dieser Arbeit nachgewiesene keilförmige Region erfolgen kann. Nach Injektion früh lokalisierender RNAs in Stadium I Oozyten könnte deren Verteilung von der Akkumulation in der mitochondrialen Wolke bis zum Transport im Stadium II verfolgt werden, was jedoch eine relativ lange Inkubationszeit der Oozyten erfordert, und so konnte bisher auch nicht nachgewiesen werden ob in vitro kultivierte Oozyten über einen längeren Zeitraum ihre vegetale Lokalisationsfähigkeit beibehalten.

Neben der Eingrenzung der Lokalisationssignale der spät bzw. früh lokalisierten 6E-, XNIF- und DEADSouth-RNA, wurde auch das Lokalisationsverhalten der äquatorial angereicherten B2B-2B-RNA im Injektionsexperiment untersucht. Da bisher noch nicht die vollständige cDNA dieses Transkriptes isoliert werden konnte, wurde hier nur der vorliegende Bereich der cDNA injiziert, der vermutlich dem 3'-untranslatierten Bereich der RNA entstammt. So konnte im Injektionsexperiment gezeigt werden, daß dieser hinreichend ist, eine Akkumulation der Reporter RNA in der ringförmigen Region zu vermitteln, die auch von der endogenen RNA eingenommen wird Abb. 3.27. In den meisten Fällen wird die RNA jedoch nach Injektion nicht lokalisiert sondern liegt über die Oozyte verteilt vor. Hierin könnte die Tatsache wiedergespiegelt sein, daß nur eine Teilsequenz der cDNA injiziert wurde und für eine effektive Lokalisation der Transkripte zusätzlich noch angrenzende Bereiche der RNA erforderlich sind. Möglicherweise ist dieser neu identifizierte Verteilungsweg in Injektionsexperimenten aber auch schwer nachzustellen und wird durch die in vitro-Bedingungen, mit denen die Oozyten für mehrere Tage in Kultur gehalten werden, nur unzureichend unterstützt. Neben einem VM1- und mehreren E2-Elementen weist diese RNA auch mehrere Uridin-reiche Bereiche auf, deren Bedeutung für den Transport der RNA jedoch nicht weitergehend untersucht wurde.

\subsection{Rekrutierung zellulärer Faktoren durch RNA-Lokalisationselemente: früh und spät lokalisierte RNAs weisen ein differentielles Bindungsverhalten auf}

RNA-Lokalisationssequenzen stellen Sequenz- oder Strukturmotive dar, die spezifisch von transagierenden Faktoren erkannt werden. Diese Lokalisationselement-interagierenden Proteine sind dabei vermutlich Adapterproteine, die eine molekulare Brücke zwischen der zu lokalisierenden RNA und zellulären Motorproteinen bilden, und die dann den Transport entlang von Filamenten des Zytoskeletts vermitteln (siehe Abb. 1.1). Bisher wurden nur Proteine genauer charakterisiert, die an das Lokalisationselement der Vg1-mRNA binden und vermutlich an deren Transport zum vegetalen Kortex beteiligt sind. Mit der Fragestel- 
lung, ob sich die Lokalisationselemente von RNAs unterschiedlicher Sortierungswege möglicherweise durch ein differentielles Protein-Bindungsverhalten unterscheiden lassen, wurden deshalb in dieser Arbeit Quervernetzungsstudien und Koimmunopräzipitationsexperimente mit den Lokalisationselementen der hier identifizierten früh und spät lokalisierten RNAs durchgeführt.

Der Annahme folgend, daß die Lokalisation von RNAs desselben Lokalisationstyps durch dieselben an diese bindende Proteine vermittelt wird, sollten sich diese somit auch in den Quervernetzungsversuchen erhaltenen Bindungsmuster ähneln bzw. gleichen. Diese Annahme konnte in der vorliegenden Arbeit so auch für die Lokalisationselemente der beiden spät lokalisierten RNAs Vg1 und 6E bestätigt werden. Die hier erhaltenen Proteinbindungsmuster ähneln so auch demjenigen, das in den UV-Quervernetzungsstudien von Mowry, (1996) für das Vg1-Lokalisationselement nachgewiesen werden konnte, weisen jedoch auch noch weitere spezifisch quervernetzte Proteine auf (eine Quervernetzung wurde in Mowry, (1996) für die p78, p69, p60, p40, p36 und p33 Proteine gezeigt). Obwohl das 6E-Element keinerlei VM1- und E2-Elemente aufweist, denen eine Schlüsselfunktion bei der Lokalisation der Vg1-RNA und Bindung von an deren Transport beteiligten Proteinen wie Vg1-RBP und VgRBP60 nachgesagt wurde, wird dieses nach Injektion in Oozyten lokalisiert und weist im UV-Quervernetzungsversuch ein $\mathrm{zu}$ demjenigen des Vg1Elementes identisches Bindungsverhalten auf Abb. 3.29 und Tab.3.2). Wie auch schon in anderen Arbeiten postuliert wurde, scheinen also Proteine, die an RNALokalisationssequenzen binden, keine definierten kurzen Sequenzelemente zu erkennen, sondern die Interaktion beruht vermutlich vielmehr auf einem Zusammenspiel des Erkennens von Sekundärstrukturelementen der RNA und möglicherweise sequenzspezifischen Interaktionen mit einzelsträngigen Bereichen in den Haarnadelstrukturen. Durch Einfügen von gezielten Deletionen- und Nukleotidaustauschen in RNA-Lokalisationselemente und die anfolgende detaillierte Analyse deren Lokalisations- und Proteininteraktionsfähigkeit könnte in weiterführenden Arbeiten diese Fragestellung untersucht werden.

In den UV-Quervernetzungsmustern der spät lokalisierten Vg1- und 6E-Elemente können auch zwei Banden einer relativen Molekülmasse von 69 und 75 kDa nachgewiesen werden, die dem Vg1-RBP(VERA) entsprechen könnten. (Vg1-RBP und VERA wurden parallel in unterschiedlichen Labors isoliert, die jedoch ein unterschiedliches Laufverhalten des Proteins im Polyacrylamidgel beschreiben). Bei dem hier identifizierten $69 \mathrm{kDa}$ Protein scheint es sich jedoch um ein nicht sequenzspezifisch RNA-bindendes Protein zu handeln, da auch eine, wenn auch etwas schwächere, Interaktion mit der nichtlokalisierten lacZ-Kontroll-RNA nachgewiesen wurde. Die Tatsache, daß bei der affinitätschromatographischen Anreicherung des Vg1-RBPs(VERA) dessen Affinität für Einzelstrang-RNA (verwendet wurden Heparin-Sepharose- bzw. Einzelstrang-DNA-Zellulose-Matrices) ge- 
nutzt wurde, deutet jedoch auch darauf hin, daß dieses in gewissem Umfang auch sequenzunspezifische RNA-Interaktionsaktivität besitzt.

Für das 75 kDa große Protein kann neben der Interaktion mit den Vg1- und 6E-Elementen auch die Bindung an das Lokalisationselement-1 der XNIF-RNA und das Lokalisationselement-1 der DEADSouth-RNA nachgewiesen werden. Handelt es sich dabei um das Vg1-RBP, so scheint dessen Bindungsaktivität also nicht auf Lokalisationselemente von RNAs des späten Transportweges beschränkt zu sein. Hinweise darauf konnten auch in UV-Quervernetzungsexperimenten mit der früh lokalisierten Xcat2-RNA gewonnen werden (Havin et al., 1998). Zur Klärung der Identitäten der interagierenden Proteine könnten mit Immunopräzipitationsanalysen gekoppelte UV-Quervernetzungsversuche durchgeführt werden. Dies ist vor allem auch im Hinblick auf die Zuordnung des Vg1-RBPs zu den Banden der 69 bzw. 75 kDa großen Proteine von Interesse, da ersteres in den hier gezeigten UV-Quervernetzungsexperimenten eher eine sequenzunspezifische RNABindungsaktivität aufweist. Die Bindungsergebnisse der in dieser Arbeit durchgeführten in vitro Koimmunopräzipitationsexperimente lassen ebenfalls an der präferentiellen Bindungsaktivität des Vg1-RBPs für Elemente spät lokalisierter RNAs zweifeln. Hier scheint dieses sogar selektiv mit den Elementen der früh lokalisierten XNIF-RNA zu interagieren und zeigt nahezu keine Bindung an Vg1, 6E oder das Lokalisationselement der DEADSouth-RNA.

Die von Zhao et al., (2001) beschriebene präferentielle Bindungsaktivität des Prrp für Lokalisationselemente spät lokalisierter RNAs konnte auch in den in vitro Koimmunopräzipitationsexperimenten der vorliegenden Arbeit bestätigt werden. Prrp besitzt eine relative Molekülmasse von $39 \mathrm{kDa}$ und so gehört auch ein Protein der Größe von $38 \mathrm{kDa}$, das diesem entsprechen könnte, zu der Population von Proteinen, die in den in dieser Arbeit durchgeführten UV-Quervernetzungsversuchen spezifisch an die Lokalisationselemente der spät lokalisierten Vg1- und 6E-RNAs bindet. Das p38-Protein bindet auch an das Lokalisationselement der früh lokalisierten DEADSouth-RNA, die sich jedoch aus bisher ungeklärten Gründen in den in vitro Bindungsexperimenten in vielerlei Hinsicht wie eine spät lokalisierte RNA verhält. Obwohl es sich bei dieser um eine früh lokalisierte RNA handelt, entspricht das im UV-Quervernetzungsversuch erhaltene Bindungsmuster demjenigen der spät lokalisierten RNAs wie Vg1 und 6E Abb. 3.29und Abb. 3.30. Möglicherweise ist die Affinität der DEADSouth RNA-Lokalisationselemente für Faktoren des frühen Transportweges geringer als z. B. die der XNIF-RNA und kann deshalb im UV-Quervernetzungsexperiment nicht nachgewiesen werden. In den gezeigten Experimenten wurden stets Proteinextrakte verwendet, die aus Oozyten aller Stadien der Oogenese gewonnen wurden. Möglicherweise ist die Konzentration der Proteine des frühen Transportweges relativ gering und diese können von weniger affinen Elementen im in vitro Interaktionsexperiment deshalb nicht gebunden werden. Die Verwendung von stadienspezifischen Extrakten, in denen die Transportfaktoren der spezifischen Verteilungswege angereichert sein sollten, könnte hier Klärung bringen. Interessant wäre in diesem 
Zusammenhang auch zu untersuchen, ob sich das Bindungsmuster der lokalisierten RNAs in Extrakten verschieder Stadien unterscheidet, Proteine also eventuell frühen oder späten Schritten des Lokalisationsprozesses zugeordnet werden können. Das Bindungsverhalten des DEADSouth-Lokalisationselementes-1 im Koimmunopräzipitationsexperiment ist nicht eindeutig demjenigen früh oder spät lokalisierter RNAs zuzuordnen. Während sich dieses bezüglich der Vg1-RBP-Bindung ebenso wie die parallel untersuchten spät lokalisierenden Vg1- und 6E-Lokalisationselemente verhält, daß heißt von diesem nur sehr schwach gebunden wird, ist das Verhalten bezüglich der Prrp-Bindung eher demjenigen der Elemente der früh lokalisierten XNIF-RNA zuzuordnen. Hierin könnte eine unterschiedliche Art der kortikalen Verankerung der Transkripte widergespiegelt sein. So scheint DEADSouth möglicherweise, wie andere früh lokalisierte RNAs auch, aufgrund ihrer Assoziation mit dem Keimplasma am vegetalen Kortex festgehalten zu werden, Vg1 dort jedoch in einer von dieser verschiedenen (Prrp-abhängigen?) Weise verankert zu werden (Alarcon und Elinson, 2001; Kloc et al., 2002).

Auch in den in dieser Arbeit durchgeführten Injektionsexperimenten konnte gezeigt werden, daß früh lokalisierte RNAs Lokalisationselemente besitzen, die den Transport entlang des Verteilungsweges spät lokalisierender RNAs vermitteln können. Diese sollten daher also auch von denselben Proteinen gebunden werden, die auch den späten Transportweg vermitteln. Im UV-Quervernetzungsversuch konnten so auch vier Proteine der Größen 78, 75,45 und $42 \mathrm{kDa}$ identifiziert werden, die sowohl mit Elementen spät, als auch früh lokalisierter RNAs quervernetzt werden, und die somit einem Proteinkomplex zugeordnet werden könnten, der die Lokalisation entlang des späten Transportweges vermittelt.

In den UV-Quervernetzungsstudien konnten zwei Proteine (p33 und p38) identifiziert werden, die nur mit Elementen spät lokalisierter RNAs interagieren und zu denen vermutlich auch das im Koimmunopräzipitationsexperiment untersuchte Prrp zählt. In gekoppelten in situ-Hybridisierungs und immunzytochemischen Analysen, konnte eine Kolokalisation von Prrp mit der Vg1-RNA am vegetalen Kortex von Stadium IV Oozyten nachgewiesen werden (Zhao et al., 2001). Die Beobachtungen, daß die Prolin-reiche Domäne des Prrp mit Profilin interagiert, einem Protein, das in Prozesse der Aktinpolymerisation involviert ist und mit Mikrofilament-assoziierten Proteinen wie Mena interagiert, sowie die Bindungsaktivität von Prrp für animal lokalisierte RNAs, lassen vermuten, daß dieses eher an der Verankerung lokalisierter RNAs mit den Elementen des Zytoskellets des Zielorts, oder deren dortiger Organisation beteiligt ist, als am Transportprozeß selbst (Gertler et al., 1996; Schluter et al., 1997; Zhao et al., 2001). Früh lokalisierte RNAs könnten also nach Injektion in späte Oozytenstadien dieselben Transportfaktoren wie spät lokalisierende RNAs für den Transport zum vegetalen Kortex rekrutieren, sich von diesen aber in der Art und Weise ihrer dortigen Verankerung unterscheiden. 
Proteine die an Lokalisationselemente binden, müssen so auch nicht zwingend direkt am Transportprozeß beteiligt sein, sondern könnten auch Funktionen wie die translationale Repression der RNA o. a. ausüben. So konnten z. B. auch in UV-Quervernetzungsstudien mit dem Translationskontrollelement der Vg1-mRNA spezifisch mit diesem interagierende Proteine identifiziert werden, die in ihren molekularen Größen teilweise mit denen, die in dieser Arbeit als Lokalisationselement-bindende Proteine identifiziert wurden, übereinstimmen (36, 42, 45 und $60 \mathrm{kDa}$ ) (Otero et al., 2001; Wilhelm et al., 2000). Interessanterweise konnte kürzlich gezeigt werden, daß das ubiquitäre Xp54-Protein, das auch in den hier gezeigten UV-Quervernetzungsversuchen mit Lokalisationselementen interagiert und das für eine DEAD-Box RNA-Helikase kodiert, in die nukleäre Assemblierung von mRNA-Partikeln, deren Export ins Zytoplasma und deren translationaler Repression involviert zu sein scheint (Minshall et al., 2001; Smillie und Sommerville, 2002). Die Beobachtung, daß auch das Drosophila Ortholog des Xenopus Xp54, ME31B, die Translation maternaler RNAs während ihres Transports von den Ammenzellen in die Oozyte unterdrückt, leitet zu der Annahme, daß die beiden Prozesse des Transports und der Translationsregulation einer lokalisierten RNA möglicherweise miteinander verbunden sind, d. h. eine RNA die sich im Lokalisationsprozeß befindet unterliegt auch der translationalen Repression (Nakamura et al., 2001).

In den UV-Quervernetzungsstudien können interresanterweise zwei Proteine einer Größe von 62 und $66 \mathrm{kDa}$ nachgewiesen werden, die selektiv mit den Elementen der früh lokalisierten XNIF-RNA interagieren und somit Kandidaten für Proteinfaktoren darstellen, die ausschließlich am Transportweg früh lokalisierter RNAs beteiligt sind Abb. 3.29 und Abb. 3.30. Das p40-Protein zeigt ebenfalls eine sehr starke Bindung an diese Elemente, interagiert jedoch auch in etwas schwächerer Weise mit der lacZ-RNA und kann mit dieser kompetiert werden, so daß die sequenzspezifität dessen Bindungsverhaltens unklar bleibt. Unterschiede weisen diese beiden RNA-Elemente in ihrer Bindung an die 75 und $78 \mathrm{kDa}$ großen Proteine, die auch mit Elementen spät lokalisierender RNAs interagieren, auf. Während diese vom Lokalisationselement-1 gebunden werden, ist für das Element-2 keine Interaktion nachzuweisen. Dieser Unterschied im Bindungsverhalten korreliert mit der Effizienz, mit der die Elemente die Lokalisation der lacZ-Reporter RNA vermitteln. Während das Lokalisationselement-1 in Injektionsexperimenten sehr effizient die Akkumulation am vegetalen Pol vermittelt, ist für das zweite Element in diesen Experimenten dort eine sehr viel schwächere Anreicherung zu beobachten (vergl. Abb. 3.24. Möglicherweise wird die Bindung dieser Proteine für eine der endogenen RNA entsprechenden Effizienz des vegetalen Transports benötigt und kann ohne diese nur in schwächerer Form vermittelt werden. Die in den UV-Quervernetzungs- und Koimmunopräzipitationsexperimenten untersuchten Proteine können aufgrund ihrer Bindungsspezifität für Elemente früh bzw. spät lokalisierter RNAs in drei verschiedene Gruppen unterteilt werden: 
1. „generelle“-Lokalisationselemente bindende Proteine, wie das p78, p75, p45 und p42, die keine differentielle Bindungsaktivität aufweisen und gleichermaßen die Elemente frühund spät lokalisierter RNAs binden. Zu diesen zählt vermutlich auch das 69 bzw. 75 kDa große Vgl-RBP.

2. Proteine, die spezifisch mit Elementen von spät lokalisierten RNAs interagieren, wie das p33 und p38, wobei letzteres vermutlich das Prrp ist, dessen differentielles Bindungsverhalten an spät lokalisierte RNAs auch im Koimmunopräzipitationsexperiment gezeigt wurde.

3. Proteine, die spezifisch mit Elementen der früh lokalisierten XNIF-RNA interagieren, wie das p62 und p66.

\subsection{Korrelation des Proteinbindungs- und Lokalisationsverhaltens vegetal lokali- sierter RNAs}

Aufgrund der in dieser Arbeit erhaltenen Ergebnisse zum Lokalisationsverhalten vegetal angereicherter RNAs und dem Bindungsverhalten Lokalisationselement-interagierender Proteine läßt sich ein erweitertes Modell des vegetalen Transports von RNAs in Xenopus Oozyten postulieren, in dem den unterschiedlichen Schritten der Lokalisationsprozesse an diesen möglicherweise beteiligte Proteine zugeordnet werden können (Abb. 4.2):

1. Während des Stadiums I der Oogenese akkumulieren früh lokalisierende RNAs in der Struktur der mitochondrialen Wolke und werden dort (vermutlich über die METRORegion) in verschiedene Kompartimente des Keimplasmas verteilt. Hier erfolgt auch die Assoziation mit Faktoren, über die die Lokalisation der RNAs späterhin auf einen begrenzten Bereich des vegetalen Kortex beschränkt wird. Zwei Kandidaten sind hierbei möglicherweise die p62- und p66-Proteine, die im UV-Quervernetzungsexperiment selektiv mit den Elementen der früh lokalisierten XNIF-RNA interagieren.

2. Während des Stadiums II der Oogenese deassembliert die mitochondriale Wolke und die früh lokalisierenden RNAs werden zum vegetalen Kortex verbracht. Hieran könnten möglicherweise auch die Proteine beteiligt sein, die ein ,generelles“ Bindungsverhalten für Lokalisationselemente aufweisen (p78, p75, p45, p42 und Vg1-RBP). Früh lokalisierte RNAs, die in Oozyten dieses Stadiums injiziert werden, lokalisieren den endogenen RNAs entsprechend und können so vermutlich auch noch nach Deassemblierung der mitochondrialen Wolke im keilförmigen Bereich mit deren Komponenten assoziieren und transportiert werden.

3. Im frühen Stadium III erfolgt die Verankerung früh lokalisierter RNAs in der begrenzten Region am vegetalen Kortex. Die Restriktion auf diesen Bereich wird wahrscheinlich von 
Faktoren vermittelt, mit denen die RNAs während ihres Aufenthaltes in der mitochondrialen Wolke assemblieren konnten. Die während des Stadiums I und II ubiquitär im Zytoplasma verteilt vorliegenden spät lokalisierenden RNAs werden nun in der ehemals von Komponenten der mitochondrialen Wolke eingenommenen keilförmigen Region angereichert und zum vegetalen Kortex transportiert. Dieser Transport erfolgt mikrotubuliabhängig und wird möglicherweise von den ,generellen“ Lokalisationselemente-bindenden Proteinen p78, p75, p45, p42 und Vg1-RBP vermittelt. Auch früh lokalisierte RNAs, die in Oozyten dieses Stadiums injiziert werden, können von diesen gebunden und entlang des späten Verteilungsweges transportiert werden.

4. In Stadium IV Oozyten werden die spät lokalisierten RNAs vom Apex ausgehend über den Kortex der gesamten vegetalen Hemisphäre verteilt. Diese Verteilung könnte möglicherweise über die für XPTB und B2B-2B beschriebene ringförmige Region erfolgen. An der kortikalen Verankerung dieser RNAs sind möglicherweise die spezifisch mit Elementen spät lokalisierter RNAs interagierenden Proteine p33 und p38 (Prrp?) beteiligt. Früh lokalisierte RNAs, die in späte Stadien der Oogenese injiziert wurden, werden in diesem Stadium, da sie sie nicht mit Komponenten der mitochondrialen Wolke assemblieren konnten, nicht auf den Apex beschränkt lokalisiert, sondern ebenfalls über den Kortex der gesamten vegetalen Hemisphäre verteilt, möglicherweise jedoch p33/p38-unabhängig verankert.

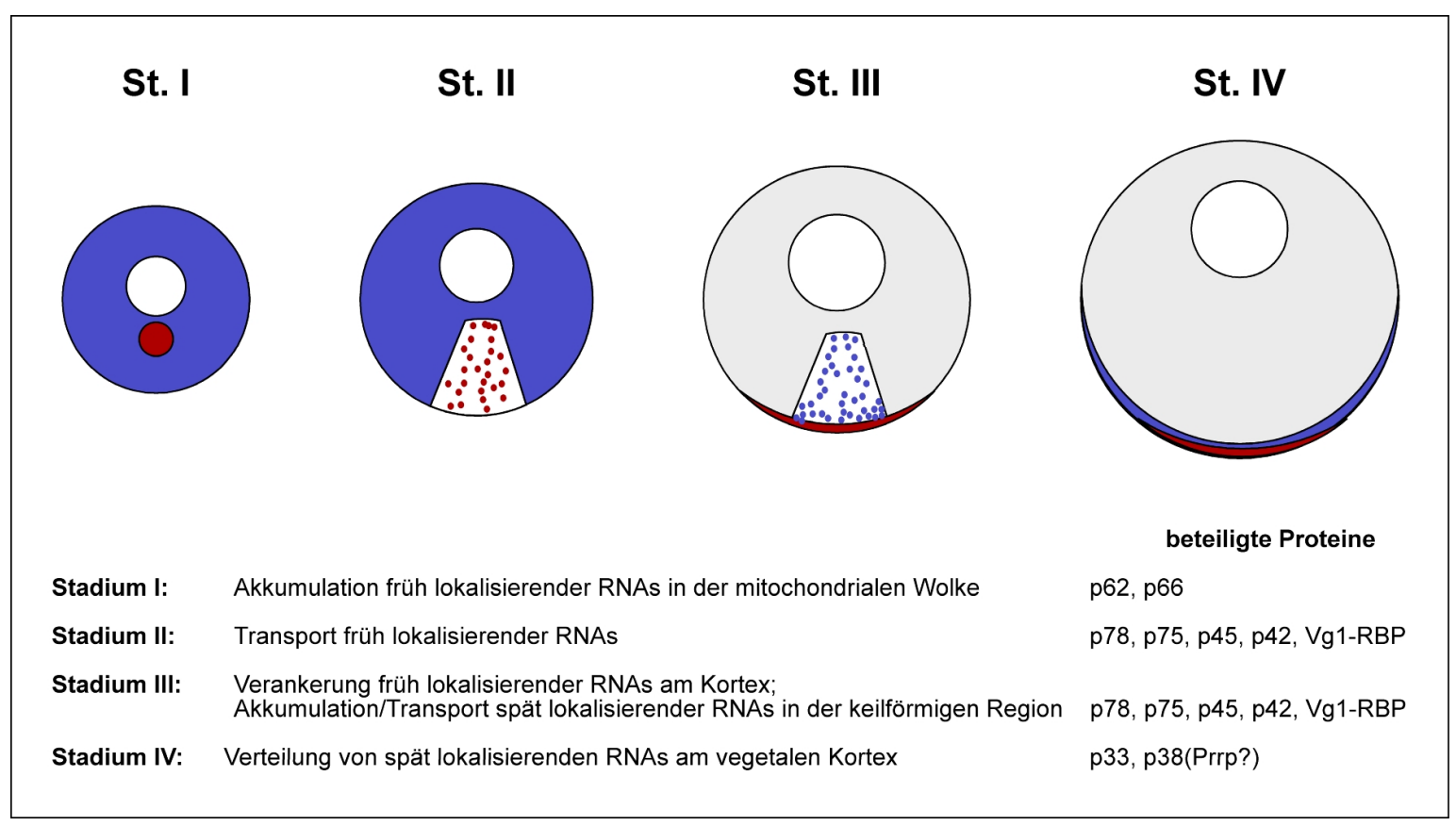

Abb. 4.2 Erweitertes Modell des vegetalen RNA-Transports in Xenopus Oozyten und daran beteiligter Proteine. Gezeigt ist die Verteilung lokalisierter RNAs in unterschiedlichen Oozytenstadien, sowie die möglicherweise an den verschiedenen Schritten des Lokalisationsprozesses beteiligten Proteine. RNAs des früh lokalisierenden Typs sind in rot, die des späten Verteilungsweges in blau dargestellt. 
Inwieweit das hier für die im Rahmen dieser Arbeit untersuchten lokalisierten RNAs aufgestellte erweiterte Modell des vegetalen Transports auch auf andere RNAs anzuwenden ist, sollte in weiterführenden Experimenten noch untersucht werden. Es ist daher von besonderem Interesse, auch weitere Lokalisationselemente früh und spät lokalisierter RNAs $\mathrm{zu}$ isolieren und diese in vergleichenden Analysen auf ihr Transport- und spezifisches Proteinbindungsverhalten hin $\mathrm{zu}$ untersuchen. In UV-Quervernetzungsexperimenten mit stadienspezifischen Extrakten könnte dann auch detaillierter ermittelt werden, welchem Schritt des Lokalisationsprozesses die spezifische Proteinbindung zuzuordnen ist. Weiterhin sollte untersucht werden, warum auch früh lokalisierende RNAs wie DEADSouth ein für spät lokalisierende RNAs typisches Quervernetzungsmuster aufweisen können und ob dieses auch in vivo funktionell relevant ist. Von besonderem Interesse ist auch die weitere Charakterisierung von spezifisch mit Lokalisationselementen früh lokalisierter RNAs interagierender Proteine wie den p62 und p66 Proteinen. Diese könnten zunächst affinitätschromatographisch aufgereinigt und dann nach der massenspektroskopischen Analyse und Klonierung der entsprechenden cDNA genauer charakterisiert werden. Durch die Aufreinigung größerer Transportkomplexe könnten so möglicherweise auch Proteine identifiziert werden, die eine Adapterfunktion zwischen der zu lokalisierenden RNA und Komponenten des Zytoskeletts vermitteln.

\subsection{DEADSouth ist möglicherweise in die Entwicklung der primordialen Keimzel- len involviert}

In Xenopus, wie auch in vielen anderen Organismen, beruht die korrekte frühe Embryonalentwicklung auf der asymmetrischen Verteilung maternaler RNAs und Proteine im Ei. Während vegetal lokalisierte RNAs wie Vg1, VegT und Xwnt11 in Prozesse der Achsenbildung und Keimblattspezifizierung involviert sind, scheint eine andere Gruppe vegetal lokalisierter RNAs, die sich im Keimplasma befinden, an der Spezifizierung der primordialen Keimzellen beteiligt zu sein. Komponenten des Xenopus Keimplasmas und diesem entsprechende Bereiche des Polplasmas in Drosophila oder die P-Granula in C. elegans, üben Funktionen wie die translationale Repression, Regulation der Zellmigration und Kontrolle der mitotischen Teilungen der primordialen Keimzellen aus (Houston und King, 2000; Kloc et al., 2001; Mahowald, 2001; Saffman und Lasko, 1999).

In der vorliegenden Arbeit konnte eine vegetal lokalisierte DEADSouth-Isoform isoliert werden, die während der frühen Entwicklung auch in den migrierenden primordialen Keimzellen des Embryos exprimiert wird. Die hier isolierte DEADSouth-Isoform unterscheidet sich von derjenigen Form, die in der Arbeitsgruppe von M.L. King isoliert wurde, durch eine 15 Aminosäuren umfassende Deletion im N-terminalen Bereich des Proteins (MacArthur et al., 2000) (siehe Abb. 3.12. Auffällig ist, daß sich die in der vorliegenden Arbeit nachgewiesene stadien- und gewebespezifische Expression von DEADSouth von 
derjenigen, die von der Gruppe um M.L. King beschrieben wurde, unterscheidet. Unter Verwendung einer 350 Nukleotide langen Probe aus dem kodierenden Bereich der DEADSouth cDNA konnte in der RNAse-Protektion die Expression des Gens nur bis zum Stadium 10 der Embryogenese nachgewiesen werden. Die verwendete Probe umfaßt auch den Bereich in dem sich die beiden DEADSouth-Isoformen unterscheiden und weist somit auf ein unterschiedliches Expressionsverhalten der beiden Varianten hin. In der NorthernHybridisierung konnte mit einer antisense Probe, die 50 Nukleotide des offenen Leserahmens und das 1,6 kb große 3'-UTR umfaßt und somit beide DEADSouth-Isoformen nachweisen sollte, die Expression im Ovar und Testis des adulten Tieres, nicht jedoch im Rückenmark, Gehirn und Leber, wie sie in der vorliegenden Arbeit beschrieben wurde, detektiert werden. Eine mögliche unterschiedliche Expression der beiden DEADSouthIsoformen, deren Proteine sich nur durch eine 15 Aminosäuren umfassende Deletion bzw. Insertion unterscheiden, könnte auf eine unterschiedliche Funktion dieser während der Keimzellentwicklung und möglicherweise auch in adulten Geweben hinweisen.

Durch gezielte Einführungen von Punktmutationen wurde in dieser Arbeit eine DEADSouth-Mutante erstellt, bei der ein Aminosäureaustausch von Glutaminsäure (E) nach Glutamat (Q) im DEAD-Box-Motiv des Proteins eingeführt wurde. Nach der Misexpression dieser vermutlich dominant negativ wirkenden Form des Proteins in Xenopus Embryonen, konnten Hinweise auf eine mögliche Funktion des Proteins bei der lokalen Verteilung der migrierenden primordialen Keimzellen gewonnen werden Abb. 3.32. Während Kontrollembryonen in Stadium 34 eine relativ verstreute Verteilung der primordialen Keimzellen aufwiesen, schienen diese in injizierten Embryonen in wenigen Inseln zusammengelagert zu werden. Eine ähnliche Zusammenlagerung der primordialen Keimzellen konnte vorangehend auch schon nach der antisense Oligonukleotid-vermittelten Depletion der XDazl-RNA beobachtet werden (Houston und King, 2000). Die Bedeutung dieser Aggregation ist bisher jedoch noch unklar. Eine ähnliche abnormale Zusammenlagerung der primordialen Keimzellen konnte auch in Polzellen von Drosophila beobachtet werden, die keine nanos-Aktivität aufweisen, was auf eine wichtige Rolle der Regulation der Zelladhäsion bei der Entwicklung primordialer Keimzellen in unterschiedlichen Spezies hinweisen könnte (Forbes und Lehmann, 1998).

DEAD-Box RNA-Helikasen sind in eine Vielzahl von Prozessen des RNA-Metabolismus, wie Transkription, Prozessierung, Translation und Degradation, von RNAs involviert, wodurch eine mögliche funktionelle Zuordnung der hier beschriebenen Effekte dieser DEADSouth-Mutante erschwert wird. Die beiden DEADSouth-Homologen aus der Hefe und dem Menschen, Dbp5(Rat8p) und hDbp5, assoziieren mit den zytoplasmatischen Fibrillen der Kernpore und sind am nukleären Export von mRNAs beteiligt (Schmitt et al., 1999; Snay-Hodge et al., 1998). Vermutlich besteht, zumindest in einigen Organismen, eine gewisse Redundanz dieser Proteine beim nukleären Export, da zum Beispiel in RNAInaktivierungsexperimenten (RNAi) in Drosophila gezeigt werden konnte, daß deren 
Dbp5-Homolog, das DBP80, nicht essentiell für das Wachstum der Zelle ist (Eisen et al., 1998; Gatfield et al., 2001). Möglicherweise existieren also in Xenopus mehrere Dbp5artige RNA-Helikasen, von denen das hier isolierte DEADSouth-Homologe spezifisch den Kernexport einer Subpopulation von RNAs in den primordialen Keimzellen regulieren könnte.

\subsection{Funktion von XNIF (B2B-10B) während der Oogenese und Embryogenese}

Die XNIF-RNA ist eine früh lokalisierte RNA und liegt in Stadium VI Oozyten, wie auch DEADSouth, auf einen relativ kleinen Bereich des vegetalen Kortex beschränkt vor. Anders als diese bleibt XNIF nach der Fertilisierung jedoch nicht auf die vegetalen Blastomeren beschränkt und segregiert mit den primordialen Keimzellen, sondern scheint in frühen Embryonalstadien auch in animalen Bereichen vorzuliegen. Zum Zeitpunkt der Neurulation ist das Einsetzen zygotischer Expression von XNIF in den sich entwickelnden Somiten nachzuweisen, was auf möglicherweise unterschiedliche Funktionen von XNIF in der Oozyte und frühen Embryonalstadien sowie späteren Stadien, hinweist (siehe Abb. 3.18. Auch die RNA von Xwnt11, die für ein sezerniertes Signalmolekül der Wnt-Familie kodiert, wird in Oozyten entsprechend dem frühen Verteilungsweg vegetal lokalisiert und mit der Maturierung des Eis vom Kortex abgelöst und ins Zytoplasma entlassen $(\mathrm{Ku}$ und Melton, 1993). Die Expression von Xwnt11 bleibt jedoch im Gegensatz zu XNIF während der frühen Embryogenese bestehen und ist in der marginalen Zone der späten Blastula, in der Urmundlippe und späterhin in einem Ring um den sich schließenden Blastoporus nachzuweisen. Interessanterweise ist auch Xwnt11 ebenso wie XNIF in späteren Stadien in den Somiten zu detektieren, wobei die Funktion bei der Somitogenese jedoch unklar ist.

Ein kürzlich beschriebenes zum XNIF homologes Protein ist das Xenopus XOs4-Protein, das an der Mesoderminduktion und der dorsalen Achsenbildung im Embryo beteiligt ist, und so könnte möglicherweise auch XNIF in die Regulation dieser Prozesse der frühen Embryogenese involviert sein (Zohn und Brivanlou, 2001). Das XNIF weist ebenso wie die in anderen Spezies identifizierten XNIF-Homologen die hoch konservierte NIFDomäne im C-terminalen Bereich des Proteins auf. Benannt wurde die NIF-Domäne nach dem homologen Protein aus dem Hühnchen, das mit dem nukleären Lim-interagierenden Protein NLI (das auch LIM binding domain, Ldb1 oder Cofactor of LIM homeodomain proteins, CLIM genannt wird) zu interagieren scheint (beschrieben unter DatenbankEingangsnummer AF189773) und sehr eng mit dem in dieser Arbeit isolierten Homolog aus Xenopus verwandt ist (vergl. Abb. 3.17. NLI ist ein nukleäres Protein, das spezifisch mit den LIM-Domänen einer bestimmten Klasse von Transkriptionsfaktoren interagiert (Jurata et al., 1998). Die LIM-Domäne ist ein evolutiv hoch konserviertes Motiv, das in vielen Proteinen mit wichtigen regulativen Funktionen bei der Zellentwicklung nachgewiesen werden kann (Jurata und Gill, 1998). Möglicherweise agiert also XNIF gemeinsam mit 
NLI und LIM-Proteinen und ist an der Regulation der Transkription spezieller Zielgene im frühem Embryo bzw. bei der Somitogenese beteiligt.

Überexpressionsstudien in Xenopus-Embryonen und Proteininteraktionsstudien mit den Xenopus NLI und Lim-Proteinen könnten in Zukunft möglicherweise einen Einblick in die Funktion von XNIF bei der frühen Embryogenese ermöglichen (Agulnick et al., 1996; Breen et al., 1998; Karavanov et al., 1996; Rebbert und Dawid, 1997; Taira et al., 1992; Taira et al., 1994; Taira et al., 1997).

\subsection{Mögliche Funktionen von XPTB während der Embryogenese und bei der Le- berentwicklung}

Wie auch die XNIF-RNA ist die XPTB-RNA, die vermutlich für ein konserviertes Protein mit einer Phosphotyrosinbindungsdomäne kodiert, nach der Fertilisierung in frühen Stadien nicht mehr nur auf vegetale Bereiche des Embryos beschränkt, sondern kann auch in animalen Blastomeren nachgewiesen werden (siehe Abb. 3.8). Ab dem Stadium 32 ist die spezifische Expression der XPTB-RNA in der embryonalen Leberanlage nachweisbar.

Die Vertebraten-Leber entwickelt sich aus dem ventralen Vorderdarmendoderm, aus dem auch die Vorläufergewebe der Lunge, des Pankreas und der Schilddrüse hervorgehen (Rossi et al., 2001). In Xenopus geht das Endoderm aus den dotterreichen Zellen hervor, die in der vegetalen Hälfte des frühen Embryos lokalisiert sind und so scheinen auch vegetal lokalisierte RNAs wie XBic-C und VegT an der Bildung und Regulation der endodermalen Genexpression beteiligt zu sein (Chan und Etkin, 2001; Clements et al., 1999; Grapin-Botton und Melton, 2000; Munoz-Sanjuan und Brivanlou, 2001; Wessely und De Robertis, 2000; Xanthos et al., 2001; Yasuo und Lemaire, 2001; Zhang et al., 1998).

Die Leber-Organogenese läßt sich in drei unterschiedliche Prozesse unterteilen: 1. Die Formation des Endoderms und Sensitivität bestimmter Bereiche desselben für Signale aus bestimmten Bereichen des Mesoderms, 2. die Spezifizierung, während derer hepatische Gene im ventralen Vorderdarmendoderm aktiviert werden und 3. die Differenzierung während derer die Leberknospe vom mesenchymalen Gewebe des Septum transversum umgeben wird und als abgegrenzte Organanlage erkennbar wird (Zaret, 2000). In Zusammenfassungen der Expressionsmuster in der Leber exprimierter Gene ist erkennbar, daß viele in ihrer Expression nicht auf dieses Gewebe beschränkt sind sondern auch im Darm und anderen endodermalen Geweben nachzuweisen sind (Zorn und Mason, 2001). Die Expression des hier isolierten XPTB ist in der in situ-Hybridisierung nur auf die Leberanlage beschränkt nachzuweisen und die mögliche Funktion desselben bei der Leberentwicklung ist deshalb von besonderem Interesse.

XPTB weist das Motiv der Phospotyrosinbindungsdomäne auf, eine Proteininteraktionsdomäne, die in vielen Signaltransduktionsmolekülen nachgewiesen werden konnte 
(Cowburn, 1997; Forman-Kay und Pawson, 1999; Shoelson, 1997). Es scheint also möglich, das dieses Protein in Signaltransduktionsprozesse bei der Endoderm-Spezifizierung im frühen Embryo und bei der Leberentwicklung involviert ist. Eine Analyse der Expression und Funktion des sehr stark homologen, hypothetischen Proteins aus dem Menschen könnte Einblicke in die möglicherweise konservierte Funktion dieses PTB-Motiv-Proteins gewähren.

\subsection{Funktion von 6E während der Oogenese und frühen Embryogenese}

Die Expression der 6E-RNA ist auf die Stadien der Oogenese und frühen Embryogenese beschränkt und kann in späteren Entwicklungsstadien in der in situ-Hybridisierung und RT-PCR nicht mehr nachgewiesen werden Abb. 3.3. In adulten Geweben wird das Transkript sehr stark im Ovar und etwas schwächer auch in den Testis, dem Gehirn und dem Rückenmark exprimiert. Die Funktion des von der 6E-RNA kodierten hypothetischen Proteins, das keine Homologien zu bereits bekannten Proteinen anderer Spezies oder konservierte Proteinmotive aufweist, ist vermutlich auf den Zeitraum der Oogenese und frühen Embryogenese beschränkt. Die Lokalisation der RNA am vegetalen Kortex und die Restriktion seiner Expression auf die frühe Phase der Entwicklung läßt vermuten, daß diese, oder das von ihr kodierte Protein, möglicherweise an der Regulation anderer lokalisierter RNAs beteiligt sein könnte, was beispielsweise auch Prozesse wie die Verankerung der lokalisierten RNAs am Kortex oder die translationale Kontrolle derselben mit einschließen könnte. Genauere Analysen der Lokalisation des Proteins in Oozyten durch immunhistochemische Analysen könnten hier einen Einblick in mögliche Funktionen von 6E bei der Verankerung von vegetalen RNAs und translationalen Kontrolle während früher Stadien der Embryogenese geben.

In der in situ-Hybridisierungs-basierten Durchmusterung der Kortex cDNA-Bibliothek konnten mehrere unabhängige cDNAs isoliert werden, die vermutlich unterschiedliche Spleißvarianten derselben mRNA sind. Diese Varianten kodieren für hypothetische Proteine, die einen identischen N-Terminus aufweisen, sich jedoch im C-terminalen Bereich in Aminosäuresequenz und Länge unterscheiden (vergl. 7.1 und 7.2 im Anhang). Die Funktionen dieser beiden Proteinvarianten ist bisher unklar.

Interessanterweise scheinen sich 6E und die entsprechenden alternativen Spleißvarianten den genomischen Locus mit dem Xenopus XPc1, das für ein Protein der Polycomb-Gruppe kodiert, zu teilen, werden jedoch von unterschiedlichen Strängen der DNA transkribiert (Strouboulis et al., 1999). So überlappt der sehr lange 3'-untranslatierte Bereich der XPc1cDNA partiell mit kodierenden Regionen und 3'-untranslatierten Bereichen der 6E-cDNA (siehe Abb. 3.2. Ob darüber hinaus auch funktionelle Zusammenhänge zwischen XPc1 und den 6E-Varianten bestehen ist bisher ungeklärt. 


\section{Zusammenfassung}

Die Lokalisation von mRNAs am vegetalen Kortex der Xenopus Oozyte erfolgt über mindestens zwei unterscheidbare Verteilungswege und stellt einen wichtigen Mechanismus der Restriktion maternaler Determinanten auf bestimmte Bereiche der Oozyte und des sich entwickelnden Embryos dar.

Mit dem Ziel, neue vegetal lokalisierte RNA-Moleküle zu isolieren, wurde in der vorliegenden Arbeit eine cDNA-Bibliothek erstellt, die angereichert vegetal-kortikal lokalisierte RNAs enthält. Diese wurde in einer whole mount in situ-Hybridisierungs-basierten Durchmusterung auf vegetal lokalisierte Transkripte durchsucht und so konnten neben der Reisolierung bereits bekannter lokalisierter Transkripte auch vier neue lokalisierte RNAs identifiziert werden, die sich aufgrund ihres charakteristischen Verteilungsmusters den sogenannten frühen oder späten Sortierungswegen zuordnen lassen. Ein weiteres Transkript lokalisiert in einer bisher nicht beschriebenen Weise am äquatorialen Kortex der Oozyte und ist somit einem neuen Lokalisationstyp zuzuordnen.

In Mikroinjektionsexperimenten wurden die Lokalisationselemente drei dieser RNAs auf 75 bis 300 Nukleotide lange Bereiche in den 3'- bzw. 5'-untranslatierten Regionen eingegrenzt, die den vegetalen Transport einer Reporter-RNA entlang des frühen bzw. des späten Verteilungsweges vermitteln können. Diese cis-agierenden Elemente weisen keine charakteristischen Konsensussequenzen auf, sondern bilden vermutlich spezifische Sekundärstrukturelemente aus, die dann von zellulären Transportfaktoren erkannt werden.

In UV-Quervernetzung- und Koimmunopräzipitationsexperimenten konnte nachgewiesen werden, daß die Lokalisationselemente unterschiedlicher Sortierungswege ein differentielles Bindungsverhalten an Proteine aus Xenopus Oozyten Extrakten, sowie an bekannte Lokalisationselement-bindende Proteine (Vg1RBP und Prrp) aufweisen. Die interagierenden Proteine können dabei in drei verschiedene Klassen unterteilt werden: 1. Proteine, die präferentiell mit Elementen früh lokalisierter RNAs interagieren, 2. Proteine, die selektiv mit Elementen spät lokalisierender RNAs assoziieren und 3. Proteine, die eine generelle Bindungsaktivität für Lokalisationselemente aufweisen und die somit unterschiedlichen Prozessen bei der Lokalisation vegetal angereicherter RNAs zugeordnet werden könnten.

Darüber hinaus konnten durch die Misexpression einer dominant-negativen Mutante Hinweise auf eine mögliche Funktion der früh lokalisierten DEADSouth-RNA an der Migration der primordialen Keimzellen gewonnen werden. 


\section{Literaturverzeichnis}

Agulnick, A. D., Taira, M., Breen, J. J., Tanaka, T., Dawid, I. B. und Westphal, H. (1996). Interactions of the LIM-domain-binding factor Ldb1 with LIM homeodomain proteins. Nature 384, 270-2.

Ainger, K., Avossa, D., Diana, A. S., Barry, C., Barbarese, E. und Carson, J. H. (1997). Transport and localization elements in myelin basic protein mRNA. J. Cell Biol. 138, 1077-87.

Alarcon, V. B. und Elinson, R. P. (2001). RNA anchoring in the vegetal cortex of the Xenopus oocyte. J. Cell Sci. 114, 1731-41.

Altschul, S. F., Gish, W., Miller, W., Myers, E. W. und Lipman, D. J. (1990). Basic local alignment search tool. J. Mol. Biol. 215, 403-10.

Aronov, S., Aranda, G., Behar, L. und Ginzburg, I. (2001). Axonal tau mRNA localization coincides with tau protein in living neuronal cells and depends on axonal targeting signal. J. Neurosci. 21, 6577-87.

Bashirullah, A., Cooperstock, R. L. und Lipshitz, H. D. (1998). RNA localization in development. Annu. Rev. Biochem. 67, 335-94.

Bashirullah, A., Halsell, S. R., Cooperstock, R. L., Kloc, M., Karaiskakis, A., Fisher, W. W., Fu, W., Hamilton, J. K., Etkin, L. D. und Lipshitz, H. D. (1999). Joint action of two RNA degradation pathways controls the timing of maternal transcript elimination at the midblastula transition in Drosophila melanogaster. EMBO J. 18, 2610-20.

Bassell, G. J., Oleynikov, Y. und Singer, R. H. (1999). The travels of mRNAs through all cells large and small. FASEB J. 13, 447-54.

Bassell, G. J., Zhang, H., Byrd, A. L., Femino, A. M., Singer, R. H., Taneja, K. L., Lifshitz, L. M., Herman, I. M. und Kosik, K. S. (1998). Sorting of beta-actin mRNA and protein to neurites and growth cones in culture. J. Neurosci. 18, 251-65.

Beach, D. L., Salmon, E. D. und Bloom, K. (1999). Localization and anchoring of mRNA in budding yeast. Curr. Biol. 9, 569-78.

Berleth, T., Burri, M., Thoma, G., Bopp, D., Richstein, S., Frigerio, G., Noll, M. und Nüsslein-Volhard, C. (1988). The role of localization of bicoid RNA in organizing the anterior pattern of the Drosophila embryo. EMBO J. 7, 1749-56.

Bertrand, E., Chartrand, P., Schaefer, M., Shenoy, S. M., Singer, R. H. und Long, R. M. (1998). Localization of ASH1 mRNA particles in living yeast. Mol. Cell 2, 437-45.

Böhl, F., Kruse, C., Frank, A., Ferring, D. und Jansen, R. P. (2000). She2p, a novel RNA-binding protein tethers ASH1 mRNA to the Myo4p myosin motor via She3p. EMBO J. 19, 5514-24.

Bouvet, P., Matsumoto, K. und Wolffe, A. P. (1995). Sequence-specific RNA recognition by the Xenopus Ybox proteins. An essential role for the cold shock domain. J. Biol. Chem. 270, 28297-303. 
Bouvet, P. und Wolffe, A. P. (1994). A role for transcription and FRGY2 in masking maternal mRNA within Xenopus oocytes. Cell 77, 931-41.

Breen, J. J., Agulnick, A. D., Westphal, H. und Dawid, I. B. (1998). Interactions between LIM domains and the LIM domain-binding protein Ldb1. J. Biol. Chem. 273, 4712-7.

Brendza, R. P., Serbus, L. R., Duffy, J. B. und Saxton, W. M. (2000). A function for kinesin I in the posterior transport of oskar mRNA and Staufen protein. Science 289, 2120-2.

Broadus, J. und Doe, C. Q. (1997). Extrinsic cues, intrinsic cues and microfilaments regulate asymmetric protein localization in Drosophila neuroblasts. Curr. Biol. 7, 827-35.

Broadus, J., Fuerstenberg, S. und Doe, C. Q. (1998). Staufen-dependent localization of prospero mRNA contributes to neuroblast daughter-cell fate. Nature 391, 792-5.

Bullock, S. L. und Ish-Horowicz, D. (2001). Conserved signals and machinery for RNA transport in Drosophila oogenesis and embryogenesis. Nature 414, 611-616.

Capri, M., Santoni, M. J., Thomas-Delaage, M. und Ait-Ahmed, O. (1997). Implication of a 5 ' coding sequence in targeting maternal mRNA to the Drosophila oocyte. Mech. Dev. 68, 91-100.

Chan, A. P. und Etkin, L. D. (2001). Patterning and lineage specification in the amphibian embryo. Curr. Top. Dev. Biol. 51, 1-67.

Chan, A. P., Kloc, M., Bilinski, S. und Etkin, L. D. (2001). The vegetally localized mRNA fatvg is associated with the germ plasm in the early embryo and is later expressed in the fat body. Mech. Dev. 100, 137-40.

Chan, A. P., Kloc, M. und Etkin, L. D. (1999). fatvg encodes a new localized RNA that uses a 25-nucleotide element (FVLE1) to localize to the vegetal cortex of Xenopus oocytes. Development 126, 4943-53.

Chartrand, P., Meng, X. H., Singer, R. H. und Long, R. M. (1999). Structural elements required for the localization of ASH1 mRNA and of a green fluorescent protein reporter particle in vivo. Curr. Biol. 9, 333-6.

Chartrand, P., Singer, R. H. und Long, R. M. (2001). Rnp localization and transport in yeast. Annu. Rev. Cell Dev. Biol. 17, 297-310.

Clark, I., Giniger, E., Ruohola-Baker, H., Jan, L. Y. und Jan, Y. N. (1994). Transient posterior localization of a kinesin fusion protein reflects anteroposterior polarity of the Drosophila oocyte. Curr. Biol. 4, 289-300.

Clark, I. E., Jan, L. Y. und Jan, Y. N. (1997). Reciprocal localization of Nod and kinesin fusion proteins indicates microtubule polarity in the Drosophila oocyte, epithelium, neuron and muscle. Development 124, 46170 .

Claußen, M., Rudt, F. und Pieler, T. (1999). Functional modules in ribosomal protein L5 for ribonucleoprotein complex formation and nucleocytoplasmic transport. J. Biol. Chem. 274, 33951-8. 
Clements, D., Friday, R. V. und Woodland, H. R. (1999). Mode of action of VegT in mesoderm and endoderm formation. Development 126, 4903-11.

Cote, C. A., Gautreau, D., Denegre, J. M., Kress, T. L., Terry, N. A. und Mowry, K. L. (1999). A Xenopus protein related to hnRNP I has a role in cytoplasmic RNA localization. Mol. Cell 4, 431-7.

Cowburn, D. (1997). Peptide recognition by PTB and PDZ domains. Curr. Opin. Struct. Biol. 7, 835-8.

Darnbrough, C. H. und Ford, P. J. (1981). Identification in Xenopus laevis of a class of oocyte-specific proteins bound to messenger RNA. Eur. J. Biochem. 113, 415-24.

de la Cruz, J., Kressler, D. und Linder, P. (1999). Unwinding RNA in Saccharomyces cerevisiae: DEAD-box proteins and related families. Trends Biochem. Sci. 24, 192-8. 5_00001376.

Deshler, J. O., Highett, M. I., Abramson, T. und Schnapp, B. J. (1998). A highly conserved RNA-binding protein for cytoplasmic mRNA localization in vertebrates. Curr. Biol. 8, 489-96.

Deshler, J. O., Highett, M. I. und Schnapp, B. J. (1997). Localization of Xenopus Vg1 mRNA by Vera protein and the endoplasmic reticulum. Science 276, 1128-31.

Ding, D., Parkhurst, S. M., Halsell, S. R. und Lipshitz, H. D. (1993). Dynamic Hsp83 RNA localization during Drosophila oogenesis and embryogenesis. Mol. Cell. Biol. 13, 3773-81.

Doyle, G. A., Betz, N. A., Leeds, P. F., Fleisig, A. J., Prokipcak, R. D. und Ross, J. (1998). The c-myc coding region determinant-binding protein: a member of a family of KH domain RNA-binding proteins. Nucleic Acids Res. 26, 5036-44.

Driever, W., Siegel, V. und Nüsslein-Volhard, C. (1990). Autonomous determination of anterior structures in the early Drosophila embryo by the bicoid morphogen. Development 109, 811-20.

Dubnau, J. und Struhl, G. (1996). RNA recognition and translational regulation by a homeodomain protein. Nature 379, 694-9.

Dumont, J. N. (1972). Oogenesis in Xenopus laevis (Daudin). I. Stages of oocyte development in laboratory maintained animals. J. Morphol. 136, 153-79.

Eisen, A., Sattah, M., Gazitt, T., Neal, K., Szauter, P. und Lucchesi, J. (1998). A novel DEAD-box RNA helicase exhibits high sequence conservation from yeast to humans. Biochim. Biophys. Acta 1397, 131-6.

Elinson, R. P., King, M. L. und Forristall, C. (1993). Isolated vegetal cortex from Xenopus oocytes selectively retains localized mRNAs. Dev. Biol. 160, 554-62.

Elisha, Z., Havin, L., Ringel, I. und Yisraeli, J. K. (1995). Vg1 RNA binding protein mediates the association of Vg1 RNA with microtubules in Xenopus oocytes. EMBO J. 14, 5109-14.

Ephrussi, A., Dickinson, L. K. und Lehmann, R. (1991). Oskar organizes the germ plasm and directs localization of the posterior determinant nanos. Cell 66, 37-50. 
Ephrussi, A. und Lehmann, R. (1992). Induction of germ cell formation by oskar. Nature 358, 387-92.

Etkin, L. D. und Lipshitz, H. D. (1999). RNA localization. FASEB J. 13, 419-20.

Ferrandon, D., Koch, I., Westhof, E. und Nüsslein-Volhard, C. (1997). RNA-RNA interaction is required for the formation of specific bicoid mRNA 3' UTR-STAUFEN ribonucleoprotein particles. EMBO J. 16, 1751-8.

Forbes, A. und Lehmann, R. (1998). Nanos and Pumilio have critical roles in the development and function of Drosophila germline stem cells. Development 125, 679-90.

Forman-Kay, J. D. und Pawson, T. (1999). Diversity in protein recognition by PTB domains. Curr. Opin. Struct. Biol. 9, 690-5.

Forristall, C., Pondel, M., Chen, L. und King, M. L. (1995). Patterns of localization and cytoskeletal association of two vegetally localized RNAs, Vg1 and Xcat-2. Development 121, 201-8.

Gard, D. L. (1995). Axis formation during amphibian oogenesis: reevaluating the role of the cytoskeleton. Curr. Top. Dev. Biol. 30, 215-52.

Gard, D. L. (1999). Confocal microscopy and 3-D reconstruction of the cytoskeleton of Xenopus oocytes. Microsc. Res. Tech. 44, 388-414.

Gard, D. L. (1994). Gamma-tubulin is asymmetrically distributed in the cortex of Xenopus oocytes. Dev. Biol. 161, 131-40.

Gard, D. L. und Klymkowsky, M. W. (1998). Intermediate filament organization during oogenesis and early development in the clawed frog, Xenopus laevis. Subcell. Biochem. 31, 35-70.

Garner, C. C., Tucker, R. P. und Matus, A. (1988). Selective localization of messenger RNA for cytoskeletal protein MAP2 in dendrites. Nature 336, 674-7.

Gatfield, D., Le Hir, H., Schmitt, C., Braun, I. C., Kocher, T., Wilm, M. und Izaurralde, E. (2001). The DExH/D box protein HEL/UAP56 is essential for mRNA nuclear export in Drosophila. Curr. Biol. 11, 171621.

Gautreau, D., Cote, C. A. und Mowry, K. L. (1997). Two copies of a subelement from the Vg1 RNA localization sequence are sufficient to direct vegetal localization in Xenopus oocytes. Development 124, 5013-20.

Gerber, W. V., Yatskievych, T. A., Antin, P. B., Correia, K. M., Conlon, R. A. und Krieg, P. A. (1999). The RNA-binding protein gene, hermes, is expressed at high levels in the developing heart. Mech. Dev. 80, 7786.

Gertler, F. B., Niebuhr, K., Reinhard, M., Wehland, J. und Soriano, P. (1996). Mena, a relative of VASP and Drosophila Enabled, is implicated in the control of microfilament dynamics. Cell 87, 227-39.

Gonzalez, I., Buonomo, S. B., Nasmyth, K., und von Ahsen, U. (1999). ASH1 mRNA localization in yeast involves multiple secondary structural elements and Ash1 protein translation. Curr. Biol. 9, 337-40. 
Gonzalez-Reyes, A., Elliott, H. und St Johnston, D. (1997). Oocyte determination and the origin of polarity in Drosophila: the role of the spindle genes. Development 124, 4927-37.

Gonzalez-Reyes, A., Elliott, H. und St Johnston, D. (1995). Polarization of both major body axes in Drosophila by gurken-torpedo signalling. Nature $375,654-8$.

Grapin-Botton, A. und Melton, D. A. (2000). Endoderm development: from patterning to organogenesis. Trends Genet. 16, 124-30.

Gutzeit, H. O. (1986). The role of microfilaments in cytoplasmic streaming in Drosophila follicles. J. Cell Sci. 80, 159-69.

Hausen, P. und Riebesell, M. (1991). The Early Development of Xenopus Laevis; Springer-Verlag.

Havin, L., Git, A., Elisha, Z., Oberman, F., Yaniv, K., Schwartz, S. P., Standart, N. und Yisraeli, J. K. (1998). RNA-binding protein conserved in both microtubule- and microfilament- based RNA localization. Genes Dev. 12, 1593-8.

Hays, T. und Karess, R. (2000). Swallowing dynein: a missing link in RNA localization? Nat. Cell Biol. 2, E60-2.

Heasman, J., Wessely, O., Langland, R., Craig, E. J. und Kessler, D. S. (2001). Vegetal localization of maternal mRNAs is disrupted by VegT depletion. Dev. Biol. 240, 377-86.

Hoek, K. S., Kidd, G. J., Carson, J. H. und Smith, R. (1998). hnRNP A2 selectively binds the cytoplasmic transport sequence of myelin basic protein mRNA. Biochemistry 37, 7021-9.

Horb, M. E. und Thomsen, G. H. (1997). A vegetally localized T-box transcription factor in Xenopus eggs specifies mesoderm and endoderm and is essential for embryonic mesoderm formation. Development 124, 1689-98.

Houston, D. W. und King, M. L. (2000a). A critical role for Xdazl, a germ plasm-localized RNA, in the differentiation of primordial germ cells in Xenopus. Development 127, 447-56.

Houston, D. W. und King, M. L. (2000b). Germ plasm and molecular determinants of germ cell fate. Curr. Top. Dev. Biol. 50, 155-81.

Houston, D. W., Zhang, J., Maines, J. Z., Wasserman, S. A. und King, M. L. (1998). A Xenopus DAZ-like gene encodes an RNA component of germ plasm and is a functional homologue of Drosophila boule. Development $125,171-80$.

Huang, Y. und Carmichael, G. G. (2001). Nucleocytoplasmic mRNA Transport. Results. Probl. Cell Differ., D. Richter, ed. (Berlin Heidelberg New York: Springer-Verlag), pp. 139-155.

Hudson, C. und Woodland, H. R. (1998). Xpat, a gene expressed specifically in germ plasm and primordial germ cells of Xenopus laevis. Mech. Dev. 73, 159-68. 
Hudson, J. W., Alarcon, V. B. und Elinson, R. P. (1996). Identification of new localized RNAs in the Xenopus oocyte by differential display PCR. Dev. Genet. 19, 190-8.

Jansen, R. P. (2001). mRNA localization: message on the move. Nat. Rev. Mol. Cell Biol. 2, 247-56.

Johnstone, O. und Lasko, P. (2001). Translational regulation and RNA localization in Drosophila oocytes and embryos. Annu. Rev. Genet. 35, 365-406.

Jurata, L. W. und Gill, G. N. (1998). Structure and function of LIM domains. Curr. Top. Microbiol. Immunol. $228,75-113$.

Jurata, L. W., Pfaff, S. L. und Gill, G. N. (1998). The nuclear LIM domain interactor NLI mediates homoand heterodimerization of LIM domain transcription factors. J. Biol. Chem. 273, 3152-7.

Karavanov, A. A., Saint-Jeannet, J. P., Karavanova, I., Taira, M. und Dawid, I. B. (1996). The LIM homeodomain protein Lim-1 is widely expressed in neural, neural crest and mesoderm derivatives in vertebrate development. Int. J. Dev. Biol. 40, 453-61.

Kashikawa, M., Amikura, R. und Kobayashi, S. (2001). Mitochondrial small ribosomal RNA is a component of germinal granules in Xenopus embryos. Mech. Dev. 101, 71-7.

Kashikawa, M., Amikura, R., Nakamura, A. und Kobayashi, S. (1999). Mitochondrial small ribosomal RNA is present on polar granules in early cleavage embryos of Drosophila melanogaster. Dev. Growth. Differ. 41, 495-502.

Kiebler, M. A., Hemraj, I., Verkade, P., Köhrmann, M., Fortes, P., Marion, R. M., Ortin, J. und Dotti, C. G. (1999). The mammalian staufen protein localizes to the somatodendritic domain of cultured hippocampal neurons: implications for its involvement in mRNA transport. J. Neurosci. 19, 288-97.

Kim-Ha, J., Smith, J. L. und Macdonald, P. M. (1991). oskar mRNA is localized to the posterior pole of the Drosophila oocyte. Cell 66, 23-35.

King, M. L. (1995). mRNA localization during frog oogenesis. In "Localized RNAs", H. D. Lipshitz, ed. (Austin, TX: Landes Publishing), pp. 137-148.

King, M. L., Zhou, Y. und Bubunenko, M. (1999). Polarizing genetic information in the egg: RNA localization in the frog oocyte. Bioessays 21, 546-57.

Kislauskis, E. H., Li, Z., Singer, R. H. und Taneja, K. L. (1993). Isoform-specific 3'-untranslated sequences sort alpha-cardiac and beta- cytoplasmic actin messenger RNAs to different cytoplasmic compartments. J. Cell Biol. 123, 165-72.

Kislauskis, E. H., Zhu, X. und Singer, R. H. (1994). Sequences responsible for intracellular localization of beta-actin messenger RNA also affect cell phenotype. J. Cell Biol. 127, 441-51.

Kleiman, R., Banker, G. und Steward, O. (1990). Differential subcellular localization of particular mRNAs in hippocampal neurons in culture. Neuron 5, 821-30. 
Kloc, M., Bilinski, S., Chan, A. P., Allen, L. H., Zearfoss, N. R. und Etkin, L. D. (2001). RNA localization and germ cell determination in Xenopus. Int. Rev. Cytol. 203, 63-91.

Kloc, M., Bilinski, S., Pui-Yee Chan, A. und Etkin, L. D. (2000). The targeting of Xcat2 mRNA to the germinal granules depends on a cis- acting germinal granule localization element within the 3'UTR. Dev. Biol. 217, 221-9.

Kloc, M., Dougherty, M. T., Bilinski, S., Chan, A. P., Brey, E., King, M. L., Patrick, C. W., Jr. und Etkin, L. D. (2002). Three-Dimensional Ultrastructural Analysis of RNA Distribution within Germinal Granules of Xenopus. Dev. Biol. 241, 79-93.

Kloc, M. und Etkin, L. D. (1999). Analysis of Localized RNAs in Xenopus Oocytes. In: A Comparative Methods Approach to the Study of Oocytes and Embryos, J. D. Richter, ed. (Oxford: Oxford University Press Inc.), 256-278.

Kloc, M. und Etkin, L. D. (1998). Apparent continuity between the messenger transport organizer and late RNA localization pathways during oogenesis in Xenopus. Mech. Dev. 73, 95-106.

Kloc, M. und Etkin, L. D. (1994). Delocalization of Vg1 mRNA from the vegetal cortex in Xenopus oocytes after destruction of Xlsirt RNA. Science 265, 1101-3.

Kloc, M. und Etkin, L. D. (1995). Two distinct pathways for the localization of RNAs at the vegetal cortex in Xenopus oocytes. Development 121, 287-97.

Kloc, M., Larabell, C., Chan, A. P. und Etkin, L. D. (1998). Contribution of METRO pathway localized molecules to the organization of the germ cell lineage. Mech. Dev. 75, 81-93.

Kloc, M., Larabell, C. und Etkin, L. D. (1996). Elaboration of the messenger transport organizer pathway for localization of RNA to the vegetal cortex of Xenopus oocytes. Dev. Biol. 180, 119-30.

Kloc, M., Spohr, G. und Etkin, L. D. (1993). Translocation of repetitive RNA sequences with the germ plasm in Xenopus oocytes. Science 262, 1712-4.

Klymkowsky, M. W. (1995). Intermediate filament organization, reorganization, and function in the clawed frog Xenopus. Curr. Top. Dev. Biol. 31, 455-86.

Kobayashi, S., Amikura, R. und Mukai, M. (1998). Localization of mitochondrial large ribosomal RNA in germ plasm of Xenopus embryos. Curr. Biol. 8, 1117-20.

Kobayashi, S., Amikura, R. und Okada, M. (1994). Localization of mitochondrial large rRNA in germinal granules and the consequent segregation of germ line. Int. J. Dev. Biol. 38, 193-9.

Kobayashi, S., Amikura, R. und Okada, M. (1993). Presence of mitochondrial large ribosomal RNA outside mitochondria in germ plasm of Drosophila melanogaster. Science 260, 1521-4.

Köhrmann, M., Luo, M., Kaether, C., DesGroseillers, L., Dotti, C. G. und Kiebler, M. A. (1999). Microtubule-dependent recruitment of Staufen-green fluorescent protein into large RNA-containing granules and subsequent dendritic transport in living hippocampal neurons. Mol. Biol. Cell 10, 2945-53. 
Kozak, M. (1989). The scanning model for translation: an update. J. Cell Biol. 108, 229-41.

Ku, M. und Melton, D. A. (1993). Xwnt-11: a maternally expressed Xenopus wnt gene. Development 119, 1161-73.

Ladomery, M. und Sommerville, J. (1994). Binding of Y-box proteins to RNA: involvement of different protein domains. Nucleic Acids Res. 22, 5582-9.

Ladomery, M., Wade, E. und Sommerville, J. (1997). Xp54, the Xenopus homologue of human RNA helicase p54, is an integral component of stored mRNP particles in oocytes. Nucleic Acids Res. 25, 965-73.

Laemmli, U. K. (1970). Cleavage of structural proteins during the assembly of the head of bacteriophage T4. Nature 227, 680-5.

Lall, S., Francis-Lang, H., Flament, A., Norvell, A., Schüpbach, T. und Ish-Horowicz, D. (1999). Squid hnRNP protein promotes apical cytoplasmic transport and localization of Drosophila pair-rule transcripts. Cell 98, 171-80.

Li, P., Yang, X., Wasser, M., Cai, Y. und Chia, W. (1997). Inscuteable and Staufen mediate asymmetric localization and segregation of prospero RNA during Drosophila neuroblast cell divisions. Cell 90, 437-47.

Linder, P. und Daugeron, M. C. (2000). Are DEAD-box proteins becoming respectable helicases? Nat. Struct. Biol. 7, 97-9.

Linder, P. und Stutz, F. (2001). mRNA export: travelling with DEAD box proteins. Curr. Biol. 11, R961-3.

Long, R. M., Gu, W., Lorimer, E., Singer, R. H. und Chartrand, P. (2000). She2p is a novel RNA-binding protein that recruits the Myo4p-She3p complex to ASH1 mRNA. EMBO J. 19, 6592-601.

Long, R. M., Gu, W., Meng, X., Gonsalvez, G., Singer, R. H. und Chartrand, P. (2001). An exclusively nuclear RNA-binding protein affects asymmetric localization of ASH1 mRNA and Ash1p in yeast. J. Cell Biol. $153,307-18$.

Luking, A., Stahl, U. und Schmidt, U. (1998). The protein family of RNA helicases. Crit. Rev. Biochem. Mol. Biol. 33, 259-96.

Lustig, K. D., Kroll, K. L., Sun, E. E. und Kirschner, M. W. (1996). Expression cloning of a Xenopus Trelated gene (Xombi) involved in mesodermal patterning and blastopore lip formation. Development 122, 4001-12.

MacArthur, H., Houston, D. W., Bubunenko, M., Mosquera, L. und King, M. L. (2000). DEADSouth is a germ plasm specific DEAD-box RNA helicase in Xenopus related to eIF4A. Mech. Dev. 95, 291-5.

MacDonald, P. M. (1990). bicoid mRNA localization signal: phylogenetic conservation of function and RNA secondary structure. Development 110, 161-71. 
Macdonald, P. M. und Kerr, K. (1998). Mutational analysis of an RNA recognition element that mediates localization of bicoid mRNA. Mol. Cell Biol. 18, 3788-95.

Mahowald, A. P. (2001). Assembly of the Drosophila germ plasm. Int. Rev. Cytol. 203, 187-213.

Markmeyer, P., Ruhlmann, A., Englisch, U. und Cramer, F. (1990). The pAX plasmids: new gene-fusion vectors for sequencing, mutagenesis and expression of proteins in Escherichia coli. Gene 93, 129-34.

Mathews, D. H., Sabina, J., Zuker, M. und Turner, D. H. (1999). Expanded sequence dependence of thermodynamic parameters improves prediction of RNA secondary structure. J. Mol. Biol. 288, 911-40.

Matova, N. und Cooley, L. (2001). Comparative aspects of animal oogenesis. Dev. Biol. 231, 291-320.

Matsumoto, K., Meric, F. und Wolffe, A. P. (1996). Translational repression dependent on the interaction of the Xenopus Y- box protein FRGY2 with mRNA. Role of the cold shock domain, tail domain, and selective RNA sequence recognition. J. Biol. Chem. 271, 22706-12.

Melton, D. A. (1987). Translocation of a localized maternal mRNA to the vegetal pole of Xenopus oocytes. Nature $328,80-2$.

Micklem, D. R., Adams, J., Grunert, S. und St Johnston, D. (2000). Distinct roles of two conserved Staufen domains in oskar mRNA localization und translation. EMBO J. 19, 1366-77.

Minshall, N., Thom, G. und Standart, N. (2001). A conserved role of a DEAD box helicase in mRNA masking. RNA 7, 1728-42.

Mosquera, L., Forristall, C., Zhou, Y. und King, M. L. (1993). A mRNA localized to the vegetal cortex of Xenopus oocytes encodes a protein with a nanos-like zinc finger domain. Development 117, 377-86.

Mowry, K. L. (1996). Complex formation between stage-specific oocyte factors and a Xenopus mRNA localization element. Proc. Natl. Acad. Sci. USA 93, 14608-13.

Mowry, K. L. und Cote, C. A. (1999). RNA sorting in Xenopus oocytes and embryos. FASEB J. 13, 435-45.

Mowry, K. L. und Melton, D. A. (1992). Vegetal messenger RNA localization directed by a 340-nt RNA sequence element in Xenopus oocytes. Science 255, 991-4.

Mueller-Pillasch, F., Pohl, B., Wilda, M., Lacher, U., Beil, M., Wallrapp, C., Hameister, H., Knochel, W., Adler, G. und Gress, T. M. (1999). Expression of the highly conserved RNA binding protein KOC in embryogenesis. Mech. Dev. 88, 95-9.

Münchow, S., Sauter, C. und Jansen, R. P. (1999). Association of the class V myosin Myo4p with a localised messenger RNA in budding yeast depends on She proteins. J. Cell Sci. 112, 1511-8.

Munoz-Sanjuan, I., und Hemmati-Brivanlou A. (2001). Early posterior/ventral fate specification in the vertebrate embryo. Dev. Biol. 237, 1-17. 
Murray, M. T. (1994). Nucleic acid-binding properties of the Xenopus oocyte $\mathrm{Y}$ box protein mRNP3+4. Biochemistry 33, 13910-7.

Nakamura, A., Amikura, R., Hanyu, K. und Kobayashi, S. (2001). Me31B silences translation of oocytelocalizing RNAs through the formation of cytoplasmic RNP complex during Drosophila oogenesis. Development $128,3233-42$.

Nielsen, F. C., Nielsen, J. und Christiansen, J. (2001). A family of IGF-II mRNA binding proteins (IMP) involved in RNA trafficking. Scand. J. Clin. Lab. Invest. Suppl. 234, 93-9.

Nielsen, J., Christiansen, J., Lykke-Andersen, J., Johnsen, A. H., Wewer, U. M. und Nielsen, F. C. (1999). A family of insulin-like growth factor II mRNA-binding proteins represses translation in late development. Mol. Cell Biol. 19, 1262-70.

Nielsen, J., Cilius Nielsen, F., Kragh Jakobsen, R. und Christiansen, J. (2000). The biphasic expression of IMP/Vg1-RBP is conserved between vertebrates and Drosophila. Mech. Dev. 96, 129-32.

Nieuwkoop, P. D. und Faber, J. (1967). Normal Table of Xenopus laevis (Daudin), 2nd edition Edition (Amsterdam: North-Holland Publ. Co. Amsterdam).

Norvell, A., Kelley, R. L., Wehr, K. und Schüpbach, T. (1999). Specific isoforms of squid, a Drosophila hnRNP, perform distinct roles in Gurken localization during oogenesis. Genes Dev. 13, 864-76.

Oka, T., Amikura, R., Kobayashi, S., Yamamoto, H. und Nishida, H. (1999). Localization of mitochondrial large ribosomal RNA in the myoplasm of the early ascidian embryo. Dev. Growth Differ. 41, 1-8.

Otero, L. J., Devaux, A. und Standart, N. (2001). A 250-nucleotide UA-rich element in the 3' untranslated region of Xenopus laevis Vg1 mRNA represses translation both in vivo and in vitro. RNA 7, 1753-67.

Palacios, I. M. und Johnston, D. S. (2001). Getting the message across: the intracellular localization of mRNAs in higher eukaryotes. Annu. Rev. Cell Dev. Biol. 17, 569-614.

Pannese, M., Cagliani, R., Pardini, C. L. und Boncinelli, E. (2000). Xotx1 maternal transcripts are vegetally localized in Xenopus laevis oocytes. Mech. Dev. 90, 111-4.

Pokrywka, N. J. und Stephenson, E. C. (1995). Microtubules are a general component of mRNA localization systems in Drosophila oocytes. Dev. Biol. 167, 363-70.

Pokrywka, N. J. und Stephenson, E. C. (1991). Microtubules mediate the localization of bicoid RNA during Drosophila oogenesis. Development 113, 55-66.

Pondel, M. D. und King, M. L. (1988). Localized maternal mRNA related to transforming growth factor beta mRNA is concentrated in a cytokeratin-enriched fraction from Xenopus oocytes. Proc. Natl. Acad. Sci. USA $85,7612-6$.

Rand, K. und Yisraeli, J. (2001). RNA localization in Xenopus oocytes. In: Results Probl Cell Differ, D. Richter, ed. (Berlin Heidelberg New York: Springer-Verlag), 157-73. 
Rebagliati, M. R., Weeks, D. L., Harvey, R. P. und Melton, D. A. (1985). Identification and cloning of localized maternal RNAs from Xenopus eggs. Cell 42, 769-77.

Rebbert, M. L. und Dawid, I. B. (1997). Transcriptional regulation of the Xlim-1 gene by activin is mediated by an element in intron I. Proc. Natl. Acad. Sci. USA 94, 9717-22.

Riechmann, V. und Ephrussi, A. (2001). Axis formation during Drosophila oogenesis. Curr. Opin. Genet. Dev. 11, 374-83.

Rivera-Pomar, R. und Jäckle, H. (1996). From gradients to stripes in Drosophila embryogenesis: filling in the gaps. Trends Genet. 12, 478-83.

Rivera-Pomar, R., Niessing, D., Schmidt-Ott, U., Gehring, W. J. und Jäckle, H. (1996). RNA binding and translational suppression by bicoid. Nature 379, 746-9.

Ross, A. F., Oleynikov, Y., Kislauskis, E. H., Taneja, K. L. und Singer, R. H. (1997). Characterization of a beta-actin mRNA zipcode-binding protein. Mol. Cell Biol. 17, 2158-65.

Rossi, J. M., Dunn, N. R., Hogan, B. L. und Zaret, K. S. (2001). Distinct mesodermal signals, including BMPs from the septum transversum mesenchyme, are required in combination for hepatogenesis from the endoderm. Genes Dev. 15, 1998-2009.

Rupp, R. A., Snider, L. und Weintraub, H. (1994). Xenopus embryos regulate the nuclear localization of XMyoD. Genes Dev. 8, 1311-23.

Saffman, E. E. und Lasko, P. (1999). Germline development in vertebrates and invertebrates. Cell. Mol. Life Sci. 55, 1141-63.

Sambrook, J., Fritsch, E. F. und Maniatis, T. (1989). Molecular cloning. A laboratory manual. (Cold Spring Harbor: CSH Press).

Saunders, C. und Cohen, R. S. (1999). The role of oocyte transcription, the 5'UTR, and translation repression and derepression in Drosophila gurken mRNA and protein localization. Mol. Cell 3, 43-54.

Schluter, K., Jockusch, B. M. und Rothkegel, M. (1997). Profilins as regulators of actin dynamics. Biochim. Biophys. Acta. 1359, 97-109.

Schmitt, C., von Kobbe, C., Bachi, A., Pante, N., Rodrigues, J. P., Boscheron, C., Rigaut, G., Wilm, M., Seraphin, B., Carmo-Fonseca, M. und Izaurralde, E. (1999). Dbp5, a DEAD-box protein required for mRNA export, is recruited to the cytoplasmic fibrils of nuclear pore complex via a conserved interaction with CAN/Nup159p. EMBO J. 18, 4332-47.

Schnorrer, F., Bohmann, K. und Nüsslein-Volhard, C. (2000). The molecular motor dynein is involved in targeting swallow and bicoid RNA to the anterior pole of Drosophila oocytes. Nat. Cell Biol. 2, 185-90.

Seeger, M. A. und Kaufman, T. C. (1990). Molecular analysis of the bicoid gene from Drosophila pseudoobscura: identification of conserved domains within coding and noncoding regions of the bicoid mRNA. EMBO J. 9, 2977-87. 
Serano, T. L. und Cohen, R. S. (1995). A small predicted stem-loop structure mediates oocyte localization of Drosophila K10 mRNA. Development 121, 3809-18.

Shoelson, S. E. (1997). SH2 and PTB domain interactions in tyrosine kinase signal transduction. Curr. Opin. Chem. Biol. 1, 227-34.

Smillie, D. A. und Sommerville, J. (2002). RNA helicase p54 (DDX6) is a shuttling protein involved in nuclear assembly of stored mRNP particles. J. Cell Sci. 115, 395-407.

Snay-Hodge, C. A., Colot, H. V., Goldstein, A. L. und Cole, C. N. (1998). Dbp5p/Rat8p is a yeast nuclear pore-associated DEAD-box protein essential for RNA export. EMBO J. 17, 2663-76.

St Johnston, D., Beuchle, D. und Nüsslein-Volhard, C. (1991). Staufen, a gene required to localize maternal RNAs in the Drosophila egg. Cell 66, 51-63.

Starz-Gaiano, M. und Lehmann, R. (2001). Moving towards the next generation. Mech. Dev. 105, 5-18.

Stennard, F., Carnac, G. und Gurdon, J. B. (1996). The Xenopus T-box gene, Antipodean, encodes a vegetally localised maternal mRNA and can trigger mesoderm formation. Development 122, 4179-88.

Strouboulis, J., Damjanovski, S., Vermaak, D., Meric, F. und Wolffe, A. P. (1999). Transcriptional repression by XPc1, a new Polycomb homolog in Xenopus laevis embryos, is independent of histone deacetylase. Mol. Cell Biol. 19, 3958-68.

Tafuri, S. R. und Wolffe, A. P. (1993). Selective recruitment of masked maternal mRNA from messenger ribonucleoprotein particles containing FRGY2 (mRNP4). J. Biol. Chem. 268, 24255-61.

Taira, M., Jamrich, M., Good, P. J. und Dawid, I. B. (1992). The LIM domain-containing homeo box gene Xlim-1 is expressed specifically in the organizer region of Xenopus gastrula embryos. Genes Dev. 6, 356-66.

Taira, M., Otani, H., Saint-Jeannet, J. P. und Dawid, I. B. (1994). Role of the LIM class homeodomain protein Xlim-1 in neural and muscle induction by the Spemann organizer in Xenopus. Nature 372, 677-9.

Taira, M., Saint-Jeannet, J. P. und Dawid, I. B. (1997). Role of the Xlim-1 and Xbra genes in anteroposterior patterning of neural tissue by the head and trunk organizer. Proc. Natl. Acad. Sci.USA 94, 895-900.

Takizawa, P. A. und Vale, R. D. (2000). The myosin motor, Myo4p, binds Ash1 mRNA via the adapter protein, She3p. Proc. Natl. Acad. Sci. USA 97, 5273-8.

Tanner, N. K. und Linder, P. (2001). DExD/H box RNA helicases: from generic motors to specific dissociation functions. Mol. Cell 8, 251-62.

Theurkauf, W. E., Smiley, S., Wong, M. L. und Alberts, B. M. (1992). Reorganization of the cytoskeleton during Drosophila oogenesis: implications for axis specification and intercellular transport. Development 115, 923-36. 
Thio, G. L., Ray, R. P., Barcelo, G. und Schüpbach, T. (2000). Localization of gurken RNA in Drosophila oogenesis requires elements in the 5' and 3' regions of the transcript. Dev. Biol. 221, 435-46.

Wagner, C., Palacios, I., Jaeger, L., St Johnston, D., Ehresmann, B., Ehresmann, C. und Brunel, C. (2001). Dimerization of the 3'UTR of bicoid mRNA Involves a Two-step Mechanism. J. Mol. Biol. 313, 511-24.

Wang, C., Dickinson, L. K. und Lehmann, R. (1994). Genetics of nanos localization in Drosophila. Dev. Dyn. 199, 103-15.

Wear, M. A., Schafer, D. A. und Cooper, J. A. (2000). Actin dynamics: assembly and disassembly of actin networks. Curr. Biol. 10, R891-5.

Weeks, D. L., Rebagliati, M. R., Harvey, R. P. und Melton, D. A. (1985). Localized maternal mRNAs in Xenopus laevis eggs. Cold Spring Harb. Symp. Quant. Biol. 50, 21-30.

Weeks, D. L. und Melton, D. A. (1987). A maternal mRNA localized to the vegetal hemisphere in Xenopus eggs codes for a growth factor related to TGF-beta. Cell 51,861-7.

Wessely, O. und De Robertis, E. M. (2000). The Xenopus homologue of Bicaudal-C is a localized maternal mRNA that can induce endoderm formation. Development 127, 2053-62.

Wharton, R. P. und Struhl, G. (1991). RNA regulatory elements mediate control of Drosophila body pattern by the posterior morphogen nanos. Cell 67, 955-67.

Wilhelm, J. E. und Vale, R. D. (1993). RNA on the move: the mRNA localization pathway. J. Cell Biol. 123, 269-74.

Wilhelm, J. E., Vale, R. D. und Hegde, R. S. (2000). Coordinate control of translation and localization of Vg1 mRNA in Xenopus oocytes. Proc. Natl. Acad. Sci. USA 97, 13132-7.

Wilkie, G. S. und Davis, I. (2001). Drosophila wingless and pair-rule transcripts localize apically by dyneinmediated transport of RNA particles. Cell 105, 209-19.

Wolffe, A. P., Tafuri, S., Ranjan, M. und Familari, M. (1992). The Y-box factors: a family of nucleic acid binding proteins conserved from Escherichia coli to man. New Biol. 4, 290-8.

Xanthos, J. B., Kofron, M., Wylie, C. und Heasman, J. (2001). Maternal VegT is the initiator of a molecular network specifying endoderm in Xenopus laevis. Development 128, 167-80.

Yaniv, K. und Yisraeli, J. K. (2001). Defining cis-acting elements and trans-acting factors in RNA localization. Int. Rev. Cytol. 203, 521-39.

Yasuo, H. und Lemaire, P. (2001). Generation of the germ layers along the animal-vegetal axis in Xenopus laevis. Int. J. Dev. Biol. 45, 229-35.

Yisraeli, J. K. und Melton, D. A. (1988). The material mRNA Vg1 is correctly localized following injection into Xenopus oocytes. Nature 336, 592-5. 
Yisraeli, J. K., Sokol, S. und Melton, D. A. (1989). The process of localizing a maternal messenger RNA in Xenopus oocytes. Development 107, 31-6.

Yisraeli, J. K., Sokol, S. und Melton, D. A. (1990). A two-step model for the localization of maternal mRNA in Xenopus oocytes: involvement of microtubules and microfilaments in the translocation and anchoring of Vg1 mRNA. Development 108, 289-98.

Zaret, K. S. (2000). Liver specification and early morphogenesis. Mech. Dev. 92, 83-8.

Zhang, J., Houston, D. W., King, M. L., Payne, C., Wylie, C. und Heasman, J. (1998). The role of maternal VegT in establishing the primary germ layers in Xenopus embryos. Cell 94, 515-24.

Zhang, J. und King, M. L. (1999). PCR basesd cloning of cortically localized RNAs from Xenopus oocytes. In: Developmental Biology Protocols, R. S. Tuan und C. W. Lo, eds. (Totowa, N.J.: Humana Press Inc.), pp. 301-306.

Zhang, J. und King, M. L. (1996). Xenopus VegT RNA is localized to the vegetal cortex during oogenesis and encodes a novel T-box transcription factor involved in mesodermal patterning. Development 122, 411929.

Zhang, Q., Yaniv, K., Oberman, F., Wolke, U., Git, A., Fromer, M., Taylor, W. L., Meyer, D., Standart, N., Raz, E. und Yisraeli, J. K. (1999). Vg1 RBP intracellular distribution and evolutionarily conserved expression at multiple stages during development. Mech. Dev. 88, 101-6.

Zhao, W. M., Jiang, C., Kroll, T. T. und Huber, P. W. (2001). A proline-rich protein binds to the localization element of Xenopus Vg1 mRNA and to ligands involved in actin polymerization. EMBO J. 20, 2315-25.

Zhou, Y. und King, M. L. (1996). Localization of Xcat-2 RNA, a putative germ plasm component, to the mitochondrial cloud in Xenopus stage I oocytes. Development 122, 2947-53.

Zhou, Y. und King, M. L. (1996). RNA transport to the vegetal cortex of Xenopus oocytes. Dev. Biol. 179, 173-83.

Zohn, I. E. und Brivanlou, A. H. (2001). Expression cloning of Xenopus Os4, an evolutionarily conserved gene, which induces mesoderm and dorsal axis. Dev. Biol. 239, 118-31.

Zorn, A. M. und Mason, J. (2001). Gene expression in the embryonic Xenopus liver. Mech. Dev. 103, 153-7.

Zuker, M., Mathews, D. H. und D.H., T. (1999). Algorithms and Thermodynamics for RNA Secondary Structure Prediction: A Practical Guide In RNA Biochemistry and Biotechnology, J. Barciszewski and B. F. C. Clark, eds.: NATO ASI Series, Kluwer Academic Publishers, 11-43. 


\section{Anhang}

\subsection{Nukleotid- und Aminosäuresequenz der A3A-3A und B2B-6E-Klone.}

Die aus den cDNA-Sequenzen der alternativen Transkripte A3A-3A und B2B-6E (MC207 und MC209) abgeleitete Aminosäuesequenz des offenen Leserasters ist oberhalb der Nukleotidsequenz dargestellt. Die Positionszahlen der Nukleotidsequenz sind am linken Rand, diejenigen der Aminosäuresequenz am rechten Rand angegeben. Das Startkodon des offenen Leserahmens ist durch Fettdruck hervorgehoben; das Terminationskodon ist durch einen Stern gekennzeichnet. Weitere im 5'-untranslatierten Bereich desselben Leserasters vorliegenden Stopkodons sind durch Umrahmung hervorgehoben. Während das B2B-6ETranskript ab Nukleotidposition 966 polyA-Sequenzen aufweist, enthält die A3A-3A cDNA einen um 400 Nukleotide verlängerten, hier grau unterlegten, 3'- untranslatierten Bereich. Die Positionen der in der PCRvermittelten Durchmusterung der Gesamt-Oozyten cDNA-Bibliothek und in den RT-PCRExpressionsanalysen verwendeten Oligonukleotide sind in der Nukleotidsequenz unterstrichen.

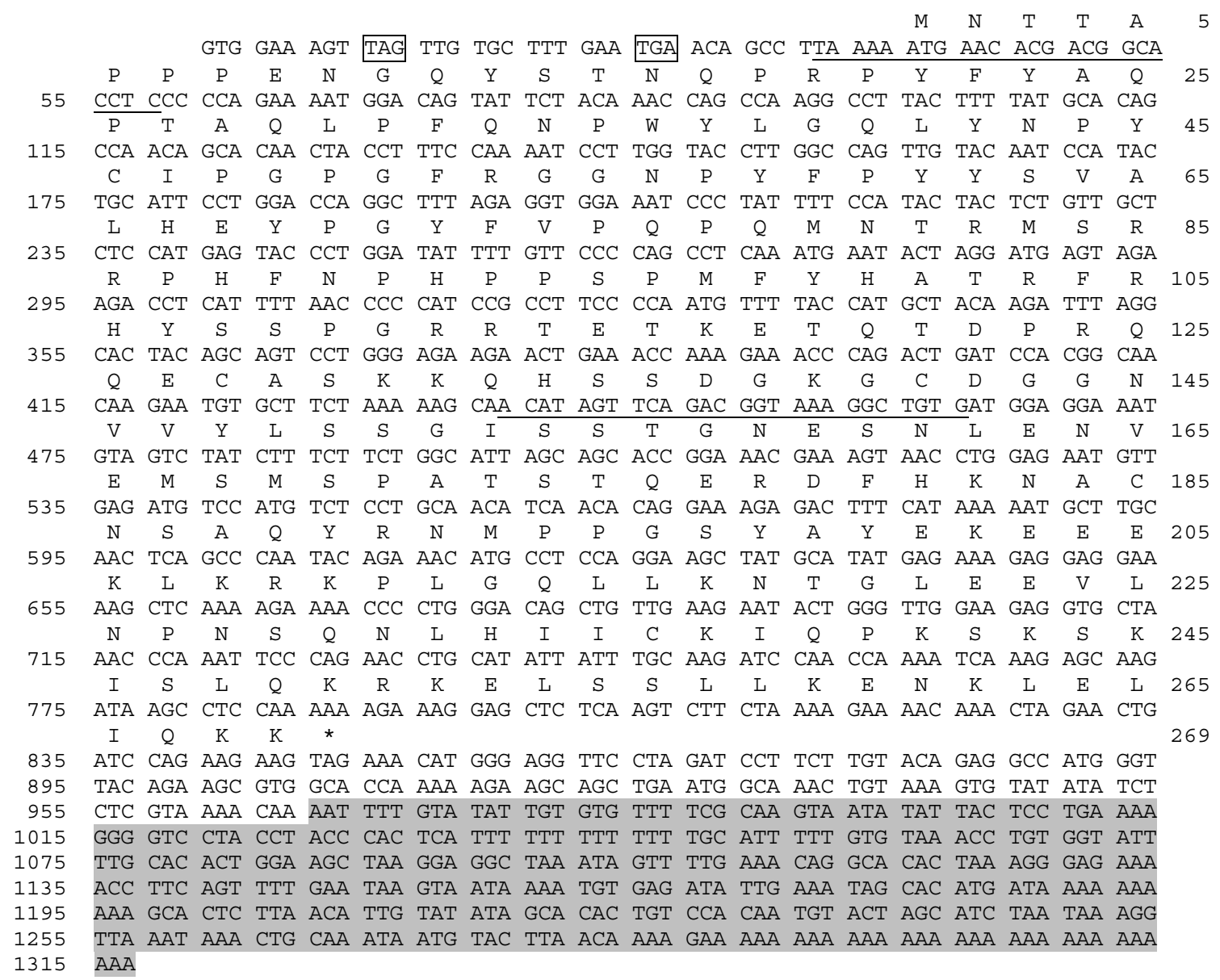

\subsection{Nukleotid- und Aminosäuresequenz des isolierten 6E-Klons}

Die von der isolierten cDNA-Sequenz abgeleitete Aminosäuesequenz des offenen Leserasters ist oberhalb der Nukleotidsequenz dargestellt. Die Positionszahlen der Nukleotidsequenz sind am linken Rand, diejenigen der Aminosuresequenz am rechten Rand angegeben. Das Startkodon des offenen Leserahmens ist durch Fettdruck hervorgehoben; das Terminationskodon ist durch einen Stern gekennzeichnet. Weitere im 5'untranslatierten Bereich desselben Leserasters vorliegenden Stopkodons sind durch Umrahmung hervorgehoben. Die Positionen der in der PCR-vermittelten Durchmusterung der Gesamt-Oozyten cDNA-Bibliothek und in den RT-PCR-Expressionsanalysen verwendeten Oligonukleotide sind in der Nukleotidsequenz unterstrichen. 
$\begin{array}{lllllllllllll}M & N & T & T & A & P & P & P & E & 9\end{array}$

TTG TGC TTT GAA TGA ACA GCC TTA AAA ATG AAC ACG ACG GCA CCT CCC CCA GAA $\begin{array}{lllllllllllllllllllll}N & G & Q & Y & S & T & N & Q & P & R & P & Y & F & Y & A & Q & P & T & A & Q & 29\end{array}$ 55 AAT GGA CAG TAT TCT ACA AAC CAG CCA AGG CCT TAC TTT TAT GCA CAG CCA ACA GCA CAA $\begin{array}{cccccccccccccccccccc}\text { L } & \text { P } & \text { F } & Q & N & P & \text { W } & \text { Y } & \text { L } & \text { G } & \text { Q } & \text { L } & \text { Y } & \text { N } & \text { P } & \text { Y } & \text { C } & \text { I } & \text { P } & \text { G } \\ \text { CTA } & \text { CCT } & \text { TTC } & \text { CAA } & \text { AAT } & \text { CCT } & \text { TGG } & \text { TAC } & \text { CTT } & \text { GGC } & \text { CAG } & \text { TTG } & \text { TAC } & \text { AAT } & \text { CCA } & \text { TAC } & \text { TGC } & \text { ATT } & \text { CCT } & \text { GGA }\end{array}$ $\begin{array}{lllllllllllllllllllll}P & G & F & R & G & G & N & P & Y & F & P & Y & Y & S & \text { V } & \text { A } & \text { L } & \text { H } & \text { E } & \text { Y } & 79\end{array}$ 175 CCA GGC TTT AGA GGT GGA AAT CCC TAT TTT CCA TAC TAC TCT GTT GCT CTC CAT GAg TAC $\begin{array}{llllllllllllllllllllll}\mathrm{P} & \mathrm{G} & \mathrm{Y} & \mathrm{F} & \mathrm{V} & \mathrm{P} & \mathrm{Q} & \mathrm{P} & \mathrm{Q} & \mathrm{M} & \mathrm{N} & \mathrm{T} & \mathrm{R} & \mathrm{M} & \mathrm{S} & \mathrm{R} & \mathrm{R} & \mathrm{P} & \mathrm{H} & \mathrm{F} & 99\end{array}$

235 CCT GGA TAT TTT GTT CCC CAG CCT CAA ATG AAT ACT AGg ATG AGT AGA AGA CCT CAT TTT $\begin{array}{lllllllllllllllllllll}\mathrm{N} & \mathrm{P} & \mathrm{H} & \mathrm{P} & \mathrm{P} & \mathrm{S} & \mathrm{P} & \mathrm{M} & \mathrm{F} & \mathrm{Y} & \mathrm{H} & \mathrm{A} & \mathrm{T} & \mathrm{R} & \mathrm{F} & \mathrm{R} & \mathrm{H} & \mathrm{Y} & \mathrm{S} & \mathrm{S} & 119\end{array}$

295 AAC CCC CAT CCG CCT TCC CCA ATG TTT tAC CAT GCT ACA AgA tTT AgG CAC tAC AgC Agt $\begin{array}{lllllllllllllllllllllllll}\mathrm{P} & \mathrm{G} & \mathrm{R} & \mathrm{R} & \mathrm{T} & \mathrm{E} & \mathrm{T} & \mathrm{K} & \mathrm{E} & \mathrm{T} & \mathrm{Q} & \mathrm{T} & \mathrm{D} & \mathrm{P} & \mathrm{R} & \mathrm{Q} & \mathrm{Q} & \mathrm{E} & \mathrm{C} & \mathrm{A} & 139\end{array}$

355 CCT GGG AGA AGA ACT GAA ACC AAA GAA ACC CAG ACT GAT CCA CGG CAA CAA GAA TGT GCT $\begin{array}{llllllllllllllllllllllllll}S & K & K & Q & H & S & S & D & G & K & G & C & D & G & G & N & V & V & Y & \text { L } & 159\end{array}$

415 TCT AAA AAG CAA CAT AGT TCA GAC GGT AAA GGC TGT GAT GGA GGA AAT GTA GTC TAT CTT $\begin{array}{lllllllllllllllllllllllllll}S & S & G & I & S & S & T & G & N & E & S & N & L & E & N & V & E & M & S & M & 179\end{array}$

475 TCT TCT GGC ATT AGC AGC ACC GGA AAC GAA AGT AAC CTG GAG AAT GTT GAG ATG TCC ATG $\begin{array}{lllllllllllllllllllllll}\mathrm{S} & \mathrm{P} & \mathrm{A} & \mathrm{T} & \mathrm{S} & \mathrm{T} & \mathrm{Q} & \mathrm{E} & \mathrm{R} & \mathrm{D} & \mathrm{F} & \mathrm{H} & \mathrm{K} & \mathrm{N} & \mathrm{A} & \mathrm{C} & \mathrm{N} & \mathrm{S} & \mathrm{A} & \mathrm{Q} & 199\end{array}$

535 TCT CCT GCA ACA TCA ACA CAG GAA AGA GAC TTT CAT AAA AAT GCT TGC AAC TCA GCC CAA $\begin{array}{lllllllllllllllllllllllll}\mathrm{Y} & \mathrm{R} & \mathrm{N} & \mathrm{M} & \mathrm{P} & \mathrm{P} & \mathrm{G} & \mathrm{S} & \mathrm{Y} & \mathrm{A} & \mathrm{Y} & \mathrm{E} & \mathrm{K} & \mathrm{E} & \mathrm{E} & \mathrm{V} & \mathrm{R} & \mathrm{I} & \mathrm{E} & \mathrm{Y} & 219\end{array}$ AAC AGA AAC ATG CCT CCA GGA AGC TAT GCA TAT GAG AAA GAG GAG GTA AGA ATA GAG TAT $\begin{array}{lllllllllllllllllllll}G & S & G & S & P & A & A & I & Q & M & \text { W } & \text { K } & \text { S } & \text { Y } & \text { K } & \text { E } & \text { T } & \text { I } & \text { P } & \text { I } & 239\end{array}$

655 GGA AGT GGT TCA CCT GCT GCC ATA CAA ATG TGG AAG TCT TAT AAA GAA ACC ATA CCA ATA $\begin{array}{llllllllllllllllllllllllll}\mathrm{Y} & \mathrm{D} & \mathrm{V} & \mathrm{A} & \mathrm{V} & \mathrm{V} & \mathrm{K} & \mathrm{E} & \mathrm{L} & \mathrm{P} & \mathrm{E} & \mathrm{N} & \mathrm{V} & \mathrm{V} & \mathrm{Q} & \mathrm{R} & \mathrm{D} & \mathrm{L} & \mathrm{F} & \mathrm{C} & 259\end{array}$

715 TAC GAT GTG GCA GTT GTT AAA GAA TTA CCA GAA AAT GTA GTG CAG CGT GAT CTT TTT TGT $\begin{array}{llllllllllllllllllllllll}\text { E } & G & \text { V } & \text { L } & \text { Y } & \text { G } & \text { P } & \text { H } & \text { A } & \text { E } & \text { G } & \text { E } & \text { E } & \text { L } & \text { A } & \text { V } & \text { Q } & \text { S } & \text { V } & \text { A } & 279\end{array}$

775 GAG GGT GTA TTA TAT GGC CCT CAT GCA GAA GGC GAG GAg CTT GCT GTG CAG AGC GTT GCC $\begin{array}{lllllllllllllllllllll}\text { F } & \text { S } & \text { N } & \text { K } & \text { D } & \text { E } & \text { C } & \text { K } & \text { N } & \text { S } & \text { L } & \text { P } & \text { P } & \text { K } & \text { L } & \text { C } & \text { I } & \text { D } & \text { A } & \text { V } & 299\end{array}$ TTT TCA AAC AAA GAT GAA TGT AAA AAT TCA CTT CCT CCT AAA CTG TGT ATT GAT GCT GTT $\begin{array}{lllllllllllllllllllll}Q & E & T & E & T & Q & T & T & I & V & Q & T & R & E & P & R & Y & E & T & S & 319\end{array}$ 895 CAA GAA ACA GAA ACC CAA ACC ACA ATA GTT CAA ACA AGG GAG CCC CGA TAT GAA ACC AGC $\begin{array}{llllllllllllllllllllllllll}K & Q & G & K & Q & V & M & K & V & K & A & T & M & E & A & E & S & P & T & M & 339\end{array}$

955 AAA CAG GGA AAA CAA GTT ATG AAA GTT AAG GCC ACA ATG GAG GCA GAA TCG CCA ACC ATG $\begin{array}{llllllllllllllllllllll}\mathrm{V} & \mathrm{T} & \mathrm{E} & \mathrm{H} & \mathrm{V} & \mathrm{E} & \mathrm{V} & \mathrm{V} & \mathrm{S} & \mathrm{P} & \mathrm{V} & \mathrm{Y} & \mathrm{D} & \mathrm{D} & \mathrm{P} & \mathrm{Q} & \mathrm{V} & \mathrm{S} & \mathrm{V} & \mathrm{P} & 359\end{array}$

1015 GTG ACG GAA CAT GTT GAA GTA GTT AGT CCT GTT TAT GAT GAT CCA CAA GTA AGT GTA CCT $\begin{array}{lllllllllllllllllllll}E & D & S & D & E & H & N & \text { L } & \text { I } & \text { T } & \text { N } & \text { G } & \text { D } & \text { L } & \text { I } & \text { E } & \text { G } & \text { S } & \text { D } & \text { G } & 379\end{array}$

1075 GAg GAT TCT GAT GAA CAT AAT CTC ATT ACA AAT GGT GAT CTT ATA GAg GGC TCA GAT GGA $\begin{array}{lllllllllllllllllllllllllll}C & P & E & Q & Q & D & I & A & N & Q & S & T & C & N & G & E & V & K & L & A & 399\end{array}$ TGT CCA GAG CAG CAA GAT ATT GCA AAT CAA TCA ACC TGT AAT GGA GAG GTG AAA TTG GCT $\begin{array}{llllllllllllllllllllll}\mathrm{N} & \mathrm{K} & \mathrm{S} & \mathrm{N} & \mathrm{M} & \mathrm{W} & \mathrm{T} & \mathrm{D} & \mathrm{D} & \mathrm{S} & \mathrm{I} & \mathrm{E} & \mathrm{K} & \mathrm{F} & \mathrm{M} & \mathrm{P} & \mathrm{S} & \mathrm{P} & \mathrm{T} & \mathrm{W} & 419\end{array}$

1195 AAC AAA AGT AAC ATG TGG ACC GAT GAT TCC ATA GAG AAA TTT ATG CCA TCA CCG ACA TGG $\begin{array}{llllllllllllllllllllll}\mathrm{L} & \mathrm{A} & \mathrm{C} & \mathrm{F} & \mathrm{E} & \mathrm{N} & \mathrm{I} & \mathrm{D} & \mathrm{A} & \mathrm{N} & \mathrm{Y} & \mathrm{D} & \mathrm{Y} & \mathrm{D} & \mathrm{V} & \mathrm{Y} & \mathrm{S} & \mathrm{S} & \mathrm{Q} & \mathrm{R} & 439\end{array}$ CTG GCT TGC TTT GAA AAT ATA GAT GCG AAC TAT GAT TAT GAT GTT TAT TCT TCG CAA AGG $\begin{array}{lllllllllllllllllllll}K & Q & K & Q & T & S & V & L & S & I & T & S & E & E & L & S & S & R & D & E & 459\end{array}$

1315 AAG CAA AAA CAG ACA AGT GTC TTA AGC ATT ACT TCA GAA GAA CTT TCA TCT AGG GAT GAA $\begin{array}{llllllllllllllllllllllllll}G & S & S & \text { L } & \text { D } & S & A & S & \text { V } & S & \text { Y } & \text { F } & \text { V } & \text { P } & \text { D } & \text { Y } & \text { I } & \text { L } & R & \text { K } & 479\end{array}$ GGA TCT TCT TTG GAT AGT GCT TCT GTA TCT TAC TTT GTC CCT GAT TAT ATT CTT AGG AAA $\begin{array}{lllllllllllllllllllll}G & L & Y & T & F & R & K & T & T & E & D & L & E & K & E & T & I & K & S & S & 499\end{array}$

1435 GGT TTG TAT ACT TTC CGA AAA ACC ACA GAG GAT TTG GAG AAG GAA ACC ATT AAA AGC AGT $\begin{array}{lllllllllllllllllllll}G & S & L & K & E & D & D & I & P & L & K & Q & S & C & N & K & Y & V & K & K & 519\end{array}$

1495 GGT TCT TTA AAG GAA GAT GAT ATA CCT CTG AAA CAA TCT TGC AAC AAG TAT GTG AAA AAA $\begin{array}{llllllllllllllllllllllll}\mathrm{Y} & \mathrm{R} & \mathrm{S} & \mathrm{S} & \mathrm{A} & \mathrm{V} & \mathrm{K} & \mathrm{A} & \mathrm{K} & \mathrm{D} & \mathrm{V} & \mathrm{S} & \mathrm{S} & \mathrm{R} & \mathrm{C} & \mathrm{R} & \mathrm{K} & \mathrm{I} & \mathrm{G} & \mathrm{V} & 539\end{array}$

1555 TAC AGg TCT TCT GCA GTG AAA GCC AAG GAT GTT TCG AGT AGA TGT AGA AAA ATT GGA GTG $\begin{array}{lllllllllllllllllllllllll}P & L & K & G & L & S & R & R & K & L & Y & S & V & K & K & N & P & K & K & S & 559\end{array}$

1615 CCT CTG AAA GGC CTC AGT AGA AGG AAA CTC TAC TCT GTA AAA AAG AAT CCA AAg AAg AGT $\begin{array}{llllllllllllllllllllllllll}Q & S & L & S & E & P & E & D & S & D & E & Y & W & V & M & E & E & E & N & N & 579\end{array}$

1675 CAG TCA TTG TCT GAA CCC GAG GAC TCT GAC GAA TAC TGG GTC ATG GAA GAA GAA AAC AAT $\begin{array}{lllllllllllllllllllll}E & E & G & D & D & E & D & D & S & E & E & E & E & Y & Y & F & Q & E & S & L & 599\end{array}$

1735 GAA GAA GGA GAT GAT GAA GAT GAT AGT GAg GAA GAG GAA TAT TAC TTT CAA GAg AGC CTT $\begin{array}{lllllllllllllllllllllll}P & H & G & Q & V & D & I & G & K & G & S & I & F & K & Q & I & A & Q & K & R & 619\end{array}$

1795 CCA CAT GGA CAG GTG GAT ATT GGC AAA GGA AGT ATC TTT AAG CAA ATC GCT CAG AAG CGA $\begin{array}{llllllllllllllllllllll}I & L & W & K & P & P & K & G & M & V & P & A & Q & I & V & G & W & P & V & K & 639\end{array}$

1855 ATT CTC TGG AAA CCT CCA AAA GGC ATG GTC CCA GCT CAA ATT GTT GGA TGG CCT GTA AAA $\begin{array}{llllllllllllllllllllll}\mathrm{E} & \mathrm{K} & \mathrm{L} & \mathrm{V} & \mathrm{T} & \mathrm{K} & \mathrm{K} & \mathrm{G} & \mathrm{A} & \mathrm{Y} & \mathrm{D} & \mathrm{A} & \mathrm{L} & \mathrm{N} & \mathrm{Q} & \mathrm{V} & \mathrm{C} & \mathrm{R} & \mathrm{L} & \mathrm{K} & 659\end{array}$

1915 GAA AAA TTG GTG ACT AAA AAG GGT GCT TAT GAC GCA CTG AAT CAG GTG TGC CGA CTT AAG $\begin{array}{llllllllllllllllllllll}D & Y & D & G & S & D & Y & \text { T } & \text { I } & \text { Y } & \text { D } & \text { K } & \text { K } & \text { I } & \text { S } & \text { K } & \text { L } & \text { N } & \text { R } & \text { G } & 679\end{array}$

1975 GAT TAT GAT GGG AGT GAC TAT ACA ATC TAT GAT AAg AAG ATT TCA AAA TTA AAC AGA GGC $\begin{array}{lllllllllllllllllllllllllll}F & I & S & E & P & K & K & S & M & Q & K & S & V & G & G & K & A & Q & K & K & 699\end{array}$ 2035 TTC ATC TCT GAg CCG AAA AAA TCG ATG CAG AAg TCC GTG GGT GGA AAA GCT CAA AAg AAA $\begin{array}{llllllllllllllllllllll}T & P & G & \text { T } & \text { A } & \text { V } & \text { E } & \text { E } & \text { Y } & \text { W } & \text { V } & \text { G } & \text { R } & \text { G } & \text { A } & \text { K } & \text { P } & \text { K } & \text { F } & \text { P } & 719\end{array}$ 2095 ACC CCT GGG ACA GCT GTT GAA GAA TAC TGG GTT GGA AGA GGT GCT AAA CCC AAA TTC CCA $\begin{array}{lllllllllllllllllllllllll}\mathrm{E} & \mathrm{P} & \mathrm{A} & \mathrm{Y} & \mathrm{Y} & \mathrm{L} & \mathrm{Q} & \mathrm{D} & \mathrm{P} & \mathrm{T} & \mathrm{K} & \mathrm{I} & \mathrm{K} & \mathrm{E} & \mathrm{Q} & \mathrm{D} & \mathrm{K} & \mathrm{P} & \mathrm{P} & \mathrm{K} & 739\end{array}$

2155 GAA CCT GCA TAT TAT TTG CAA GAT CCA ACC AAA ATC AAA GAG CAA GAT AAG CCT CCA AAA $\begin{array}{llllllllllllllllllllll}K & K & G & A & L & K & S & S & K & R & K & 0 & T & R & T & D & P & E & E & V & 759\end{array}$ 2215 AAG AAA GGA GCT CTC AAG TCT TCT AAA AGA AAA CAA ACT AGA ACT GAT CCA GAA GAA GTA $\begin{array}{llllllllllllllllllllll}E & T & W & E & V & P & R & S & F & \text { L } & \text { Y } & \text { R } & \text { G } & \text { H } & \text { G } & \text { L } & Q & \text { K } & \text { R } & \text { G } & 779\end{array}$ 2275 GAA ACA TGG GAg GTT CCT AGA TCC TTC TTG TAC AGA GGC CAT GGg TTA CAg AAg CGT GGC 
$\begin{array}{llllllllllllll}T & K & K & K & Q & \text { L } & N & G & K & \text { L } & *\end{array}$

2335 ACC AAA AAG AAG CAG CTG AAT GGC AAA CTG TAA AGT GTA TAT ATC TCT CTT AAA ACA AAA 2395 TTT TGT ATA TTG TGT GTT TTC GCA AGT AAT ATA TTA CTC CTG AAA AGG GGT CCT ACC TAC 2455 CCA CTC ATT TTT TTT TTG CAT TTT TGT GTA AAC CTG TGG TAT TTT GCA CAC TGG AAG CTA 2515 AGG AGG CTA AAT AGT TTT GAA ACA GGC ACA CTA AAG GGA GAA AAC CTT CAG TTT TGA ATA 2575 AGT AAT AAA ATG TGA GAT ATT GAA ATA GCA CAT GAT AAA AAA AAA GCA CTC TTA ACA TTG 2635 TAT ATA GCA CTG TGT CCA CAA TGT ACT AGC ATC TAA TAA AGG TTA AAT AAA CTG CAA ATA 2695 ATG TAC TTA AAA AAA AAA AAA AAA AA

\subsection{Nukleotid- und Aminosäuresequenz des isolierten A3A-11C(XPTB)-Klons}

Die Nukleotidpositionen der partiellen cDNA-Sequenz ist am linken Rand, die Positionen der daraus abgeleiteten Aminosäuresequenz am rechten Rand angegeben. Das Terminationskodon des offenen Leserahmens ist mit einem Stern gekennzeichnet. Die aus der Xenopus-EST-Datenbank importierten, weiter 5'-gelegenen Sequenzen sowie das hierin enthaltene Startkodon bzw. Startmethionin des offenen Leserahmens sind in Fettdruck dargestellt. Ein im 5'-untranslatierten Bereich dieses Leserahmens des EST-Klons gelegenes Stopkodon ist durch Umrahmung gekennzeichnet. Die Positionen der in der PCR-vermittelten Durchmusterung der Gesamt-Oozyten cDNA-Bibliothek und in den RT-PCR-Expressionsanalysen verwendeten Oligonukleotide sind in der Nukleotidsequenz unterstrichen. Die in der vorhergesagten Proteinsequenz identifizierte konservierte Phosphotyrosin-bindende Domäne ist in grau unterlegt.

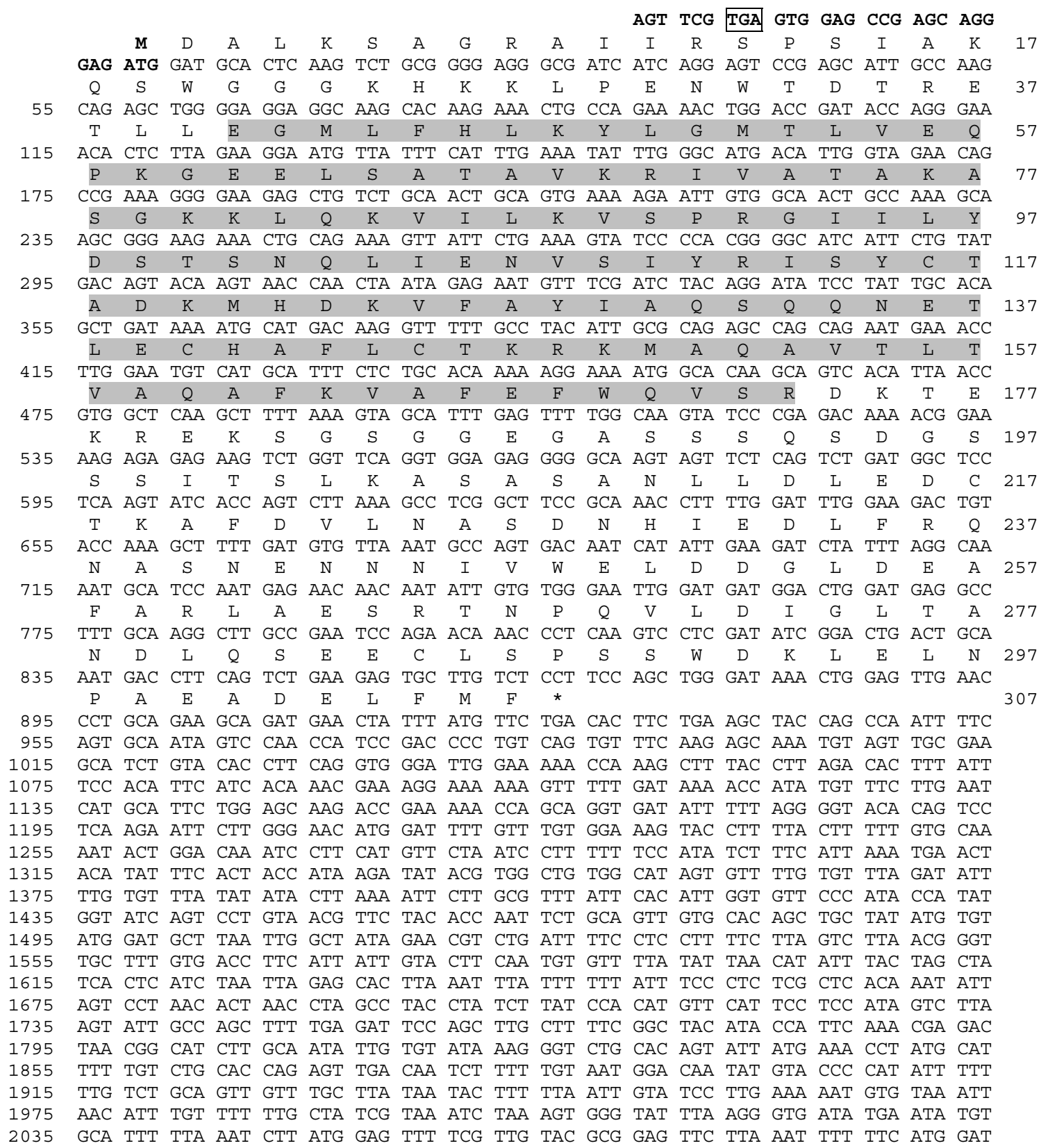


2095 GAA AGT ATT TGA TAG CCT CAA AGT AAA TCT GAC CCG TAT TAA GGA GTA TAA TAT CTA CTA 2155 ACA TCT AGT CCA TGT TCA TTA GCA CTA CCT ATT TCT ATT CAA AAT TGT TCT GGG TTG AGC 2215 TGT TAC TGC AGG GGG TGT TTG GTT TTC CTA GGT AAA ATG GCC AGC TCC TTA TGT ATA ATG 2275 TTT CCT GAA GCC ATT TTA GAA CCA AAG TAA CTG CTA TTT TAC TCG TGC TCT GTT TAA CAA 2335 TGT TGA ATA ACA ACA TGG CAA TTC TAT TTA GAT ATA AAG CTA TAT GTA ATG GAG GTG AAA 2395 ATC AGG CAA ATT TTG GGA AAA CTA GAC ATG AAA TGG CTG CAA ATT GTC CAC CAC ATT TTT 2455 AAT GTA ATT CAC ATG AAC GTT ATT TTA ACG GCC ATA AAA TGT AAC ATG AGA ATG CAT CTG 2515 TGC AGC ATG CAG ACT GGG TAT TTC TAT CAT TTG TAG CTC AAT ACA CCC AGG CCT TGC ACC 2575 TTG GGA TTC ATG ACC ATA CGT TTC TAA AGC ACT ATC TTA CTG GAG GTT TTT TAT CTT ACA 2635 CCT TTC GTT TGG TCT TCC CTG CCG TGT CAT GTG AAA AGA GCA AAA ATT TAT GGT ATT TTA 2695 CAC AAC AGG AAG CGT TTT CTT CAC AGG CAG ACT TTA TAC GTA GCT ATG CAT TTT AAG CAT 2755 TAA CAG ATT ATT TAT ATT AAT ACC AAT GGC TTC ATA AAT AAA TAT GGT TTA AAA GCA CAG 2815 GTA AAC AGA TGG AGG GCT ACA GAT TGA CTA TCC TTC ATG TAT TAG TTC AGT TTG GGA AAC 2875 ACC CTA AAT NTT CAC CAC TTC AAC ACC CTT TAT GTT CTT GAA CTG AAC AAA ATC CGG TTG 2935 CTC CTT CAA CCA TGC CTT TAA AAT ATG GAA GTA AAA TCN CAA TGT TAA ACA GCA CAT GGG 2995 GGT AAT GTT CCT TTA ATC TTC TCT TAG CTT CCA GCT CTC CAC ACA TTC TGC TGT ACT GTA 3055 AAT ATT GGC AAT ATT TAA AAT GCT ATT GAC AAT GTA TCG GAA ACC AGA ATA AAT ATT TTT

3115 GGT TTA ATG TCC AAA AAA AAA AAA AAA AAA AAA AAA AAA

\subsection{Nukleotid- und abgeleitete Aminosäuresequenz der DEADSouth cDNA}

An der linken Seite sind die Nukleotidpositionen der DEADSouth-Isoform cDNA angegeben; an rechten Seite die daraus abgeleiteten Aminosäurepositionen des offenen Leserahmens. Das Startkodon der Sequenz ist durch Fettdruck hervorgehoben; das Terminationskodon des durchgehenden Leserahmens ist mit einem Stern gekennzeichnet. Die Positionen der in der PCR-vermittelten Durchmusterung der Gesamt-Oozyten cDNABibliothek und in den RT-PCR-Expressionsanalysen verwendeten Oligonukleotide sind in der Nukleotidsequenz unterstrichen. Charakteristische Sequenzmotive der Familie der DEAD-Box Proteine sind in der Aminosäuresequenz in grau unterlegt.

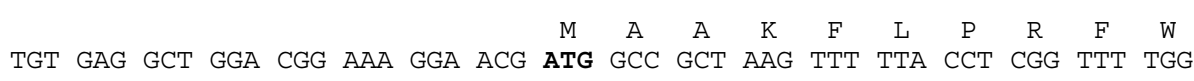
$\begin{array}{llllllllllllllllllllllllllllllllll}R & S & G & S & Q & A & E & L & L & D & F & Q & N & N & N & V & V & A & E & G & 30\end{array}$

55 CGA AGC GGT TCT CAA GCG GAA TTG TTG GAC TTT CAA AAC AAT AAT GTC GTT GCG GAG GGA $\begin{array}{lllllllllllllllllllllllll}K & \mathrm{~L} & \mathrm{D} & \mathrm{F} & \mathrm{E} & \mathrm{H} & \mathrm{G} & \mathrm{T} & \mathrm{L} & \mathrm{K} & \mathrm{G} & \mathrm{K} & \mathrm{S} & \mathrm{E} & \mathrm{D} & \mathrm{L} & \mathrm{A} & \mathrm{N} & \mathrm{H} & \mathrm{S} & 50\end{array}$

115 AAg CTG GAT TTT GAA CAC GGC ACA CTT AAA GGA AAA AGT GAg GAC CTA GCC AAT CAC TCT $\begin{array}{lllllllllllllllllllllllllll}\mathrm{L} & \mathrm{L} & \mathrm{N} & \mathrm{K} & \mathrm{L} & \mathrm{L} & \mathrm{R} & \mathrm{R} & \mathrm{T} & \mathrm{L} & \mathrm{V} & \mathrm{D} & \mathrm{S} & \mathrm{P} & \mathrm{H} & \mathrm{N} & \mathrm{V} & \mathrm{E} & \mathrm{V} & \mathrm{L} & 70\end{array}$

175 CTC TTA AAT AAA CTT CTC CGA AGG ACC CTA GTC GAC TCT CCT CAC AAT GTT GAA GTT TTG $\begin{array}{lllllllllllllllllllllllll}\mathrm{Q} & \mathrm{R} & \mathrm{D} & \mathrm{P} & \mathrm{T} & \mathrm{S} & \mathrm{P} & \mathrm{L} & \mathrm{F} & \mathrm{S} & \mathrm{V} & \mathrm{K} & \mathrm{S} & \mathrm{F} & \mathrm{E} & \mathrm{E} & \mathrm{L} & \mathrm{H} & \mathrm{L} & \mathrm{K} & 90\end{array}$

235 CAG AGG GAT CCC ACA TCA CCA CTC TTT TCT GTT AAG TCA TTT GAG GAG CTA CAT CTA AAG $\begin{array}{llllllllllllllllllllll}\mathrm{N} & \mathrm{E} & \mathrm{L} & \mathrm{L} & \mathrm{R} & \mathrm{G} & \mathrm{I} & \mathrm{Y} & \mathrm{A} & \mathrm{M} & \mathrm{G} & \mathrm{F} & \mathrm{N} & \mathrm{R} & \mathrm{P} & \mathrm{S} & \mathrm{K} & \mathrm{I} & \mathrm{Q} & \mathrm{E} & 110\end{array}$

295 AAC GAA CTG CTA CGT GGT ATA TAT GCT ATG GGC TTC AAC AGA CCT TCA AAA ATC CAA GAG $\begin{array}{lllllllllllllllllllllllll}\mathrm{N} & \mathrm{A} & \mathrm{L} & \mathrm{P} & \mathrm{M} & \mathrm{M} & \mathrm{L} & \mathrm{A} & \mathrm{D} & \mathrm{P} & \mathrm{P} & \mathrm{Q} & \mathrm{N} & \mathrm{L} & \mathrm{I} & \mathrm{A} & \mathrm{Q} & \mathrm{S} & \mathrm{Q} & \mathrm{S} & 130\end{array}$

355 AAT GCC CTT CCA ATG ATG CTT GCA GAT CCT CCC CAG AAT CTG ATA GCA CAG AGC CAA TCT $\begin{array}{lllllllllllllllllllllll}\text { G } & T & G & K & T & A & A & F & \text { V } & \text { L } & \text { A } & \text { M } & \text { L } & \text { S } & \text { R } & \text { V } & \text { D } & \text { A } & \text { N } & K & 150\end{array}$

415 GGA ACG GGC AAA ACA GCT GCA TTT GTA CTG GCT ATG CTG AGT CGT GTG GAT GCA AAC AAG $\begin{array}{lllllllllllllllllllllllll}K & Y & P & Q & C & I & C & L & S & P & T & F & E & \text { L } & \text { A } & \text { L } & \text { Q } & \text { T } & G & K & 170\end{array}$

475 AAg TAT CCA CAG TGC ATC TGT CTT AGT CCT ACA TTT GAA CTG GCT TTG CAG ACT GGG AAA $\begin{array}{llllllllllllllllllllllll}\mathrm{V} & \mathrm{V} & \mathrm{E} & \mathrm{E} & \mathrm{M} & \mathrm{G} & \mathrm{K} & \mathrm{F} & \mathrm{C} & \mathrm{A} & \mathrm{G} & \mathrm{I} & \mathrm{E} & \mathrm{V} & \mathrm{I} & \mathrm{Y} & \mathrm{A} & \mathrm{L} & \mathrm{R} & \mathrm{G} & 190\end{array}$

535 GTC GTT GAA GAg ATG GGg AAg TTC TGT GCT GGA ATT GAA GTC ATC TAT GCC TTA CGA GGA $\begin{array}{llllllllllllllllllllllll}N & R & P & G & K & G & S & R & L & E & A & Q & I & V & I & G & T & P & G & T & 210\end{array}$

595 AAT AGA CCT GGA AAA GGA AGC AGA TTA GAA GCA CAG ATC GTA ATA GGT ACC CCT GGT ACT $\begin{array}{lllllllllllllllllllllllll}\mathrm{V} & \mathrm{L} & \mathrm{D} & \mathrm{W} & \mathrm{C} & \mathrm{F} & \mathrm{K} & \mathrm{L} & \mathrm{R} & \mathrm{L} & \mathrm{I} & \mathrm{T} & \mathrm{V} & \mathrm{E} & \mathrm{N} & \mathrm{I} & \mathrm{S} & \mathrm{V} & \mathrm{F} & \mathrm{V} & 230\end{array}$

655 GTA CTG GAC TGG TGC TTT AAA CTG CGG CTG ATA ACT GTT GAA AAC ATC TCT GTG TTT GTG $\begin{array}{lllllllllllllllllllllllllllll}\mathrm{L} & \mathrm{D} & \mathrm{E} & \mathrm{A} & \mathrm{D} & \mathrm{V} & \mathrm{M} & \mathrm{I} & \mathrm{N} & \mathrm{V} & \mathrm{Q} & \mathrm{G} & \mathrm{R} & \mathrm{S} & \mathrm{D} & \mathrm{H} & \mathrm{S} & \mathrm{V} & \mathrm{R} & \mathrm{V} & 250\end{array}$

715 TTA GAT GAG GCT GAT GTT ATG ATA AAT GTT CAA GGT CGT TCT GAT CAC AGT GTC CGT GTT $\begin{array}{llllllllllllllllllllll}\mathrm{K} & \mathrm{R} & \mathrm{S} & \mathrm{M} & \mathrm{P} & \mathrm{K} & \mathrm{S} & \mathrm{C} & \mathrm{Q} & \mathrm{M} & \mathrm{L} & \mathrm{L} & \mathrm{F} & \mathrm{S} & \mathrm{A} & \mathrm{T} & \mathrm{F} & \mathrm{E} & \mathrm{D} & \mathrm{S} & 270\end{array}$

775 AAA AGA TCA ATG CCA AAA AGT TGC CAG ATG CTT CTC TTC TCT GCC ACC TTT GAG GAT TCT $\begin{array}{lllllllllllllllllllllllllllll}\mathrm{V} & \mathrm{W} & \mathrm{A} & \mathrm{F} & \mathrm{A} & \mathrm{E} & \mathrm{R} & \mathrm{I} & \mathrm{V} & \mathrm{P} & \mathrm{D} & \mathrm{P} & \mathrm{N} & \mathrm{I} & \mathrm{I} & \mathrm{K} & \mathrm{L} & \mathrm{K} & \mathrm{K} & \mathrm{E} & 290\end{array}$

835 GTG TGG GCC TTT GCT GAA AGA ATT GTA CCA GAC CCA AAT ATC ATA AAA CTG AAG AAA GAA $\begin{array}{llllllllllllllllllllllllll}\mathrm{E} & \mathrm{L} & \mathrm{T} & \mathrm{L} & \mathrm{K} & \mathrm{N} & \mathrm{I} & \mathrm{Q} & \mathrm{Q} & \mathrm{F} & \mathrm{Y} & \mathrm{D} & \mathrm{Q} & \mathrm{C} & \mathrm{E} & \mathrm{N} & \mathrm{K} & \mathrm{E} & \mathrm{Q} & \mathrm{K} & 310\end{array}$

895 GAG TTA ACT CTT AAA AAT ATA CAG CAA TTT TAT GAT CAA TGT GAA AAC AAA GAG CAA AAA $\begin{array}{llllllllllllllllllllll}\mathrm{Y} & \mathrm{S} & \mathrm{A} & \mathrm{L} & \mathrm{C} & \mathrm{N} & \mathrm{L} & \mathrm{Y} & \mathrm{G} & \mathrm{V} & \mathrm{I} & \mathrm{T} & \mathrm{I} & \mathrm{A} & \mathrm{Q} & \mathrm{A} & \mathrm{I} & \mathrm{V} & \mathrm{F} & \mathrm{C} & 330\end{array}$

955 TAC TCG GCA CTA TGT AAC CTT TAT GGA GTT ATA ACA ATT GCC CAA GCA ATT GTA TTT TGT $\begin{array}{llllllllllllllllllllllllll}\mathrm{Q} & \mathrm{T} & \mathrm{R} & \mathrm{K} & \mathrm{I} & \mathrm{A} & \mathrm{S} & \mathrm{W} & \mathrm{L} & \mathrm{S} & \mathrm{Q} & \mathrm{K} & \mathrm{L} & \mathrm{S} & \mathrm{D} & \mathrm{D} & \mathrm{G} & \mathrm{H} & \mathrm{Q} & \mathrm{V} & 350\end{array}$

1015 CAG ACT CGT AAA ATT GCT AGT TGG CTT TCT CAA AAG CTG TCG GAT GAC GGG CAC CAA GTA $\begin{array}{lllllllllllllllllllll}\mathrm{A} & \mathrm{L} & \mathrm{L} & \mathrm{S} & \mathrm{G} & \mathrm{E} & \mathrm{L} & \mathrm{P} & \mathrm{I} & \mathrm{Y} & \mathrm{D} & \mathrm{R} & \mathrm{A} & \mathrm{D} & \mathrm{M} & \mathrm{I} & \mathrm{Q} & \mathrm{R} & \mathrm{F} & \mathrm{R} & 370\end{array}$

1075 GCA TTG TTA AGT GGT GAA CTT CCA ATT TAT GAC CGT GCT GAC ATG ATA CAA AGA TTC CGT $\begin{array}{llllllllllllllllllllllll}E & G & R & E & K & V & L & V & T & T & N & V & C & A & R & G & I & D & V & E & 390\end{array}$

1135 GAA GGG AGG GAG AAA GTA CTT GTT ACT ACT AAC GTT TGT GCA CGA GGT ATT GAT GTT GAA $\begin{array}{lllllllllllllllllllllllll}\mathrm{O} & \mathrm{V} & \mathrm{S} & \mathrm{I} & \mathrm{V} & \mathrm{V} & \mathrm{N} & \mathrm{F} & \mathrm{D} & \mathrm{L} & \mathrm{P} & \mathrm{V} & \mathrm{N} & \mathrm{V} & \mathrm{D} & \mathrm{G} & \mathrm{S} & \mathrm{V} & \mathrm{D} & \mathrm{F} & 410\end{array}$ CAG GTC TCC ATT GTA GTG AAT TTT GAC CTG CCA GTA AAT GTT GAT GGC TCA GTA GAC TTT $\begin{array}{lllllllllllllllllllll}E & T & Y & L & H & R & I & G & R & T & G & R & F & G & K & K & G & I & A & V & 430\end{array}$

1255 GAA ACC TAC TTG CAT CGT ATT GGC CGC ACT GGG CGA TTT GGA AAg AAg GGT ATT GCA GTG 
$\begin{array}{llllllllllllllllllllll}\mathrm{S} & \mathrm{L} & \mathrm{I} & \mathrm{E} & \mathrm{N} & \mathrm{F} & \mathrm{F} & \mathrm{V} & \mathrm{Y} & \mathrm{M} & \mathrm{L} & \mathrm{K} & \mathrm{E} & \mathrm{I} & \mathrm{E} & \mathrm{D} & \mathrm{H} & \mathrm{F} & \mathrm{N} & \mathrm{T} & 450\end{array}$

1315 AGC CTT ATT GAA AAT TTC TTT GTG TAC ATG CTA AAG GAG ATT GAA GAT CAC TTC AAC ACA

$\begin{array}{lllllllllllllllllll}K & I & T & K & L & N & S & M & D & M & D & E & M & G & K & I & W & K & * \\ \end{array}$

1375 AAG ATT ACA AAG CTA AAC AGT ATG GAC ATG GAT GAG ATG GGG AAA ATA TGG AAG TAA AGT

1495 AAT GCC AAA TGA ACT TTT GTT AAG GGG AAA AAA AGT AAA GTT ATT TTA AAA TAT TGA ATA

1555 AAA GTA AAA CAT TTT GTG ATC TTG CTG AAT GCA GTA CTA GTG AAC AAT CTG AAG TTA TGG

1615 AAA GAT CAT TCA TGT GTG TTT TTT TTT CTC TGA AAG TAA TAT TCA GGA TAT GCC TGT TTA

1675 CCA ATG ATT CTA TTA ATA ATG TGT TGC AGC ACA GTT TTG GAG TTT TAG GCT TGA CCG TTT

1735 TTC ACA TGA GCA CTT TTT CAT ACA TCA CTA GAA AAC TAA AAA AAA TTT TTT TAT AAC TTC

1795 ACC TGT TGA AGG TCT TGG TTA TTT GCA AAA TGT GTT CTT GCA CTT TCT TTG TTT GCA TGT

1855 TAA TTA TTC ATT TGT ATT ATT TAA AAA ATG CAT GTA TTA CAG AGT TTG TTT TCA AAA CAC

1915 CAT TAT AAT TAT CTG CAC TAT ATT TTA TTG CAT GTA TGG CCT TAC AAA TTG TGT AGA ATC

1975 GCC CAC TTC ACA GCA AAT TTG GCT GAC TAA GCA CTT GAA TTT TGT TTT GTT ACC ACT TCA

2035 TGG GTT TTC TCT GTT ATG TTG TGT AAA TGT AAT TCC TGA AAA AGA ATA TTG CTT CTA GTA

2095 CCG TTG TGC AAG GCA TAA GTG GGA TAT TTG CAT TTC TAA CGA TTT TTT TTT TTT TTT CTC

2155 CAA AAA AAT CCT TTT TAT AGG TTT TGG CTT TTA GCA ACA GTT ATT TCG GTC TGT AGA GAC

2215 TTA GTT TTG GGA AAT TCA AAA AAA AAA AAA AAA AAG TTT AAA AGT AGC ATT TAA GTT ATG

2275 TAT GCC ATC CCC CAG TGA ATT GTT TTT TTC TCC CCA AGC TGG CAC TAC TCT TCT AGA AAA

2335 GAA GTT CAC CAG CCC AGG ACT GTC GTC ATT CAT AGA TTA GCT ATT TCT GCT CTA TTG CAG

2395 GGA CAT CTT GCA GTG TGT ACA TGC ACA GTA TAG TAA ACA AAA AAT TAC TAT CCT GAG CAT

2455 GCT CCT GCC GTA AAG TGG TTT TGT GAT GCT CTG ATA AAA GTA CCC TGG ACT GGT GTG TTT

2515 CTT CCA GAC AAG GAG TAG CAG CCC AGG AAA AAA GCA AGT GTT GAC TGC GGT ACA CAA CAA

2575 TTT GGC TTT TCT TAT CCT TTA AAT CCA TTT TAT TTT AAG GAA TAT TTG TAC TTC CAA ACT

2635 TTT TGT ACT TGC ATG CAC TCA TTT ATT TAA TCC TGG TCC TCG GAC CAC ATT AAA CAG AAA

2695 TTA ACG CAA TAA AAA TCA CAG AAA AAG CTT ATC GGC TTC TGA TGT ATT CCA TAT GAC ATT

2755 TTT CTG CAT GAA ACT AAG CAT TAT TTT CTC CAT CCC AAA ATA CAA ACC ATT GTC CAA TTG

2815 GCC TAC TCT TTC TTT ATC CTG TGT TAC TGT GCC ATT GTC CTT TGT TTG TTA AGC CGC AAT

2875 GCA GAT ACT TTA ATG TAA AAG CAA AGC CTA AAG GTT GAA CGG TTC CAA AAT TAC CCG CAT

2935 TAG TAG TAT TTG TCT GTT TTT TGT TTT TTT TAT ATT TGT GAT TGT TTA CCA AAA TAA AAA

2995 GGT CAT TAA AGA GGA AAA AAA AAA AAA AAA AAA AAA AAA AAA AA

\subsection{Nukleotid- und abgeleitete Aminosäuresequenz von B2B-10B (XNIF)}

Die Nukleotidpositionen der cDNA-Sequenz sind am linken Rand angegeben; die Positionen der aus dieser abgeleiteten Aminosäuresequenz am rechten. Das Startkodon des offenen Leserahmens ist durch Fettdruck markiert; das zugehörige Terminationskodon ist durch einen Stern kenntlich gemacht. Weitere, im 5'untranslatierten Bereich der RNA gelegene Stopkodons desselben offenen Leserahmens sind durch eine Umrahmung markiert. Die Positionen der in der PCR-vermittelten Durchmusterung der Gesamt-Oozyten cDNABibliothek und in den RT-PCR-Expressionsanalysen verwendeten Oligonukleotide sind in der Nukleotidsequenz unterstrichen. Die konservierte Region NLI-ähnlicher Fragmente ist in der Darstellung in grau unterlegt.

TCC GAC CTT AGA CTC GAC CGC CCA ACC GAC AGG CCC TCA GCC TTC CAT CAT CTC TAT ATA GCG GTG TTT GCT CTT CCA GGG AAC CCC CCT CTT CCC TCA CAG CGC CCC GCC TGG GCT TCA TGC TGA GCA AGA GAA GGA AAG AGC AGG GAG CCG ACC CGG CCT CGG ACA CAC GGG GGA TTC TGA GCC AAC CGA CAC ATT GGG ACT TCT CCT CAG GCG GAT AGA ACT CTC CCT CCA TCT TCC ATT TCA CCC TCA TTC CCC TCA CAC ACA CAC ACA GGA CAT AAA GCC ATT TCT ATA CAC GGC CTG ACT CCC AGT ATT GAT ATA CAC ACG TTA TAT TCA CCT TTT ATT CAC CTA CTG ACC CTG CCA TCT CCC CCT CCT ACA CCA ACA TCA CTA TAT ATA CTT CCC TCA TTC TCC AGC AGC CTC TAT ACA CCT ATT ACA CAC ATA TAT ATA TAT TTA TAT ATT TAT ATA CCT ACA CAC ACA CAT ATA TAT ATA TAT ATA TAT ATA TCT ACA CAC ACA TAT ATA CCT ACA CAG ACA GTC CCT TGC AGC TCA GTA TAT CCT CTT TAT TTG CAG ACA TTT CCA CAG CAT AAC CCC GAG TCC AGT CCC TAC ATC CAA TGA GAT CAC CTG CCA TCC GAC ATA CAG GAA TAC ACT GAG CCA GGC AGA GAT CGT CCT CCC ATA ATA CAG GCT TCT AGA CCC CTC TGC TGC ACA GTC CAG ACA GCA CTA CGT ACC CTT CCT GCC CAT AAC ATT GGA TGC TTT CAC CGT ACA GCG TTC TTT ACT GGC GGC ACC AAT TCC GCA AAG TAT AGA GCA GAA AAA ACG TAG ATA TTT CTC CAC CAG CTC ATT CTC TGC CAG CCT AGC GAC ATA CAT AAT CGG TGT TTT ATA AGC GTA TGC GTA GAA TTA GGT CAT TTT GTT CGT TAA CAT TCA CAT AGA GTT CAC TTG CAG TTT GTA GAA CAT GAA CAA ATA GCT CTC TCT CTT TCT CAA ATA CAA CAT TGT CTC ATC TCC TTA TAT ACA TAC TTT GCA CAC TCT TCT TCT CCG ACA TTC AGA GCC AGA ACT GCC TCC ATT TTC CCC TAA CAT ACA CAC CAG CAA CTC TGC CAC TCT CCC CGG CAT ATA AAA CAC TCC AGA CAG ATT AGA CTT CAC GGC AGC AAG CTC TTC TAT AAG AAA CAC CTG CGT AAC AGC TTT CAC CCT CAC AGT GAT CCC CCT CAA GGC ACA AAA TAC ACT CTC ACC ATT TCA TAC ACC CTA TAA CAG CAC TGC ATC CCC AAG CCA GTC TCG AAC TGC GGA TTA GAT AAA GAG GAC AAG AAC AAC AGC CAA TTC GTT TCC ATG GAC $\begin{array}{llllllllllllllllllllllll}N & T & S & I & I & T & Q & V & S & N & P & \text { K } & \text { E } & \text { E } & \text { G } & \text { I } & \text { L } & \text { S } & \text { C } & \text { A } & 22\end{array}$ AAC ACG TCC ATC ATC ACC CAG GTC TCT AAC CCC AAG GAG GAG GGA ATC CTG TCC TGT GCC $\begin{array}{llllllllllllllllllllll}Q & \mathrm{E} & \mathrm{K} & \mathrm{V} & \mathrm{S} & \mathrm{Q} & \mathrm{C} & \mathrm{N} & \mathrm{I} & \mathrm{S} & \mathrm{L} & \mathrm{K} & \mathrm{K} & \mathrm{Q} & \mathrm{R} & \mathrm{N} & \mathrm{R} & \mathrm{S} & \mathrm{I} & \mathrm{F}\end{array}$ CAG GAA AAG GTC TCC CAA TGC AAT ATT AGC CTA AAA AAG CAA AGG AAC AGA AGC ATC TTC $\begin{array}{lllllllllllllllllllll}G & S & L & F & C & C & F & R & S & Y & S & V & E & P & P & N & S & N & N & N\end{array}$

GGC TCC TTA TTC TGC TGT TTC CGT AGT TAC AGC GTA GAG CCA CCA AAC TCG AAT AAT AAC 
$\begin{array}{llllllllllllllllllllll}\mathrm{S} & \mathrm{S} & \mathrm{P} & \mathrm{L} & \mathrm{P} & \mathrm{P} & \mathrm{L} & \mathrm{V} & \mathrm{E} & \mathrm{E} & \mathrm{N} & \mathrm{G} & \mathrm{G} & \mathrm{I} & \mathrm{Q} & \mathrm{K} & \mathrm{G} & \mathrm{D} & \mathrm{Q} & \mathrm{T} & 82\end{array}$

1495 AGT AGC CCT CTT CCT CCG CTG GTG GAA GAA AAT GGG GGC ATT CAG AAG GGT GAT CAG ACT $\begin{array}{lllllllllllllllllllll}Q & \mathrm{~A} & \mathrm{~L} & \mathrm{~T} & \mathrm{I} & \mathrm{P} & \mathrm{S} & \mathrm{P} & \mathrm{P} & \mathrm{T} & \mathrm{K} & \mathrm{Y} & \mathrm{L} & \mathrm{L} & \mathrm{P} & \mathrm{E} & \mathrm{L} & \mathrm{K} & \mathrm{V} & \mathrm{S} & 102\end{array}$

1555 CAA GCC CTT ACC ATT CCC AGT CCA CCT ACT AAA TAC CTC CTT CCT GAA CTG AAA GTA TCC $\begin{array}{lllllllllllllllllllll}\mathrm{E} & \mathrm{Y} & \mathrm{G} & \mathrm{K} & \mathrm{K} & \mathrm{C} & \mathrm{V} & \mathrm{V} & \mathrm{I} & \mathrm{D} & \mathrm{L} & \mathrm{D} & \mathrm{E} & \mathrm{T} & \mathrm{L} & \mathrm{V} & \mathrm{H} & \mathrm{S} & \mathrm{S} & \mathrm{F} & 122\end{array}$

1615 GAA TAT GGG AAG AAG TGC GTG GTC ATT GAC CTG GAT GAA ACC TTA GTG CAC AGT TCA TTT $\begin{array}{lllllllllllllllllllll}K & \mathrm{P} & \mathrm{I} & \mathrm{N} & \mathrm{N} & \mathrm{A} & \mathrm{D} & \mathrm{F} & \mathrm{I} & \mathrm{V} & \mathrm{P} & \mathrm{V} & \mathrm{E} & \mathrm{I} & \mathrm{D} & \mathrm{G} & \mathrm{T} & \mathrm{I} & \mathrm{H} & \mathrm{Q} & 142\end{array}$

1675 AAG CCT ATA AAC AAC GCA GAC TTC ATT GTT CCA GTT GAA ATA GAT GGA ACA ATA CAT CAG $\begin{array}{lllllllllllllllllllll}\mathrm{V} & \mathrm{Y} & \mathrm{V} & \mathrm{L} & \mathrm{K} & \mathrm{R} & \mathrm{P} & \mathrm{H} & \mathrm{V} & \mathrm{D} & \mathrm{E} & \mathrm{F} & \mathrm{L} & \mathrm{Q} & \mathrm{K} & \mathrm{M} & \mathrm{G} & \mathrm{E} & \mathrm{M} & \mathrm{F} & 162\end{array}$

1735 GTC TAT GTG TTA AAA CGA CCC CAC GTA GAT GAA TTT CTT CAA AAA ATG GGC GAG ATG TTT $\begin{array}{lllllllllllllllllllll}\text { E } & \text { C } & \text { V } & \text { L } & \text { F } & \text { T } & \text { A } & \text { S } & \text { L } & \text { A } & \text { K } & \text { Y } & \text { A } & \text { D } & \text { P } & \text { V } & \text { A } & \text { D } & \text { L } & \text { L } & 182\end{array}$

1795 GAA TGC GTT CTC TTC ACA GCC AGC CTT GCG AAG TAT GCC GAT CCA GTG GCT GAT CTG CTA

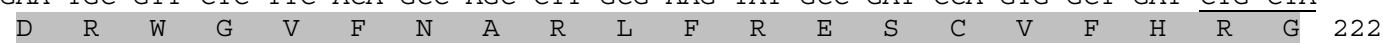

1855 GAC CGG TGG GGA GTG TTC AAC GCA CGA CTC TTC CGA GAA TCC TGT GTT TTT CAC AGG GGA $\begin{array}{lllllllllllllllllllllll}N & \text { Y } & \text { V } & \text { K } & \text { D } & \text { L } & \text { S } & \text { R } & \text { L } & \text { G } & \text { R } & \text { E } & \text { L } & \text { S } & \text { K } & \text { V } & \text { I } & \text { I } & \text { I } & \text { D } & 242\end{array}$

1915 AAC TAC GTC AAA GAT TTA AGC CGC TTA GGT AGA GAA CTG AGC AAA GTG ATT ATA ATC GAT $\begin{array}{llllllllllllllllllllll}\mathrm{N} & \mathrm{S} & \mathrm{P} & \mathrm{A} & \mathrm{S} & \mathrm{Y} & \mathrm{I} & \mathrm{F} & \mathrm{H} & \mathrm{P} & \mathrm{E} & \mathrm{N} & \mathrm{A} & \mathrm{V} & \mathrm{P} & \mathrm{V} & \mathrm{M} & \mathrm{S} & \mathrm{W} & \mathrm{F} & 262\end{array}$

1975 AAC TCT CCT GCG TCA TAC ATC TTC CAT CCA GAG AAT GCC GTT CCT GTA ATG TCT TGG TTC $\begin{array}{lllllllllllllllllllll}\mathrm{D} & \mathrm{D} & \mathrm{M} & \mathrm{A} & \mathrm{D} & \mathrm{T} & \mathrm{E} & \mathrm{L} & \mathrm{L} & \mathrm{D} & \mathrm{L} & \mathrm{L} & \mathrm{P} & \mathrm{F} & \mathrm{F} & \mathrm{E} & \mathrm{G} & \mathrm{L} & \mathrm{S} & \mathrm{K} & 282\end{array}$

2035 GAC GAC ATG GCG GAT ACA GAG CTG CTC GAT CTC CTT CCT TTC TTC GAG GGA CTG AGC AAA $\begin{array}{llllllllllllllll}E & E & N & V & Y & N & M & L & N & K & L & C & N & R & * & \end{array}$

2095 GAA GAA AAC GTT TAC AAC ATG CTA AAT AAG TTA TGT AAC AGG TAG CCC TGG CCA AGC TCT 2155 CCG CTG TGA AAA AGC TGC GAA TTG CAG CAG CTT CAG ACT GAG CCC CGT CTC TTG ACT CTT 2215 CGC TTC TCC ACC CTG ACA TGT TTT GCT CTG AAC CAA TAA GCT CTG CCA AAC AGA AAT CCA 2275 TCA CAA GAA GAT CAG CTC TTG TTC TCC CGA AGG GTT TGA ATG ATG CTG TGC AGC CTT TCA 2335 CAA CTC CAT TGA ACT CAA TTC TCT AAC CGA GTA AAA CAT TTT GTT GCC GAA TGG AAA AGC 2395 CGC TTG CCG ATT CTT CGG CAT CTC TGG GGG TCA CTG AGC AAT GGA CGG TGG AAA GAC AAT 2455 ATT TTT TAA AGA TAA ACT TTT TGT CTC TAA TTT TTC TTA AAA TTA ATA TGG ACT TTC AGG 2515 CTT TTA TAA CCA GAA GAA AAC AAC ACA CCA AAT GAA ACT GAA TCT ACA AAG AAG AAC ATA 2575 GTA AAT GGT TGA TGC TAA TGA TGC TAA AAA AAA AAA AAA AAA AA

\subsection{Nukleotidsequenz der partiellen B2B- 2B-cDNA}

Gezeigt ist die Nukleotidsequenz der partiellen cDNA des äquatorial lokalisierten 2B-Transkriptes. Die jeweiligen Nukleotidpositionen sind am linken Rand der Sequenz angegeben. Die Positionen der in der PCRvermittelten Durchmusterung der Gesamt-Oozyten cDNA-Bibliothek und in den RT-PCR-Expressionsanalysen verwendeten Oligonukleotide sind in der Nukleotidsequenz unterstrichen.

CGG GGG GGG AAC GTT CAT TTA CAT GAC ACT AGG GTT GTA TTG TTT GGC CTA ACC CGG ACA ACT GCT TTA TTG GTG TGT CCC CTA CTA AAC CAA ACT CTT AAT GGG GCT TAT TCA CTT CTG GAC ACT TTC TCA GTG CCT CCC TCA TTA GTA TCA CAC AGG ATA TTT TTT CCC CAA ACA CTG AAT ATC TCT GAG GCT GTA TAT GGG TAT CAT TGT TCT CTT TTT ATC TTT ACC CAA TAC TTT ACA ACA TGT CAG GGA ATT CTA AAG GGC TCC ATG AAT TGT CAT TAA AAA AGA GCC AGg ATG CAT CAA TTC CAG AAA ATG AAA TAT CAA CCA GTA AAG GTT AGC TTT CAG AAA TGG GTG GTA CAC CTT TAA GTA AAC TTT TAG TTT GGA ATG GCC AAT TCT AAG CTA CTT TTC CAT TGG TTT TCA TTA TTT TTT ATA GTT ATT TGC CTT TTT CTT CTG TCT CTT TCC AGC TTG CAG ATG GGT GTC GCC GAC CCC ATC TAA AGA GCA AAT GCT CTG TAA GGC TAC ACA CTT ATT ATT ATT GCT ACT TTT TAT TAC TCA TCT TTC TAG TAA GGT CCT CTC CTA TTC TTG TTC CGG TCT CTT ATT CAA ATC AAT GCA TGG TTA CTA GGG AAA TTT GGA TCC TAT AAT AGA AAT TGA AGA ACT GCT GAA TAA AAA GCT AAC TCA AAA ATC TTA TAT AAT AAA AAA TGA AAA CCA ATT GCA AAT ACT AAA AGT TAA CTC AAA GGT GAT CAA CCC CTT TAA AGC AAT TTA ATG ATA AAG CTG TTT CAC AGG GCT GGT TCC AAA GAG GCA AGA AAA TGA TGA AAA AGG ATT CTG TGC TGT TAT TGG CTC ACC TGT GGG TGA TGT TAT GGT ATT TGA GTG TGG GGT GAG GTC ATA AAG AAA TTG TGC CTC GAA AGT CTT GGT CCA GCC CTA GCT ATG GAA AAT AAT GTG TAC ATA GGA ATG TTC AGT TGT GTA GAG AGA TCT GCT GTG TGT ATA AAT TGT AAT TAT AAG TAT ATA TTA TTC TTT CCA AGA GAA TTG TTT TTT TTG GGg TTT TTT TTA CAA ATC TGC AAT TTT TCC TAC TTC ATG TGT TAA ATA AAC CCA ATT CAC ATT TTT TTT TTT TTT TTT TCA TTT AGT CCA AAA TGT ATT CAA AAT TAT TTT CAC CTA TGA AAT GAC TCT CCC TGT ACA AGC ACA CAT GGA GAA TAG ATG CTG TTG GAA AAT GAA AAT TTA ATA TAA TCT TTG GCA TAC TGA AAT GGG AAA CTT TCT AGA TAC AAT CAA TTA AAT ATT CTG TAC CAT TTC TGA AAT AAT CGA GTT TGT CTT CAC TCT TCC TCT CGG CAT CGG TTT CTC TTC ATT TTG TTT TCA TGC AGG AGT TGG GCG TCA GAT AGT CAT TGA CAG TTC AAT AAT CCA ATA ATA GGg GGg CTT TCC TGC AGA TGA ATT AGA GCT CAC TCA GAT GAC TGA TTC CAG TAC AAA CAG GGT CTA ACG AGG TGA CTG CCT TTT GCA CAA ATC CTG CAT GAT GTC TCT TGG AGT GAG CTC TAA TGC ATC TTC TAG GCA AAG CCA CCC CCT TAT AAA CTG CAC TGG CCC AGG ATA CTT TCT CCA AGA ATG CTG TGC ATG ATT GAA CCT TTT CCA AGT ATG CCA CAC TGG GCT GTT CCA CTG GAG CAC TNT AAA CCC AGT GTT GGA CTG GGA TGC CAG GGG CCC ACC AGA AAA CAT TAG GCT GAA GGC CCA CTT TCC AAA CTA TTA TAC CTC CTC TCC TCA CTC AAC CTT TTA ATT CTC CTA GTC TCT TTT CTC TAA ATA CTC TAC TCT ATT CTT CCA TTA TTA CGC CTC TTT ATT TCC ATA AAC AGG GAA TGA CCA TGA ACT AGG CCA AAT GTT TAG AAG CAA GAG GCC CAC TGA CAC CTG GGC CCA CCG GGA GTT TTC CCA GTG GGC CAG TTC GAC ACT TAT TTT TAA AAA AAA AAG AGA ATA AAT TCT ATA AAA AAA AAA AAA AAA AAA AAA AAA AAA AA 


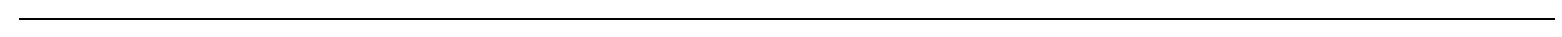




\section{Danksagung}

Mein herzlicher Dank gilt Herrn Prof. Dr. Tomas Pieler für die interessante

Themenstellung, die gewährte experimentelle Freiheit und die Betreuung der Arbeit.

Für die freundliche Übernahme des Korreferats bedanke ich mich bei Herrn Prof. Dr. G. Braus.

Allen Mitgliedern der Arbeitsgruppe Prof. Dr. T. Pieler möchte ich für die stete Hilfsbereitschaft, wertvolle Tips und Diskussionen danken. Mein ganz besonderer Dank gilt Dr. Falko Rudt, Susanne Loop, Katja Horvay, Gudrun Kracht, Marion Sölter und Jörg Wischnewski.

Ganz besonders danke ich auch meinen Eltern, die mich während meines ganzen Studiums auf vielfältige Weise unterstützt haben. 


\section{Lebenslauf}

Name:

Geburtsdatum:

Geburtsort:

Nationalität:

Familienstand:

Adresse:

\section{Ausbildung}

1979-1983

1983-1985

1985-1992

1992

1994

1994-1998

1997-1998

1998

seit Mai 1998
Maike Claußen

20.10 .1972

Oldenburg

deutsch

ledig

Am Goldgraben 9

37073 Göttingen
Grundschule in Oldenburg

Orientierungsstufe in Oldenburg

Gymnasium Cäcilienschule in Oldenburg

Abitur am 19.5.1992

Beginn des Studiums der Biologie an der Universität Oldenburg

Vordiplom am 29.8.1994

Hauptstudium der Biologie an der Universität Göttingen

Anfertigung der Diplomarbeit am Institut für Biochemie, Abteilung Entwicklungsbiochemie, Arbeitsgruppe Prof. Dr. T. Pieler Titel der Diplomarbeit: Funktionelle Analyse des Kerntransportsignals und der RNA-bindenden Domänen im eukaryotischen ribosomalen Protein L5

Diplom am 24.6.1998

Promotionsarbeit am Institut für Biochemie der Universität Göttingen, Abteilung Entwicklungsbiochemie, Arbeitsgruppe Prof. Dr. T. Pieler

Veröffentlichungen: Claußen, M., Rudt, F. und Pieler, T. (1999). Functional modules in ribosomal protein L5 for ribonucleoprotein complex formation and nucleocytoplasmic transport. J. Biol. Chem. 274, 33951-8 